\title{
AUTOMATED HYBRID SOLAR AND MAINS SYSTEM FOR PEAK TIME POWER DEMAND
}

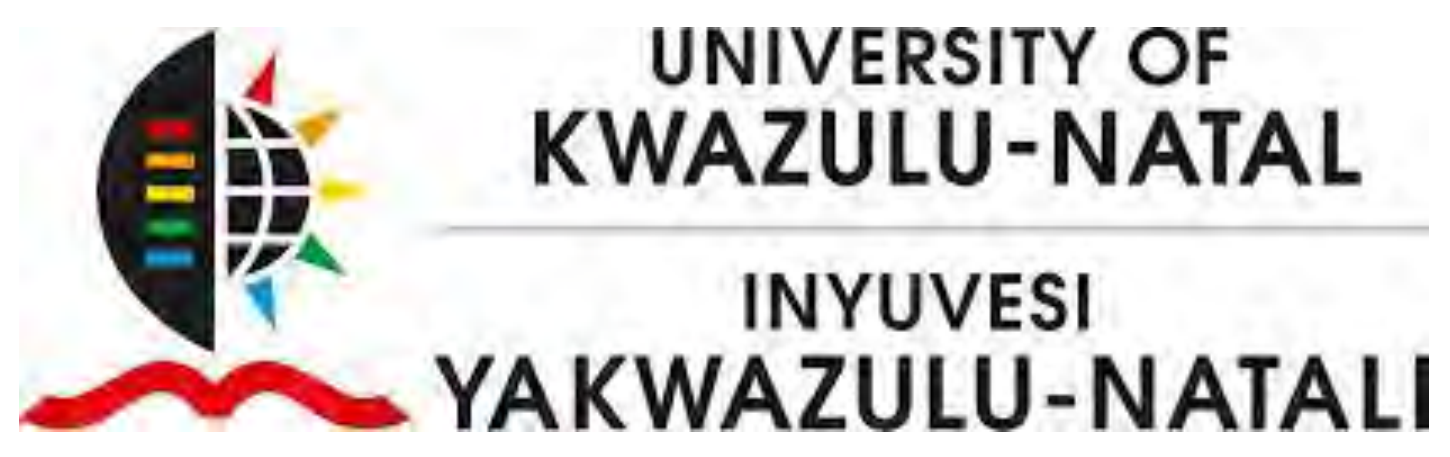

Mathew Habyarimana

In fulfillment of the Masters in Electrical Engineering

College of Agriculture, Engineering and Science,

University of KwaZulu-Natal

30 November 2015

Dr. Chitra Venugopal 
As the candidate's supervisor, I have approved this dissertation for submission.

Signed........................ Date..............................

Name: Dr. Chitra VENUGOPAL 


\section{DECLARATION 1 - PLAGIARISM}

I ...Mathew Habyarimana.., declare that

1. The research reported in this thesis, except where otherwise indicated, is my original research.

2. This thesis has not been submitted for any degree or examination at any other university.

3. This thesis does not contain other persons' data, pictures, graphs or other information, unless specifically acknowledged as being sourced from other persons.

4. This thesis does not contain other persons' writing, unless specifically acknowledged as being sourced from other researchers. Where other written sources have been quoted, then:

a. Their words have been re-written but the general information attributed to them has been referenced

b. Where their exact words have been used, then their writing has been placed in italics and inside quotation marks, and referenced.

5. This thesis does not contain text, graphics or tables copied and pasted from the Internet, unless specifically acknowledged, and the source being detailed in the thesis and in the References sections.

Signed

Date. 


\section{DECLARATION 2 - PUBLICATIONS}

DETAILS OF CONTRIBUTION TO PUBLICATIONS:

Publication:

M. HABYARIMANA and C. Venugopal, "Automated Hybrid Solar and Mains System for

Peak Time Power Demand," presented at the Domestic Use of Energy (DUE), 2015

International Conference, Cape Town, South Africa, April 2015.

Signed:

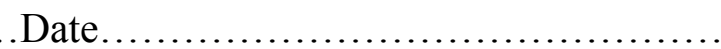




\section{ACKNOWLEDGEMENTS}

I wish to extend my gratitude to: my supervisor, Dr. Chitra Venugopal for her unending support and positive criticism throughout the period of the study. Her guidance and suggestions throughout the study period is especially acknowledged.

My thanks are extended to my all family members, colleagues, friends for their supports in many ways.

To all of you, May God shower his blessings upon you, shows you mercy and grant you his favour always. 


\begin{abstract}
The power demand during peak period causes large power fluctuations in the commercial grid. The reduction in using grid supply during peak time benefits the supplier and consumer. There are many methods such as monitoring the usage of grid supply, load shedding, using local generators and disconnecting unwanted loads during peak time used to reduce grid dependency during peak time. These methods reduce power demand from grid by either supplying interrupted power to the load or by establishing additional power source. In South Africa, solar energy is abundantly available and it can be utilized to solve the power demand during peak time. In this research, solar and grid power are chosen as two power sources and automatic switching system to select the power source to supply uninterrupted power to the load is designed. The important aspect of using solar system is estimating the system output. The maximum power point tracking system using perturb and observe algorithm is designed. The boost converter and inverter circuits are designed to supply power to the coffee shop loads at Howard College Campus. Battery charger circuit is designed to charge the battery from solar or grid and supply power to the load whenever required. The switching algorithm connects the load to solar or battery during peak time and connects it to grid during off peak time. The switching algorithm is designed to supply uninterrupted power to the load by connecting it to available source when any one of the source failure occurs. The power output from the panel is maximized by automatic panel cleaning system. The panel cleaning starts at the pre-programmed schedule and provision for manual override option to reschedule panel cleaning operation is also provided. The designed system is tested in MATLAB and Proteus simulation software. The results of each section are discussed. It can be seen that designed automatic selection of power sources for supplying $1 \mathrm{~kW}$ of power during peak time to the selected coffee shop considerably reduces the cost and power demand from the grid during peak time. The designed system is economically feasible and efficient in supplying uninterrupted power to the load.
\end{abstract}


TABLE OF CONTENTS

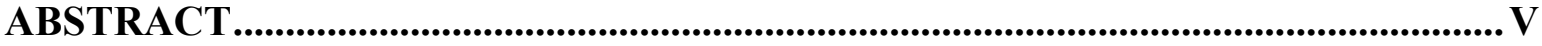

LIST OF FIGURES ................................................................................................................ X

LIST OF TABLES ................................................................................................................ XI

NOMENCLATURE.................................................................................................

CHAPTER 1 INTRODUCTION ..............................................................................................

1.1 Preface

1.2 Automatic Switch Based on ESKOM's off and Peak Time's Electricity and Demand

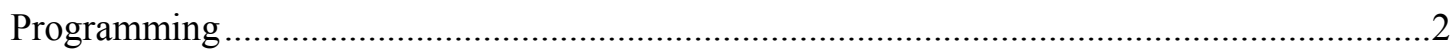

1.3 Maximum Power Point Tracker -MPPT ........................................................................

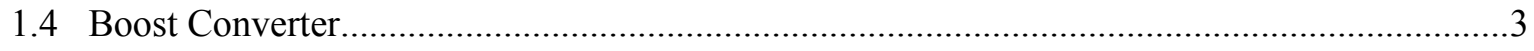

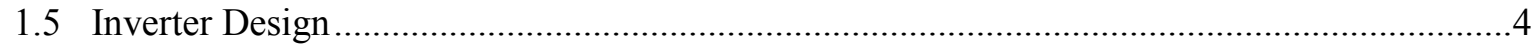

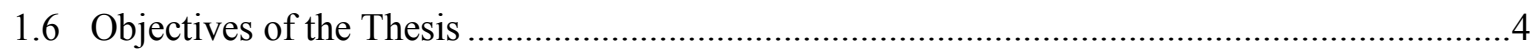

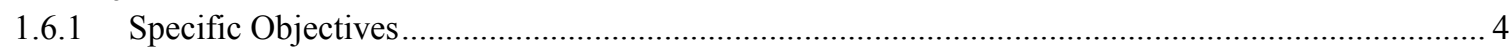

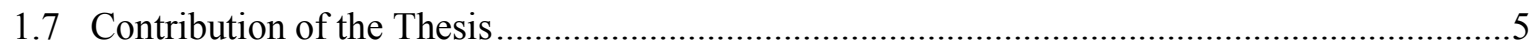

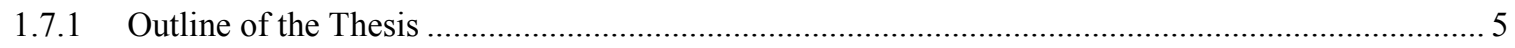

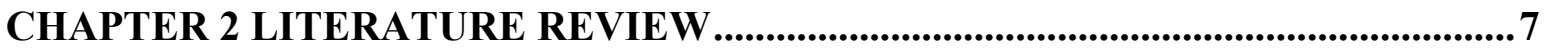

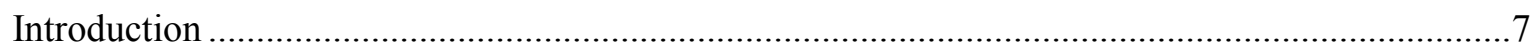

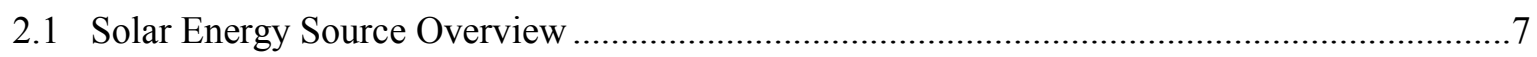

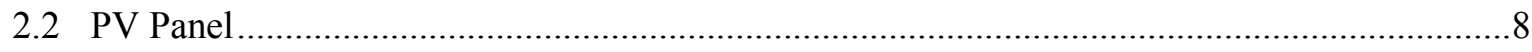

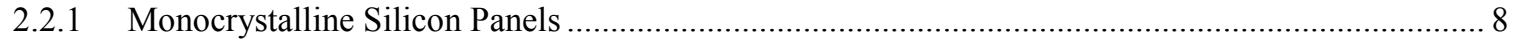

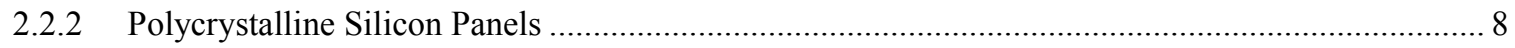

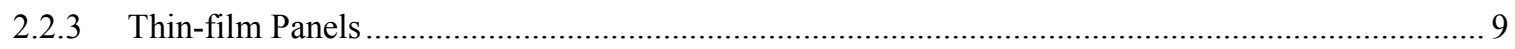

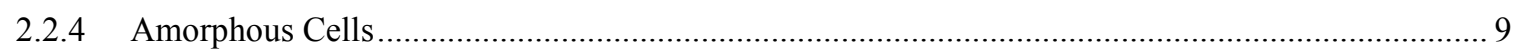

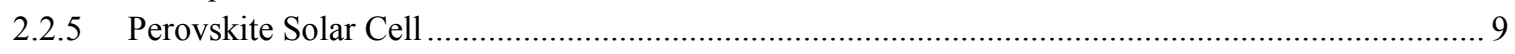

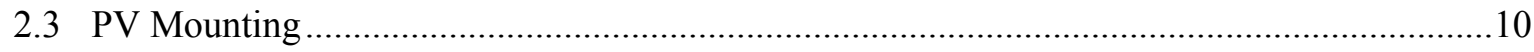




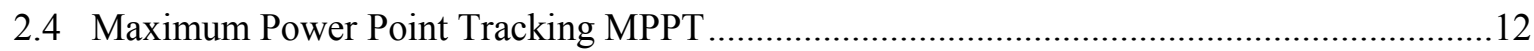

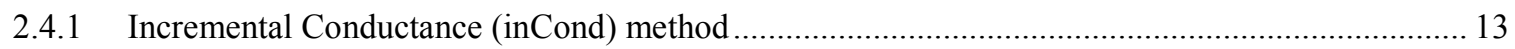

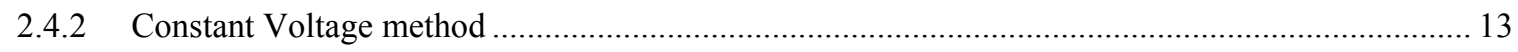

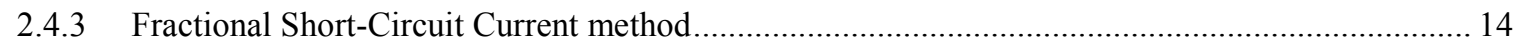

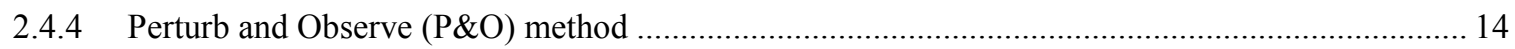

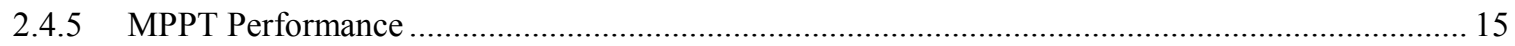

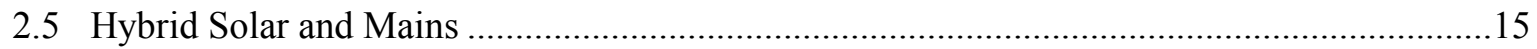

2.6 Earlier Alternative Solutions for Peak Power Demand .........................................................16

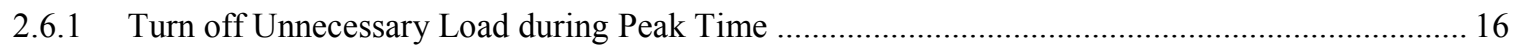

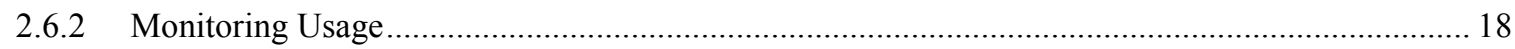

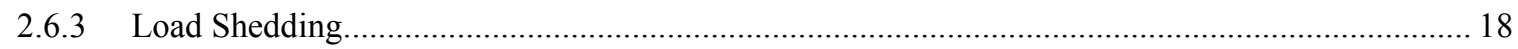

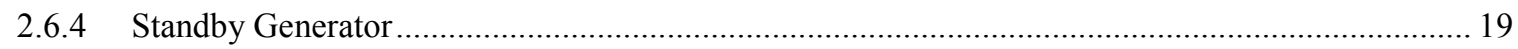

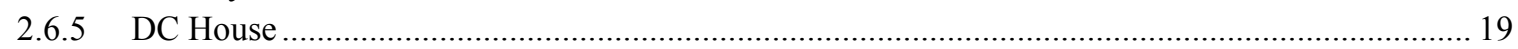

2.6.6 Hybrid Renewable Energy Systems (HRES) …….................................................................. 20

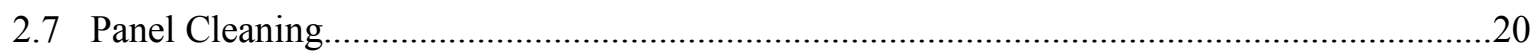

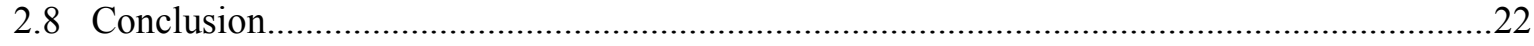

CHAPTER 3 SOLAR AND MAINS SYSTEM TECHNOLOGY....................................23

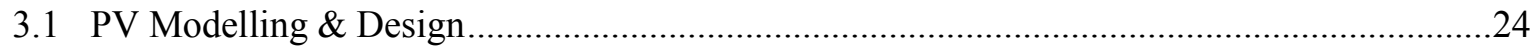

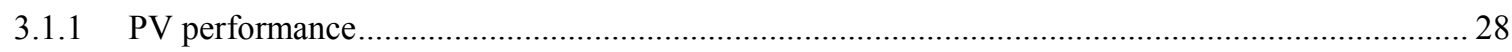

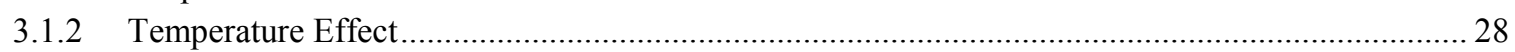

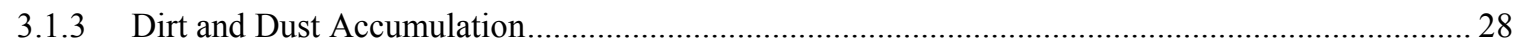

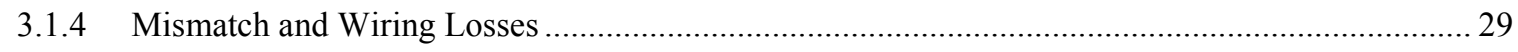

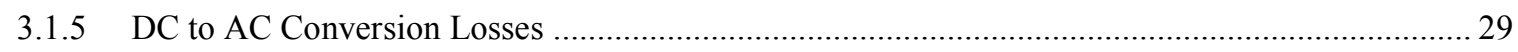

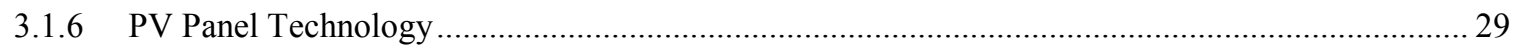

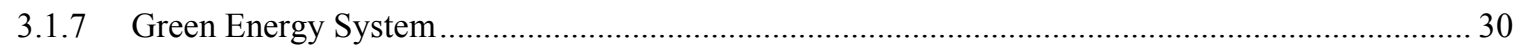

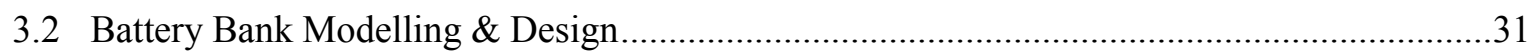

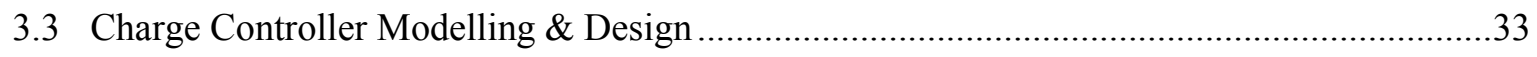

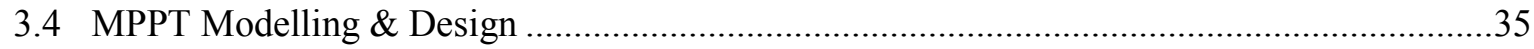

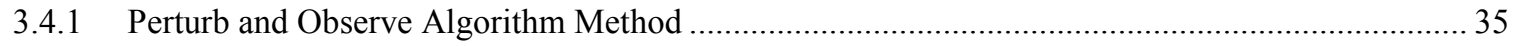

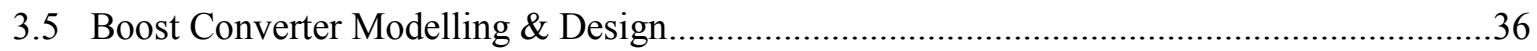

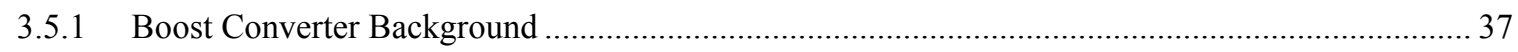

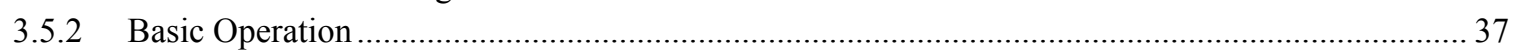

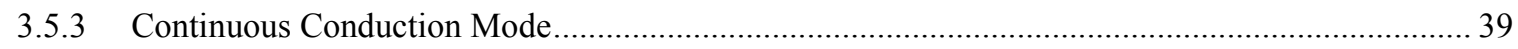

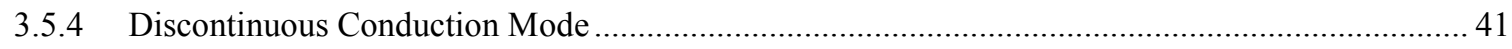

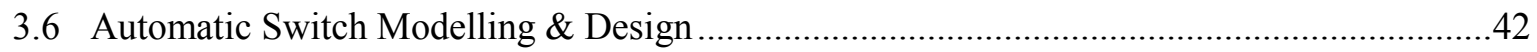

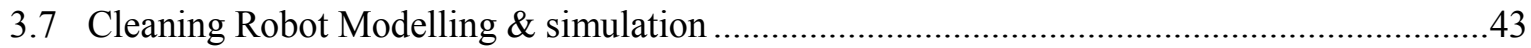


Introduction .

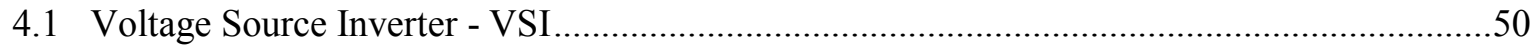

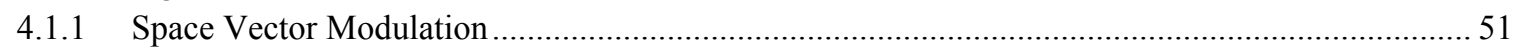

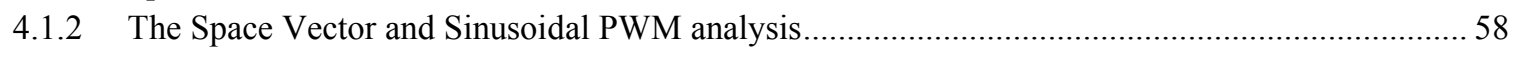

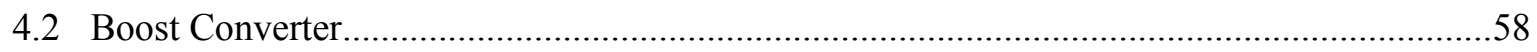

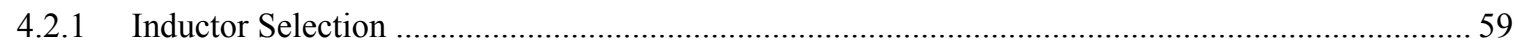

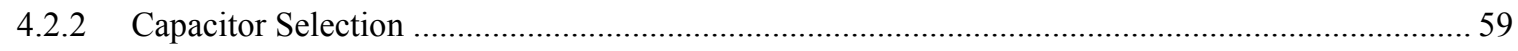

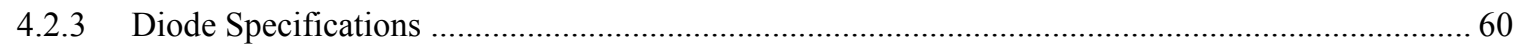

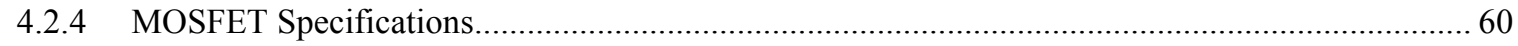

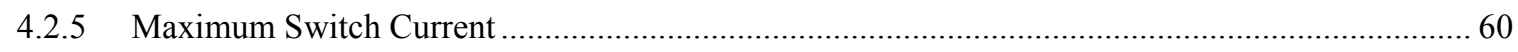

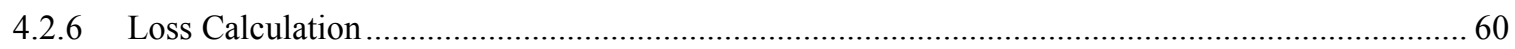

4.3 Automatic Switch Based on ESKOM's off and Peak Time's Electricity and Demand

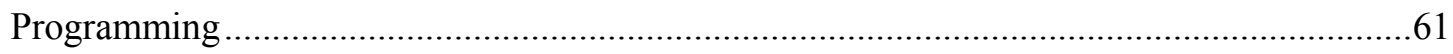

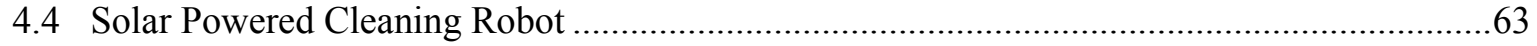

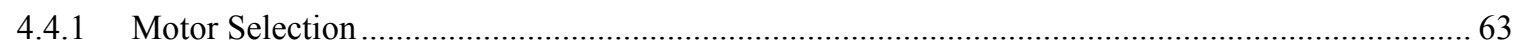

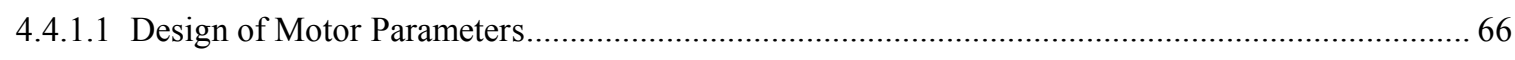

CHAPTER 5 SIMULATION RESULTS AND DISCUSSION .....................................69

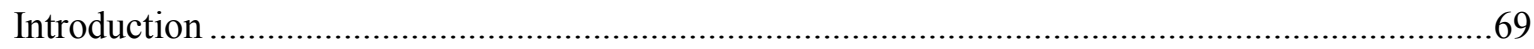

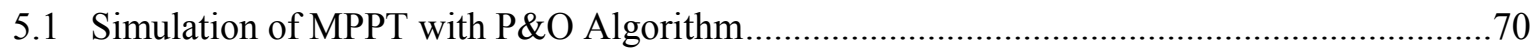

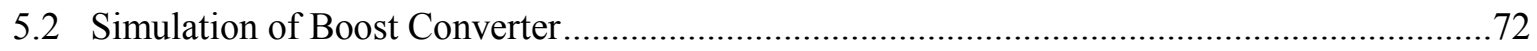

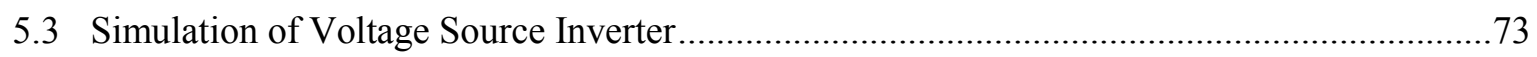

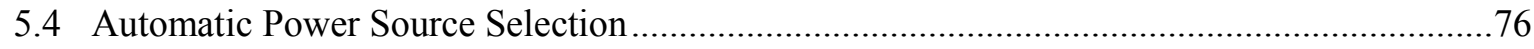

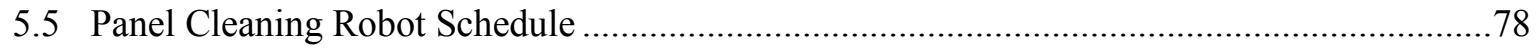

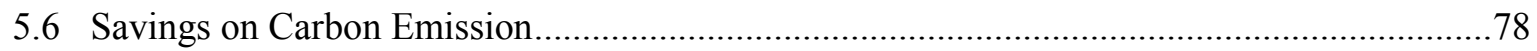

\section{CHAPTER 6 CONCLUSIONS AND RECOMMENDATION FOR FUTURE}

STUDIES .......................................................................................................................................8

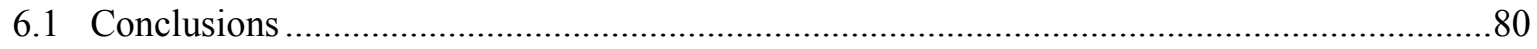

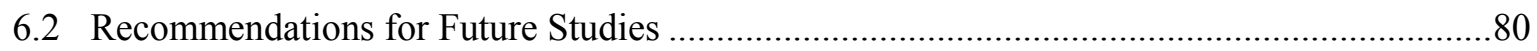




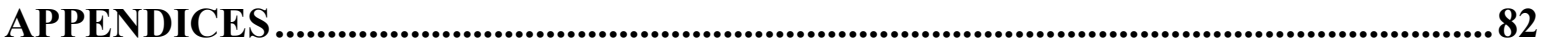

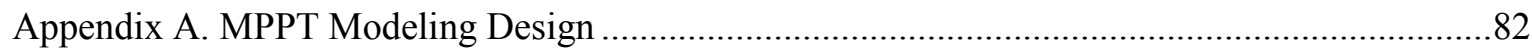

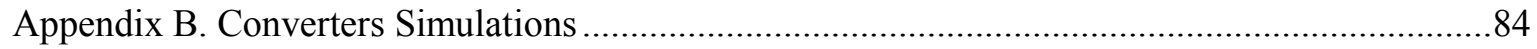

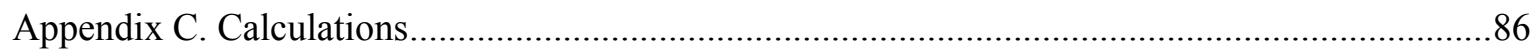

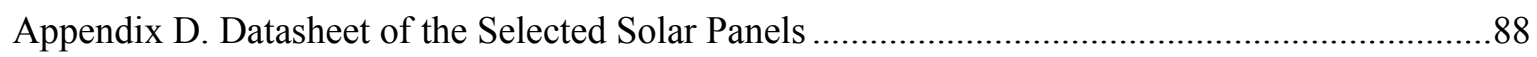

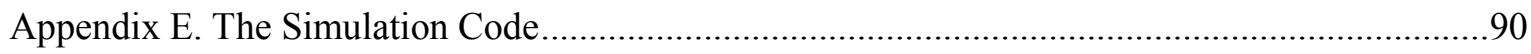

REFERENCES 


\section{List of Figures}

FIGURE 2-1: DIAGRAMS OF PHOTONS FROM THE SUN TO THE EARTH THROUGH THE ATMOSPHERE ................... 7

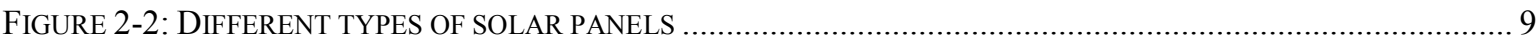

FigURE 2-3: SOLAR PANEL I-V CURVE (ORANGE) AND P-V CURVE (BLUE) ................................................ 14

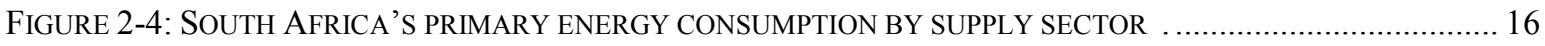

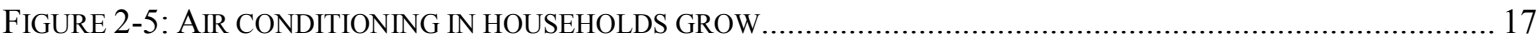

FigURE 2-6 AVERAGE SOUTH AFRICAN HOUSEHOLD DAILY ELECTRICITY CONSUMPTION PATTERN................. 18

FIGURE 2-7: COMBINED SOLAR AND AC MAINS POWERED LED LIGHTING SYSTEM....................................... 20

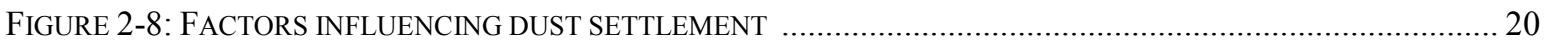

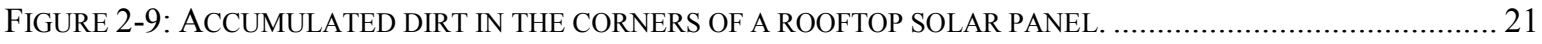

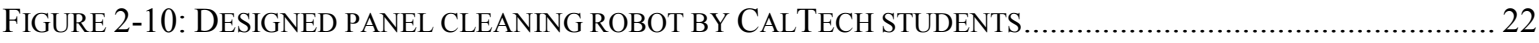

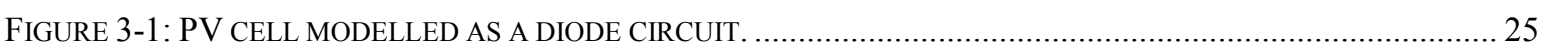

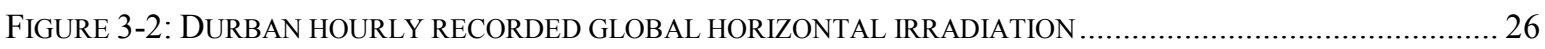

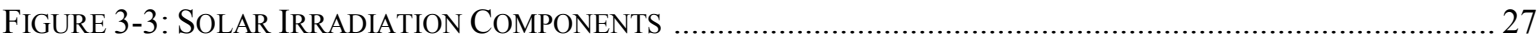

Figure 3-4: Durban Monthly Minimum Global HoRizonTAL IRRADIANCE .......................................28

FIGURE 3-5: SOLAR I-V RADIATION CURVES AND TEMPERATURE CHANGES WITH THE MPP ..........................29

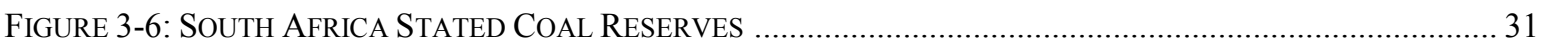

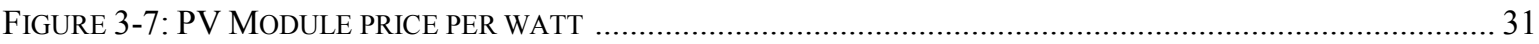

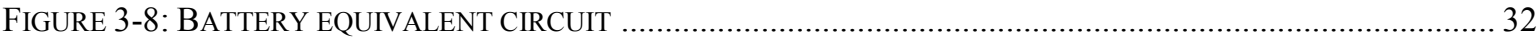

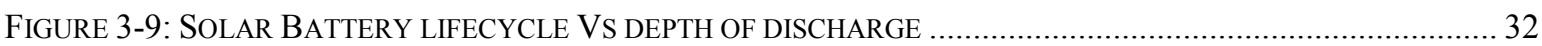

FIGURE 3-10: BATTERY LIFETIME FOR GIVEN DIFFERENT TEMPERATURE AND DEPTH OF DISCHARGE

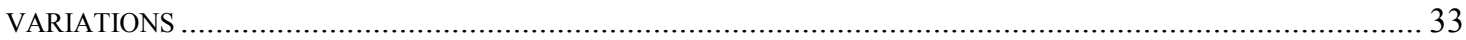

FIGURE 3-11: BATTERY CHARGING AND DISCHARGING CHARACTERISTICS .............................................. 34

Figure 3-12: Measured Battery voltage, State of Charge And Charging CurRent ....................... 34

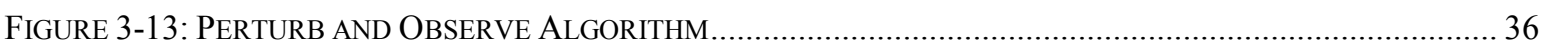

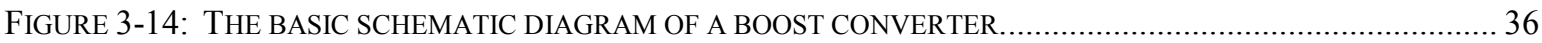

FIGURE 3-15: DC-DC BOOST CONVERTER AT THE BOUNDARY CONTINUOUS-DISCONTINUOUS CONDUCTION .. 38

Figure 3-16: Inductor CuRRENT AND Voltage FOR CONTINUOUS-CONDUCTION MODE OF BoOST CONVERTER

FIGURE 3-17: INDUCTOR CURRENT FOR VOLTAGE FOR DISCONTINUOUS - CONDUCTION MODE OF BOOST

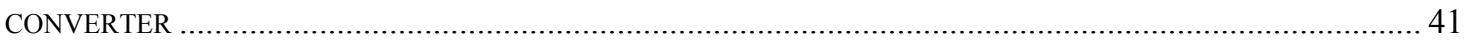

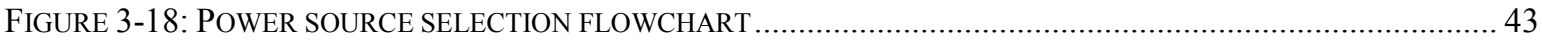

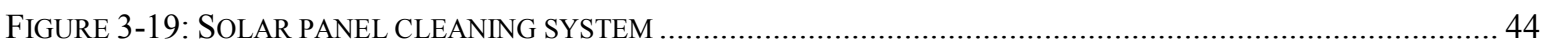

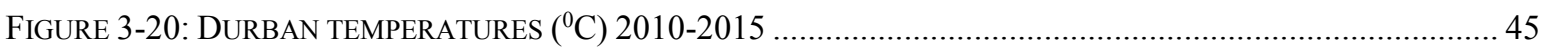

FIGURE 3-21: EFFECT OF CHANGE IN TEMPERATURE AND IRRADIANCE. ...................................................46

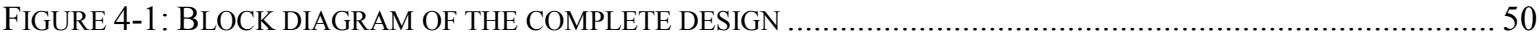

FIGURE 4-2: THE VOLTAGE SOURCE INVERTER FOR OUR DESIGN APPLICATION.......................................... 51 
Figure 4-3: Space Vector Modulation Vectors AND SECTORS .......................................................... 52

Figure 4-4: Vector COMBINATION TO GET REFERENCE VeCTOR...............................................................52

FigURE 4-5: (A) COMPARISON OF MAXIMUM LINEAR CONTROL VOLTAGE IN SPWM AND SVM ..................... 53

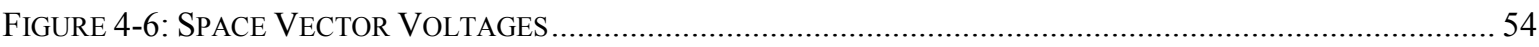

FIGURE 4-7: DETERMINATION OF REFERENCE VECTOR FROM ADJACENT VECTORS AT N=1 .............................55

FIGURE 4-8: SWITCHING PATTERNS OF EACH SWITCH FOR ALL SECTORS. .................................................... 57

FIGURE 4-9: COMPARISON OF SPACE VECTOR AND SINUSOIDAL PWM LOCUS ............................................ 58

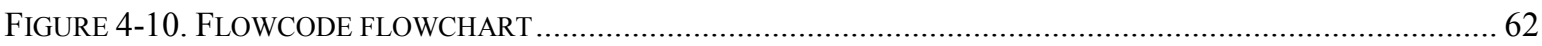

FigURE 4-11: ProteUS SIMULATION MODEL OF AUTOMATIC POWER SOURCE SELECTOR ................................63

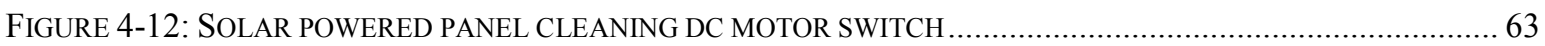

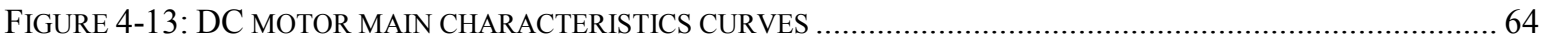

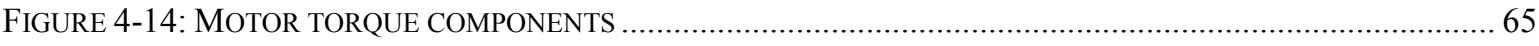

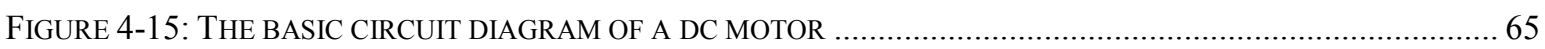

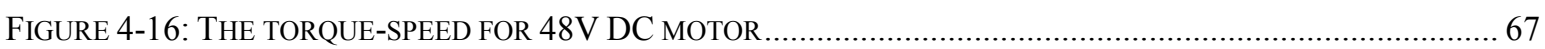

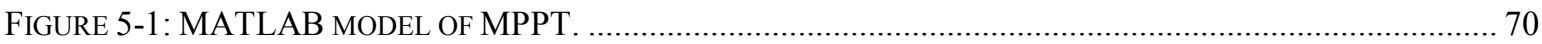

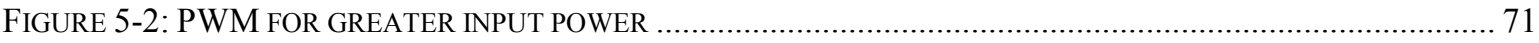

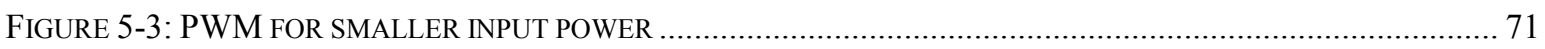

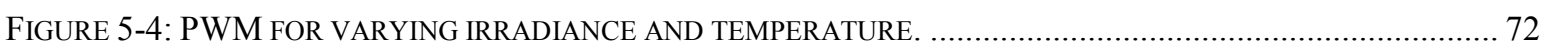

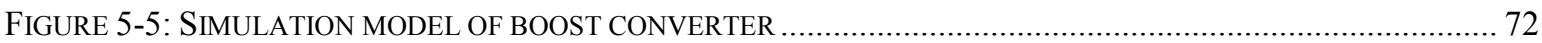

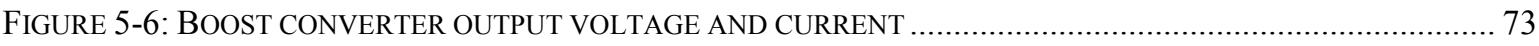

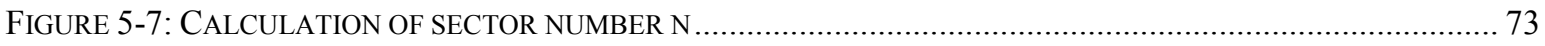

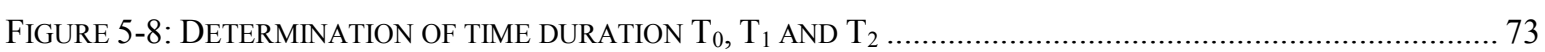

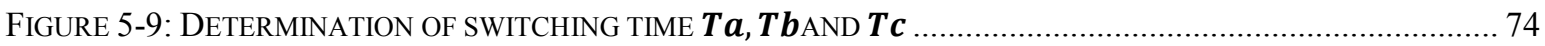

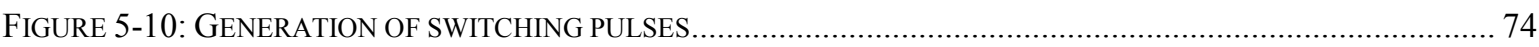

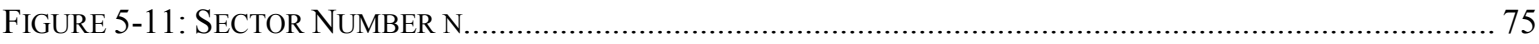

FIGURE 5-12: SIMULATION MODEL OF DC TO AC INVERTER …............................................................. 75

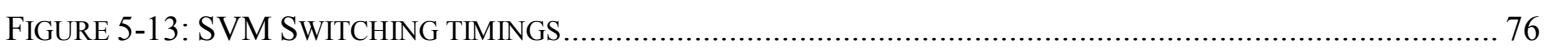

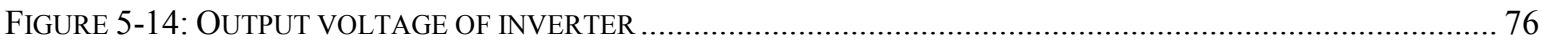

FIGURE 5-15 (A) - (K). LCD POWER SOURCE SELECTION DISPLAY …................................................ 78

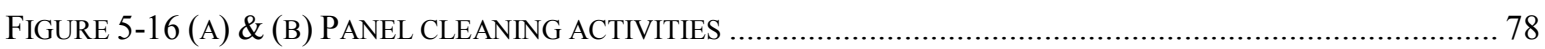

\section{List of tables}

TABLE: 2-1 EFFICIENCY OF DIFFERENT MPPT ALGORITHMS ............................................................ 15

TABLE 4-1: SWITCHING VECTORS, PHASE VOLTAGE AND OUTPUT LINE TO LINE VOLTAGE ..............................53

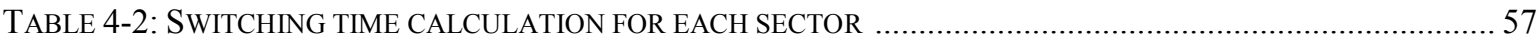

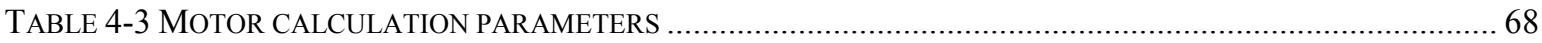




\section{Nomenclature}

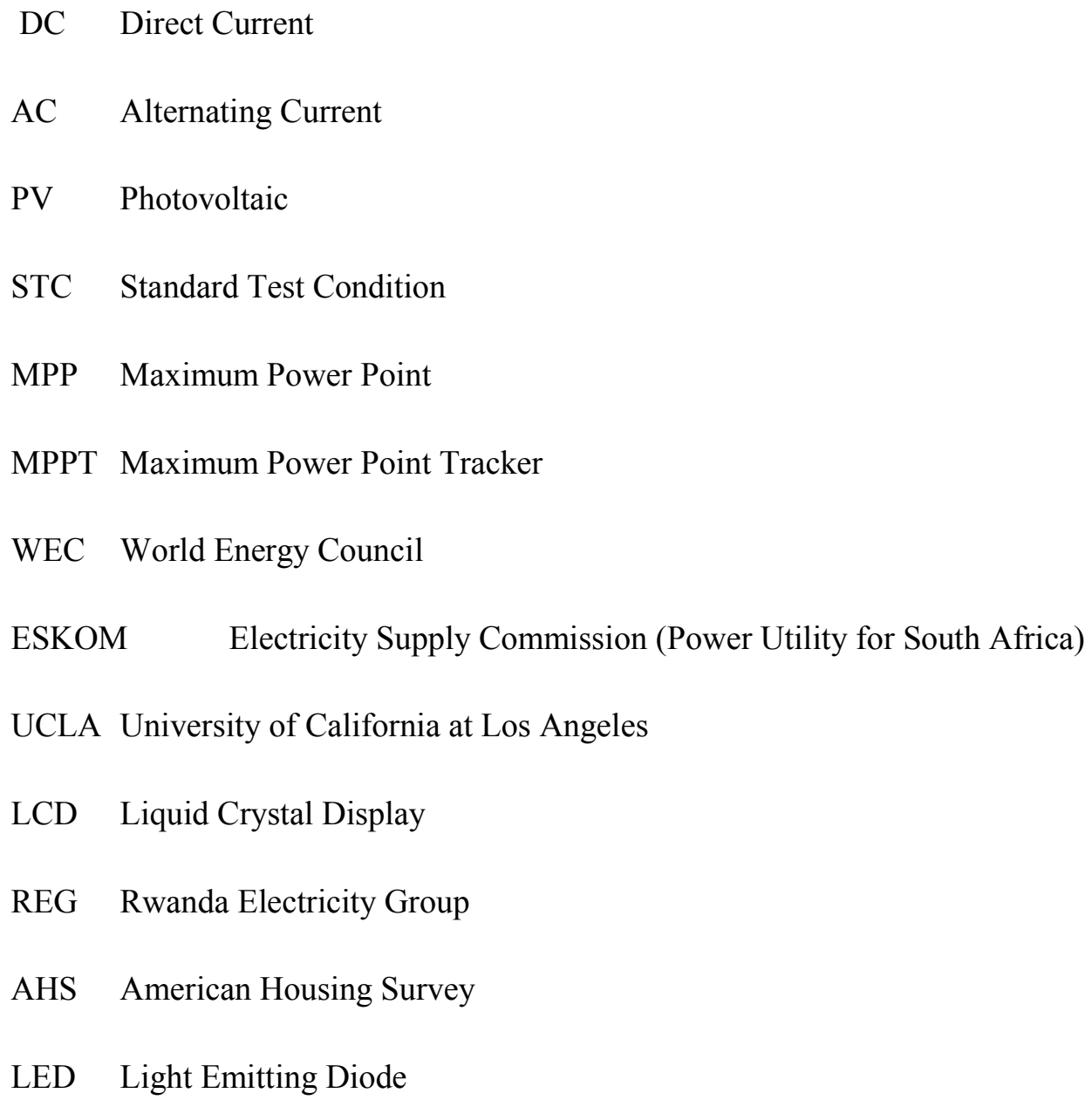


ESR Equivalent Series Resistance

SVM Space Vector Modulation

VSI Voltage Source Inverter

HVDC High Voltage Direct Current

SPWM Sinusoidal Pulse Width Modulation

ATMEGA AT refers to Atmel the manufacturer, Mega means that the microcontroller belonging to Mega-AVR category

AVR Automatic Voltage Regulation

CPU Central Processing Unit

EIA Energy Information Administration

HRES Hybrid Renewable Energy System 


\section{CHAPTER 1 \\ INTRODUCTION}

\subsection{Preface}

Commercial grid power supply fluctuations largely depend on the peak power demand load. This challenge is further compounded by the fact that most generation plants are located far away from the cities, and the losses that occur during the transmission increase due to the distance factor $[1,2]$. The capacity in the supply lines become often insufficient during peak time. The problem is not only raised by the transmission failures during peak times, but also by generation capacity shortages.

In order to help alleviate such fluctuations as well as insufficiency of generated power, suppliers use local power generators in some countries during peak periods but most of these generators are costly oil or gas-fired plants. This has a ripple effect where the price of electricity gets increased considerably for big consumers [3].

The reduction in using grid electricity during peak time benefits both sides: consumers and suppliers on consumer side, the price will be reduced and on suppliers side there will not be any constraints due to the transmission of electricity during this peak time. As a result, any method that can be used to reduce total dependence on grid power during peak period is highly welcome. Despite many alternative measures taken by the electricity suppliers to reduce the peak time energy demand, it remains a problem due to the reality of the need for electrical power supply during peak time.

This leads us to the need of alternative energy to be combined with the mains by using the time based power source selection. The alternative energy source should be preferably renewable (in this study, we selected Solar energy). In South Africa, thermal energy is popular for supplying power to the grid. The use of biomass, nuclear, solar, wind, and wave power generations are the other ways to generate electricity. The benefit of renewable energy systems was realised at an international renewable energy conference in Bonn, June 2004 - a follow-up to the 2001 world summit on sustainable energy development held in Johannesburg. The major factors motivating the use of renewable energy were economic reasons, energy security and climatic change mitigation [4].

The adoption of solar energy is from two major advantages, in particular:

a) Availability; as South Africa is listed as having areas of the highest solar irradiation levels in the world [5].

b) Indefinitely renewable [6].

The important aspect of using photovoltaic (PV) system is estimating the system output. The power produced by a PV system is proportional to the sunlight striking the solar array surface, which is not regular due to weather condition and the time of the day. This also leads to the factors that contribute to the variation effects in the output of a solar power system. They are important in giving the end user with realistic expectations of overall system output and economic benefits under unstable weather conditions over time. Also the mounting and installation of PV system is an important aspect in meeting the peak power demand.

Different methods developed to solve the problem of peak power demand are: 
a) Turn off unnecessary load during peak time: this is the traditional and very elemental method used by the consumers and/or suppliers but sometimes finds difficulties in selecting which unnecessary load to be turned off as compared to another.

b) Monitoring usage: this is a method used by predicting the demand of the next period of time where the alarm of the maximum demand is set for the operator to take action, but this intervention of the human being in such instantaneous operations have been found inadequate.

c) Load shedding: is the voluntarily stop of supply to one or more consumers to quickly restore the balance between production and consumption network. This solution is good for supplier but not good to consumers when their time for load shedding arrives since electricity is needed at any time.

d) Standby generator: a common solution for power outages but limited to power failure whatever may be the cause, but not tackle the problem of peak time power demand.

e) DC house: a power saver project of using only DC load, and the concept is good since the peak time power demand is basically caused by high power demand but this system is limited to low power load consumption.

In the above listed methods, either the load is disconnected from the source or the alternate power source is used during power failure. These methods could not solve the power demand during peak time. This research has been conducted to solve the high power demand from grid during peak time and to avoid the frequent load shedding problem.

f) Hybrid power system or simply "hybrid system" is a combination of different but complementary energy generation systems. The current research is focused on the automated hybrid solar and mains system for peak time power demand. The main problem of the existing hybrid renewable energy systems is the complexity in control and supervision of the energy distribution system.

\subsection{Automatic Switch Based on ESKOM's off and Peak Time's Electricity and Demand Programming}

In this study, the automatic power source selection between mains power and solar power during peak time is designed. The load is supplied by the mains $230 \mathrm{~V}, 50 \mathrm{~Hz}$ from the grid during normal times commonly known as Off-Peak (Monday to Friday at 11h00-17h59 \& 21h00-06h59 and the whole Saturday to Sunday) [7].

During the peak times (Monday to Friday; at 07:00-10:00 and 18:00-20:00) [7], solar power is obtained from the designed system where the solar panels with the Maximum Power Point Tracker (MPPT) provide the power (at the maximum point) to the battery bank for storage and from battery bank to the DC-DC boost converter designed for providing the 220Volts (DC) which will be fed to the inverter to be converted it to the alternating current as required by the load. The switching activity is done by the programmed microcontroller and it is automated. The switching program also provides an uninterruptable power supply to the load by switching the load to an available source all the times (mains or solar) when one failed for any reason, another source is automatically selected. This is to say for example if during the peak time, the load is normally switched to the solar system and it unfortunately fails during this time, the microcontroller will automatically switch the load to the mains or vice versa and without affecting normal time for switching schedule. The switching can be done in both ways: automatically and manually: any time the user may want the load to be supplied by either solar system or mains irrespective the programmed switching time schedule, the manual switch is provided as shown on the block diagram, Figure 4-1. 
In addition to power source selection the automatic panel cleaning robot has also been designed for optimizing the solar panel output. The cleaning activity is done periodically and the power supply to the robot is directly from the solar panel then through the DC-DC regulator for getting the stable output to be fed to the DC motor of the robot.

The switching is also done in both ways; automatically and manually. The user may need to switch the cleaning robot manually at any time, then the switch is provided. The system has also got the DC supply for the DC load which is the power from the $48 \mathrm{~V}$ battery bank.

All activities done for switching and panel cleaning are instantaneously shown on the LCD screen.

\subsection{Maximum Power Point Tracker -MPPT}

Photovoltaic inverters have an integrated system to detect and lock onto the maximum power point of the photovoltaic group. This system is called MPPT (Maximum Power Point Tracking). The MPPT therefore forces the generator to work at its maximum power point (MPP), leading to an overall improvement of the electrical conversion system performance.

However, the MPPT system works only for an input voltage range of the inverter defined by the manufacturer. When the inverter input voltage DC side is lower than the minimum MPPT voltage, the inverter continues to operate but the network provides the corresponding power to the minimum MPPT voltage.

Maximum power point trackers may implement different algorithms and switch between them based on the operating conditions of the array as detailed in the literature review. These algorithms include:
a) Perturb and observe $(\mathrm{P} \& \mathrm{O})$
b) Incremental conductance
c) Current sweep
d) Constant voltage

Perturb And Observe (P\&O) is chosen in this research for its ease of implementation in its basic form [8]. It is also Applicable for most of the systems, it does not require any information about the PV panel, but only the measured voltage and current [9].

Although incremental conductance is able to provide marginally better performance, the increased complexity of the algorithm will require more expensive hardware, and therefore may have an advantage over perturb and observe only in large PV arrays.

Current Sweep Method is only feasible if the power consumption of the tracking unit is lower than the increase in power that it can bring to the entire PV system [10].

The constant Voltage Method is simple and the facility cost is low, however the tracking accuracy used in this method is low and the error is big [11].

\subsection{Boost Converter}

The boost converter is a high efficiency step-up DC to DC switching converter which uses a transistor switch, typically a MOSFET, to pulse width modulate the voltage into an inductor. The output voltage is always greater than its input voltage. It is a class of switched-mode power supply (SMPS) 
containing at least two semiconductors (a diode and a transistor) and at least one energy storage element, a capacitor, inductor, or the two in combination.

\subsection{Inverter Design}

Power inverter is a device that converts electrical power from DC form to AC form using electronic circuits. It is typical application is to convert battery voltage into conventional household $\mathrm{AC}$ voltage allowing the use of electronic devices when an AC power is not available.

There are basically three kinds of Inverter out of which, the first set of inverters made, which are now obsolete, produced a Square Wave signal at the output [12].

The Modified Square Wave also known as the Modified Sine Wave Inverter which produces square waves with some dead spots between positive and negative half-cycles at the output. The cleanest Utility supply like Power source is provided by Pure Sine Wave inverters for which the market is going through a shift from traditional Modified Sine Wave Inverter to Pure Sine Wave inverters because of the benefits that these inverters offer. The designed and simulated inverted in this thesis is the square Modified Sine Wave in Simulink and Pure Sine wave in Proteus as shown in Appendix B.

\subsection{Objectives of the Thesis}

The global requirement of Green energy solution to meet the power demand from grid during peak time is the motivation for this research. The solar power system has to be used as an alternate source to supply power at peak times and during off peaks times when the mains is not available. Thus the general objectives of the thesis are:

a) To design a hybrid of solar and mains power system which is used to supply power during peak power demand time to the load in the coffee shop located at Howard College Campus, University of KwaZulu-Natal, Durban.

b) To design an automated switching system to switch between solar and mains using microcontroller and relays.

c) To design a self-powered automatic panel cleaning system with pre-programmed cleaning schedules to maximize the power output from solar panel.

\subsubsection{Specific Objectives}

In this research, a hybrid system using AC mains and PV array is designed to supply power to the load during peak power demand timings estimated by ESKOM. This design is an automatic system; where at peak power demand time, solar power and/or battery power is used while at other times the mains power is used as the source. This design also includes a scheduled panel cleaning system controlled by a microcontroller. The LCD displays the selection of power source at the required time. The provision of an overriding automatic source selection and panel cleaning activities by manual switching is also included. The automation of the design makes it user friendly.

To fulfil the general objectives, the following specific objectives are required to be fulfilled:

a) Design of P\&O algorithm to get MPPT and to drive boost converter. 
b) Design of the charge controller to charge the batteries, blocks reverse current and prevents battery from overcharging and electrical overload and/or displays battery status and the flow of power in the battery.

c) Design of Boost Converter for stepping up 48V DC input voltage to $220 \mathrm{~V}$ DC output voltage.

d) Design of DC-AC inverter to convert 220V, 3A DC voltage from boost converter to meet the load demand.

e) Design of switching algorithm using microcontroller to switch between solar and mains power during peak time and emergency situation.

f) Design of panel cleaning robot is which operates from the command given by programmed microcontroller. The core motor of the robot is $48 \mathrm{~V} \mathrm{DC}$ designed to rotate in forward and reverse directions and these motions will make the brushes and squeezes to perfectly clean the whole surface of the panel through the arrangements of the gear system and bearings.

\subsection{Contribution of the Thesis}

The main contributions of the thesis are:

a) The combination of renewable and non-renewable technology to meet the power demand from grid during peak time is discussed and designed.

b) The sizing of solar panel and converters to meet the power demand of the coffee shop in University of KwaZulu-Natal is analysed and the cost benefits compared with the mains system.

c) Design of automatic switching system to switch between solar and mains power sources during peak time.

The contribution of the Publication is presented in Chapter 4.

\subsubsection{Outline of the Thesis}

This thesis presents an overview and progressive arrangement of chapters. This thesis is also supported by one Publication (P1). The scientific contribution of the thesis is organized as follows:

Chapter one introduces the subject matter and objectives of this thesis. The major problems caused by the peak time power demand are addressed, different techniques used to handle them, the proposed method used in this research as well as the objectives of this thesis are discussed.

In Chapter two, literature study about solar energy resources in South Africa; earlier challenges and alternative solutions for peak power demand have been investigated through different works and researches. The previous works done on the panel cleaning robot have been investigated.

Chapter three discusses the solar and mains system technology as well as presentations of calculation results from calculations. The design of solar system including boost converter for MPPT and connecting it with the mains systems to meet the load requirements is discussed in detail. 
In Chapter four, the design of sub systems included in the automatic source selection is discussed. The design of inverter, boost converter and hybrid solar and mains for automatic switching is designed and the modelling is presented.

Chapter five summarizes the simulation, results and discussion of the publication.

Finally, Chapter six concludes and recommends the future studies. 


\section{CHAPTER 2}

\section{LITERATURE REVIEW}

\section{Introduction}

In South Africa, the electrical energy from mains is mainly generated from non-renewable sources and it is highly vulnerable to fluctuations during the peak power demand load. This challenge is handled by calling upon the projects working on the use of alternative renewable energies. The automated hybrid solar and mains system is discussed in this thesis. The choice of solar energy is motivated by its availability, renewability and being the most promising renewable energy source.

\subsection{Solar Energy Source Overview}

The energy from the sun reaches the earth in the form of light originating from the core of the sun through radiation phenomenon in which the nuclear activity generates radiation and reaches the surface of the earth in the form of massless photons [13]. Different photons carry different wavelengths of light, some of these photons carry infrared and ultra-violet lights which are nonvisible lights whilst others carry visible white light. Overtime, these photons will come out from the core of the sun. The time for pushing out from the core to the surface of the sun can reach one million of year, and once they reach the surface, they rush through space at speed of 1.09 billion $\mathrm{km} / \mathrm{hr}$, that to say an average of 8 minutes and 20 seconds to travel from the Sun to the Earth [6].

Photons on their journey from the sun to the earth are absorbed or deflected by colliding with other particles which will absorb radiation generating heat. This is the reason why for example we feel warm on a sunny day; our bodies absorb photons from the sun. The photons from the sun travel the thinner layer of atmosphere to reach the earth during the day whereby their intensity is much higher, but at the end of the day when the sun is setting the photons have to travel through a much thicker layer of atmosphere (Figure 2-1). Moreover, the layer travelled by photons during the winter is thicker than the one travelled during the summer to reach the earth. This also explains the reason why a sunny day in winter is colder than a sunny day in summer [14].
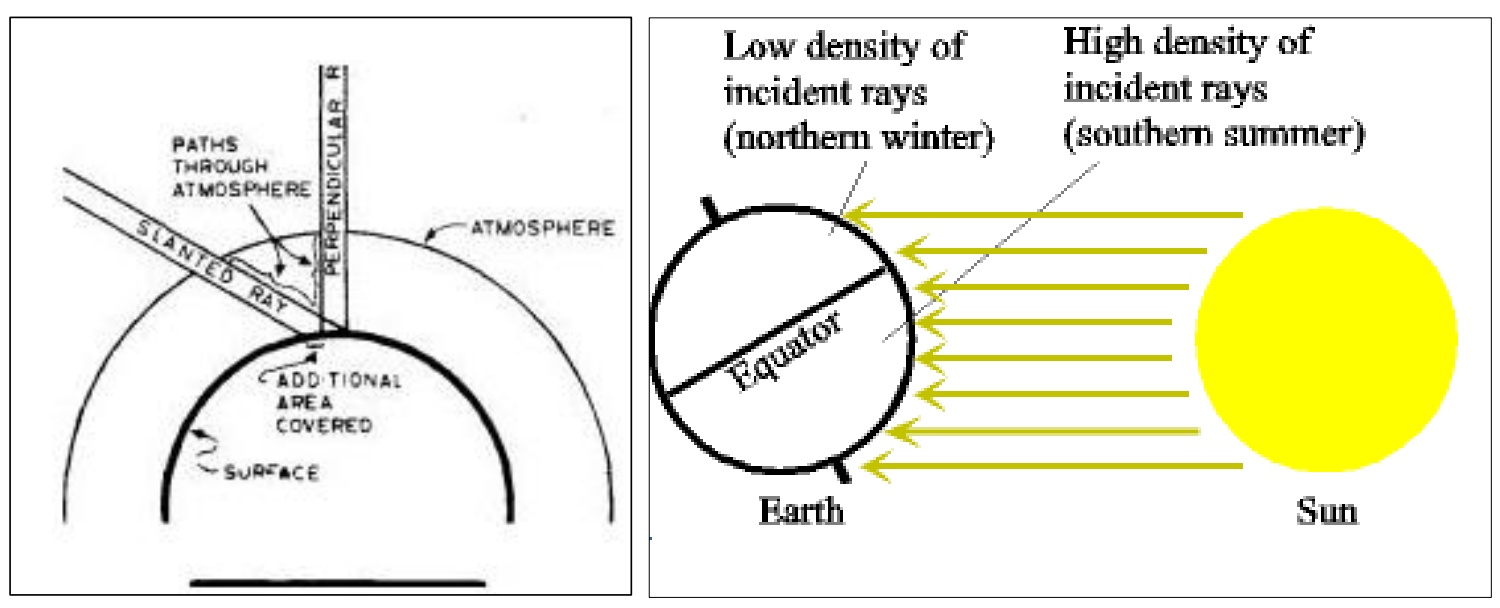

Figure 2-1: Diagrams of photons from the sun to the earth through the atmosphere [15-17]

The sunlight hits the solar cells in solar panels and through a photovoltaic process turns this light into power. 
One may wonder what quantity of energy is obtainable from the Sun. The law of energy conservation states that 'energy is neither created nor destroyed' [18]. This is a pointer that the volume of energy required to have smooth running activities are available naturally. Our main challenge is developing technologies which will help in conversion process.

Energy obtained from the Sun is in two patterns; heat and light, leading to the two main divisions of solar power system. These are solar thermal systems which capture heat to warm up water, and/or the solar PV systems which convert sunlight into electricity used to various activities [19].

Direct current (DC) is generated when PV modules are exposed to direct sunlight. The DC is then converted through a DC-DC boost converter then inverted into alternating current (AC) electricity that is fed into the AC load. The generated electricity from PV system may serve for dual purpose: On-Grid (or Grid-Connected or Grid-Tied) and Off-Grid (or Stand-Alone) solar PV systems [19].

\subsection{PV Panel}

For efficiency and economics reasons, PV materials are categorized as either crystalline or thin film [20] or perovskite [21]. It is therefore essential to know the characteristics of each to assess the performance of photovoltaic solar panels to be installed [22]. Crystalline technology is having the advantage of greater conversion efficiency even where available space is very limited. Another point to take into consideration when sizing the array for a multi-year project is that up to $25 \%$ drop off rapidly in conversion efficiency of thin-film panels in the first few years of its operation. The PV technology which is more appropriate for a given application will be determined on the peculiarity of the project as there situations where thin-film is preferred to be more suitable based on the lighter weight and greater flexibility.

\subsubsection{Monocrystalline Silicon Panels}

The monocrystalline silicon panels are considered when a higher voltage is desirable. This would be in an instance where the DC power has to be transmitted some distance before being utilized or stored in a battery bank. These panels have average efficiency of $14 \%$ to $17 \%$ which makes it one of the most efficient but the production method is laborious and difficult and therefore, very expensive because it takes a lot of energy in the process of getting a pure crystal.

\subsubsection{Polycrystalline Silicon Panels}

The polycrystalline silicon panels are commonly used in polar applications and much cheaper than mono-crystalline with efficiencies ranging from $12 \%$ to $14 \%$. They are very popular on the market and dolly visibility of cells (Figure 2.2 (a)). Polycrystalline cells are made from a block of silicon crystallized in the form of multiple crystals, polycrystalline cells are viewed closely. You can see the different orientations of the crystals as shown in Figure 2-2 (b). They have an efficiency of 11$13 \%$, but the production cost is lower than monocrystalline cells [23].

Both monocrystalline and polycrystalline cells are the most common but their fragility requires protection by glass plates, which increases more the weight of the solar panel. The base material is silicon, which is very abundant in the earth's crust. However, the quality necessary to achieve the cells should be of very high purity and therefore, its cost becomes larger in the total cost of installation. 


\subsubsection{Thin-film Panels}

The thin film panels include amorphous silicon, cadmium telluride, copper-indium diselenide, and others. They have initial cost advantage but the efficiencies are comparatively low. The initial $8 \%$ to $10 \%$ efficiencies recorded in new panels quickly degrade to about $3 \%$ to $6 \%$ after several months of exposure to sunlight [24]. Newer, triple-junction thin-film technologies which appear to have higher efficiencies still experience less degradation over time.

\subsubsection{Amorphous Cells}

The amorphous cells are shown in Figure 2-2 (c), and are also known as "thin-film cells", they have a much lower production cost, unfortunately their performance is only $8-10 \%$. This technology allows the use of very thin layers of silicon. Therefore they can be applied in very thin amorphous silicon layers on glass, flexible plastic or metal, by a vacuum evaporation method. The amorphous silicon is found mostly in small consumer products such as calculators and watches, but also more recently on large areas used for covering roofs.

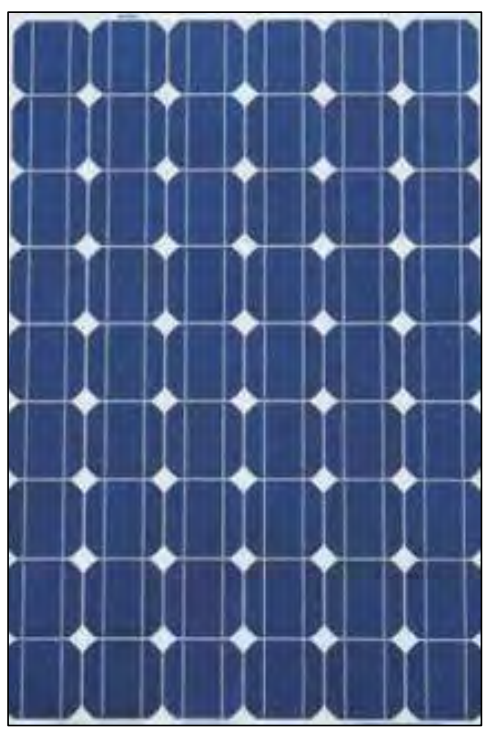

(a)

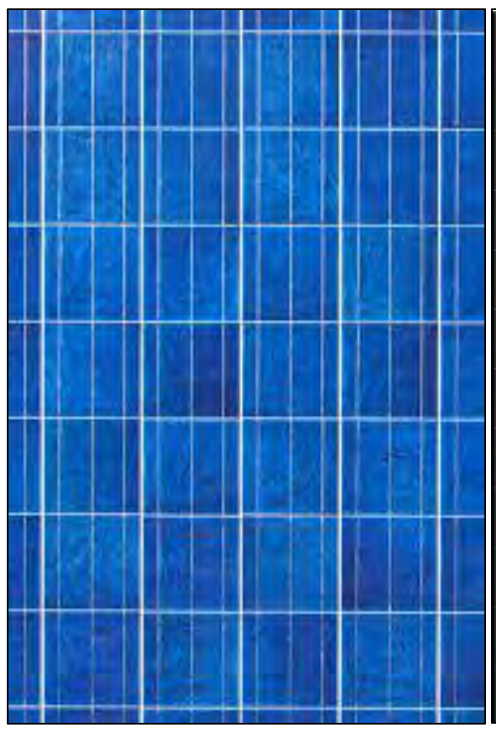

(b)

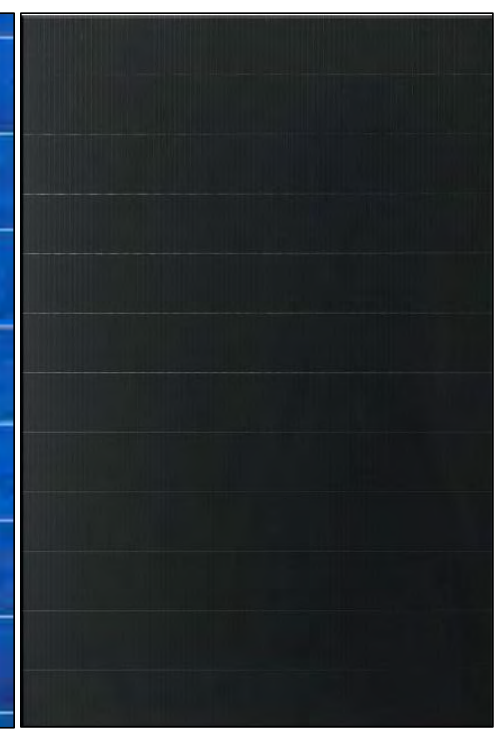

(c)

Figure 2-2: Different types of solar panels[25]

(a) Monocrystalline (b) Polycrystalline and (c) Amorphous

\subsubsection{Perovskite Solar Cell}

The perovskite solar cell is a type of solar cell made of a perovskite compound structure. It is in a form of hybrid organic-inorganic lead or tin halide-based material, as the light-harvesting active layer [21]. The name Perovskite is given to this kind of cells from the Russian Mineralogist L. A. Perovski (1792-1856) who discovered it together with Gustav Rose in 1839. It is a material of the same type of crystal structure as calcium titanium oxide (CaTiO3) or XIIA2+VIB4+X2-3 with the oxygen in the face centre [26], it has been discovered in the Ural mountains of Russia.

The materials in which Perovskite is made such as the methylammonium or formamidinium lead halides are relatively cheap to produce and simple to manufacture. The production of this type of solar cell dates from 2009 whereby it experienced a rapid progress; the efficiency increased from $3.8 \%$ in 2009 [27] to a certified $20.1 \%$ in 2015 [21]. 
The chosen type in this project: monocrystalline for its overall better efficiency as also discussed in details in section 3.1.

\subsection{PV Mounting}

Apart from the very small and or portable solar PV panels which are placed anywhere depending on the usage, the relatively big solar panels are mounted in various ways for their effectiveness in utilization.

The research done by T. Mali [28] came out with basic principles to follow when installing the PV array are listed below:

a) Select a packaged system based on customer need which may include reduction in monthly electricity bill, environmental benefits, desire for backup power, initial budget constraints, size and pattern of PV array to provide the expected electrical power and energy

b) Ensure the roof area or other installation site is capable of handling the desired system size

c) Specify sunlight and weather resistant materials for all outdoor equipment

d) Locate the array to minimize shading from foliage, vent pipes, and adjacent structures

e) Design the system in compliance with all applicable building and electrical codes

f) Design the system with a minimum of electrical losses due to wiring, fuses, switches, and inverters.

g) Properly house and manage the battery system

More generally, the essential steps to follow when installing a PV System are [13]:

a) Ensure the roof area or other installation site is capable of handling the desired system size

b) If roof mounted, verify that the roof is capable of handling additional weight of PV system

c) Properly seal any roof penetrations with roofing industry approved sealing methods

d) Install equipment according to manufacturers' specifications, using installation requirements and procedures from the manufacturers' specifications

e) Properly ground the system parts to reduce the threat of shock hazards and induced surges

f) Check for proper PV system operation by following the checkout procedures on the PV system installation checklist

g) Ensure the design meets local utility interconnection requirements

The PV panel mounting types are [29-31]:

\subsubsection{Ground Mounted Type}

Solar panels can be installed directly on the ground. The panels are placed on the ground with support frames at a certain height. 
The advantages of ground mounting are:
a) fast installation
b) orientation and inclination of the modules easy to optimize
c) simplified maintenance
d) good ventilation solar panels

The disadvantages of ground mounting are:

a) requires significant scope

b) panels can easily be hindered by shadows, particularly the building

c) on the ground installations require the construction of a foundation clamped to the ground

d) more susceptible to theft/vandalism and excessive snow accumulation at the bottom of the array.

\subsubsection{Roof Mounted Type}

The most common PV mounting is roof mounted type. In this case, the solar panels are incorporated into the roof where in many cases they also ensure the sealing function.

The advantages of roof mounting:
a) best visual
b) building integration is indicated for starting construction
c) performance promises are better because masking items may be few
d) solar panels are harder to steal
e) keep the wire run distances between the solar array and battery bank to a minimum

The disadvantages of roof mounting are:
a) risks associated with the waterproofing of the roof
b) the cost of work is higher on an old building
c) ventilation solar panels is more delicate

\subsubsection{Pole Mounted Type}

Pole mounted solar panels use a pole (instead of roof or ground) to elevate and support them to the desired height. Pole mount solar panel is commonly used in backyard applications to keep the panels off the ground and out of harm's way but yet still easy enough to adjust and clean. 
The advantages of pole mounting are:

a) optimizing the orientation and inclination of the modules is easy

b) good air ventilation of the modules, easing performance due to heat losses

c) the system can easily be made by avoiding masking elements

d) easy maintenance

e) reduce the risk of theft/vandalism (as compared to a ground mount)

f) for cold climates snow slides off easily

The disadvantage of pole mounting is:

a) cumbersome visual appearance

\subsubsection{Wall Mounted Type}

The PV mounting can also be done on the wall. In this case, the solar panels replace a member of the closed side of the building as a wall portion. The panels will also play a closing role and protecting the building i.e. a dual purpose and offsetting some costs.

The advantages of wall mounting are:

a) visual and architectural interest

b) the available surface area is greater than for a roof integration

The disadvantages of wall mounting are:

a) the angle of incidence of the light is not optimal, which reduces the efficiency

b) more exposed to the shadows of the surrounding elements such as trees

For the On-Grid system (PV system that is connected to the utility grid), the load has two parallel power supplies, one from the solar PV system and the other from the power grid. The advantage of this type is when the generated power from the solar PV supply exceeds the building's demand, the excess electricity is then released into the grid and power grid will supply all of the building's demand. This system is an effective way of reducing dependence on utility.

On the other hand, Off-grid solar PV systems (i.e. when utility power is not accessible) are usually installed at isolated sites where the power grid is far away such as rural areas and isolated islands. It requires the use of rechargeable batteries such as lead-acid, nickel-cadmium or lithium-ion batteries in storing electricity for use in periods when generation is little or not in view.

\subsection{Maximum Power Point Tracking MPPT}

The Maximum Power Point Tracking is a common control mechanism used to regulate the DC voltage in such a way that the maximum possible power output is delivered with respect to the weather conditions $[32,33]$. In other words: MPPT is an electronic DC to DC converter that optimizes the 
match between the PV solar array (or wind turbines) and the battery bank (or utility grid). It is a full electronic system that varies the operating point of the modules to achieve optimal operating point and is embedded inside the charge controller or inverting interface [33].

There MPPT algorithms commonly implemented are [8, 33-38] :

a) Incremental Conductance (inCond) method

b) Constant Voltage method

c) Fractional Short-Circuit Current

d) Perturb and Observe (P\&O) method

\subsubsection{Incremental Conductance (inCond) method}

Based on the observation from equation (2.1), the incCond algorithm holds the maximum power point.

$$
d i_{p v} / d v_{p v}+i_{p v} / v_{p v}=0
$$

The algorithm starts the first cycle by obtaining measurements of current values of $\operatorname{Ipv}(\mathrm{n})$ and $\operatorname{Vdc}(\mathrm{n})$ and corresponding values $\operatorname{Ipv}(\mathrm{n}-1)$ and $\mathrm{Vdc}(\mathrm{n}-1)$ and the changes are approximately $\Delta \operatorname{Ipv}=\operatorname{Ipv}(\mathrm{n})$ $\operatorname{Ipv}(\mathrm{n}-1)$ and $\Delta \mathrm{Vdc}=\mathrm{Vdc}(\mathrm{n})-\mathrm{Vdc}(\mathrm{n}-1)$ and these changes $\mathrm{dIpv} / \mathrm{dVdc}$ are equated in equation (2.1) $(\mathrm{dIpv} / \mathrm{dVdc}+\mathrm{Ipv} / \mathrm{Vdc})$ and if this equation yields a negative value means the operating point on the $\mathrm{P}-\mathrm{V}$ curve is to the right of the maximum power point and the voltage Vdc will be increased in steps towards maximum point and if yields positive value then operating point is to the left of the maximum point therefore the voltage Vdc will be decreased in step towards the maximum point [39]. Two more checks in the algorithm to detect whether a control adjustment is required when the maximum point has been previously been reached $(\mathrm{dVdc}=0)$, checking if $(\mathrm{dIpv} \neq 0)$ for the purpose of checking change in environment and if $(\mathrm{dIpv} \neq 0)$ then a search for new maximum position by changing $\mathrm{Vdc}$ or else bypass the perturbation step.

Practically, the condition $d I_{p v} / d V_{d c}=-I_{p v} / V_{d c}$ seldom occurs because of the approximations made in calculations $d I_{p v}$ and $d V_{d c}$, therefore an absolute value $\varepsilon$ which determines the sensitivity of the MPPT to reduce potential oscillations. The maximum is assumed when $\left|\frac{d i_{p v}}{d v_{p v}}+\frac{i_{p v}}{v_{p v}}\right|<\varepsilon$. The voltage increment step $\Delta \mathrm{V}$ determines the algorithm speed. This algorithm performs well under rapidly changing environmental conditions but requires two sensors to measure instantaneous voltage and current which results in high cost and complex system [40].

\subsubsection{Constant Voltage method}

This algorithm makes use of the fact that at the maximum power point, voltage changes slightly with varying irradiance but dependent on temperature levels. The ratio $\mathrm{k}$ in equation (2.2) depends on the solar cell parameters. It is approximately $71 \%-78 \%$ for different irradiance and temperature levels. In this algorithm the MPPT momentary disconnects PV array to allow measurements of the arrays open circuit voltage. Then the operating voltage $\mathrm{Vm}$ is the multiple of the ratio and open circuit voltage Voc. The disadvantage of this algorithm is that energy is wasted every time the MPPT disconnects and the operating point is not always between $71 \%-78 \%$ of the arrays open circuit voltage 
[41]. To prevent the momentary disconnections, [42] suggested the use of pilot cells from which Voc can be obtained.

$$
V_{m} \approx k V_{o c}
$$

This algorithm is simple and only requires one measurement and is suitable for use where the optimal operation is not required. It is more suitable to measure the open circuit voltage at start up and set the operational voltage $\mathrm{Vm}$.

\subsubsection{Fractional Short-Circuit Current method}

Fractional Isc described by equation (2.3) is very similar to constant voltage technique with the constant $\mathrm{K}_{1}$ generally found to be between 0.78 and 0.92 . Measuring $\mathrm{I}_{\mathrm{sc}}$ during operation is problematic. An additional switch usually has to be added to the power converter to periodically short the PV array so that Isc can be measured using a current sensor [43].

$$
I_{m} \approx K_{1} I_{s c}
$$

where $\mathrm{K}_{1}$ is a proportionality constant. Power output is not only reduced when measuring Isc but also does not always operate between 78\%-92\% [37].

\subsubsection{Perturb and Observe (P\&O) method}

As compared to other MPTT techniques, the P\&O is efficient and simple to implement [44]. In the Figure 2-3, the blue curve has a maximum power point $P_{m p}$ for which a given operating voltage $\mathrm{P} \& \mathrm{O}$ algorithm will be perturbed periodically by adjusting the voltage in a direction to climbing the P-V curve in small changes of $\Delta \mathrm{V}$. The direction of the change is determined by the measured power $P_{n}$ subtracting $P_{n-1}$ previously measured and if it happens that $d p / d V>0$ this means that; the gradient is positive climbing up the $\mathrm{P}-\mathrm{V}$ curve towards the maximum power point, therefore the $\mathrm{P} \& \mathrm{O}$ will continue to perturb in the same direction. But if $d p / d V<0$ negative gradient that means the maximum power point is passed and the $\mathrm{P} \& \mathrm{O}$ needs to reverse its direction therefore perturb backwards.

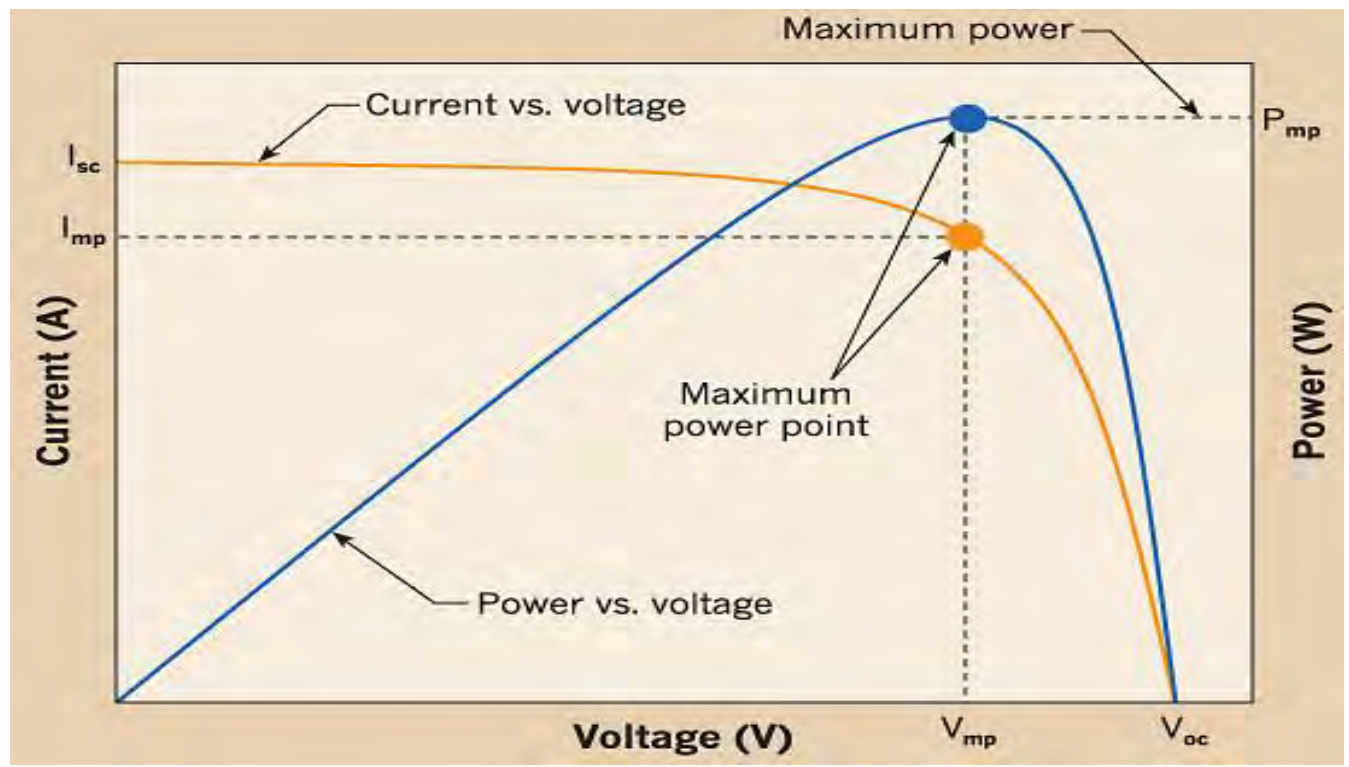

Figure 2-3: Solar panel I-V curve (orange) and P-V curve (blue) [44] 
The problem with $\mathrm{P} \& \mathrm{O}$ is it oscillations around the maximum point during steady state operations and can also track incorrectly under rapid change of irradiance or temperature. These two disadvantages cause power loss. The oscillations can be minimized by reducing the perturbation step size but this will slow down the MPP tracking system [45, 46]. The problem of missing tracking MPP during rapid change of environment conditions can be solved by introducing a third reference $V d c(n+3)[47,48]$. In order to implement the $\mathrm{P} \& \mathrm{O}$ algorithm the following three conditions are need to be satisfied.

The three conditions are:

a) $\mathrm{dp} / \mathrm{dV}>0$ increase $+\Delta \mathrm{Vdc}$

b) $\mathrm{dp} / \mathrm{dVdc}<0$ decrease $-\Delta \mathrm{Vdc}$

c) $\mathrm{dp} / \mathrm{dVdc}=0$ (at MPP)

\subsubsection{MPPT Performance}

The important factors of an efficient MPPT is the tracking speed and the tracking accuracy, ideally less steps (tracking accuracy) and higher frequency (tracking speed) should work perfectly since small duty cycle will decrease oscillation and high frequency will increase the speed but from $[37,46]$ it is not practical to operate the MPPT due to noise and time delay. In the case of a rapid change in atmospheric conditions the MPPT will be less efficient especially on cloudy days. Therefore it is important to set the duty cycle step low but also allow system to reach new steady state first before perturbation.

\subsubsection{Efficiency of MPPT Algorithm}

The efficiency of the different algorithms is compared in [8] and the results are tabled Table2-1

Table: 2-1 Efficiency of different MPPT algorithms

\begin{tabular}{|c|c|c|c|}
\hline & P\&O & IncCond & CV \\
\hline Array & $96.50 \%$ & $98.20 \%$ & $88.10 \%$ \\
\hline Simulator & $97.20 \%$ & $98.50 \%$ & $92.70 \%$ \\
\hline
\end{tabular}

As expected the constant voltage has the lowest efficiency followed by the P\&O algorithm and IncCond has a better efficiency. Similar studies were done in [33,36], and both show incCond has a higher efficiency then $\mathrm{P} \& \mathrm{O}$ and last the constant voltage with a lower efficiency. The $\mathrm{P} \& \mathrm{O}$ and incCond have quite close efficiencies relatively but the incCond has more complexity then the P\&O. Also, another advantage of $\mathrm{P} \& \mathrm{O}$ algorithm is that its output can directly drive the boost converter for higher efficiency. Hence, the Perturb and Observe (P\&O) technique is implemented in this research.

\subsection{Hybrid Solar and Mains}

The hybrid of solar and mains is the technique of combining the power from mains with solar power from solar photovoltaic system. The purpose of hybrid solar and mains is mainly economic, energy security policy and climatic change mitigation [4]. The system can either be off-grid solar with utility backup power, or on-grid solar with battery storage.

Different modelling techniques on the solar system and mains have been studied by many researchers $[22,49-51]$. In this thesis, the combination of solar and mains is developed for the purpose of both 
beating the peak time demand and having the uninterrupted power supply, in addition to the stated advantages of solar system (availability, renewability and environmental friendly).

Nevertheless, on the highest aspect of the PV array, the output is nonlinear and time dependent varying with solar intensity and cell temperature. The effect of cell temperature has been investigated in this thesis, as many researches have evoked this important point [52-55]. Additionally, power rating of PV devices do not usually give an accurate indication of their outdoor performance [56] due to meteorological conditions that could cause an $18 \%$ reduction of output power as discussed in Chapter 3.

The technology of combining more than one source requires to use the second one preferably renewable for its advantages. Similar projects done are focussed on the reduction of the transmission losses due to peak times as well as the cost of electricity from mains consumption tariffs whereby alternate energy sources are created at the utilization load to second the existing power from the mains.

Non-renewable energy sources include: Petroleum, Nuclear Fuel, Fossil Fuel, Coal, and Diesel.

Coal covers $74 \%$ of energy source in South Africa (Figure 2-4).

Dale Vince OBE the founder of Ecotricity, the Britain Green Electricity company said: "The coal reserves are finite - it's only a matter of when they run out - not if" [7].

Nowadays the second alternate sources used to beat the peak times include: solar, wind, diesel, steam turbo-alternator, etc.

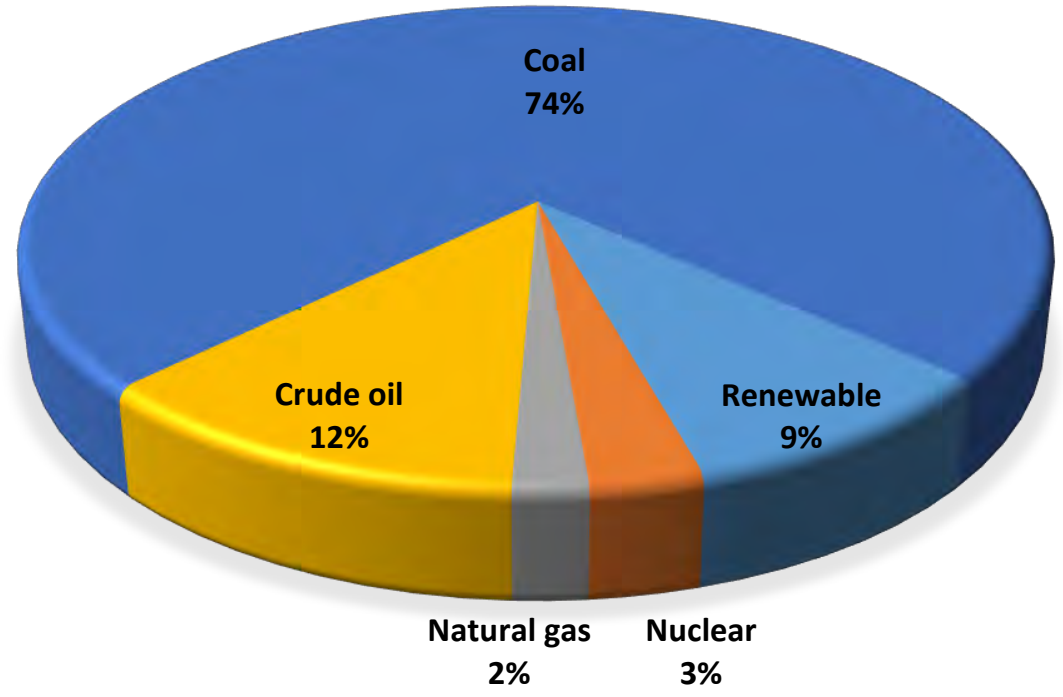

Figure 2-4: South Africa's primary energy consumption by supply sector [57] .

\subsection{Earlier Alternative Solutions for Peak Power Demand}

\subsubsection{Turn off Unnecessary Load during Peak Time}

The very first solution for electricity production companies as well as distribution authorities take for solving the problems related to the peak time power demands is to give advice to the consumers of turning off unnecessary loads and making clear of the drawbacks of consuming much electricity during the peak times. These drawbacks include the incremental of the price; in formal public 
statements and announcements: here "Eskom estimates that HVAC (heating, ventilation, air conditioning) contribute 5400MW (about 15\%) to peak demand." [58].

Nevertheless, this solution seems not favourable due to the following reasons;

a) There are unavoidable consumption loads for which can bring forth problems when turned off during peak time, like the air conditioning and fans which constitute the largest consumer of electricity in households $[4,59]$, especially during winter and or summer seasons. The hotter the day, the longer the fans and/or air conditionings are on and the colder the day the longer the air conditioning needs to heat rooms. Moreover, the ownerships of air conditioning in houses increases everywhere [5].

The air conditioner ownership is growing more rapidly every day. Figure 2-5 shows the percentage of all households having any type of air conditioning between 1970 and 2005 in America. Similar trend of outcome may be observed in all other countries.

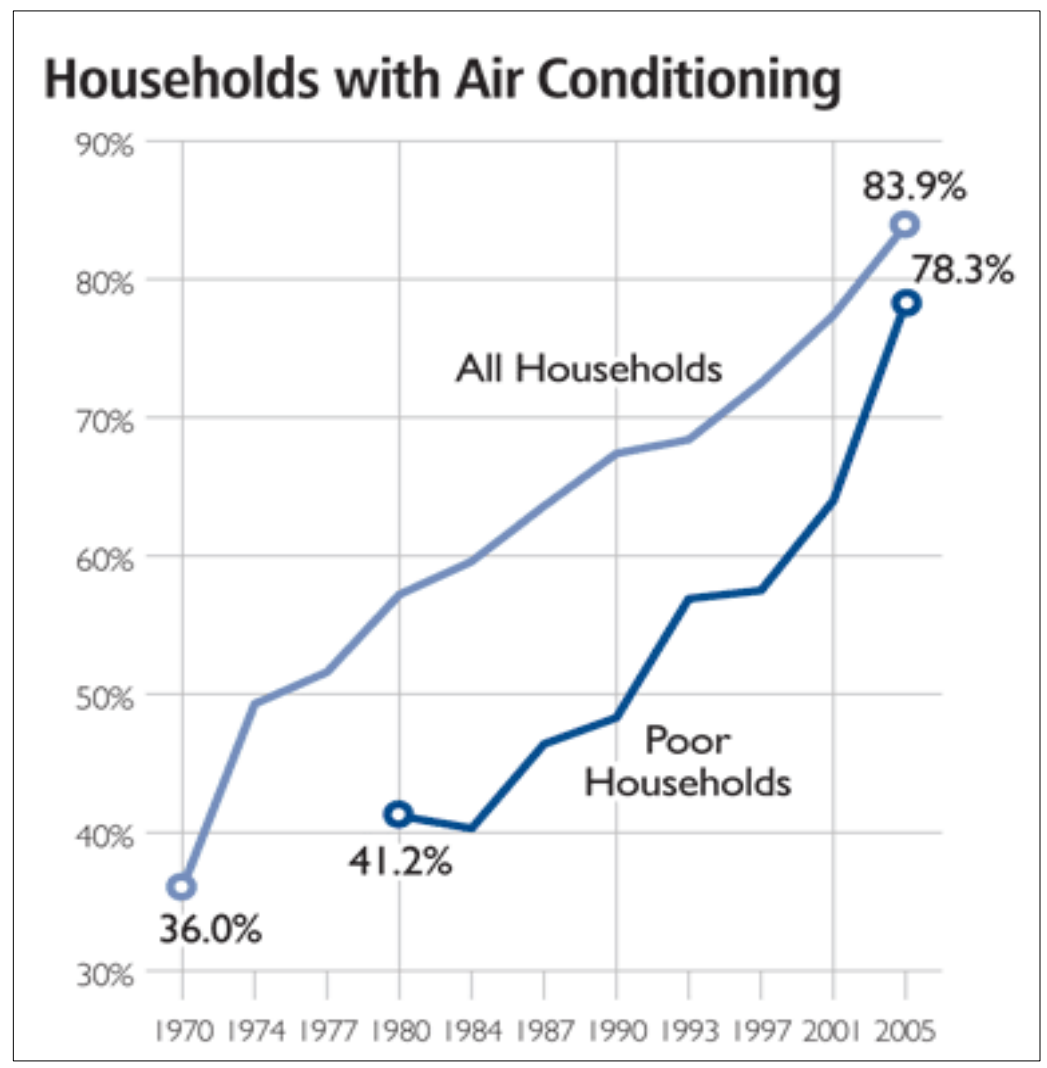

Figure 2-5: Air conditioning in households grow. Source: American Housing Survey (AHS) [60].

b) In addition to this, the time for bathing, cooking (recalls Geyser and electric stove) and business activities cannot easily be changed due to the reality of the people's need of electricity time and this comes about peak time demand.

Figure 2-6 shows the Average South African household daily electricity consumption pattern. 


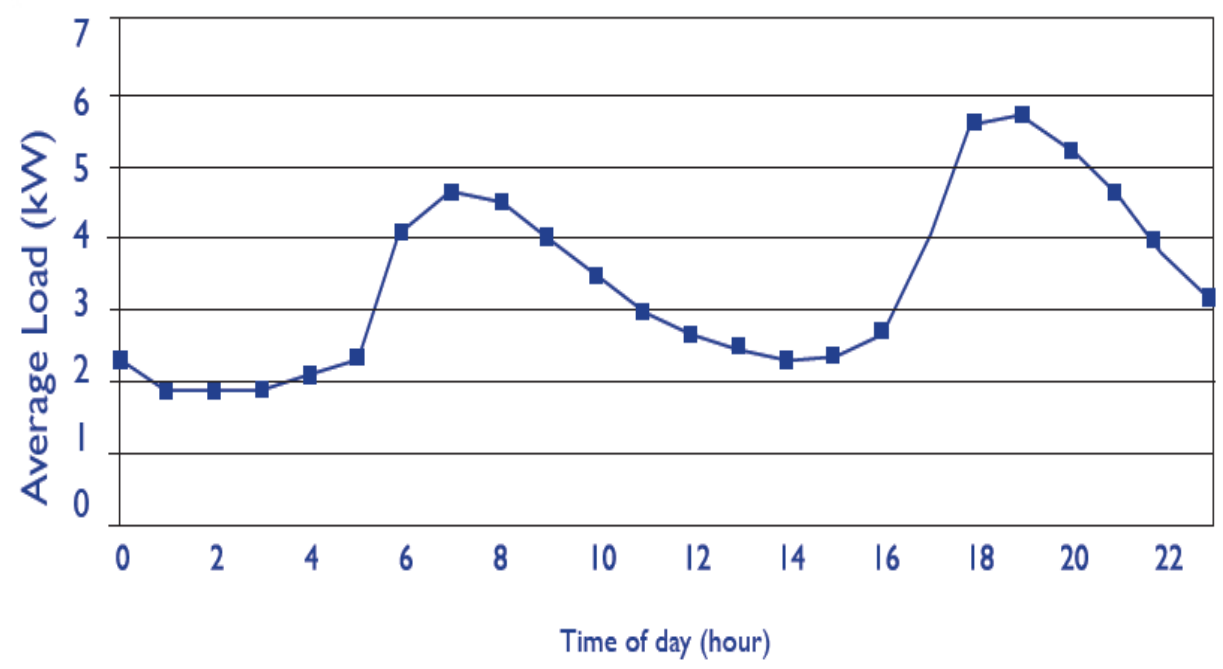

Figure 2-6 Average South African household daily electricity consumption pattern [61]

The current research works over the peak time demand without turning off any load.

\subsubsection{Monitoring Usage}

This is the alternative method acquired by electricity suppliers or big consumers, where the monitoring system is applied which predicts the demand for the next period of time: In this system, the alarm is set on at the maximum power demand level. When the set value is reached, an alarm alerts system users to take action. Actions that can be taken are: reducing usage by means of load shedding or adding the generation capacity [50]. This system reduces the peak power demand when the actions are taken accordingly; ESKOM estimates that understanding power alert makes a measurable difference [62], of course it needs the intervention of the human being and the load is interrupted.

\subsubsection{Load Shedding}

In a power system as discussed previously in section 2.5 .2 , load shedding is to voluntarily stop the supply of one or more consumers to quickly restore the balance between production and consumption network. This is a safeguard measure designed to avoid the risk of voltage or frequency collapse that could cause the cut of an entire subnet.

There are four types of load shedding [63]:

a) Load shedding by order: depending on consumption peak hours

b) Load shedding on energy metering: by measuring the average power consumed in a given period of time (generally 10 seconds) compared to the contracted power (green tariff)

c) Load shedding on power threshold and / or power: when a threshold is exceeded, load shedding relay cut non-priority feeders

d) Load shedding on frequency threshold: when the grid frequency exceeds a threshold set by the measuring device, power grid operators must implement load shedding if the grid 
frequency is within the margin not allowed. The application of this measure has probably allowed the power failure to degenerates into network failure [25]

\subsubsection{Local Shedding}

In some industrial premises or in a private home, local-shedding is used for stopping the supply of certain non-critical devices (e.g. electric heating) in case of power consumption too close to the service plan. This has an advantage of not over sizing the subscription for one-time power needs often linked to unusual and temporary use of several large electrical units (heating + oven + dishwasher + dryer, etc.).

This can manage multiple zones manually or offload a particular area, thus making energy savings. In our research we do not need to distinguish loads to be shed or not at any time, making it less complex.

\subsubsection{Standby Generator}

The use of standby generator is a common solution for power outages as a culture of safety. A quite number of consumers prefer to have their own local plant as a back-up to the existing power sources (mains). This alternative solution works mainly for the purpose of keeping the power during the load shedding times. The power outage is something experienced by nearly every electricity user at home, business, etc... at some point.

The advantage of our current project is that it is designed for both; keeping the power on during the load shedding and or power outage and working in terms of peak and off peaks consumption times.

Users having also their own local plants as a back-up to the existing power sources during peak time demand like Solar/Mains/Diesel Hybrid Uninterrupted Power System [22]. This method would be useful when the selection of the source to supply the load between mains and the other one would be done automatically and also the alternate source be the renewable source; the section which has been developed in this thesis.

\subsubsection{House}

A DC house is a house whose electricity is from DC power source rather than traditional AC power. The concept of DC house is not new, because by looking around the house; Lightning: LEDs, DC fans, DC hot plate, radio, computer, battery charger, refrigerator, TV, telephone chargers and sound systems run on DC. The realization of DC house is also possible for the user who is usually connected to $\mathrm{AC}$ mains whereby the DC load is connected to AC mains supply with AC wiring next to which appear the $\mathrm{AC}$ to $\mathrm{DC}$ conversion $[64,65]$. This conversion requires extra components resulting in power loss when converting voltage from low to high voltage or vice versa. DC house has been successful by looking at the scale of: (a) supplying electricity to remote areas (which was the primary motivation), (b) helps the use solar energy more efficient by getting rid of inverter and also (c) the DC loads are low power consumers in general i.e.: power saver for the same.

Figure 2-7 is the case of the combined solar and AC mains powered LED lighting system. With DC house, energy consumption from AC mains is less by 15\% [49]. The shortcoming of DC house is that it requires DC load types only. Changing the AC load types to DC may result in extra cost and again there are AC loads which cannot easily be replaced by DC load types like HVAC loads. 


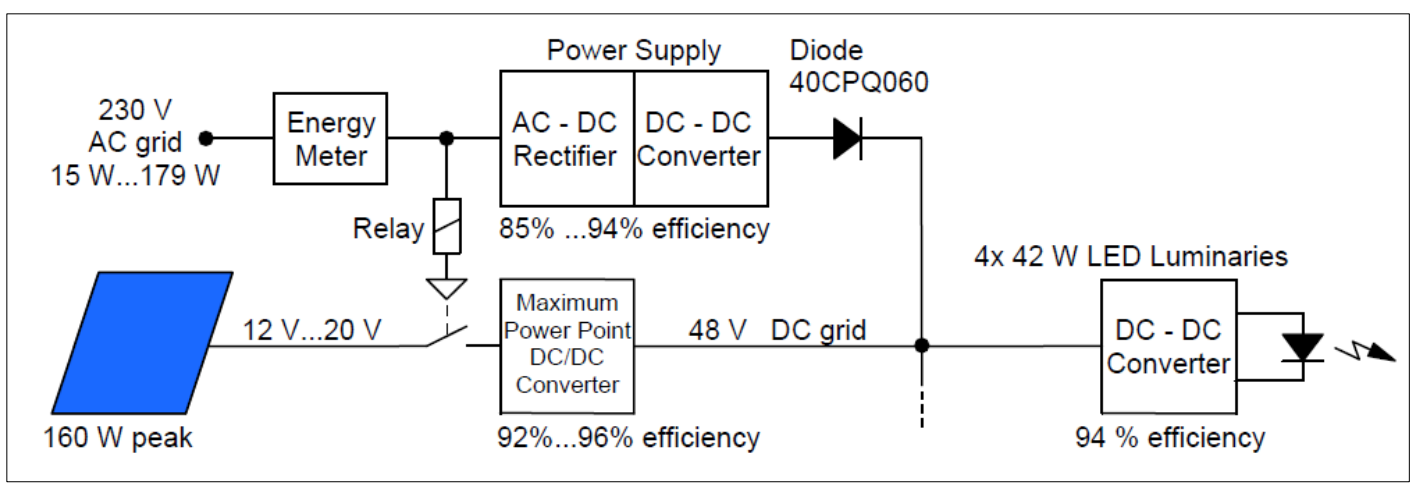

Figure 2-7: Combined solar and AC mains powered LED lighting system [49].

In our research, the consumers' load types will not need to be replaced and there is no power limit: it can work on $\mathrm{AC}$ as well as on DC at any power value.

\subsubsection{Hybrid Renewable Energy Systems (HRES)}

Hybrid energy systems is generally a combination of two or more energy sources for producing electricity. Approximately $90 \%$ of HRES studies are on design/economic aspects and have reported it to be highly costly [66]. The cost reduction and technological development of hybrid energy systems in recent years has been encouraging, but they still remain an expensive source of power.

In many applications, research has focused on the performance analysis [67, 68] of demonstration systems and the development of efficient power converters, such as bi-directional inverters, battery management units and maximum power point trackers [69, 70]. Various simulation programs [71] are available, which allow the optimum sizing of hybrid energy systems. However, fewer studies were reported on control of HRES [66]. The current research deals with the design and control of the hybrid solar and mains system for the peak time power demand. The cost analysis of the designed system has also been discussed.

\subsection{Panel Cleaning}

The panel cleaning robot is needed to maximize solar panels exposure, by keeping on cleaning them from the dust or any other impurity after a certain period of time for its optimum performance. On PV solar panel, the dust settles due to the following factors shown in Figure 2-8.

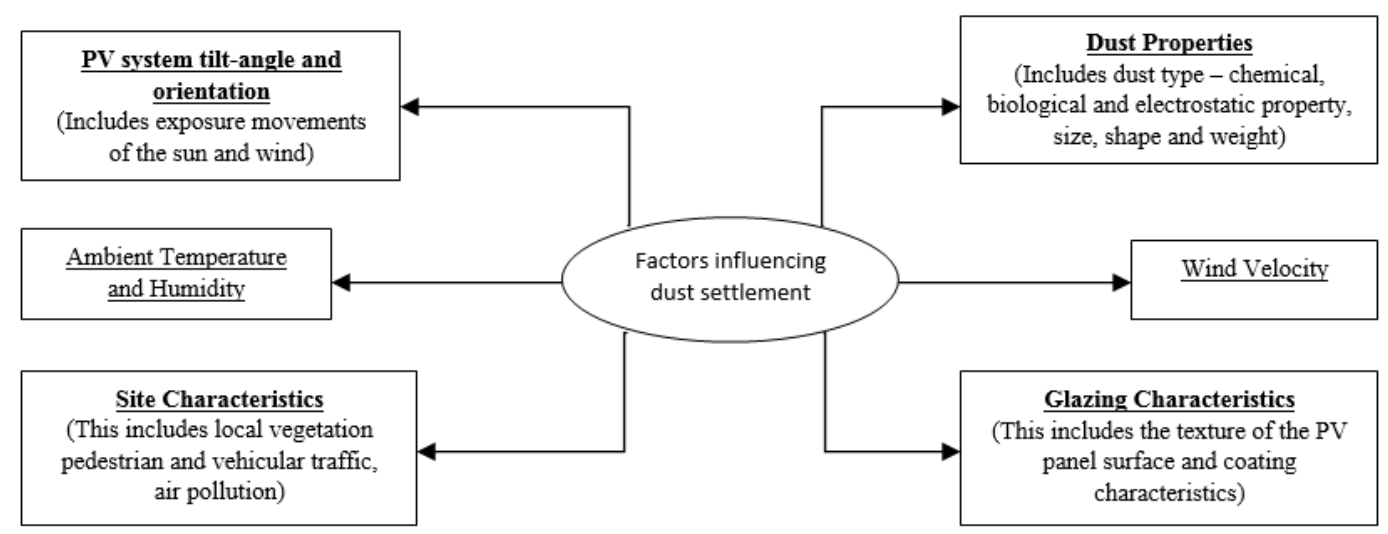

Figure 2-8: Factors influencing dust settlement [53]. 
The more PV panels are dirty - the lower amount of electricity they will produce. According to the German National Renewable Energy laboratory; "Individual dealers of solar panels have reported losses as high as 30\% for some customers who failed to ever clean their panels" [72]. But the study of M. Mani and R. Pillai found that the accumulated dust on the surface of photovoltaic solar panel can reduce the system's efficiency by up to $50 \%$ [53].

Cleaning solar panel is one aspect of its maintenance that should not be taken lightly since solar panels does not have any moving parts and sometimes the tilt angle may even 5degrees (almost horizontal) this make the accumulation of dust, dirt, pollen, bird droppings and other debris and easily stay (Figure 2-9). The Rain is considered as a means of cleaning, but with low efficiency. However, a good heavy rainstorm will actually wash away most of the accumulated soiling.

In 2009 Google conducted an experiment at their 1.6 MW solar farm in Mountain View of California investigating if actually cleaning the solar panels make them more effective. They found that cleaning the solar was the number one way to maximize the output energy they produce. The cleaned solar panels had been in operation for 15 months and then after they doubled their energy output [60].

According to A. M. Mathias, the same study found that the rain has never been a satisfying way of cleaning solar panels. In this study, solar panels that were cleaned professionally have been increased by $12 \%$ higher output of electricity as compared to those which were cleaned by rain [73].

Manual cleaning is also done but relatively a tedious and accidental work, for example if the array is mounted on the top of a 3.6 meters roof. A person mounting this height for cleaning the arrays has a risk of falling.

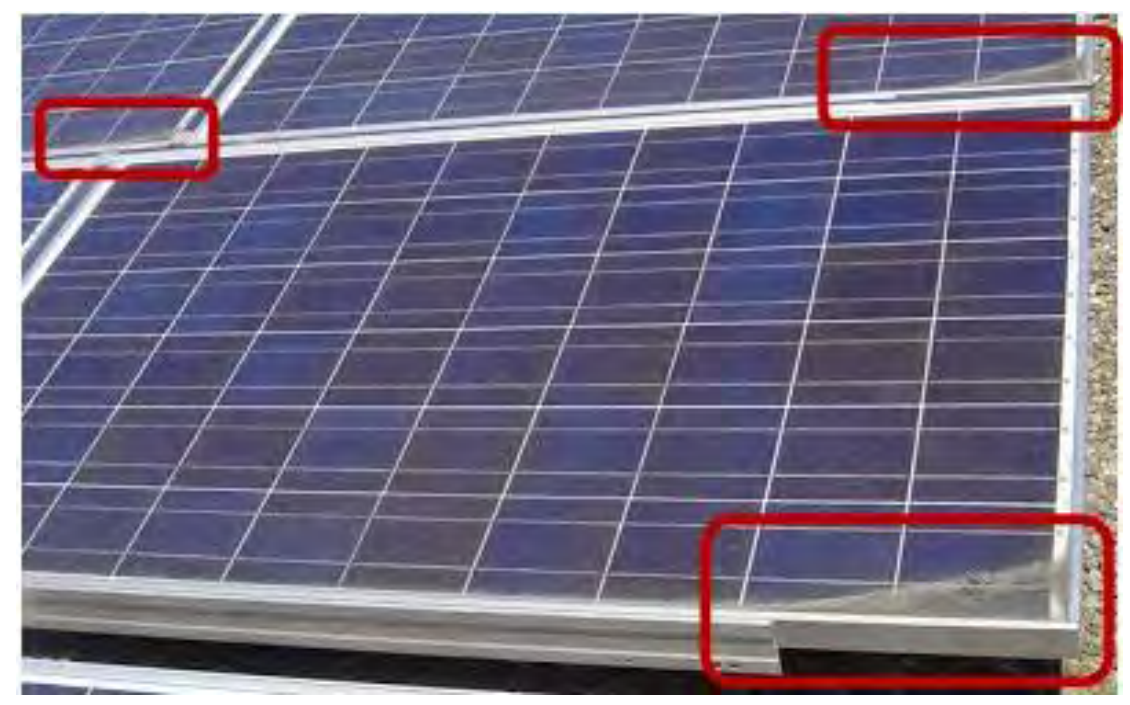

Figure 2-9: Accumulated dirt in the corners of a rooftop solar panel.

Photo Google, accessed 28/12/2014 23:16

There are other methods of cleaning the panels which have been developed too; in 2014 a group of students from CalTech (California Institute of Technology) and UCLA (University of California) have developed a robot that cleans solar panels (Figure 2-10). This is an indication that cleaning solar panels is an important problem that must be considered in design and implementation of PV systems. 


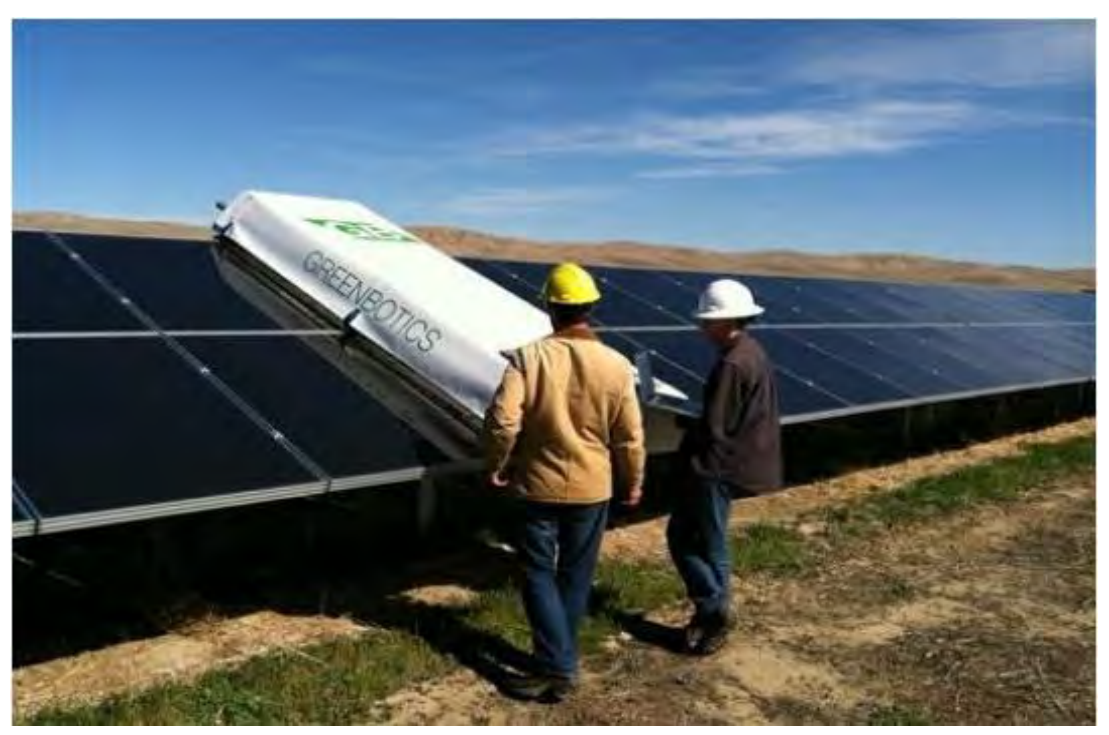

Figure 2-10: Designed panel cleaning robot by CalTech students [74]

According to T. Singh, the designed robot has got rotating brushes, squeegees, lightweight and covers the average sized solar panel at a time. This robot, also moves to each side of the panels, it uses water to clean the panel and also, it is controlled by two operators who place it at the beginning and then monitor its cleaning progress using a computer [74] and this cleaning robot has improved the solar electrical generation by 15 percent.

Our current designed solar cleaning system will not need any human operator nor computer to monitor its movements. It will work as standalone from the programmed microcontroller. This will greatly lower the cost of maintaining the PV system.

\subsection{Conclusion}

Different projects done to reduce the fluctuations during the peak power demand by adopting the use of renewable energy sources in combination with the existing ones have succeeded in improving the power transmission stability by minimizing the fluctuation caused by the peak power demand load. The current project contributes with the idea of selection between power source to feed the load based on the peak time demand between the solar energy and mains with the automatic cleaning panel, all done through the programmed microcontroller.

Another benefit of the current project is the "Energy conservation": Since harvesting the power from the solar panels, (PV solar system with battery charger) has often got a challenge in many designs due to the fact that when the battery is full and there is a sun the power collected form solar panel is wasted. For example, if the battery get fully charged after 3 hours, there will be other time when there will be sun producing power on the solar panel and not being collected.

To avoid this loss, in the current project this power is also used for driving the de motor which drives the panel cleaning robot discussed in the next section.

The solar output power from panels basically depends on its geographic location (the available solar insolation and the latitude) and the installation design (altitude, orientation and tilt). 


\section{CHAPTER 3 \\ SOLAR AND MAINS SYSTEM TECHNOLOGY}

\section{Introduction}

The word "photovoltaic" means "Capable of producing a voltage, usually through photoemission when exposed to radiant energy" and this energy is from the sun, mostly called "Sol" by astronomers [75]. Even more, the term "photovoltaic" itself, basically means "light-electricity"; a device that converts light into electricity, etymologically: "photo + voltaic" the word-forming two elements:

a) Photo, which originates from Greek, "light" or "photographic" or "photoelectric" or in other words: "to shine" [76].

b) Voltaic, designating electricity produced by chemical action, formed in memory of Italian physicist Alessandro Volta (1745-1827), who perfected a chemical process used in electrical batteries [77].

For this kind of solar system, the "greenhouse effect" technology is used. The "greenhouse effect," is simply the ability of a reflective surface to transmit short wave radiation and reflect long wave radiation. In the solar water heater, the greenhouse (also called "glasshouse"), the radiation from the sun is absorbed inside the glass box of the solar water heater and re-radiated inside in all directions. The heat is kept inside due to the solar radiation wavelength which is in a form of shortwave capable to refract the glass then the reflection from inside of the glass box is emitted in the form of long wave which does not easily refract back from the glass cover. Concisely, solar water heating collectors capture and retain heat from the sun and transfer this heat to a liquid (usually water).

Solar PV technology is not new. Its history spans from the 19th Century [78]:

a) 1839: French physicist Edmond Becquerel (the grand-son of Antoine Henri Becquerel who discovered radioactivity) discovered the process of using sunlight to produce electric current in a solid material. This is the photovoltaic effect.

b) 1875: Werner von Siemens outlines to the Berlin Academy of the Sciences article on the photovoltaic effect in semiconductors. But until the Second World War, the phenomenon was still a laboratory curiosity.

c) In 1923: Albert Einstein won the Physics Noble Prize for explaining the photovoltaic principle [79].

d) 1954: Three American researchers (Chapin, Fuller, Pearson and Prince) working for Bell Telephone Laboratories (now Alcatel-Lucent Bell Labs today) developed a photovoltaic cell with high efficiency of $6 \%$.

e) In the same year; Bell Labs researchers found out that silicon photo-sensibility could be increased by adding "impurities". This is a technique called "doping", used in semiconductors. But despite the interest of scientists over the years, it is during the space race that cells left laboratories. 
f) 1958: A cell with $9 \%$ efficiency is developed. The first satellite powered by solar cells is sent into space.

g) 1973: The first house powered by photovoltaic cells is constructed in the University of Delaware.

h) 1983: The first car powered by photovoltaic energy travels a distance $4000 \mathrm{~km}$ Australia.

i) Today, photovoltaic energy is available to businesses and individuals and photovoltaic panels have efficiency of about $20 \%$. An important problem of increasing the efficiency is tackled in our research by introducing self-cleaning of panels.

The electricity corresponds to an electron displacement. Also, to make them more mobile electrons, silicon is cut into thin slice "doped". The photovoltaic cell is actually composed of two zones: a zone in which a portion of the silicon atoms are replaced by phosphorus atoms and another area in which a portion of the silicon atoms are replaced by Bohr's atoms. This results in the creation of an electric field at the interface between these two areas.

\section{Who is Bohr?}

Niels Henrik David Bohr (7 October 1885 - 18 November 1962) a Danish physicist who made foundational contributions to understanding atomic structure and quantum theory, for which he received the Nobel Prize in Physics in 1922 [58]

The phosphorus atom has one electron more than the silicon atom in its outermost shell, and the Bohr's atom has one less.

So when the light enters the silicon, it provides energy as photons. Photons will communicate their energy to silicon atoms, leading to the creation of electrical charges. The electrons of the phosphorous doped region will join the holes at the outside connection. They are then collected by metal grids. Incidentally, their movement creates an electrical current.

Practically, a photovoltaic cell in crystalline technology is composed of several active layers [80]:

a) An "anti-reflective" layer on the front face whose purpose is to facilitate maximum penetration of a maximum of photons

b) A conductive grid before "collecting electrons"

c) An N-doped layer (usually through Bohr's atoms) with negative free charge carriers (electrons)

d) A P-doped layer (usually through the phosphorus atoms) with positive charge carriers (holes)

e) A rear metal contact to collect positive charges.

\subsection{PV Modelling \& Design}

The photons from the sun light with different wavelengths of energy particles hit a photovoltaic cell with the possibility of reflecting aside, cut through or getting absorbed into. The energy absorbed from photons is transferred to the electrons of the cell atoms. This energy will cause the electrons to escape from the orbit associated with the atoms and become part of a current in an electrical circuit. The current is then generated by the flow of electrons. When metal contacts are placed on both sides 
of the photovoltaic cell, the generated current can be extracted for external use. However the electrical properties of a cell will not allow it to generate sufficient energy to make a standard voltage electric device work: 12, 24 or 48 volts. Hence, the cells have to be interconnected, encapsulated and mounted on a framework structure, to make up the photovoltaic module.

A solar cell can be modelled as a diode circuit as shown in Figure 3-1.

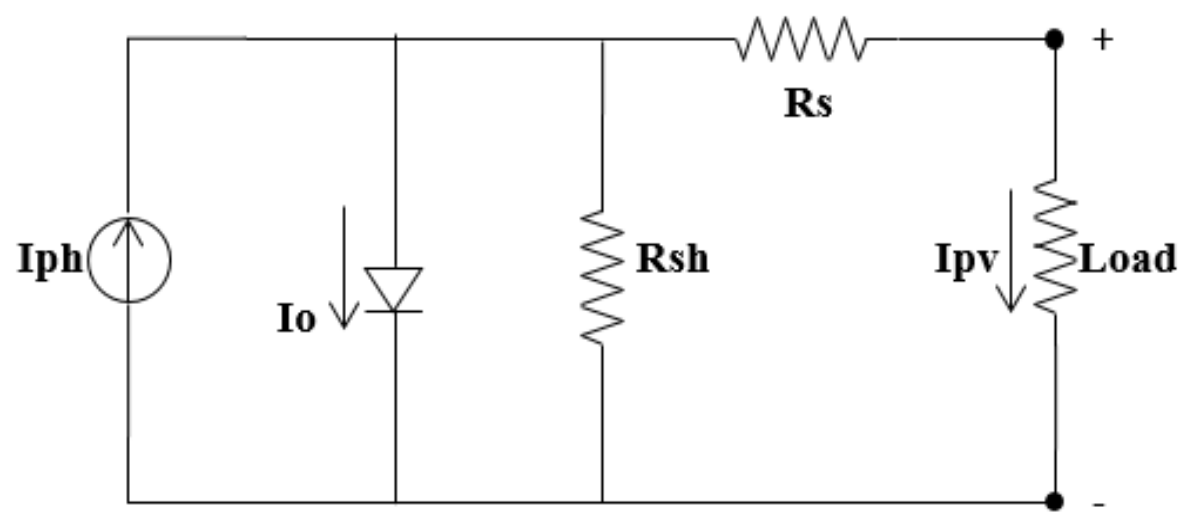

Figure 3-1: PV cell modelled as a diode circuit.

The current source $I_{p h}$ represents the cell photocurrent. $R_{s h}$ and $R_{s}$ are the intrinsic shunt and series resistances of the cell, respectively. Usually the value of Rsh is very large and $R_{S}$ is very small, hence they may be neglected to simplify the analysis. PV cells are grouped in larger units called PV modules which are further interconnected in a parallel-series configuration to form PV arrays.

The I-V characteristic equation of the photovoltaic cell is given by [81].

$$
I=I_{L}-I_{o}\left[\exp \left(\frac{q V}{k T}\right)-1\right]
$$

Where, $I_{L}$ is the cell (light) current which is equal to the short circuit current $(\mathrm{V}=0)$,

$I_{o}$ is the reverse saturation (dark) current, A,

$q=1.6 \times 10^{-9}$ Coul,

$k=1.38 \times 10^{-23} \mathrm{~J} / \mathrm{K}$ and

$T$ is the cell temperature, $K$.

The I-V performance of the cell is sensitive to the operating temperature $\mathrm{T}$. The cell temperature $\mathrm{T}$ can be calculated as [82].

$$
T=T_{a}+\frac{T_{N}-20}{800} G_{C}
$$

Where, Ta is the ambient air temperature, $\mathrm{C}$ and

$\mathrm{T}_{\mathrm{N}}$ is the nominal operating cell temperature, $\mathrm{C}$.

The $T_{N}$ is assumed as [83].

$$
T_{N}=T-T_{a}+(0.035) G_{C}
$$

To determine $I_{0}$, the current $\mathrm{I}$ in equation (3.1) is set to zero. Hence V becomes open circuit voltage $\mathrm{V}_{0}$ and is given as [84].

$$
V_{0}=\left(\frac{k T}{q}\right) \operatorname{Ln} \frac{I_{L}-I_{0}}{I_{0}} \cong\left(\frac{k T}{q}\right) \operatorname{Ln} \frac{I_{L}}{I_{0}}
$$


Since $\mathrm{I}_{\mathrm{L}}>>\mathrm{Io}$

$$
I_{0}=I_{L} \exp \left(-\frac{q V_{0}}{k T}\right)
$$

Since the cell light current, $I_{L}$ is directly proportional to the cell irradiance, the value of $I_{L}(G)$ at any other irradiance, $\mathrm{I}_{\mathrm{L}}(\mathrm{G})$ is given by:

$$
I_{L}(G)=\left(-\frac{q V_{0}}{k T}\right) I_{L}\left(G_{S}\right)
$$

Where $\mathrm{I}_{\mathrm{L}}(\mathrm{G})$ is known under standard conditions of $\mathrm{G}(\mathrm{s})$ at $25^{\circ} \mathrm{C}$. The above gives the value of voltage and current produced by a cell. The power output of the cell is given as [85].

Where, $\mathrm{F}$ is the cell fill factor and

$$
P=F I V
$$

F can be written as:

$$
F=\frac{V_{0}-\left(\frac{k T}{q}\right) \operatorname{Ln}\left(\frac{V_{0}}{q}\right) \operatorname{Ln}\left(\frac{q V_{0}}{k T}+0.72\right)}{V_{0}+k T / q}
$$

Solving the above equations the output current and output voltage from the PV array can be obtained as function of time.

Considering the above conditions, the supplying $1 \mathrm{~kW}$ power during the peak power demand hours ( 5 Hours daily) for the coffee shop, the sizing of the panel is calculated as follows:

The total energy consumed during five hours is $5,000 \mathrm{Wh}$ as calculated in appendix $\mathrm{C}$.

The Figure 3-2 shows the daily solar irradiation as measured form SAURAN station in UKZN Howard College, Durban.

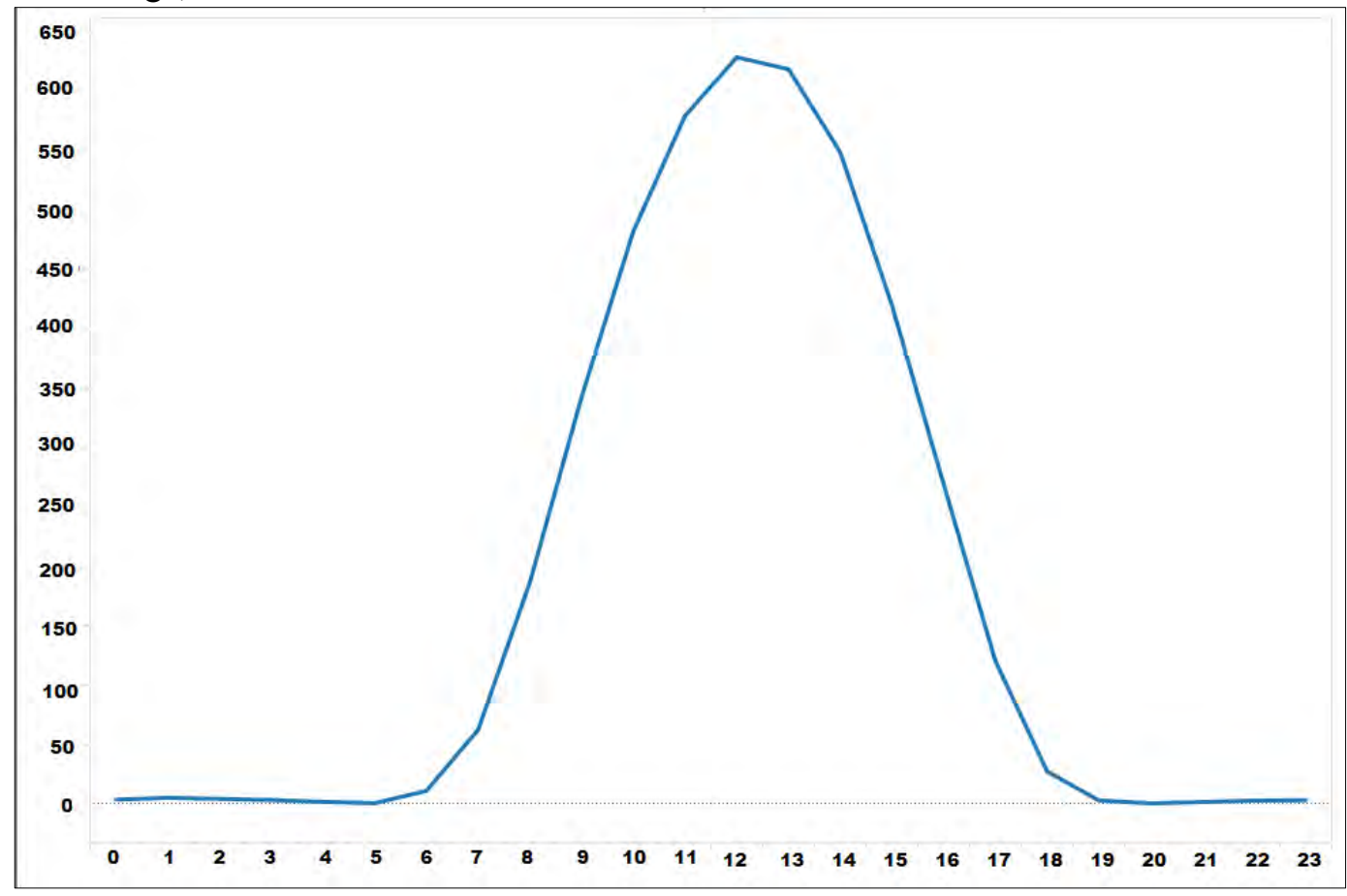

Figure 3-2: Durban hourly recorded global horizontal irradiation [in w/m2] (Jan 2012-Nov 2014) 
The amount of solar irradiation measurements used is for the GHI - Global Horizontal Irradiance besides the DNI (Direct Normal Irradiation) and the DHI (Diffused Horizontal Irradiation). The DNI is referred as the amount of solar radiation coming directly from the sun to the perpendicular unit area; it is considered as the irradiance without any disturbance or ideal irradiance for which its quantity measurement is done to maximize the amount of solar received by a surface annually. The DHI is in turn the illumination or amount of radiation received on the surface of the earth through the clouds after being scattered by the molecules and particles. In this thesis, the calculations are done based on the GHI recordings which is the combination of DNI and DHI as shown in Figure 3-3 and they are named as "three components of solar irradiation" measured with Pyranometer [86].

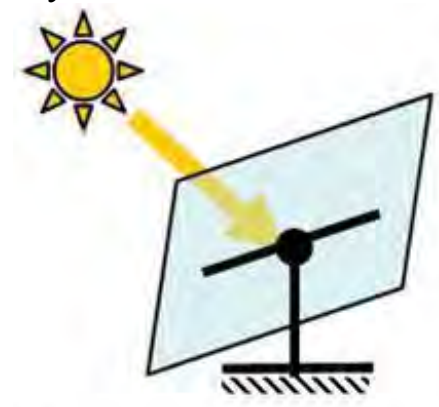

(a)

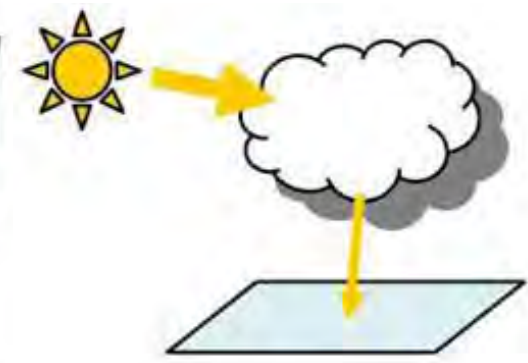

(b)

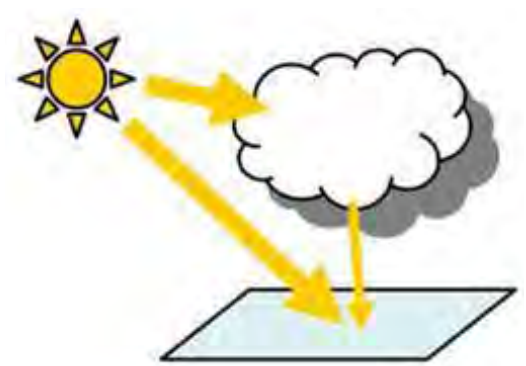

(b)

Figure 3-3: Solar Irradiation Components (a) DNI-Direct normal irradiation, (b) DHI-Diffuse Horizontal Irradiation, (c) GHI-Global Horizontal Irradiation [86]

Considering the irradiance and average monthly temperature variation in Durban taken from www.sauran.net [87], we will need the surface of $7.56 \mathrm{~m}^{2}\left(1,000 \mathrm{w} / 132.3 \mathrm{w} / \mathrm{m}^{2}\right.$ where $132.3 \mathrm{~W} / \mathrm{m}^{2}$ is the available power on solar panels during the worst case where a minimum irradiance is recorded as shown in the Figure 3-4).

Considering the $300 \mathrm{w}, 1960 * 982 * 50 \mathrm{~mm}$ solar panel available on the market, 4 panels will be used, each having $300 \mathrm{w}, 24 \mathrm{~V},\left(7.56 \mathrm{~m}^{2} / 1.92 \mathrm{~m}^{2}=4\right.$ where $\left.1960 \times 982=1.92 \mathrm{~m}^{2}\right)$ in series-parallel connection.

Monocrystalline cells have a higher efficiency than polycrystalline cells due to the structure being made from one large crystal as opposed to many small ones. In addition to having an overall better efficiency, monocrystalline panels can perform up to $10 \%$ better than polycrystalline panels in high ambient temperatures. Since monocrystalline panels are more efficient per area, the size of the solar panel is less than a polycrystalline solar panel for the same wattage. The disadvantage of monocrystalline panels are costly and complete power cut off due to leakage. Polycrystalline panels are efficient in hot temperature compared to monocrystalline panels and are cheap. But the polycrystalline panels are not space efficient and the efficiency is less than monocrystalline panels. Hence monocrystalline panel can be chosen for this research work. 


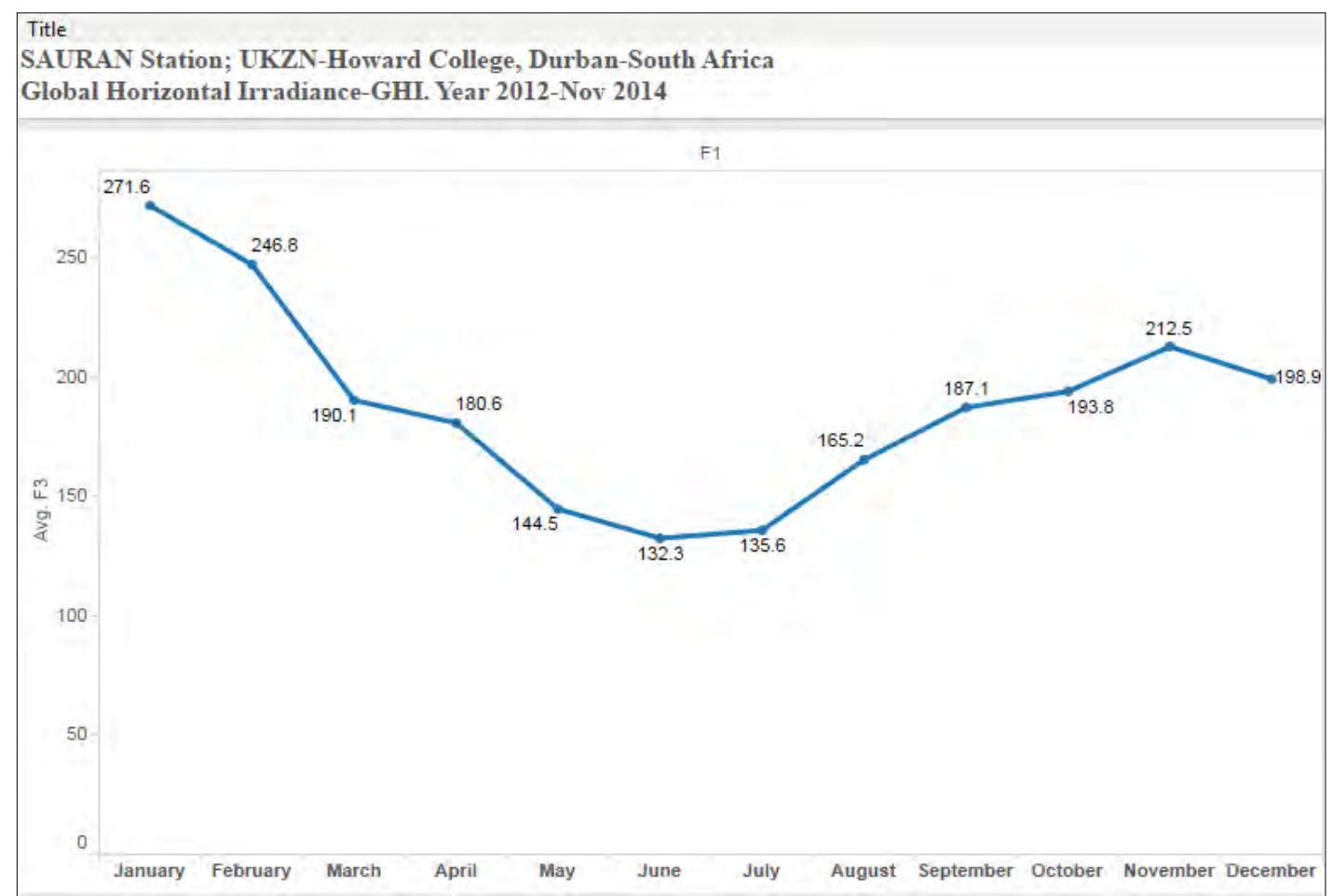

Figure 3-4: Durban Monthly Minimum Global Horizontal Irradiance [in w/m²] (Jan2012-Nov2014) [87]

\subsubsection{PV performance}

The DC electricity produced by solar modules is to be in line with the manufacturers rating under Standard Test Conditions (STC).

The STC conditions are:

Solar cell temperature $=25^{\circ} \mathrm{C}$;

Solar irradiance (intensity) $=1000 \mathrm{~W} / \mathrm{m}^{2}$ (comparable to clear summer noon time intensity).

There is always a production tolerance of $+/-5 \%$ of the rating, but it is advisable to use the low end which means, 95 Watts for a 100-watt module [28].

\subsubsection{Temperature Effect}

Module performance increases with reduction in temperature (Figure 3-5) [88, 89]. For crystalline modules, a typical temperature reduction factor recommended by the CEC is $89 \%$ or 0.89 . So, in the middle of a spring or fall day, under full sunlight conditions, the 100-watt module of 95 Watt will operate at (95 Watts x 0.89) 85 Watts.

\subsubsection{Dirt and Dust Accumulation}

Accumulation of dirt and dust on the solar module surface, with time, may block some of the sunlight and reduce output. Depending on the climatic condition of a particular area which may cause accumulation of dust, it is more realistic to estimate system output taking into account the reduction due to dust buildup in the dry season. A typical annual dust reduction factor to be used is $93 \%$. This brings the 100 Watt module, by real calculation to (85Watts x 0.93 ) which is 79 Watts [90]. 


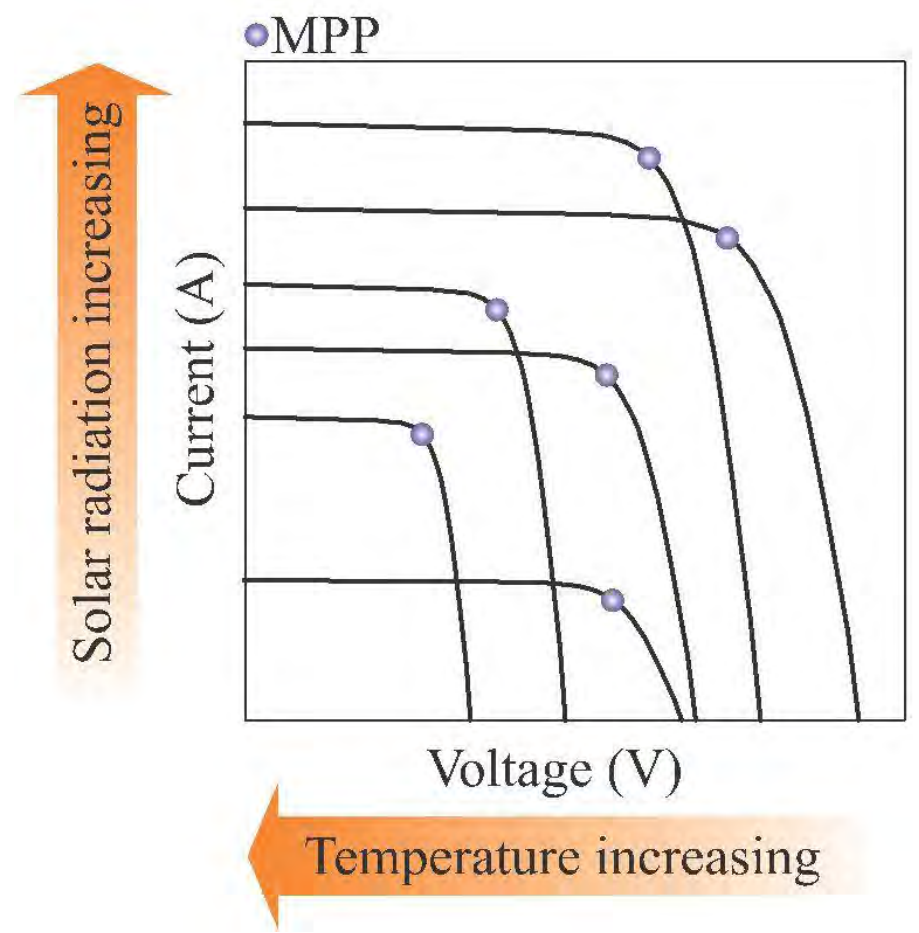

Figure 3-5: Solar I-V radiation curves and temperature changes with the MPP (Maximum Power Point) [89]

\subsubsection{Mismatch and Wiring Losses}

Due to slight variation in performance from one module to the other, the total maximum power output of a PV array is always less than the sum of the maximum output of the individual modules. This is called module mismatch and its amounts is to be at least $2 \%$ loss in system power output. Also there is a power loss due to resistance in the system wiring. A mismatch and wiring losses reduction factor for these losses is given as $95 \%$ [91].

\subsubsection{DC to AC Conversion Losses}

Inverters are used to convert the DC produced by the PV modules to AC for meeting the domestic power demand. The $\mathrm{DC}$ to AC conversion process results in some power losses. Modern inverters commonly used in residential PV power systems have peak efficiencies of $92-94 \%$ as indicated by many manufacturers, but actual field conditions usually result in overall DC-AC conversion efficiencies of about $88-92 \%$, with $90 \%$ as a reasonable compromise. So for 100 -watt module output, considering heat, dust, wiring, AC conversion, and other losses, the AC power delivered to the load during the middle of a clear day may be $(100$ Watts $\times 0.95 \times 0.89 \times 0.93 \times 0.95 \times 0.90) 67$ Watts. PV panels tend to work much better in cold weather than in hot climates[92]. Sometimes output on the rating panel is exceeded up to $20 \%$ greater when a reflective snow surface is added [93].

\subsubsection{PV Panel Technology}

For efficiency and economics reasons, PV materials are categorized as either crystalline or thin film [20]. Crystalline technology is having the advantage of greater conversion efficiency even where available space is very limited. Another point to take into consideration when sizing the array for a multi-year project is that up to $25 \%$ drop off rapidly in conversion efficiency of thin-film panels in the first few years of its operation. Which PV technology is more appropriate for a given application 
will be determined on the peculiarity of the project as there situations where thin-film is preferred to be more suitable based on the lighter weight and greater flexibility.

Mono-crystalline silicon panels are considered implemented when a higher voltage is desirable. This would be in an instance where the DC power has to travel some distance before being utilized or stored in a battery bank. These panels have average efficiency of $14 \%$ to $17 \%$ which makes it one of the most efficient methods.

Polycrystalline silicon panels are commonly used in polar applications and much cheaper than monocrystalline with efficiencies ranging from $12 \%$ to $14 \%$.

Thin-film technologies include amorphous silicon, cadmium telluride, copper-indium diselenide, and others. They have initial cost advantage but the efficiencies are comparatively low. The initial $8 \%$ to $10 \%$ efficiencies recorded in new panels quickly degrade to about $3 \%$ to $6 \%$ after several months of exposure to sunlight [24]. Newer, triple-junction thin-film technologies which appear to have higher efficiencies still experience less degradation over time.

\subsubsection{Green Energy System}

No air pollution from solar energy as compared to coal power plants: these has been shown as the power plant having the very dangerous effects on human respiratory system, cardiovascular and nervous systems by releasing nitrogen oxides, sulfur dioxide, particulate matter, mercury, and dozens of other hazardous substances human health which causes each year the 24,000 premature deaths, tens of thousands of asthma attacks and 38,200 of non-fatal heart attacks, all originating from the burnt Black carbon in the power plants[94]. In 2011, the American Lung Association has released a report showing that the coal-fired power plant pollute the atmosphere than any other industrial pollution source [17].

However, we cannot be totally dependent on PV (as well as other renewable energy sources) in the near future since the non-renewable energy sources are still potential. South Africa as one of the countries heavily depending on coal as energy source; in 2010 the Word Energy Council - WEC released a report showing that the coal reserve in South Africa is 30 Billions of tons (Figure 3-6). Yet the coal reserve is the state of flux; between 1998 and 2010, the South Africa's hard coal reserves were reduced by about $50 \%$, from 60 billion tons to 30 billion tons [95]. As luck would have it, the price of PV comes down so rapidly (Figure 3-7) depending on [96]:
a) increasing efficiency of solar cells
b) dramatic manufacturing technology improvements
c) economies of scale
d) intense competition

So, the combination of renewable and non-renewable technology nowadays is the most needed as this research makes the hybrid solar and mains system. 


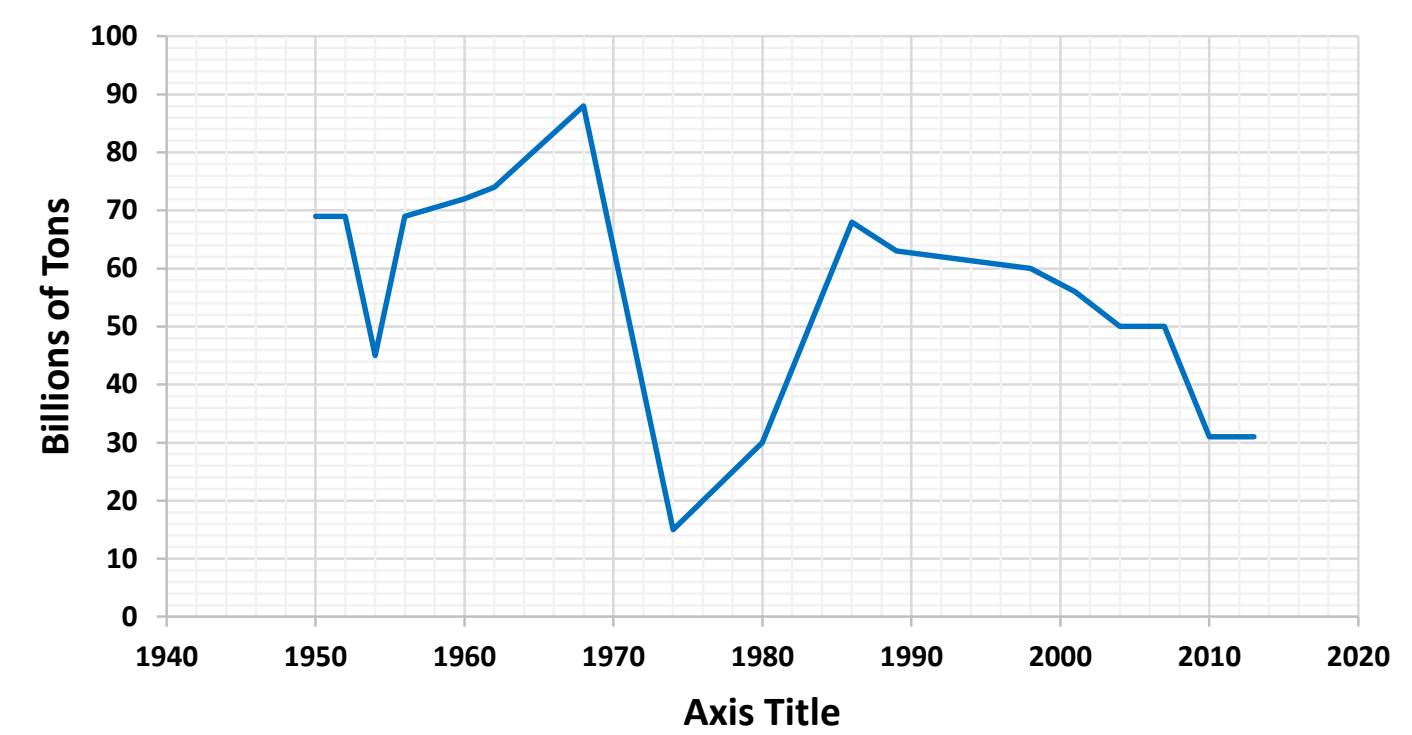

Figure 3-6: South Africa Stated Coal Reserves (1950-2013) [95]

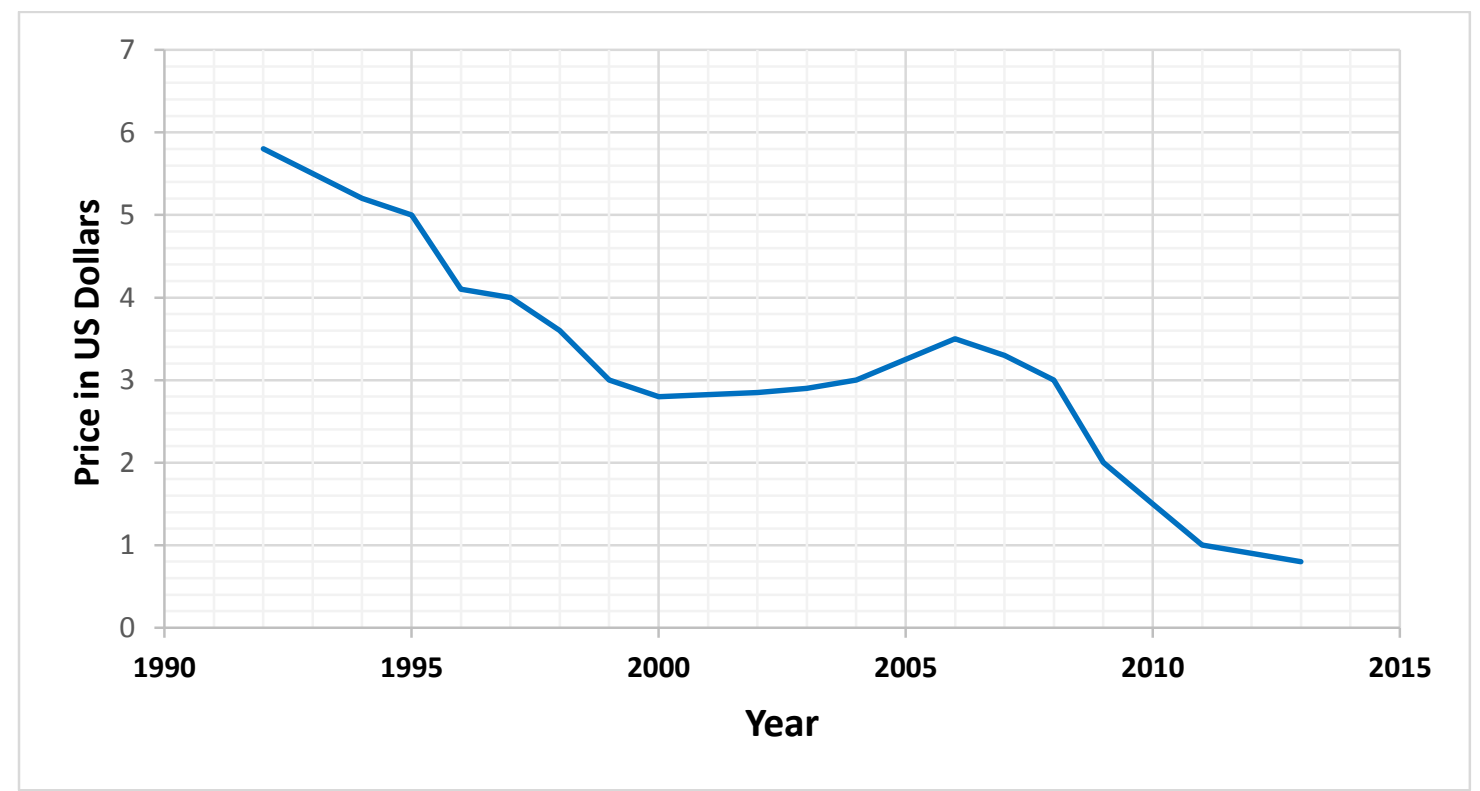

Figure 3-7: PV Module price per watt (1992-2013) [96]

\subsection{Battery Bank Modelling \& Design}

For a $1 \mathrm{~kW}$ solar plant, we need an inverter with a minimum power rating of $1 \mathrm{~kW}, 48 \mathrm{~V}$. Hence minimum of two $24 \mathrm{~V}, 300 \mathrm{Ah}$ batteries connected in series is required. More batteries gives more backup but it requires more charging time.

A battery as a an electrochemical cell (enclosed and protected) to be charged electrically, provides a static potential for power and releases electrical charge when needed, performs best if it is charged and discharged slowly (especially relevant for charging). The Figure 3-8 shows the equivalent circuit of a battery. 


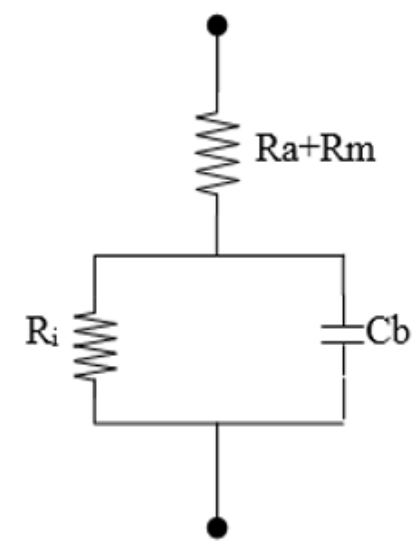

Figure 3-8: Battery equivalent circuit [97]

with:

a) $\mathrm{Rm}$, the metallic resistance of electrodes and inter-connections

b) $\mathrm{Ra}$, the electrochemical path resistance (including the electrolyte and the separator)

c) $\mathrm{Cb}$, the parallel plate's capacitance (forming the electrodes of the cell)

d) Ri, the non-linear contact resistance between the electrode and the electrolyte (in order of milliohms)

The Lower the discharge rate higher the capacity. If a battery is charged too quickly, then it will be hindered from reaching full capacity. Moreover, the deeper the discharge is, the shorter its lifespan (Figure 3-9).

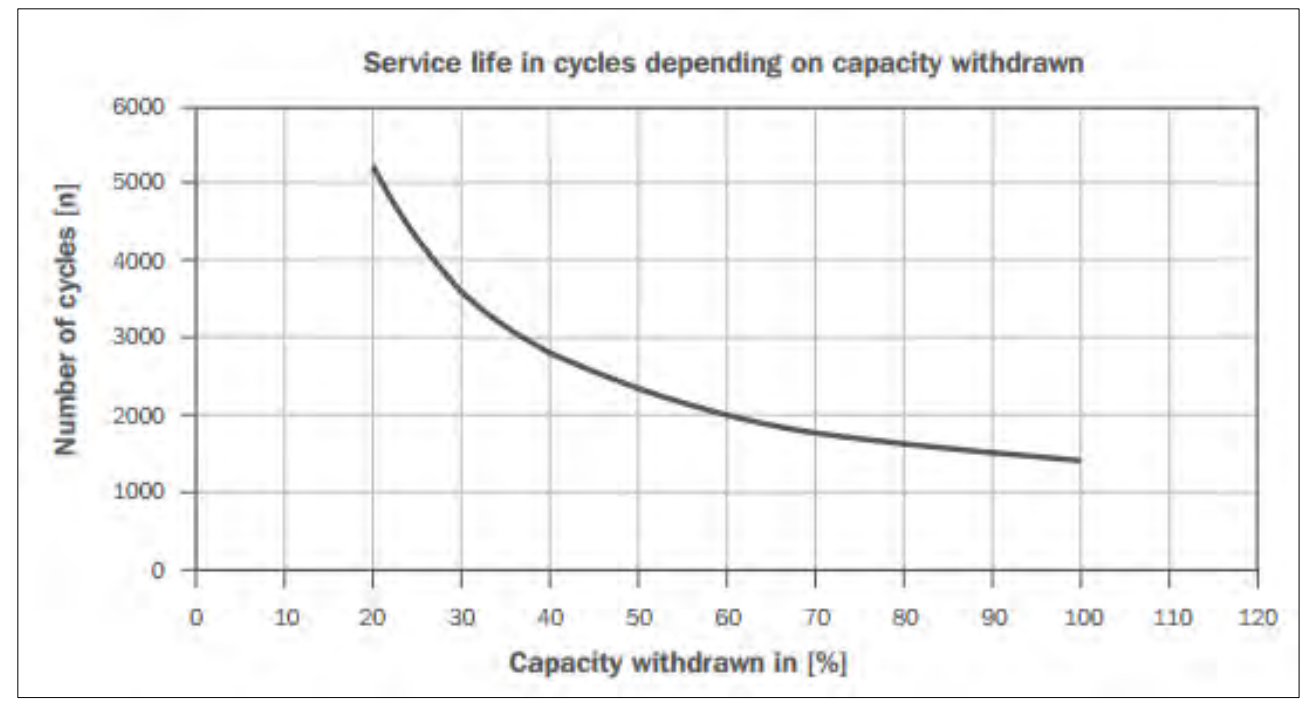

Figure 3-9: Solar Battery lifecycle Vs depth of discharge (battery type: LiIon/LiPo) [98]

Charging time (Tch): the chosen LiIon/LiPo battery type, 90\% efficient, 10 Amperes load current and $30 \mathrm{Ah}$.

Charging time: 


$$
T_{\text {ch }}=\text { Capacity } /(\text { efficiency } * \text { charge rate })
$$

Then it will be fully charged after 33.3hours. The calculations are shown in appendix C

Discharging time is $12.96 \mathrm{hrs}$

$$
T_{d c h}=\frac{\text { Capacity } * \text { Battery Voltage } * \text { Ef ficieny }}{\text { Applied load }}
$$

Say,

N.B: The above calculated charging time is for the case when the battery is to be charged from scratch otherwise the charging time depends on the depth of discharge (DOD) which is the fraction of power that can be withdrawn from the battery without causing any damage, the DOD value is provided by the manufacturer. If the battery is $20 \%$ DOD then, only $20 \%$ of the battery capacity can be used by the load.

The battery lifetime is also affected by the temperature. For any given battery the lifetime is decreased with the increment of the temperature as shown in Figure 3-10. The temperature value for any specific battery is calculated by the Nernst Equation for the safe battery voltage.

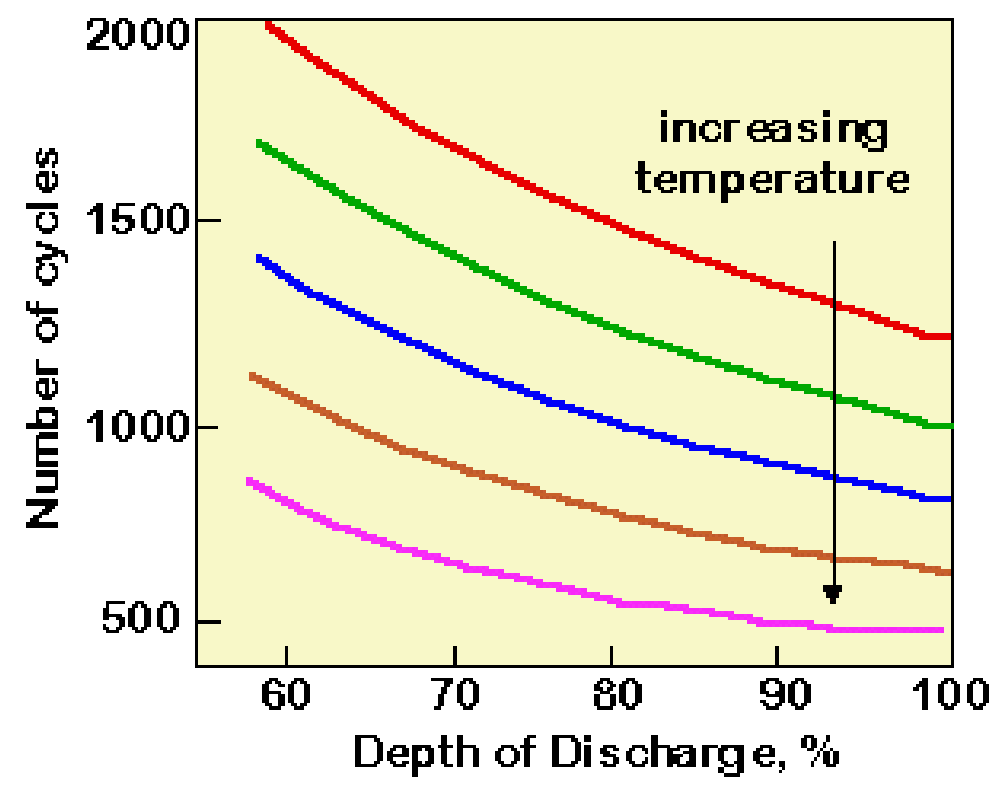

Figure 3-10: Battery lifetime for given different temperature and depth of discharge variations [98]

\subsection{Charge Controller Modelling \& Design}

Solar charge controllers are required to couple the solar panel with battery by regulating the fluctuating output from solar panel. It can also protect over and under charging of battery. Also the reverse current flow from battery to solar panel during night and poor sunlight days is prevented by solar charge controllers. The $1 \mathrm{~kW}$ solar array is charging a battery bank of $48 \mathrm{~V}$.

Considering a safety factor of 1.25 to account for variable power outputs, we will need one charge controller of 26Amps.

An electric battery, a device consisting of electrochemical cells that convert stored chemical energy into electrical energy while charging and from electrical to chemical energy while discharging, is simulated by Simulink as shown in Figure 3-11. Electrolytes allow ions to move between the 
electrodes and terminals allowing current to flow out of the battery to the external connection or load. In this research, it is connected to the DC load and to the DC to DC boost converter.

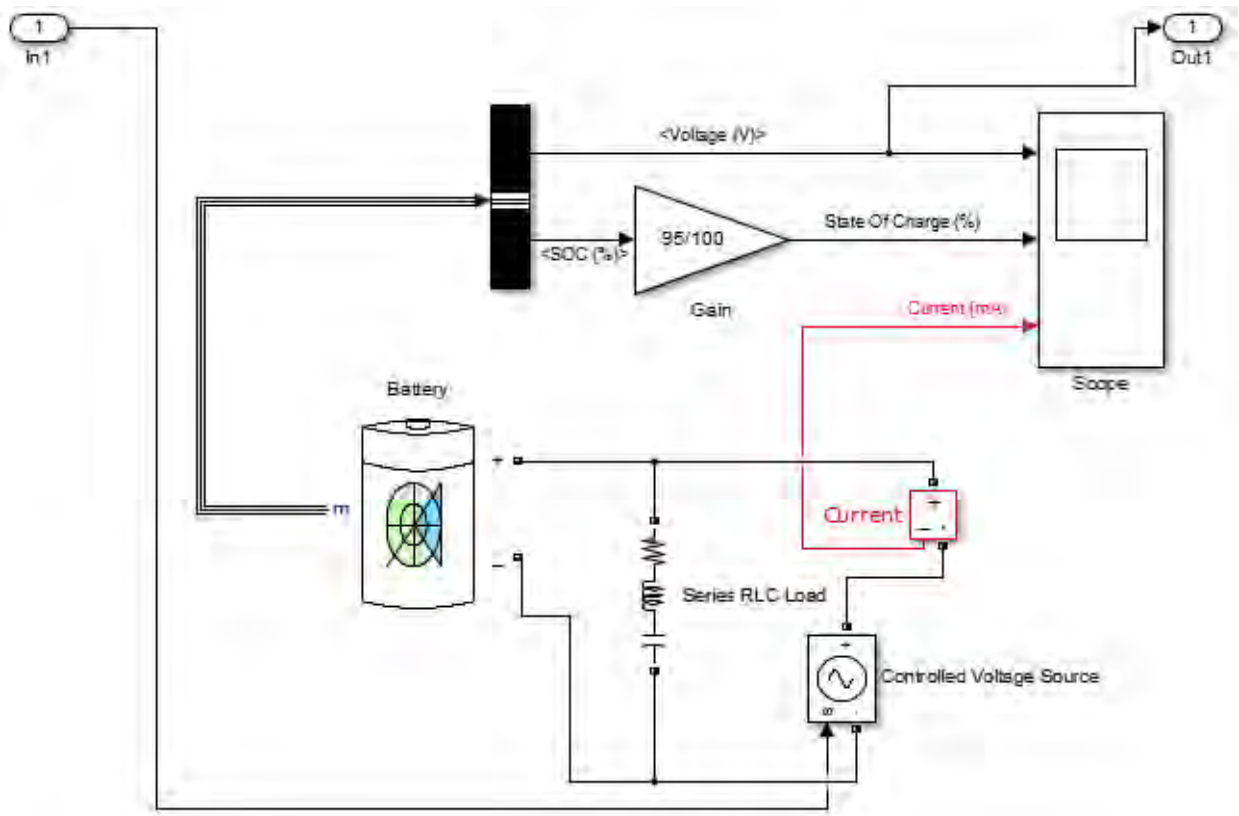

Figure 3-11: Battery charging and discharging characteristics

The State of Charge (SOC) is measured in percentage points $(0 \%=$ empty; $100 \%=$ full). The alternate measure of SOC is Depth of Discharge (DOD) also measured in percentage $(100 \%=$ empty; $0 \%=$ full). The simulation done for battery charging shown in Figure 3-11 has got the results shown in Figure 3-12 where the measurements are shown on the scope: the SOC of the used battery in the simulation is $95 \%$ which means that it in being charged, the reason why the measured current which is the charging current is negative. The term DOD is normally used when discussing the current state of a battery in use and it is most often seen when discussing the lifetime of the battery after repeated use as discussed in chapter 3, section 3.2. Generally, the charging and or discharging protocol depends on the size and type of the battery being charged.

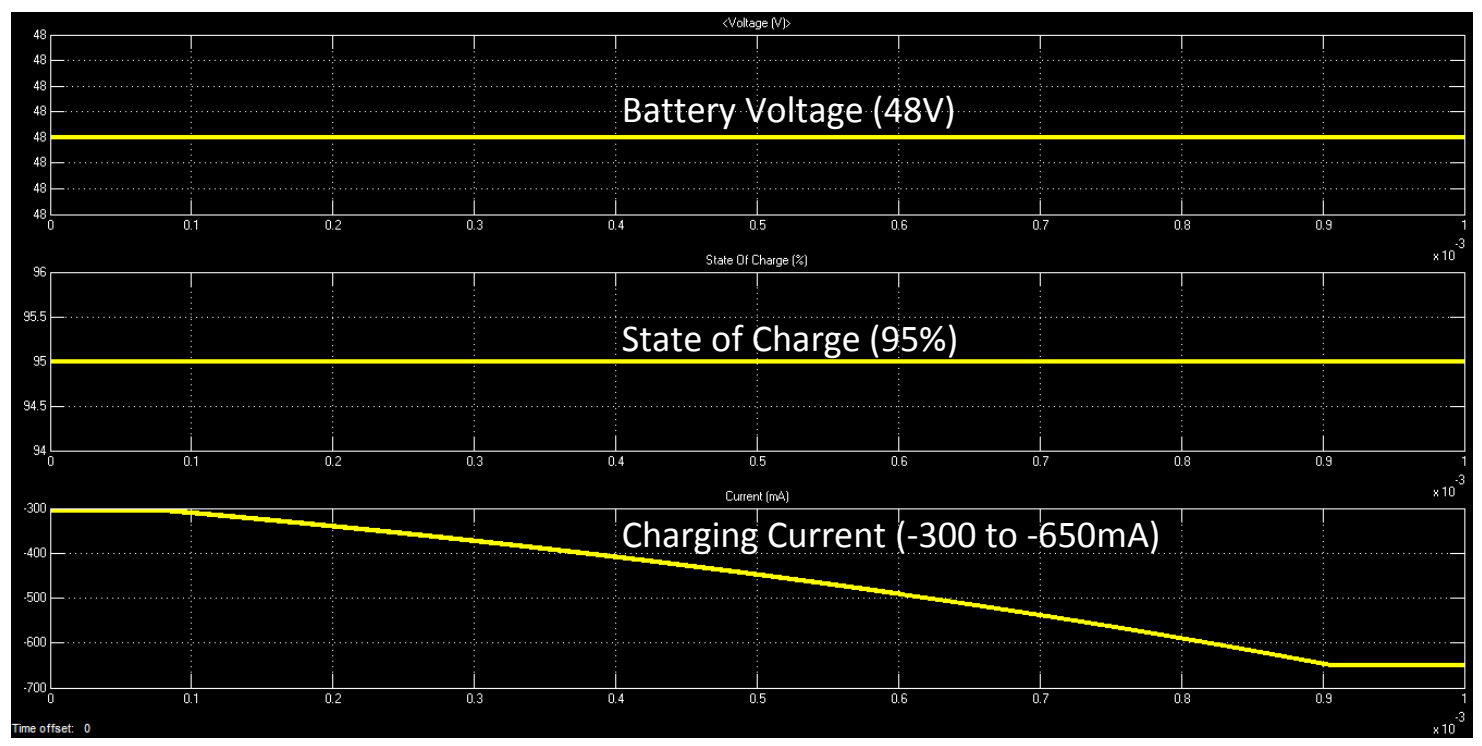

Figure 3-12: Measured Battery voltage, State of Charge and Charging Current 


\subsection{MPPT Modelling \& Design}

The efficiency of the solar panels can be increased by tracking the maximum power at any time. The MPPT system achieves maximum output by varying the operating point on the cell I-V curve shown in Figure 2-2.

As discussed in Chapter 2, the most commonly used methods are Perturb and Observe (P\&O) method and Incremental Conductance method because they offer the best efficiency [44]. The incremental conductance method offers better efficiency than the P\&O method but is difficult to implement. Therefore for this design the $\mathrm{P} \& \mathrm{O}$ method is used for this design.

The P\&O algorithm compares the current output power with the previously measure output power from the boost converter and checks the solar panel output voltage. The PWM signal of the boost converter and/or the position of the solar panel is adjusted accordingly. The algorithm is implemented using microcontroller. It has been observed in the simulation process that the width of the PWM output increases when current input power is less than previous output power and reduces when the current output power is higher than previous output power (Figure 5-2 and Figure 5-3).

\subsubsection{Perturb and Observe Algorithm Method}

The Perturb and Observe method is chosen due to its efficiency to drive the boost converter. The algorithm is shown below:

Stage 1: Measure the voltage and the current output of the buck chopper

Stage 2: Calculate the power produced by solar

Stage 3: Compare the newly measured power to the previously measured

Stage 4: There are two possible cases that arise at this point:

Case 1: If the previously measured voltage is greater than the newly measured voltage, the voltage of the panel is checked. This is represented by the Figure 3-13 and Figure A-1 in Appendix A (PV curves of the solar characteristics).

The module voltage is decreased and moves towards MPP. The opposite is where the previously measured voltage is lower than the newly measured, where the voltage of the panel is dropped (Figure A-2 in Appendix A). The module voltage is increased and moves towards MPP.

Case 2: If the previously measured voltage is less than the newly measured voltage, the voltage of the panel is checked and if the new voltage is greater than the previously measured one, then the module voltage is further increased as represented in the Figure A-3 in Appendix A (P-V curve characteristics of the solar panel). Increasing the module voltage in this case, moves the operating point closer to the MPP. However if the newly measured voltage was lower than the previously measured voltage, then the module voltage will be decreased. This is depicted in Figure A-4 in appendix A via the use of the characteristic P-V curve of the solar panel. Decreasing the module voltage in this case, moves the operating point closer to the MPP. 


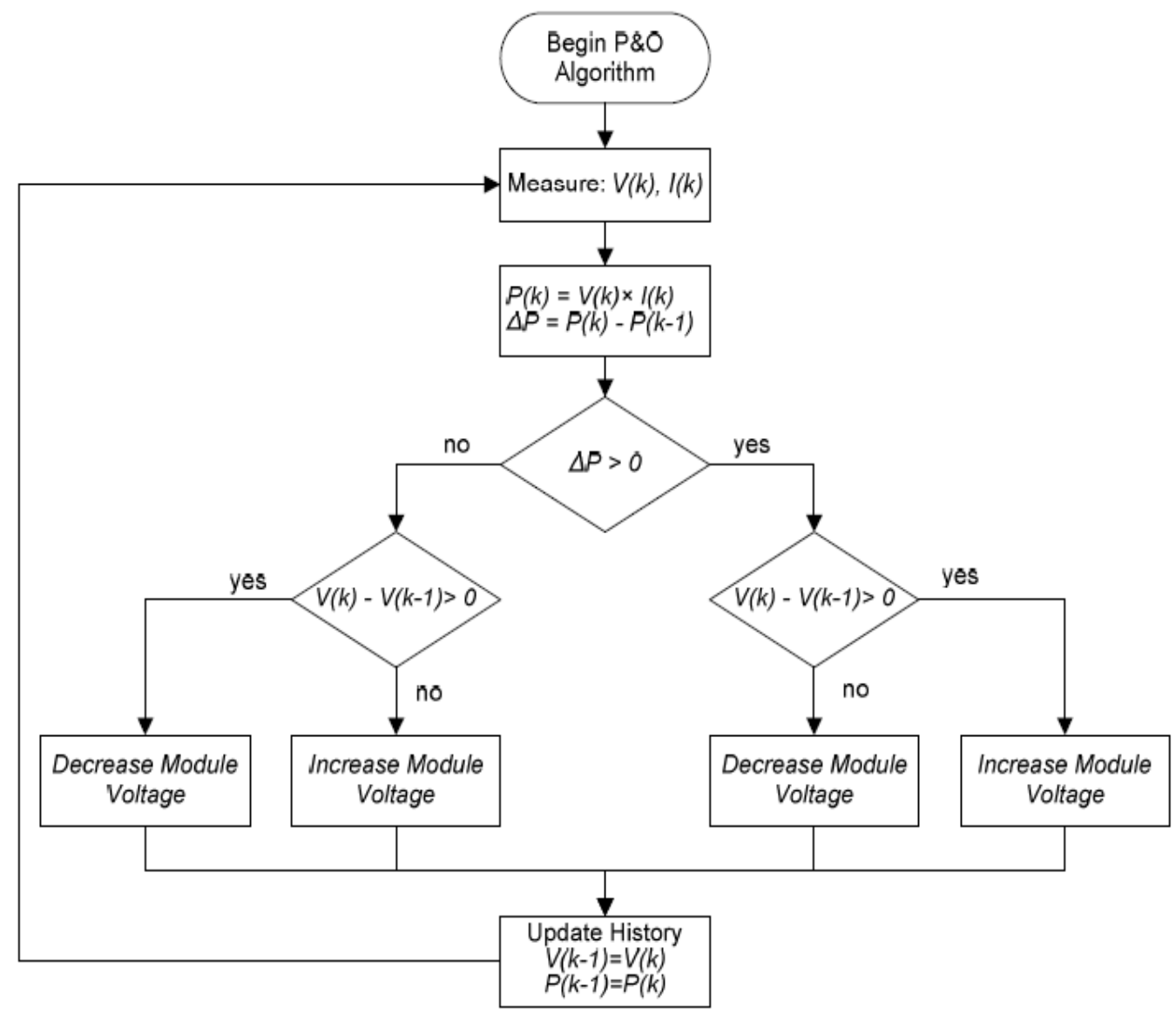

Figure 3-13: Perturb and Observe Algorithm

This will all be controlled by a microcontroller which will sense the PV current and voltage then adjust accordingly and output a pulse width modulation signal which will be fed to a boost converter.

\subsection{Boost Converter Modelling \& Design}

A boost converter also called a step-up converter since it steps up the voltage source. It is a DC to DC power converter with an output voltage greater than its input voltage. The basic schematic diagram of a boost converter is shown in Figure 3-14.

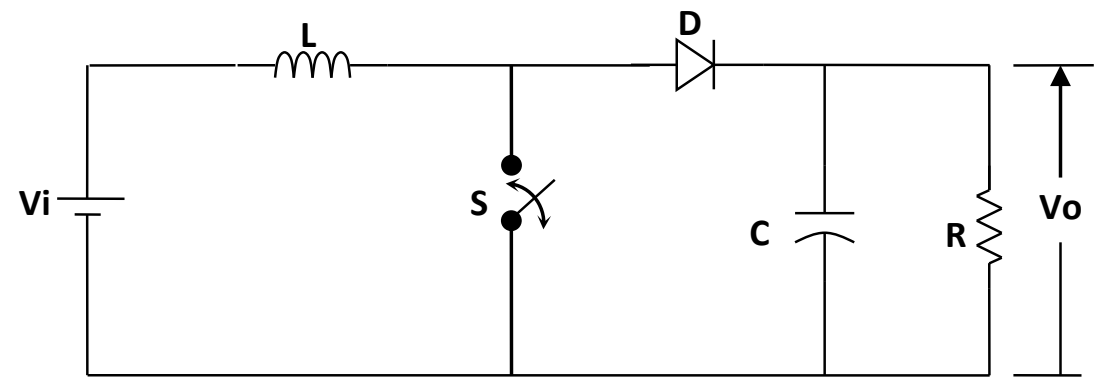

Figure 3-14: The basic schematic diagram of a boost converter.

The switch is typically a MOSFET, BJT or MOSFET. 
With any suitable input DC power source: battery, solar panel, rectifier, DC generator etc., a boost converter steps up the input voltage with the conservation principle of power; where the output power is equal to the input power. Keeping that principle, the output current is consequently less that the input current.

\subsubsection{Boost Converter Background}

The boost converter technology started in the early 1960s whereby it came with the great contribution to the problem of storage space and performance of batteries in the aerospace, in hybrid electric vehicles, in industries and elsewhere. The use of batteries delivering the high voltage was becoming more cumbersome, yet the high voltage DC was needed in small space with lightweight and efficient devices. For battery power systems, the higher the amount of voltage is achieved, the more the combination of batteries cells in series, resulting in high weight and cost, sometimes with the challenge of cell stack. The publication of R. D. Middlebrook in 1977, of the models of DC-DC converters led to the development and success of DC-DC boost converters used today [65].

Boost converters are also used in small scale applications; where for instance a 3V LED (Light Emitting Diode) lamp can be powered by a single $1.5 \mathrm{~V}$ alkaline cell in portable lighting systems.

\subsubsection{Basic Operation}

In the boost converter, the used inductor follows the principle of resisting current changes by creating the magnetic field in it. These led to the two following facts [63]:

a) When the switch S (Figure 3-14) is closed, this results in the increase of the current in the inductor therefore storing an amount of energy in the form of magnetic energy. The diode $\mathrm{D}$ is reverse biased and the load is disconnected from power source.

b) When the switch is open, the inductor is then in series with the generator and its electromotive force is added to that of the generator (booster effect). Hence, the current flows through the inductor then through diode $\mathrm{D}$, capacitor $\mathrm{C}$ and load $\mathrm{R}$. As result, the two voltage sources will be in series causing a higher voltage to charge the capacitor through the diode $\mathrm{D}$.

The output load voltage will always be higher than the input as long as the switch is cycled fast enough since the inductor will not discharge fully in between the charging stages

This can also be explained in such a way that; once the switch is open, the capacitor in parallel with the load is charged from and combined voltage (from the voltage source and the inductor). When the switch is then closed, the right hand side of the Figure 3-14 is isolated from the left hand side, therefore the capacitor provides the voltage and energy to the load, in other words; the capacitor discharges through the load. The role of the diode is to block the capacitor from discharging through the switch or simply the left hand side circuit. The switching frequency must also be high to prevent the capacitor from too much discharge.

Examining the current inductor conduction during switching stages, the boost converter is said to have a power stage which can operate in continuous or discontinuous conduction modes. In continuous conduction mode, the current $\mathrm{I}_{\mathrm{L}}$ flows continuously in the inductor during the entire switching cycle in steady-state operation. In discontinuous conduction mode, the inductor current is zero for a portion of the switching. 
The output current and voltage are always higher than the input. Keeping the output constant while the input is varying is done by commuting the duty cycle in the PWM of the closed loop boost converter where the feedback circuit plays an important role (Figure 3-15) in the instantaneous variation of the duty cycle.

The PWM firing the switching device (MOSFET) is in a such way that the output width increases when the input power is less than previous output power and decreases when the output power is higher than previous output power as discussed in section 4.2.3. The result is that the DC output voltage and current reaches respectively the constant $220 \mathrm{~V}$ and $3 \mathrm{~A}$ from $48 \mathrm{~V}$ input voltage. Unfortunately the time delay of 0.01 second makes the output voltage and current graphs not a straight line as it should be for the direct current.

In the DC-Dc boost converter, there is a boundary between continuous and discontinuous conduction.

Figure 3-15 (a) shows the steady state waveforms for the continuous conduction mode. $I_{L}$ goes to zero at the end of the off interval. The average value of the inductor current at this boundary is:

$$
\begin{gathered}
I_{L B}=\frac{1}{2} I_{L, \text { peak }} \\
=\frac{1}{2} \frac{V_{d}}{L} t_{\text {on }} \\
=\frac{T_{S} V_{o}}{2 L} D(1-D)
\end{gathered}
$$

In the boost converter, the input current and inductor current are in series or they are equal i.e.: $\left(i_{d}=\right.$ $i_{L}$ ). From Equation (3.16) and (3.17) we find that the average output current at the edge of continuous conduction is:

$$
I_{O B}=\frac{T_{S} V_{o}}{2 L} D(1-D)^{2}
$$

In Figure 3-15 (b), the output voltage $V_{o}$ and $\mathrm{I}_{\mathrm{OB}}$ are plotted as a function of duty ratio $D$. Keeping $V_{o}$ constant and varying the duty ratio imply that the input voltage is varying.

Figure 3-15 (b) shows that $I_{L B}$ reaches a maximum value at $\mathrm{D}=0.5$ :

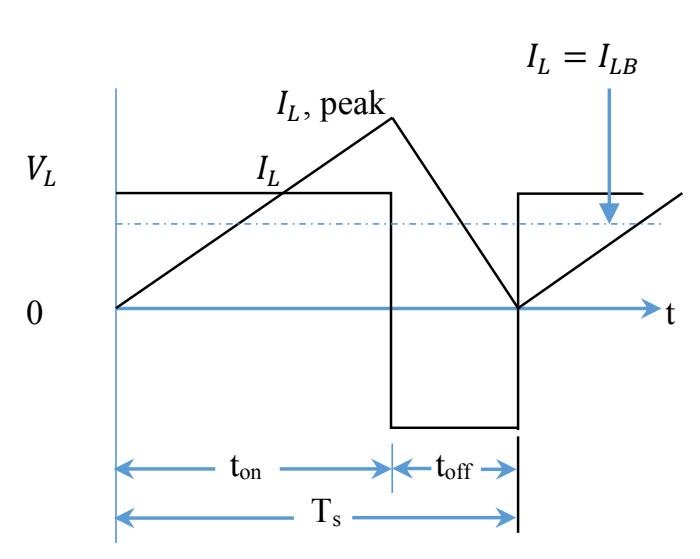

(a)

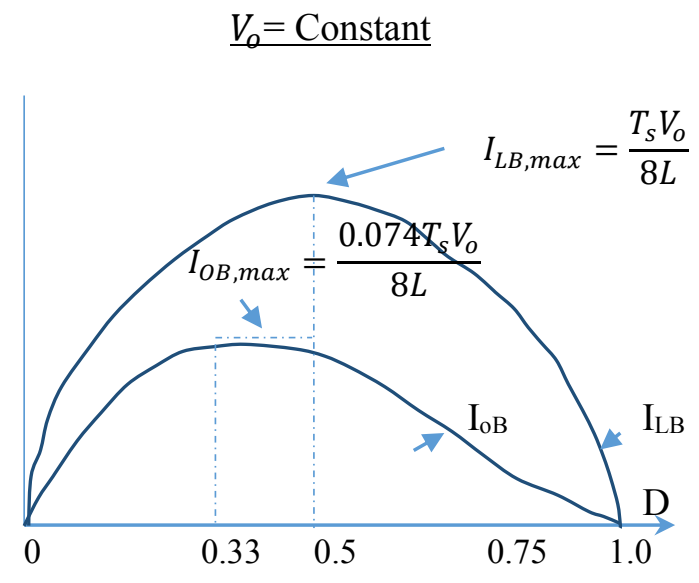

(b)

Figure 3-15: DC-DC Boost converter at the boundary continuous-discontinuous conduction [12] 
Also, $I_{O B}$ has its maximum at $D=0.333$ :

$$
I L_{B, \max }=\frac{T_{S} V_{O}}{8 L}
$$

$$
I_{o B, \max }=\frac{2}{27} \frac{T_{S} V_{O}}{L}=0.074 \frac{T_{S} V_{O}}{L}
$$

In terms of their maximum values, $I_{L B}$ and $I_{O B}$ can be expressed as:

and

$$
I_{L B}=4 D(1-D) I_{L B, \max }
$$

$$
I_{O B} \frac{27}{4} D\left(1-(1-D)^{2} I_{O B, \max }\right.
$$

\subsubsection{Continuous Conduction Mode}

When a boost converter is operating in continuous conduction mode, the current through the inductor $I_{L}$ never falls to zero as shown in Figure 3-16.

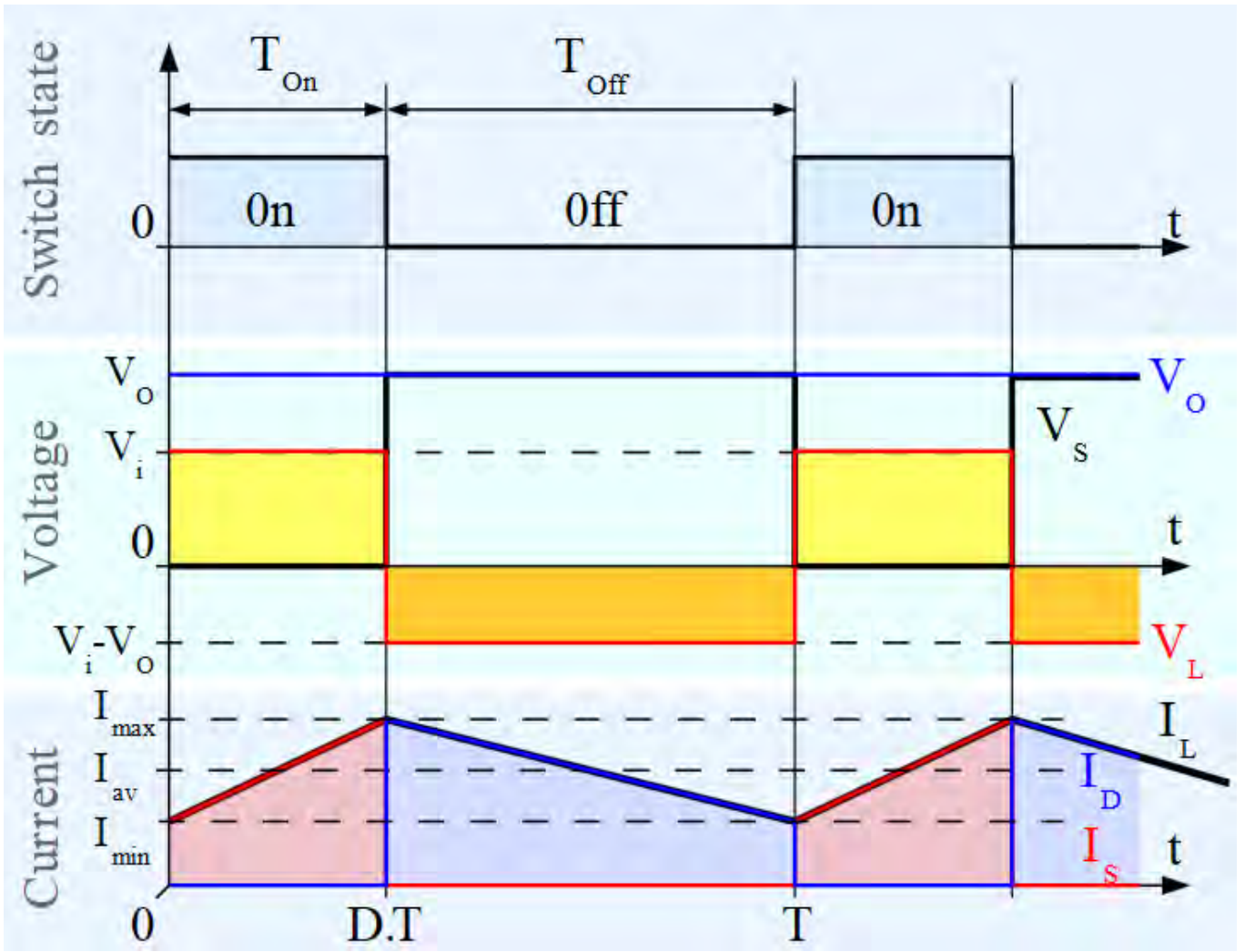

Figure 3-16: Inductor Current and Voltage for Continuous-Conduction Mode of Boost Converter Where: [32].

$T_{o n}$ is the switching on time

$T_{\text {off }}$ is the switching off time

$V_{i}$ is the input voltage

$V_{o}$ is the output voltage

$T$ is he switching period

$I_{\text {max }}$ is the Maximum current 
$D$ is the duty cycle

$V_{S}$ is the voltage across the switch

For an ideal converter, the output voltage can be calculated as follows:

During the On-state, the switch $\mathrm{S}$ is closed which causes the change in voltage $\Delta \mathrm{I}_{\mathrm{L}}$ across the inductor, which also causes a change in current $\Delta \mathrm{I}_{\mathrm{L}}$ flowing through the inductor during the time period $(\mathrm{t})$, this gives the equation below [33]:

$$
\frac{\Delta I_{L}}{\Delta t}=\frac{V_{i}}{L}
$$

After On-state, the current through inductor $\mathrm{I}_{\mathrm{L}}$ is increased by:

$$
\Delta I_{\text {Lon }}=\frac{1}{L} \int_{0}^{D T} V_{i} d t=\frac{D T}{L} V_{i}
$$

$D$ is the duty cycle representing the fraction of the commutation period $\mathrm{T}$ during which the switch is on. Therefore $\mathrm{D}$ ranges between 0 and 1.

By considering the off state of the switch, with the ideal conditions where the voltage drop in the diode is zero and a capacitor large enough to maintain its constant voltage. The evolution of $\mathrm{I}_{\mathrm{L}}$ is [33]:

$$
V_{i}-V_{o}=L \frac{d I_{L}}{d t}
$$

During off period, $\mathrm{I}_{\mathrm{L}}$ is varied by:

$$
\Delta I_{L o f f}=\int_{D T}^{T} \frac{\left(V_{i}-V_{o}\right) d t}{L}=\frac{\left(V_{i}-V_{o}\right)(1-D) T}{L}
$$

The energy stored in the inductor is given by:

$$
E=\frac{1}{2} L I_{L}^{2}
$$

This yields that the overall change in the inductor current changes is zero:

$$
\Delta I_{\text {Lon }}+\Delta I_{\text {Loss }}=0
$$

Substituting $\Delta I_{\text {Lon }}$ and $\Delta I_{\text {Loff }}$ by their expressions, the equation (3.30) becomes [33]:

$$
\Delta I_{\text {Lon }}+\Delta I_{\text {Loff }}=\frac{V_{i} D T}{L}+\frac{\left(V_{i}-V_{o}\right)(1-D) T}{L}=0
$$

This can be written as:

$$
\frac{V_{o}}{V_{i}}=\frac{1}{1-D}
$$

This shows that $V_{o}$ is always higher than $V_{i}$ and it increas with D. Mathematically, $V_{o}$ tends to infininty as $\mathrm{D}$ approaches 1 [43]. From there, the converter is reffered to as step-up converter.

Rearranging the equation, $\mathrm{D}$ becomes:

$$
D=1-\frac{V_{i}}{V_{o}}
$$




\subsubsection{Discontinuous Conduction Mode}

The discontinuous mode occurs whenever there is a high ripple amplitude of the current. In this case there is a deep discharge of the inductor before the end of the commutation cycle. This mostly take place under light loads and has a significant effect on the output voltage equation.

The Figure 3-17shows that straight after the switch is off; the current through the inductor falls to zero.

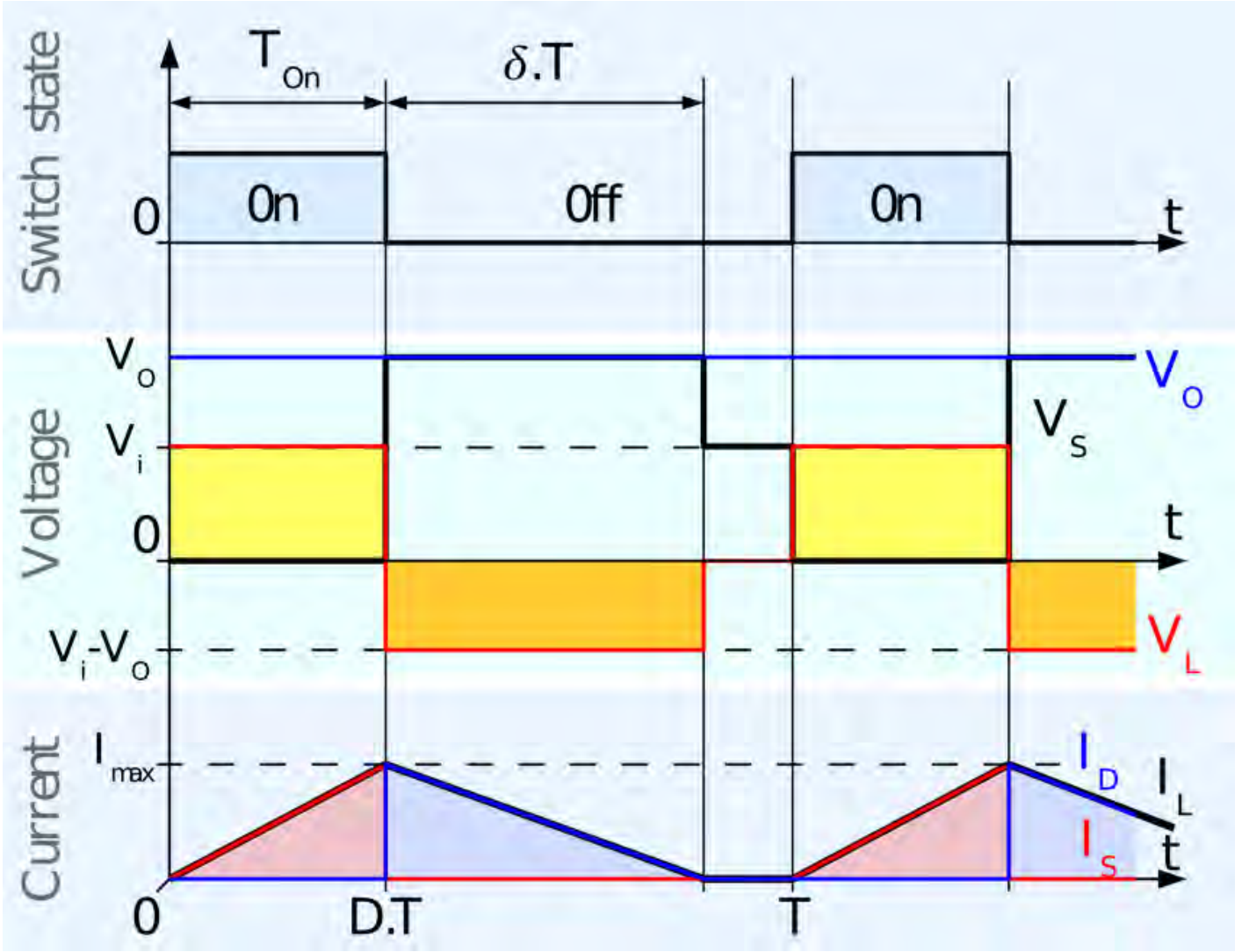

Figure 3-17: Inductor Current for Voltage for discontinuous - conduction mode of boost converter [32]

As the inductor current at the beginning of the cycle is zero, its maximum value $\left(I_{L \max }\right.$ at $\left.t=D T\right)$ can be calculated as follows:

$$
I_{L \max }=\frac{V_{i} D T}{L}
$$

During the off-period, $I_{L}$ falls to zero after $\delta T$ :

$$
I_{L \max }+\frac{\left(V_{i}-V_{0}\right) \delta T}{L}=0
$$

Equating equations ( $3.34 \& 3.35), \delta$ becomes:

$$
\delta=\frac{V_{i} D}{V_{o}-V_{i}}
$$

Figure 4-13 shows that the load current $I_{o}$ is equal to the average diode current $\left(I_{D}\right)$ and during the off-state the diode current is equal to the inductor current. Therefore the output current can be written as: 


$$
I_{o}=I_{D}=\frac{I_{L \max }}{2} \delta
$$

Replacing $I_{L \max }$ and $\delta$ in the equation above;

$$
I_{o}=\frac{V_{i} D T}{2 L} \times \frac{V_{i} D}{V_{o}-V_{i}}=\frac{V_{i}^{2} D^{2} T}{2 L\left(V_{o}-V_{i}\right)}
$$

The output voltage gain can be written as:

$$
\frac{V_{o}}{V_{i}}=1+\frac{V_{i} D^{2} T}{2 L I_{o}}
$$

\subsection{Automatic Switch Modelling \& Design}

The automatic power source selector of the hybrid system is designed using Proteus Virtual System Modelling simulator. The flow code software is used to write the algorithm which also enables the user to download the program into a microcontroller and also user friendly.

The design automatically selects solar panel power from battery to supply $1 \mathrm{~kW}$ load during peak power demand period and during mains power shut off period. The selection between solar and mains power is automatic; the system does automatically check the availability of the sources to switch between solar and mains during peak and off peak times.

During night when the mains shuts off, battery is utilized to power the load. The program is user friendly and can be changed any time according to the requirement. Also, for emergency needs, manual switching is provided to change the source. The program is written based on the ESKOM's off and peak time's electricity demands as discussed in chapter 4 . The switching algorithm is shown below:

Start.

Input 5 variables: Power from Mains (M), Power from inverter (I), Power from DC-DC regulator $(\mathrm{R})$, Day $(\mathrm{D})$, and Time $(\mathrm{T})$

Step $\mathrm{D}_{1}$. If Day is Monday to Friday, go to step $\mathrm{D}_{2}$, else, go to Step $\mathrm{D}_{6}$

Step $\mathrm{D}_{2}$. If Time is either $07 \mathrm{~h} 00-10 \mathrm{~h} 00$ or $10 \mathrm{~h} 00-20 \mathrm{~h} 00$ go to step $\mathrm{D}_{3}$, else go to Step $\mathrm{D}_{4}$

Step $\mathrm{D}_{3}$. If Inverter is on, go to $\mathrm{A}_{1}$, else go to Step $\mathrm{D}_{4}$

Step $\mathrm{D}_{4}$. If Power from Mains is on, go to $A_{2}$, else go to $\mathrm{D}_{3}$

Step $\mathrm{D}_{5}$. If Time is 14:00-14:30, go to $\mathrm{A}_{3}$

Step $\mathrm{D}_{6}$. If Day is Saturday, go to $\mathrm{D}_{4}$, else go to $\mathrm{D}_{7}$

Step. $\mathrm{D}_{7}$. If Day is Sunday, go to $\mathrm{D}_{4}$ and $\mathrm{D}_{5}$, else go to $\mathrm{D}_{1}$

Step $A_{1}$. Switch to the inverter (I), go to Step $D_{1}$

Step $A_{2}$. Switch to the mains (M), go to Step $D_{1}$

Step $A_{3}$. Switch to Regulator (R), go to Step $D_{1}$

Note: $\mathrm{D}_{\mathrm{i}}$ denotes decision $\mathrm{i}$

$\mathrm{A}_{\mathrm{i}}$ denotes Action $\mathrm{i}$

Figure 3-18 shows the flow chart of the program. 


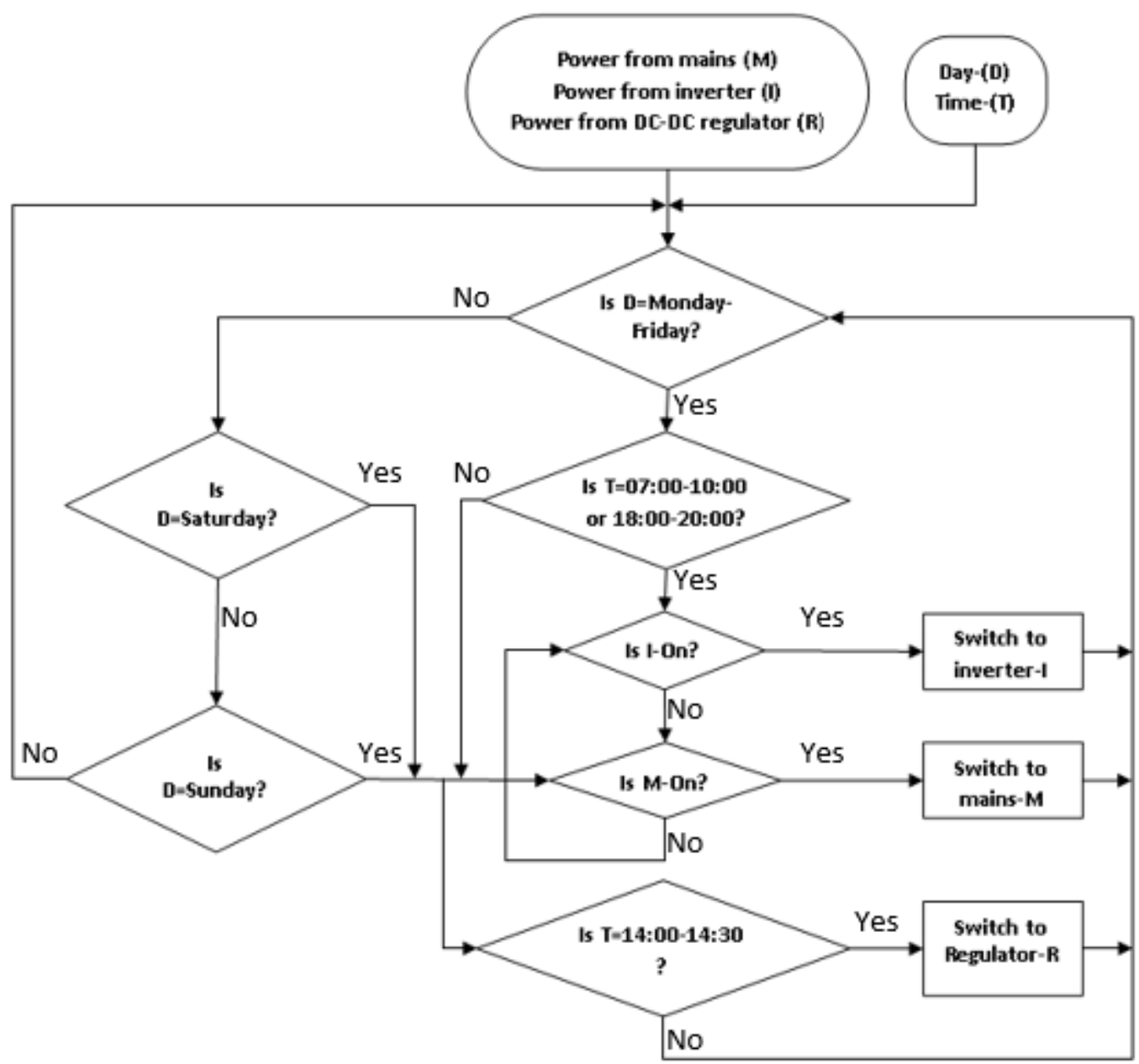

Figure 3-18: Power source selection flowchart

The designed system can work continuously and the monitoring is done on second to second basis depending on the frequency of the used microcontroller.

In this simulation we have used ATMEGA 3290P with its CPU (Central Processing Unit) frequency of $16 \mathrm{MHz}$ [99].

\subsection{Cleaning Robot Modelling \& simulation}

The power from the solar panel is used to drive the cleaning robot. It is a $48 \mathrm{~V}$ DC motor programmed to run in both forward and reverse directions. While the motor runs, the sweeper or brushes or squeegees connected to its shaft continuously brooms the panels as shown in Figure 3-19. 


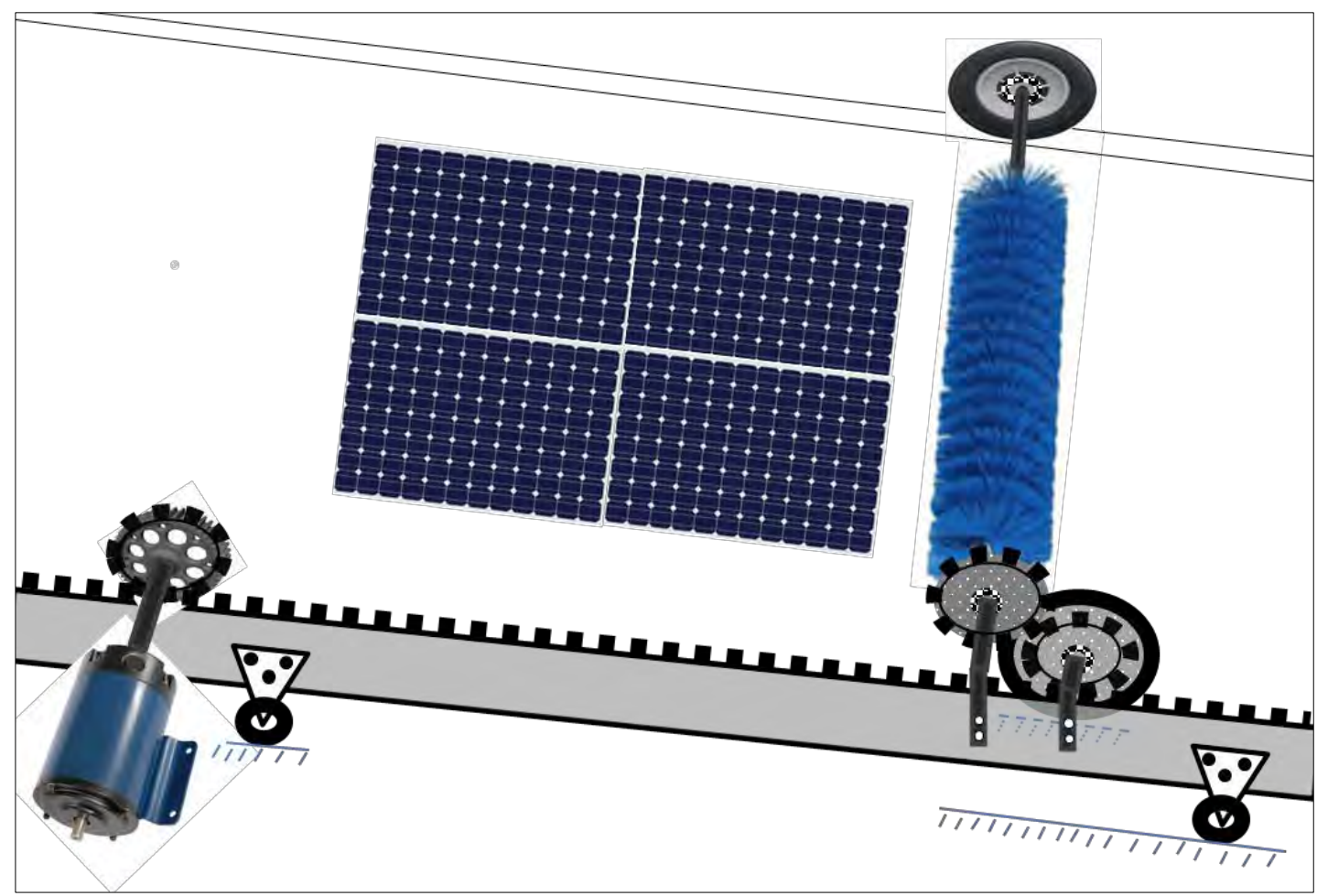

Figure 3-19: Solar panel cleaning system

The cleaning cycle is informed by the environmental dust accumulation rate. This rate varies vastly according to seasons of the year even day-by-day. Its variability makes it difficult to obtain a deterministic value hence we assume a reasonable cyclic cleaning mechanism. In this project the number of cycles used is 10 and the cleaning is done once a week (Sunday from 14:00 to 14:30). The timing is strategically chosen to target the period of the day after which maximum solar irradiation is experienced. This should give the battery bank enough time to charge before powering the cleaning process. The cleaning process will however proceed regardless of the charge level of the batteries. In the event of no solar irradiation at the time regulated for cleaning, the process will await for the next scheduled cleaning cycle.

In this design the load of 5,000Watts being "on" for 5 hours, the energy consumed will be 25,000 Watthours. The $48 \mathrm{~V}$ battery system will be used with the capacity of 520.83 Amperehour.

For a battery of $80 \%$ SOC (State of Charge) and with a 520.83 Ah capacity, the storage in the battery is $416.66 \mathrm{Ah}$.

So, in order to have the needed capacity, the value of the obtained result is divided by $80 \%$ and becomes 625AmpereHours.

Considering a battery of $48 \mathrm{Ah}$, we will use 8 batteries.

The minimum power required by load is a $1.1 \mathrm{~A}$ DC motor of 52.8 Watts.

The motor load will be supplied by the solar panel at 14:00-14:30 and normally, at this time the sun is almost at zenith whereby the maximum power from the panel is expected. And the reason of not setting this activity at 12:00 whereby the sun is at zenith is discussed in details in Chapter 4 . As it is said; "This should give the battery bank enough time to charge before powering the cleaning process" [100]. 
Since the motor is directly connected to the solar panel source, the panel is expected to work only when the sun is out, meaning from sunrise to sunset (06:00-18:00) on average. That means the Panel is expected to work for $12 \mathrm{hrs}$ a day consuming energy of 633.6 Watt-hour.

Other known values:

Maximum Irradiance ( $\mathrm{Y}$ ) value obtained from January 2012 to November 2014 from the average irradiance data record is $645.4 \mathrm{~W} / \mathrm{m}^{2}$ [101].

Minimum Durban Temperature $\left(\mathrm{T}_{\min }\right)$ value obtained from irradiance data (Figure $\left.3-20\right)$ is $17.28^{\circ} \mathrm{C}$ [87].

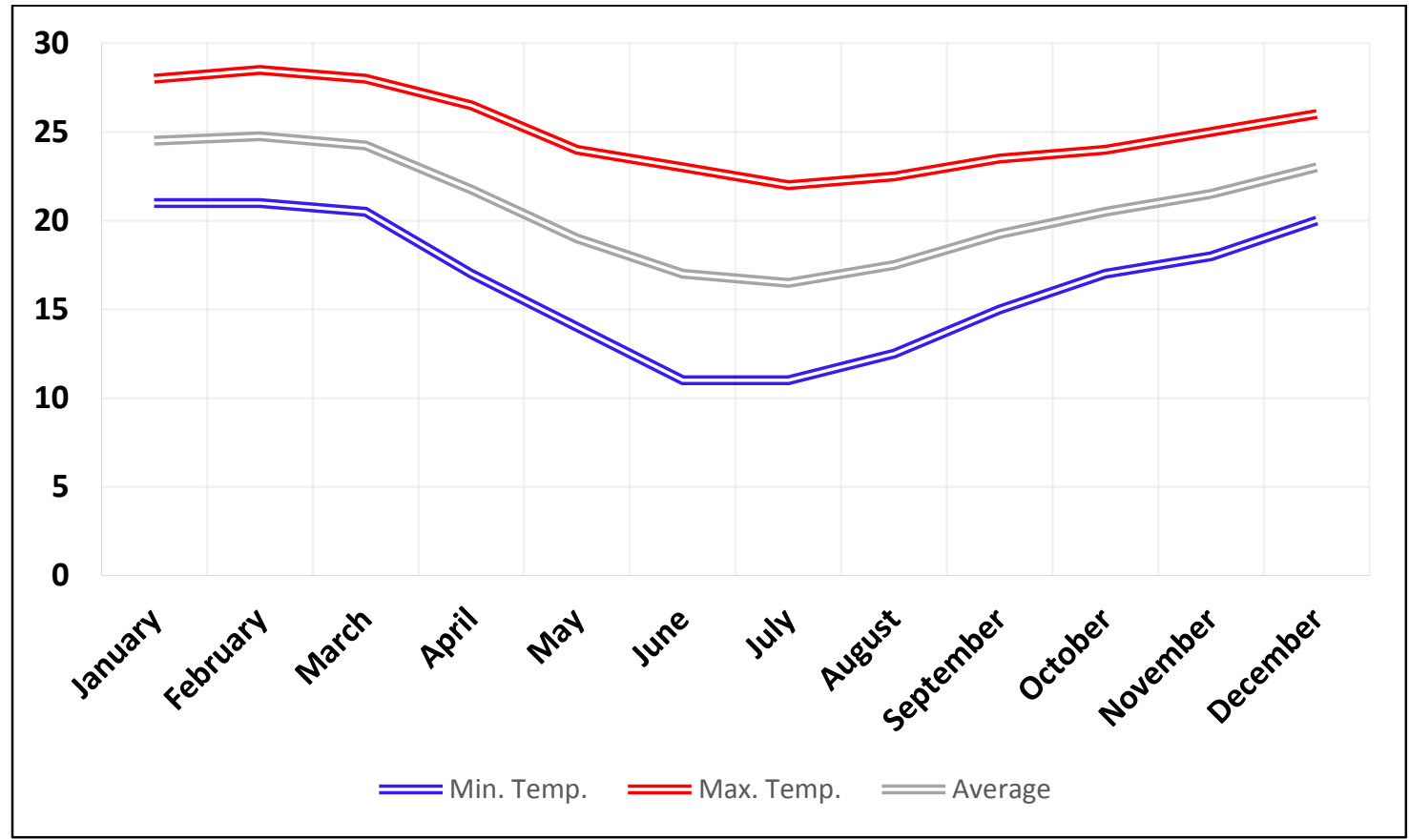

Figure 3-20: Durban temperatures $\left({ }^{0} \mathrm{C}\right) 2010-2015$ [87]

Maximum Irradiance and minimum temperature values were chosen because for a given irradiance level, PV panels produce higher power at colder temperatures as shown in the Figure 3-21. 


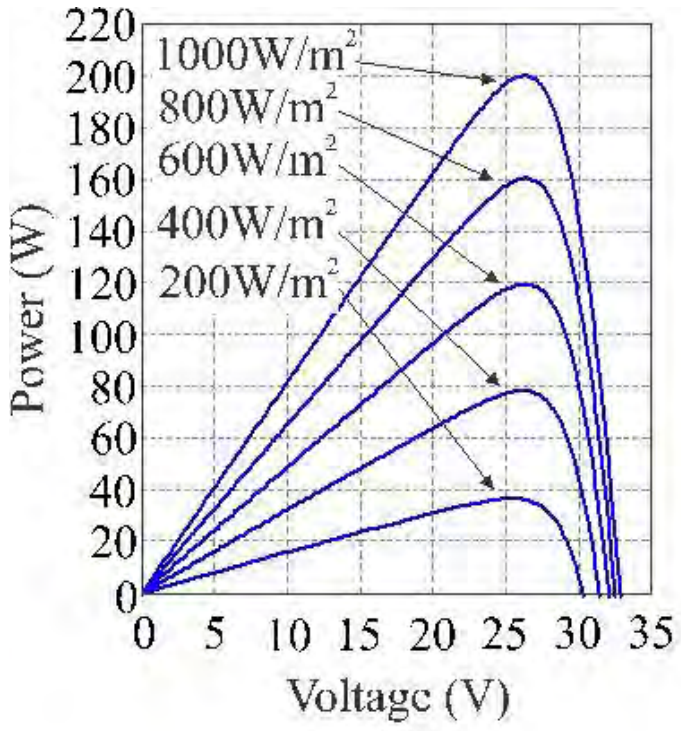

(a)

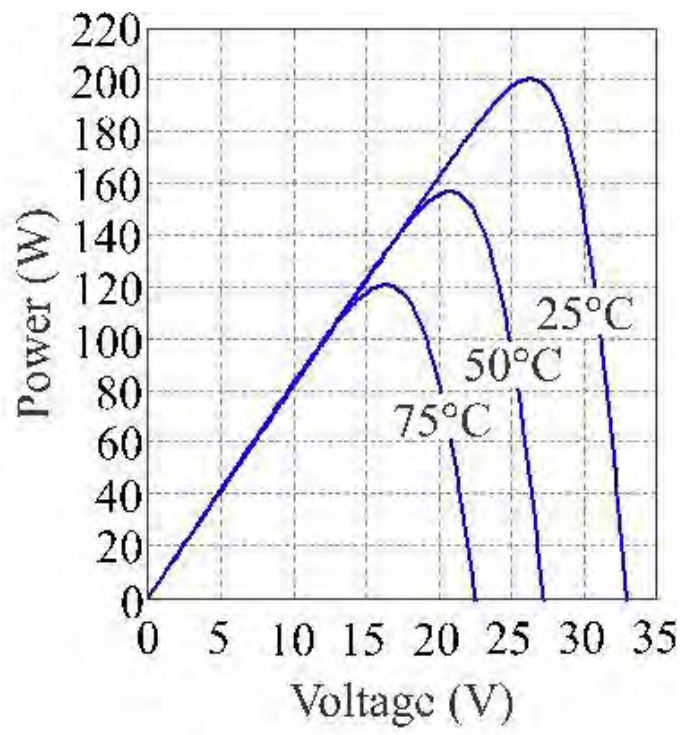

(b)

Figure 3-21: Effect of change in temperature and irradiance [89].

(a) Constant temperature and (b) constant solar radiation characteristics

Therefore substituting these values (known as rating values of PV):

$I_{p v}=1.1 A$ (= the net current flowing through the diode, $\left.\mathrm{I}_{\mathrm{d}}\right)$,

and $V_{p v}=48 V$ (= applied voltage across the terminals of the diode, $\mathrm{V}_{\mathrm{d}}$ )

Which are the load parameters, they provide a guide for the PV output power needed [8]:

$$
\begin{gathered}
I_{p h}=\left[I_{s c}+K_{i}(T-298)\right] \times 8 / 1000 \\
I_{p h}=\left[I_{s c}+0.0017 \times(273+17.28-298) \times 645.4 / 1000\right] \\
I_{p h}=\left[I_{s c}-0.0085\right]
\end{gathered}
$$

Then,

$$
\begin{gathered}
I_{o}=I_{r S}\left[\frac{T}{T_{r}}\right]^{3} \exp \left[\frac{q \times E_{g o}}{B K}\left\{\frac{1}{T_{r}}-\frac{1}{T}\right\}\right] \\
I_{0}=I_{r s}\left(\frac{273+17.28}{298}\right)^{3} \exp \left[\frac{1.69 \times 10^{-19} \times 1.1}{1.6 \times 1.3805 \times 10^{-23}} \times\left\{\frac{1}{298}-\frac{1}{273+17.28}\right\}\right] \\
I_{0}=0.436 I_{r s}
\end{gathered}
$$

And finally, current output of PV module is calculated as [66]:

$$
\begin{gathered}
I_{p v}=N_{p} \times I_{p h}-N_{p} \times I_{o}\left[\exp \left\{\frac{q \times\left(V_{p v}+I_{p v} R_{s}\right)}{N_{s} A k T}\right\}-1\right] \\
I_{p v}=N_{p} \times\left(I_{s c}-0.0085\right)-N_{p} \times\left(0.439 I_{r s}\right)\left[\exp \left\{\frac{1.6 \times 10^{-19} \times\left(48+0.1 I_{P V}\right)}{N_{s} \times 1.5 \times 1.38 \times 10^{-23} \times(273+17.28)}\right\}\right.
\end{gathered}
$$


Unknown values:

$N_{p}$ the number of cells connected in parrallel

$N_{s}$ the number of cells connected in series

$I_{s c}$ the PV Panel short circuit current

$I_{r s}$ the module reverse saturation current

$N_{p}$ and $N_{s}$ are based on the size of the panel chosen which will further be discussed in this report

$I_{s c}$ and $I_{r s}$ values may be chosen with the guadiance that $I_{p v}$ should at least be equal to or greater than $1.1 \mathrm{~A}$ which is the required load current

\section{Values assigning and calculations:}

$\mathrm{Np}=\mathrm{Ns}=2$ since we have 4 panels; ( 2 panels connected in series and 2 connected in parallel), each panel having $24 \mathrm{~V}$.

The PV panel short circuit current $I_{s c}$, is 8.52A from the datasheet [102]

The Module Reverse Saturation current is given by [103, 104]:

$$
I_{d}=I_{r s}\left(e^{\frac{q V d}{K T}}-1\right)
$$

Where: $\mathrm{q}$ is the electron charge $\left(=1.6 \times 10-19^{\circ} \mathrm{C}\right)$

$I=$ the net current flowing through the diode

$V_{d}=$ applied voltage across the terminals of the diode;

$I_{d}=$ the net current flowing through the diode

$K=$ Boltzmann's constant $(=1.38 \times 10-23 \mathrm{~J} / \mathrm{K})$

$T=$ absolute temperature $(\mathrm{K})$

$$
\text { at } 25^{\circ} \mathrm{C} \text { : }
$$

$$
\begin{gathered}
I_{d}=I_{r s}\left(e^{\frac{q V d}{0.026}}-1\right) \\
I_{r s}=\frac{I_{d}}{e^{\frac{V_{d}}{0.026}-1}}
\end{gathered}
$$

Since, we have 2 panels in parallel, equation (3.32) becomes,

$$
\begin{aligned}
I_{r s} & =\frac{8.52 \times 2}{e^{\frac{48}{0.026}-1}} \\
I_{r s} & =9.94 \times 10^{-3}
\end{aligned}
$$

Then:

$$
\begin{gathered}
I_{p v}=N_{p} \times\left(I_{s c}-0.0085\right)-N_{p} \times\left(0.439 I_{r S}\right) \exp \left\{\frac{1.6 \times 10^{-19} *\left(48+0.1 I_{P V}\right)}{N_{S} \times 1.5 \times 1.38 \times 10^{-23} \times(273+17.28)}\right\} \\
I_{p v}=2 \times(8.52-0.0085)-2 \times\left(0.439 \times 9.94 \times 10^{-3}\right) \exp \left\{\frac{1.6 \times 10^{-19} \times\left(48+0.1 I_{P V}\right)}{2 \times 1.5 \times 1.38 \times 10^{-23} \times(273+17.28)}\right\} \\
I_{p v}=17.014 \exp \left\{\frac{1.6 \times 10^{-19} \times\left(48+0.1 I_{P V}\right)}{1.202 \times 10^{-20}}\right\}
\end{gathered}
$$




$$
\begin{gathered}
I_{p v}=17.014 \exp \left\{\frac{\left(7.68 \times 10^{-18}+2.56 \times 10^{-19} I_{P V}\right)}{1.202 \times 10^{-20}}\right\} \\
I_{p v}=17.014 \exp \left\{\frac{7.68 \times 10^{-18}}{1.202 \times 10^{-20}}+\frac{2.56 \times 10^{-19} I_{p v}}{1.202 \times 10^{-20}}\right\} \\
I_{p v}=17.01 e^{638.94} e^{21.31 I_{p v}}
\end{gathered}
$$

This leads to the equation:

$$
I_{p v} e^{-21.31 I_{p v}}=17.014 e^{638.94}
$$

For which the solution is given by:

$$
I_{p v}=\frac{-W\left(-21.3 \times 17.014 e^{638.94}\right.}{21.3}=-30.69-0.15 i
$$

Where W stands for the Product Logarithm (also called Lambert Function) [6] .

We note that $I_{p v}$ is a complex number with modulus: $\left\|I_{p v}\right\|=30.69 \mathrm{Amps}$

This value will explain that the available current for the selected load is enough sufficient and it has also to be noted that the motor load is connected to the same output to the overall load. This means that the motor load will draw:

$1.1 / 30.69=3.6 \%$ of the total available PV current source 


\section{CHAPTER 4 \\ SUB-SYSTEM DESIGN AND MODELLING}

\section{Introduction}

In this chapter, the modelling of converters used in solar system have been discussed. The automatic cleaning system used to increase the efficiency of the solar panels has been designed. The solar panels are periodically and automatically cleaned by the programmed microcontroller. The maximum power point tracker has been designed for optimizing the possible power from photovoltaic modules since the solar irradiance, the panel resistance and the temperature produce non-linear output efficiency and observed to have a complex relationship when analysed by different techniques; we have analysed this relationship from the I-V curve.

The power flows in the following way as also shown on the block diagram, Figure 4-1.

The solar panel receives power from the sun and the solar panel is connected to the Maximum Power Point Tracker (MPPT), a fully electronic system that varies the electrical operating point of the modules so that the modules are able to deliver the maximum available power. Additional power harvested from the modules is then made available as increased battery charge current [37]. MPPT can be used in conjunction with a mechanical tracking system, but the two systems are completely different. In this study the mechanical MPPT system has not been tackled.

The power harvested from the PV panel and MPPT is then stored in the battery bank and converted through the DC-DC boost converter and through DC-AC inverter then fed to the AC load during the peak time demand. The switching of this solar energy to the load is done automatically by means of the time-based programmed microcontroller as switch. Alternatively, the load is supplied by the power from the $\mathrm{AC}$ mains of the grid during the Off-Peak time according to ESKOM's data source [105] by means of the same automated switch.

The panel cleaning robot is directly fed from the solar power after being converted through the DCDC converter for getting the linear output power. The cleaning cycle is also automatically done by the same programmed microcontroller and the program is set according to the panel dirt settlement rate of the area.

Besides the common AC load, the system is designed to supply also the DC load and this supply is directly from the battery bank

All automatic switches are combined (or installed in parallel) with a manual switches for the user to take action any time manually. In addition to this, the LCD screen displays any activity done instantaneously. 


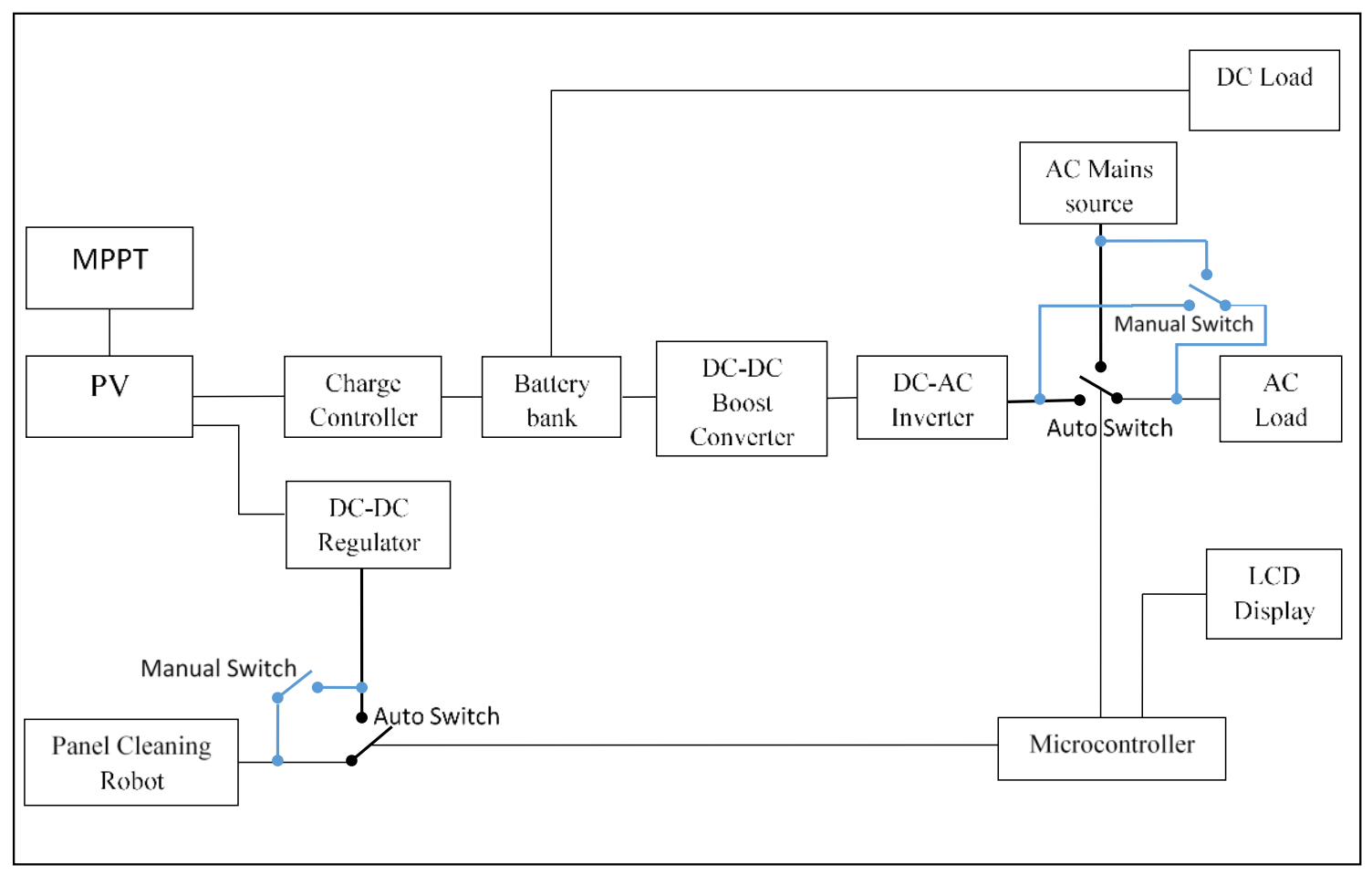

Figure 4-1: Block diagram of the complete design

\subsection{Voltage Source Inverter - VSI}

It is normally used for converting DC to AC voltage, but it is also fund in many applications such as:

a) Solar panel or batteries where it supplies AC from DC source.

b) High voltage direct current (HVDC) power transmission

c) Variable frequency drive: in our design, the VSI is used to drive the speed of an induction motor at any frequency as shown in Figure 4-2

The VSI converts DC voltage to three phase AC voltage by means of six semiconductor switches turned off and on (Figure 4-2) the two at a time. The switches used here are IGBTs and the corresponding reverse recovery diodes. The role of the rectifier here is to generate pulses signal on the DC supply and the capacitor smoothens this ripple and imparts it to the input of the inverter.

The PWM method is used in switching on and off the six IGBTs. There are three PWM modulation techniques, these include: SVM technique, Hysteresis PWM current control technique and sinusoidal PWM, each one has its particular benefits [67]. 


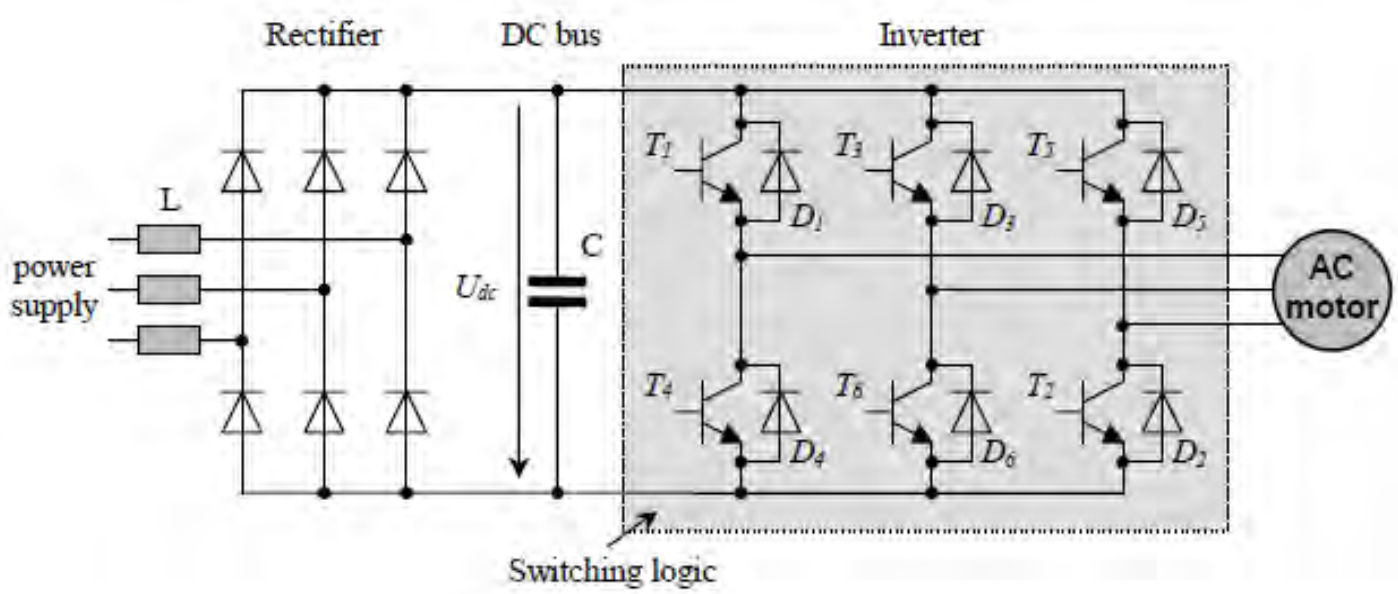

Figure 4-2: The voltage Source Inverter for our design application [9].

The hysteresis PWM current control technique is very easy to implement and it is monitored directly from the current control, the maximum voltage is supplied until the minimum current is within predetermined boundaries. However, it has got the disadvantages of not having a fixed PWM frequency due to the involuntary lower sub harmonics and these ones are generated by the hysteresis controller. In addition, there is no interaction between three phases which is the source of unlimited current errors, increased switching frequency which generate losses mainly at lower modulation, it is also implemented in the three phase separately [9].

On the other hand, the PWM technique has got an advantage of having a fixed PWM frequency simultaneously used for all phases. The interaction between the three phases results in good switching state. It is easy to implement it in software as well as in hardware whereby in hardware analogy integrators and comparators for the generation of the carrier and switching states are used. It has got the drawbacks of high semiconductor losses and particularly higher harmonics at the motor terminals [9].

The SVM techniques has got the advantage of providing efficient use of the supply voltage and very low harmonic distortion in both output voltage and current [11]. It is easily implemented with modern DSP-based control systems [9]. However it is it is complex to understand compared to the other techniques. SVM has been chosen in our design.

\subsubsection{Space Vector Modulation}

SVM technique supplies the AC motor with the minimised harmonic contents and with the desired voltage [21]. The amount of copper losses contribute to the overall losses in the machine and they are determined by the harmonic content in the input supply. Therefore, they are determined by the harmonic content in the input supply. Hence, these copper losses are minimised by the harmonics reduction $[21,27]$. 


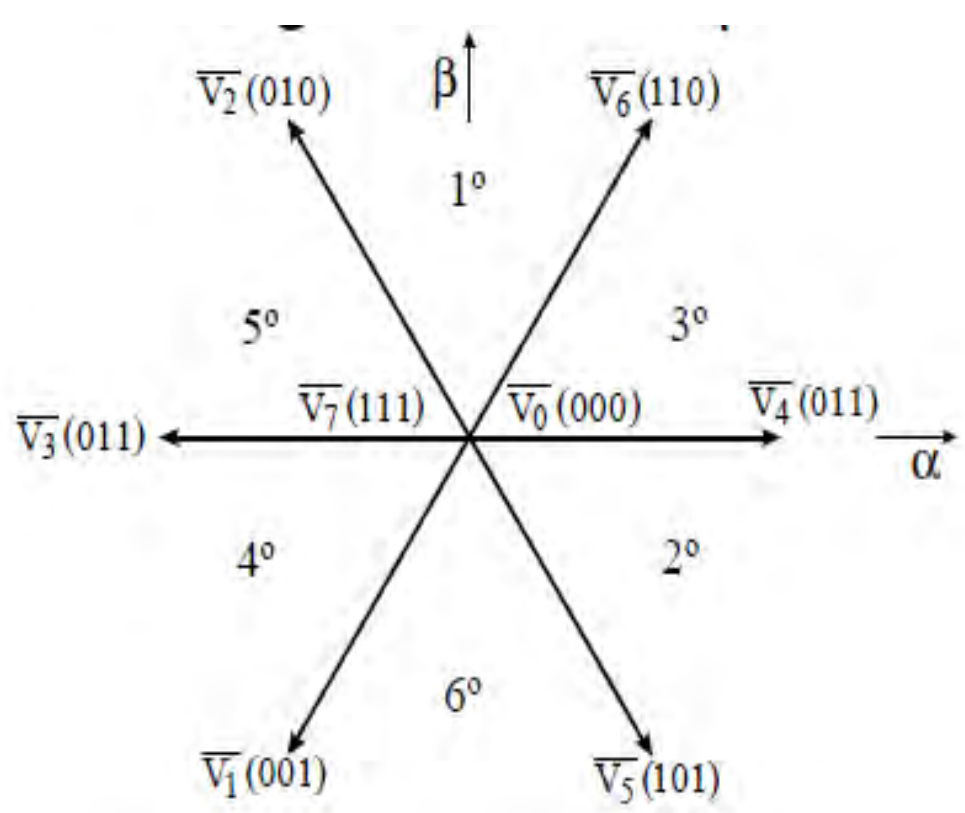

Figure 4-3: Space Vector Modulation Vectors and Sectors [21]

The orientation of vectors is divided into six sectors shown in Figure 4-3. Two adjacent vectors are obtained by identifying the sector in which the reference voltage belongs to. The difference between the two adjacent is one bit, implying that only one upper transistor conducts when the switching pattern moves from one vector to the adjacent one [21].Then, the output voltage is determined by these two vectors. Assuming that the reference vector $V_{\text {ref }}$ is in the $3^{\circ}$ sector (Figure 4-4), the time duration for vectors $V_{4}$ and $V_{6}$ are respectively $T_{4}$ and $T_{6}$, and $T_{o}$ is the time during which the zero vectors are applied. These can be determined when the reference voltage and the sample periods are known.

The Table 4-1 shows the switching sequence; the switching variables a, a', b, b', c and c' control the switches from S1 to S6. Once an upper transistor is switched on; one of the switching variables a, b or $\mathrm{c}$ is 1 and the corresponding lower transistor is switched off which means that the corresponding switching variable $\mathrm{a}^{\prime}, \mathrm{b}^{\prime}$ or $\mathrm{c}^{\prime}$ is 0 . Therefore the output voltage can be determined by the "on" and "off" states of the upper transistor S1, S3 and S5 [9].

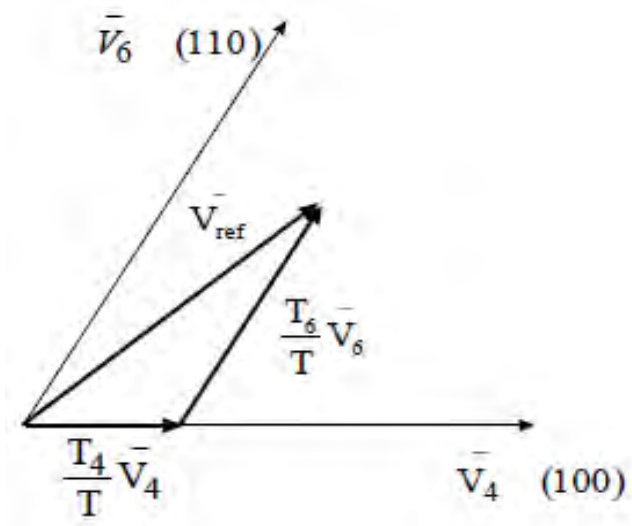

Figure 4-4: Vector Combination to get Reference Vector [37] 
The three upper switches can operate in eight possible combinations: once the states of the upper switches are known, the "on" and "off" states of the lower switches opposite to the upper ones are easily determined [8]. The results of the equations, the eight switching vectors, the output line-toneutral voltage and the output line-to-line voltages in terms of DC-link $V_{d c}$, are given in the Table 4$1[11]$.

Table 4-1: Switching vectors, phase voltage and output line to line voltage [11]

\begin{tabular}{|c|c|c|c|c|c|c|c|c|c|}
\hline \multirow{2}{*}{$\begin{array}{c}\text { Voltage } \\
\text { Vectors }\end{array}$} & \multicolumn{3}{|c|}{ Switch Vectors } & \multicolumn{3}{c|}{ Line to neutral voltage } & \multicolumn{3}{c|}{ Line to line voltage } \\
\cline { 2 - 9 } & $\mathrm{a}$ & $\mathrm{b}$ & $\mathrm{c}$ & $\mathrm{V}_{\mathrm{an}}$ & $\mathrm{V}_{\mathrm{bn}}$ & $\mathrm{V}_{\mathrm{cn}}$ & $\mathrm{V}_{\mathrm{ab}}$ & $\mathrm{V}_{\mathrm{bc}}$ & $\mathrm{V}_{\mathrm{ca}}$ \\
\hline $\mathrm{V}_{0}$ & 0 & 0 & 0 & 0 & 0 & 0 & 0 & 0 & 0 \\
\hline $\mathrm{V}_{1}$ & 1 & 0 & 0 & $02-\mathrm{Mar}$ & -0.33333 & -0.33333 & 1 & 0 & -1 \\
\hline $\mathrm{V}_{2}$ & 1 & 1 & 0 & $01-\mathrm{Mar}$ & $01-\mathrm{Mar}$ & -0.66667 & 0 & 1 & -1 \\
\hline $\mathrm{V}_{3}$ & 0 & 1 & 0 & -0.33333 & $02-\mathrm{Mar}$ & -0.33333 & -1 & 1 & 0 \\
\hline $\mathrm{V}_{4}$ & 0 & 1 & 1 & -0.66667 & $01-M a r$ & $01-M a r$ & -1 & 0 & 1 \\
\hline $\mathrm{V}_{5}$ & 0 & 0 & 1 & -0.33333 & -0.33333 & $02-\mathrm{Mar}$ & 0 & -1 & 1 \\
\hline $\mathrm{V}_{6}$ & 1 & 0 & 1 & $01-\mathrm{Mar}$ & -0.66667 & $01-\mathrm{Mar}$ & 1 & -1 & 0 \\
\hline $\mathrm{V}_{7}$ & 1 & 1 & 1 & 0 & 0 & 0 & 0 & 0 & 0 \\
\hline
\end{tabular}

The SVM refers to the special switching sequence of the three upper power transistors for a three phase power inverter [11]. It has been shown that the SVM generates less harmonic distortion in the output voltages and currents applied to the phases of an AC motor and provides more efficient use of supply voltage as compared to the sinusoidal PWM technique as shown in the Figure 4-5(a) [105]. The Figure 4-5(c) shows the eight inverter vectors $\left(\mathrm{V}_{0}-\mathrm{V}_{7}\right)$.

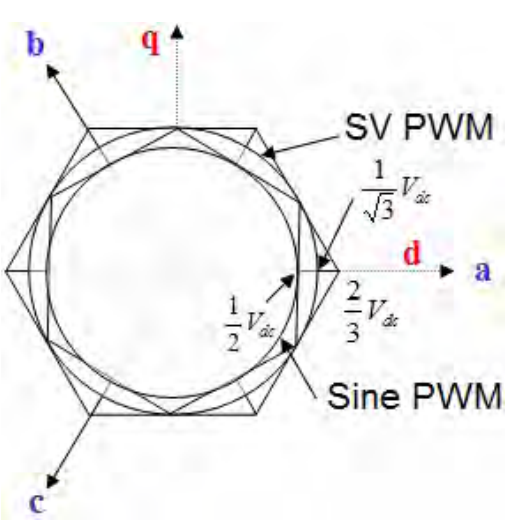

(a)

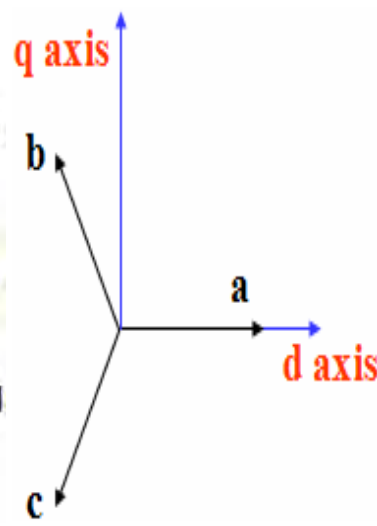

(b)

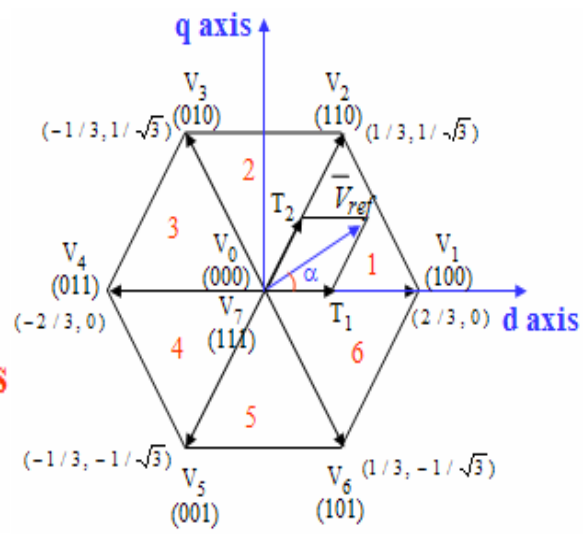

(c)

Figure 4-5: (a) Comparison of maximum linear control voltage in SPWM and SVM [26]

(b) The relationship of abc and dq reference frames.

(c) Switching vectors and sectors numbers.

The implementation of the SVM is alleviated by the transformation of the voltage equations from abc reference frame to the stationary one. This is equivalent to an orthogonal projection of $[a, b, c]$ onto the two dimensional perpendicular vector $[1,1,1]$ which is equivalent to $d-q$ plane in a three dimensional coordinate system [11] (Figure 4-5(b)). The reference voltage vector $\mathrm{V}_{\text {refis }}$ obtained by applying similar transformation to the output voltage. V1-V6 are the six non-zero vectors portrayed in Figure 4-5(c). Between each two adjacent vectors there is 60 degrees while $\mathrm{V}_{0^{-}} \mathrm{V}_{7}$ (the zero vectors) 
are at the origin. Moreover, these eight vectors: $\mathrm{V}_{0}, \mathrm{~V}_{1}, \mathrm{~V}_{2}, \mathrm{~V}_{3}, \mathrm{~V}_{4}, \mathrm{~V}_{5}, \mathrm{~V}_{6}$ and $\mathrm{V}_{7}$ are called "the basic space vectors".

The very simple method of approximating the reference voltage sector $\mathrm{V}_{\text {ref }}$ for the $\mathrm{SVM}$ is to generate the average output of an inverter in a small period, $\mathrm{T}$ (sampling technique) to be the same as that of $\mathrm{V}_{\text {ref }}$ in the same period [37], the method which sometimes become difficult with the trigonometric calculation.

The implementation of SVM consists of determining [11]:

The $V_{d}, V_{q}, V_{\text {ref }}$, and angle $(\alpha)$. (step1)

The time duration $T_{1}, T_{2}, T_{0}$. (step2)

The switching time of each switch $\left(\mathrm{S}_{1}\right.$ to $\left.\mathrm{S}_{6}\right)$. (step3)

\subsubsection{Determination of $V_{d}, V_{q}, V_{\text {ref }}$ and angle ( $\left.\alpha\right)$}

From the Figure 4-6 shown below, these parameters are determined. It shows that, the summation of vectors $V_{d}$ and $V_{q}$ can give these parameters.

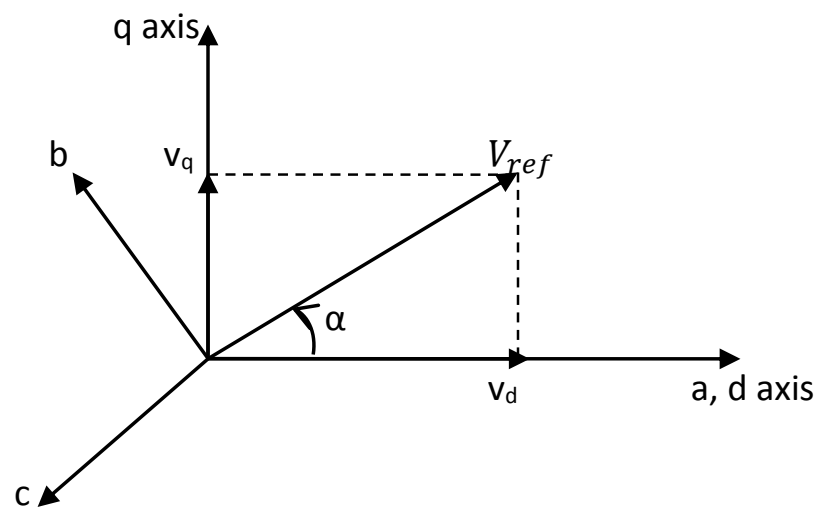

Figure 4-6: Space Vector Voltages [11]

Considering $\mathrm{a}, \mathrm{b}$ and $\mathrm{c}$ as components of $\mathrm{V}_{\mathrm{d}}$ and $\mathrm{V}_{\mathrm{q}}$ respectively, they can be expressed as:

$$
\begin{gathered}
V_{d}=V_{a n}-V_{b n} \cos 60-V_{c n} \cos 60=V_{a n}-\frac{1}{2} V_{b n}-\frac{1}{2} V_{c n} \\
V_{q}=0-V_{b n} \cos 30-V_{c n} \cos 30=V_{a n}+\frac{\sqrt{3}}{2} V_{b n}-\frac{\sqrt{3}}{2} V_{c n}
\end{gathered}
$$

In matrix form, the expressions are as becomes:

$$
\left[\begin{array}{l}
V_{d} \\
V_{q}
\end{array}\right]=\frac{2}{3}\left[\begin{array}{ccc}
1 & \frac{-1}{2} & \frac{-1}{2} \\
0 & \frac{\sqrt{3}}{2} & \frac{\sqrt{3}}{2}
\end{array}\right]\left[\begin{array}{l}
V_{a n} \\
V_{b n} \\
V_{c n}
\end{array}\right]
$$

After obtaining the $\mathrm{V}_{\mathrm{d}}$ and $\mathrm{V}_{\mathrm{q}}$ then, the reference voltage and angle are determined as follows:

$$
V_{\text {ref }}=\sqrt{V_{d}^{2}+V_{q}^{2}}
$$




$$
\propto=\tan ^{-1}\left(\frac{V_{q}}{V_{d}}\right)=\omega t=2 \pi f t
$$

Where $\mathrm{f}$ is the fundamental frequency.

$\propto$ and $V_{r e f}$ are the two important parameters required for performing SVM.

\subsubsection{Identification of the Sector Number - $n$}

Given the frequency f and the time t, the period can be expressed in terms of angle $\theta$, given by:

$$
\theta=2 \pi f t=\omega t
$$

where $0 \leq \theta \geq 2 \pi$ for any given value of $t$

Dividing $\omega t$ by $2 \pi$ the value of $\theta$ can be kept between 0 and $2 \pi$ using $\bmod (\omega t, 2 \pi)$.

Now, since there are six sectors, therefore each sector is $2 \pi / 6$. This implies that, the value of the sector number $n$ can be obtained by taking the integer value of $\omega t / 6$. The number obtained is incremented by 1 to avoid getting sector number $n=0$.

\subsubsection{Time Durations $T_{1}, T_{2}$ and $T_{0}$}

The determination of time durations is done by using the geometrical method as shown in Figure 47.

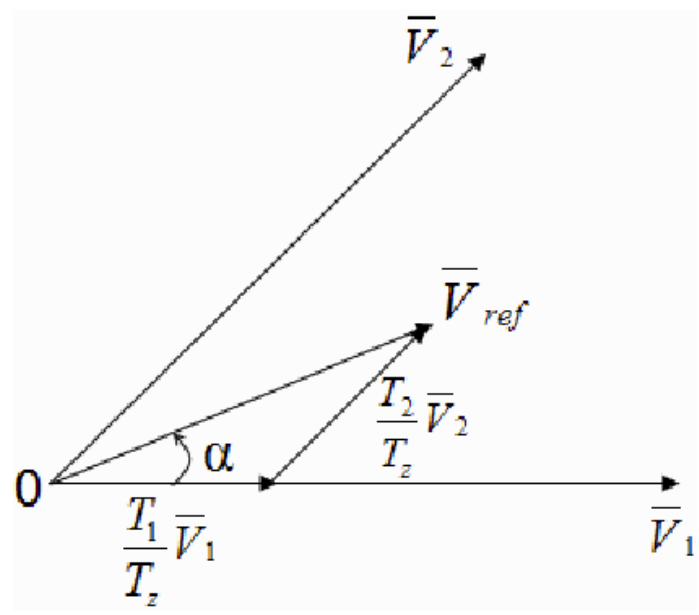

Figure 4-7: Determination of reference vector from adjacent vectors at $n=1$ [11].

\subsubsection{3 (a) Switching Time Duration at the First Sector}

$$
\begin{gathered}
\int_{0}^{T_{Z}} V_{\text {ref }}=\int_{0}^{T_{1}} V_{1} d t+\int_{T 1}^{T_{1}+T_{2}} V_{2} d t+\int_{T_{1}+T_{2}}^{T_{Z}} V_{0} \\
T_{z} V_{\text {ref }}=\left(T_{1} V_{1}+T_{2} V_{2}\right) \\
T_{z}\left|\overline{V_{\text {ref }}}\right|\left[\begin{array}{c}
\cos (\alpha) \\
\sin (\alpha)
\end{array}\right]=T_{1} \frac{2}{3} V_{d c}\left[\begin{array}{l}
1 \\
0
\end{array}\right]+T_{2} \frac{2}{3} V_{d c}\left[\begin{array}{c}
\cos (\alpha) \\
\sin (\alpha)
\end{array}\right]
\end{gathered}
$$


Where, $0 \leq \propto \geq 60^{\circ}$

$$
\begin{aligned}
& T_{1}=T_{z} a \frac{\sin (\pi / 3-\alpha)}{\sin (\pi / 3)} \\
& T_{2}=T_{z} a \frac{\sin (\alpha)}{\sin (\pi / 3)} \\
& T_{0}=T_{z}-\left(T_{1}+T_{2}\right)
\end{aligned}
$$

Where, $T_{z}=1 / f_{z}$ and $a=V_{\text {ref }} / 2 / 3$ Vdc

\subsubsection{3 (b) Switching Time Duration at any Sector}

$$
\begin{gathered}
T_{1}=\frac{\sqrt{3} T_{z}\left|\overline{V_{r e f}}\right|}{V_{d c}}\left(\sin \left(\frac{\pi}{3}-\alpha+\frac{n-1}{3} \pi\right)\right)=\frac{\sqrt{3} T_{z}\left|\overline{V_{r e f}}\right|}{V_{d c}}\left(\sin \left(\frac{n}{3} \pi-\alpha\right)\right) \\
T_{1}=\frac{\sqrt{3} T_{z}\left|\overline{V_{r e f}}\right|}{V_{d c}}\left(\sin \left(\alpha-\frac{n-1}{3} \pi\right)\right) \\
T_{2}=\frac{\sqrt{3} T_{z}\left|\overline{V_{r e f}}\right|}{V_{d c}}\left(\sin \left(\frac{\pi}{3}-\alpha+\frac{n-1}{3} \pi\right)\right) \\
T_{2}=\frac{\sqrt{3} T_{z}\left|\overline{V_{r e f}}\right|}{V_{d c}}\left(-\cos (\alpha) \sin \left(\frac{n-1}{3} \pi\right)+\sin (\alpha) \cos \left(\frac{n-1}{3} \pi\right)\right) \\
T_{0}=T_{z}-T_{1}-T_{2}
\end{gathered}
$$

Where $n$ is the sector number varying from 1 to 6 and $0 \leq \propto 60^{\circ}[11]$

\subsubsection{Switching Time of Each Switch}

The Figure 4-8 shows the switching patterns for different sectors:

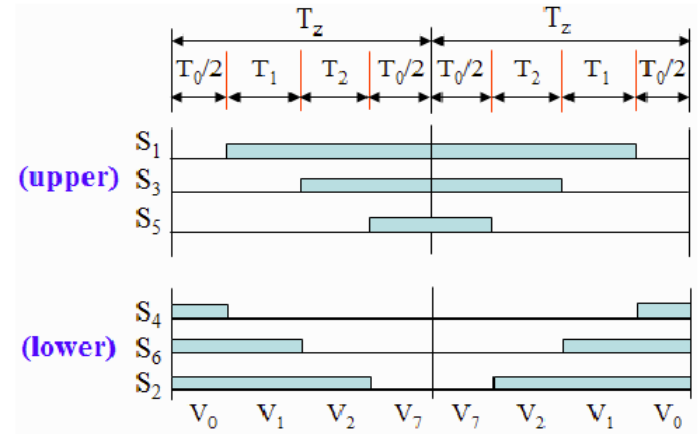

(a) Sector 1 .
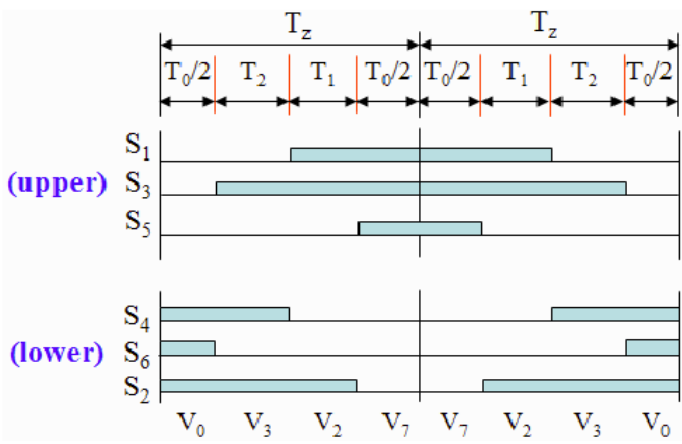

(b) Sector 2 . 


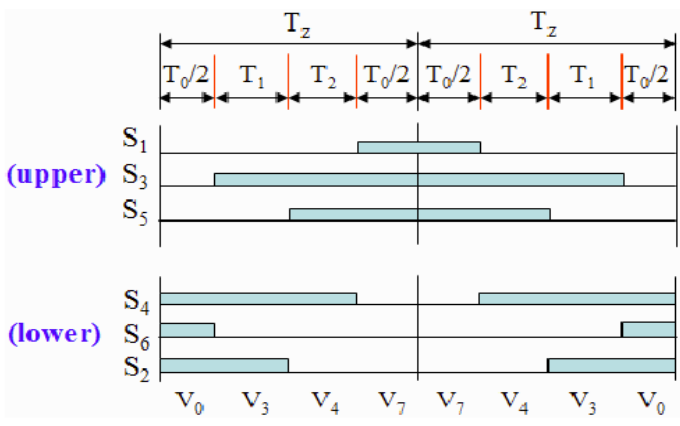

(c) Sector 3 .

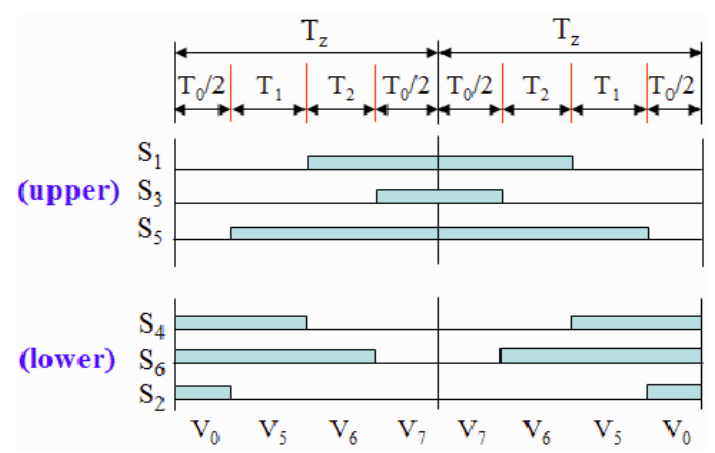

(e) Sector 5 .

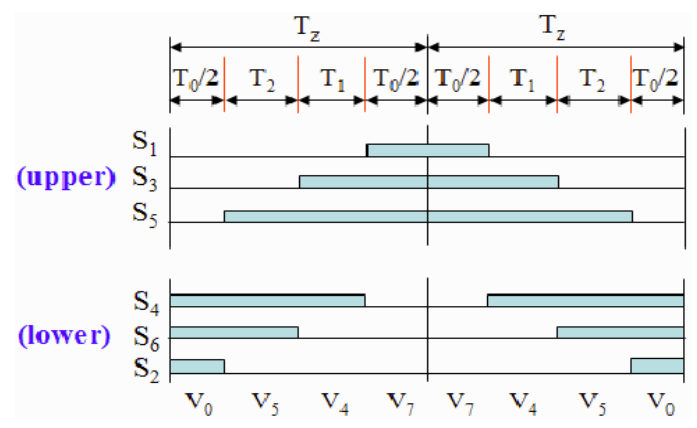

(d) Sector 4 .

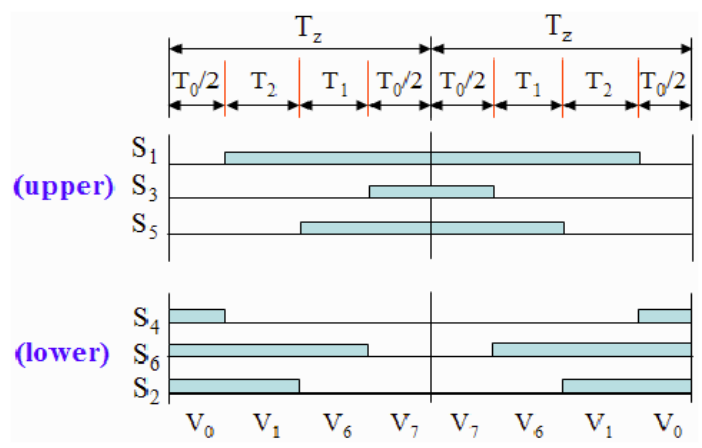

(f) Sector 6 .

Figure 4-8: Switching patterns of each switch for all sectors [11].

Table 4-2 shows the patterns used to determine switching time for all sectors.

Table 4-2: Switching time calculation for each sector [11]

\begin{tabular}{|c|c|c|}
\hline Sector Number & Upper Switches (i.e. S1, S3, S5) & Lower Switches (i.e. S4, S6, S2) \\
\hline \multirow{3}{*}{1} & $\mathrm{~S} 1=\mathrm{T} 1+\mathrm{T} 2+\mathrm{T} 0 / 2$ & $\mathrm{~S} 4=\mathrm{T} 0 / 2$ \\
\hline & $\mathrm{S} 3=\mathrm{T} 2+\mathrm{T} 0 / 2$ & $\mathrm{~S} 6=\mathrm{T} 1+\mathrm{T} 2+\mathrm{T} 0 / 2$ \\
\hline & $\mathrm{S} 5=\mathrm{T} 0 / 2$ & $\mathrm{~S} 2=\mathrm{T} 1+\mathrm{T} 0 / 2$ \\
\hline \multirow{3}{*}{2} & $\mathrm{~S} 1=\mathrm{T} 1+\mathrm{T} 0 / 2$ & $\mathrm{~S} 4=\mathrm{T} 2+\mathrm{T} 0 / 2$ \\
\hline & $\mathrm{S} 3=\mathrm{T} 1+\mathrm{T} 2+\mathrm{T} 0 / 2$ & $\mathrm{~S} 6=\mathrm{T} 0 / 2$ \\
\hline & $\mathrm{S} 5=\mathrm{T} 0 / 2$ & $\mathrm{~S} 2=\mathrm{T} 1+\mathrm{T} 2+\mathrm{T} 0 / 2$ \\
\hline \multirow{3}{*}{3} & $\mathrm{~S} 1=\mathrm{T} 0 / 2$ & $\mathrm{~S} 4=\mathrm{T} 0 / 2$ \\
\hline & $\mathrm{S} 3=\mathrm{T} 1+\mathrm{T} 2+\mathrm{T} 0 / 2$ & $\mathrm{~S} 6=\mathrm{T} 1+\mathrm{T} 2+\mathrm{T} 0 / 2$ \\
\hline & $\mathrm{S} 5=\mathrm{T} 2+\mathrm{T} 0 / 2$ & $\mathrm{~S} 2=\mathrm{T} 1+\mathrm{T} 0 / 2$ \\
\hline \multirow{3}{*}{4} & $\mathrm{~S} 1=\mathrm{T} 0 / 2$ & $\mathrm{~S} 4=\mathrm{T} 1+\mathrm{T} 2+\mathrm{T} 0 / 2$ \\
\hline & $\mathrm{S} 3=\mathrm{T} 1+\mathrm{T} 0 / 2$ & $\mathrm{~S} 6=\mathrm{T} 2+\mathrm{T} 0 / 2$ \\
\hline & $\mathrm{S} 5=\mathrm{T} 1+\mathrm{T} 2+\mathrm{T} 0 / 2$ & $\mathrm{~S} 2=\mathrm{T} 0 / 2$ \\
\hline \multirow{3}{*}{5} & $\mathrm{~S} 1=\mathrm{T} 2+\mathrm{T} 0 / 2$ & $\mathrm{~S} 4=\mathrm{T} 1+\mathrm{T} 0 / 2$ \\
\hline & $\mathrm{S} 3=\mathrm{T} 0 / 2$ & $\mathrm{~S} 6=\mathrm{T} 1+\mathrm{T} 2+\mathrm{T} 0 / 2$ \\
\hline & $\mathrm{S} 5=\mathrm{T} 1+\mathrm{T} 2+\mathrm{T} 0 / 2$ & $\mathrm{~S} 2=\mathrm{T} 0 / 2$ \\
\hline \multirow{3}{*}{6} & $\mathrm{~S} 1=\mathrm{T} 1+\mathrm{T} 2+\mathrm{T} 0 / 2$ & $\mathrm{~S} 4=\mathrm{T} 0 / 2$ \\
\hline & $\mathrm{S} 3=\mathrm{T} 0 / 2$ & $\mathrm{~S} 6=\mathrm{T} 1+\mathrm{T} 2+\mathrm{T} 0 / 2$ \\
\hline & $\mathrm{S} 5=\mathrm{T} 1+\mathrm{T} 0 / 2$ & $\mathrm{~S} 2=\mathrm{T} 2+\mathrm{T} 0 / 2$ \\
\hline
\end{tabular}




\subsubsection{The Space Vector and Sinusoidal PWM analysis}

The foremost advantage of the SVM in the 3-phase motor is its capacity of generating the minimum distortion of the current in the windings [21]. Additionally, the use of SVM is found more efficient in the supply voltage as compared to the sinusoidal modulation methods [66]. Comparing the sinusoidal signals with triangular carrier signal in the conventional sinusoidal modulation, the locus of the reference vector is inside the circle of $\frac{1}{2} V_{d c}[23]$.

The length of each SVM vectors is $\frac{2}{3} V_{d c}$ and in steady state, their magnitude is constant. In the drawing of these different reference loci vectors for the SVM shown in Figure 4-9, it is observed that the locus of the reference vector is smaller than the hexagon thus having a radius of $\frac{1}{\sqrt{3}} V_{d c}[21]$.

Ultimately, based on the theory of the Space Vector, the maximum output is as large as $\frac{2}{\sqrt{3}}\left(\frac{O M}{O N}\right)$ times the conventional sinusoidal modulation. Thus, the SVM is more efficient than sinusoidal PWM method on the supply voltage [8] which is also the advantage for another type of inverter: "stepped wave inverter". In fact, this inverter is simple in its design but it has lower order harmonics which cannot be eliminated by filters [68]. However, these harmonics can be eliminated by the use of SVM technique which gives $15 \%$ increment in maximum voltage compared to SPWM.

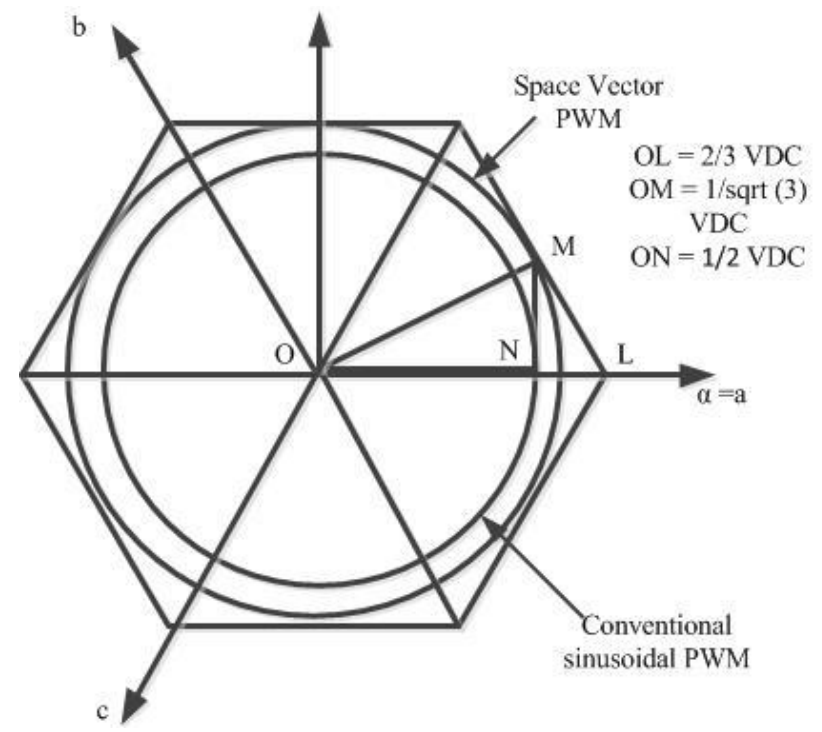

Figure 4-9: Comparison of Space Vector and Sinusoidal PWM locus [21]

Space Vector Modulation provides excellent output performance, enables efficient use of DC voltage at optimized efficiency and is highly reliable as compared to similar Inverters with conventional PWM [105].

\subsection{Boost Converter}

The theory of boost converter is discussed in Chapter 3. The design of boost converter requires the value of load resistance, inductor, capacitor, diode and switch specifications.

$$
\text { Load Resistance, } R=\frac{V_{o}}{I_{o}}
$$


Assuming $\mathrm{I}_{\mathrm{o}}$ to be $3 \mathrm{~A}$, the resistance is $73 \Omega$ and the duty cycle is 0.78 calculation is shown in appendix $\mathrm{C}$

\subsubsection{Inductor Selection}

The formula for calculating the inductor value is as given below [38]:

Where,

$$
L=\frac{V_{i} \times\left(V_{o}-V_{i}\right)}{\Delta I_{L} \times f S \times V_{o}}
$$

$V_{i}$ is the input voltage

$V_{o}$ is the output voltage $f S$ is the switching frequency

$\Delta I_{L}$ is the inductor ripple current. This value is not known, but what we know is that it is $20 \%$ to $40 \%$ of the output current [45].

$$
\Delta I_{L}=(0.2 \text { to } 0.4) \times\left(I_{o} \times \frac{V_{o}}{V_{i}}\right)
$$

Selecting optionally $30 \%$, the $\Delta I_{L}$ equation and taking the switching frequency $f s$ of $200 \mathrm{kHz}$ inductance can be calculated. The detail of calculation is shown in Appendix C.

\subsubsection{Inductor Specifications [71]}

Family: $54 z$

Minimum Quality Factor: 27 at $8 \mathrm{MHz}$

Test Frequency: $8 \mathrm{MHz}$

Tolerance: $10 \%$

Lead Style - Axial

Type - Lower Choke

Product Length $-19 \mathrm{~mm}$

Diameter $-0.8 \mathrm{~mm}$

Technology- Wire Wound

Inductance $-1 \mathrm{mH}$

\subsubsection{Capacitor Selection}

The calculation of the used capacitor is also given by the following formula:

Where:

$$
C=\frac{I_{o} \times D}{f_{s} \times \Delta V_{o}}
$$

$\Delta V_{o}$ is the desired output voltage ripple, and it is calculated as:

$$
\Delta V_{o}=E S R \times\left(\frac{I_{O}}{1-D} \times \frac{\Delta I_{L}}{2}\right)
$$

Where:

$E S R$ is the equivalent series resistance of the used output capacitor.

The ESR for ceramic capacitors range between 0.01 and 0.1 ohms [37] ceramic capacitor is selected and optionally the ESR of $0.1 \mathrm{ohms}$ is used. The detail of calculation is shown in Appendix C. 


\subsubsection{Capacitor Specifications [10]}

High ESR Tantanum Capacitor

No. - TRSE 22006K050R002

Capacitance: $2.2 \mathrm{mF}$

Maximum Output Voltage: $500 \mathrm{~V}$

Tolerance: $\pm 10 \%$

\subsubsection{Diode Specifications [10]}

No. - IN5820

Maximum voltage $-50 \mathrm{~V}$

Maximum Current - 5A

Schottky Diode

Forward voltage drop at peak current $=0.4 \mathrm{~V}$

\subsubsection{MOSFET Specifications [10]}

Output Voltage: $50 \mathrm{~V}$

Load Current: 5A

$\mathrm{R}_{\mathrm{DS}}=0.002 \Omega$

$\mathrm{F}=250 \mathrm{KHz}$

N Channel MOSFET

\subsubsection{Maximum Switch Current}

The maximum switch current is given by the formula shown in equation (3.53) [42]:

$$
I_{S w(\max )}=\frac{\Delta I_{L}}{2}+\frac{I_{\text {out }}}{1-D}
$$

Where: $I_{s w(\max )}$ is the maximum switch current.

$\Delta I_{L}$, the inductor ripple current is $15.605 \mathrm{~A}$ the detail of calculation is shown in Appendix C.

This is our MOSFET switching current. It's range can also be verified from the datasheet [36] for the selection.

\subsubsection{Loss Calculation}

Diode Loss

$$
\text { Diode loss }=V_{d} \times I_{o}(1-D)
$$

The detail of the diode loss calculation is shown in the Appendix C

\section{Switching Loss}

$$
\begin{aligned}
V_{G S} & =V_{\text {Threshold }} \\
E_{1} & =t_{1} \frac{V_{S} I_{O}}{2} \\
E_{2} & =t_{2} \frac{V_{S} I_{O}}{2}
\end{aligned}
$$




\section{Gate Circuit Loss}

$$
P_{s w}=\left(t_{1}+t_{2}\right) \frac{V_{S} I_{o}}{2} f_{s}
$$

Considering the driver pull up and gate resistance, the gate current is given by

$$
I=\frac{V_{D D}-V_{S P}}{R_{\text {driver }}+R_{\text {gate }}}
$$

\section{Conduction Loss}

$$
I_{o}^{2} \times D \times R=0.21 \mathrm{~mW}
$$

Efficiency

$$
\text { Effiency }=\frac{\text { output }}{\text { Output }+ \text { Losses }}
$$

\subsection{Automatic Switch Based on ESKOM's off and Peak Time's Electricity and Demand Programming}

In this research, the solar system is used as a standby supply and it will be selected during the peak time. According to ESKOM's daily profile of a typical high-consumption residential customer data, the peak time is averagely five hours per day, from Monday to Friday; at 07:00-10:00 and 18:0020:00 [7] . The hybrid automatic power source selector system is designed using Proteus Virtual System Modelling simulator. The flow code software is used to write the algorithm which also enables the user to download the program into a microcontroller and also user friendly. The programming algorithm and the flowchart are explained in Chapter 3, subsection 3.6. The Figure 4-11 shows the initial steps of the Flowcode program.

The implementation of the hybrid system is shown in Figure 4-10 


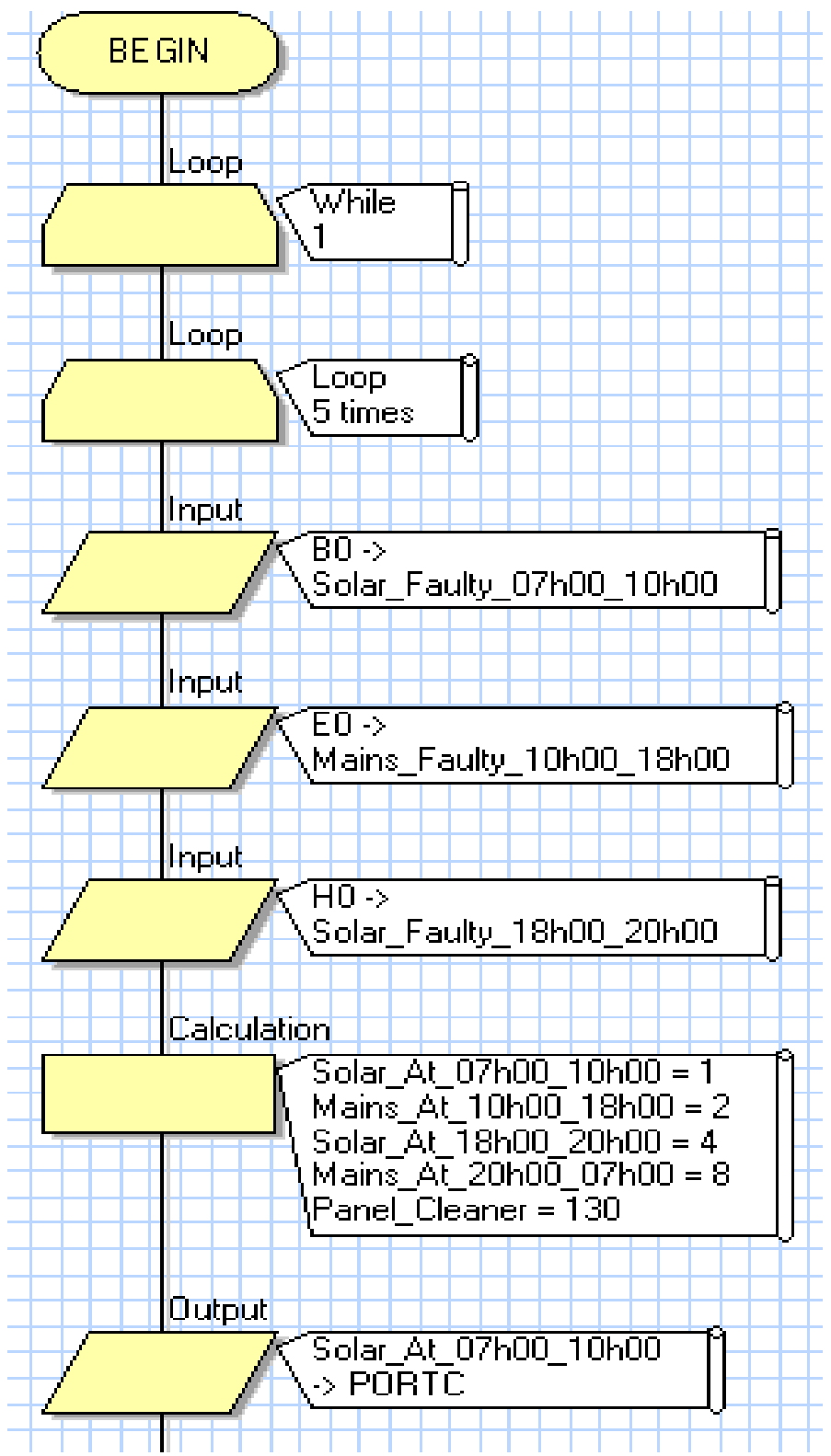

Figure 4-10. Flowcode flowchart 


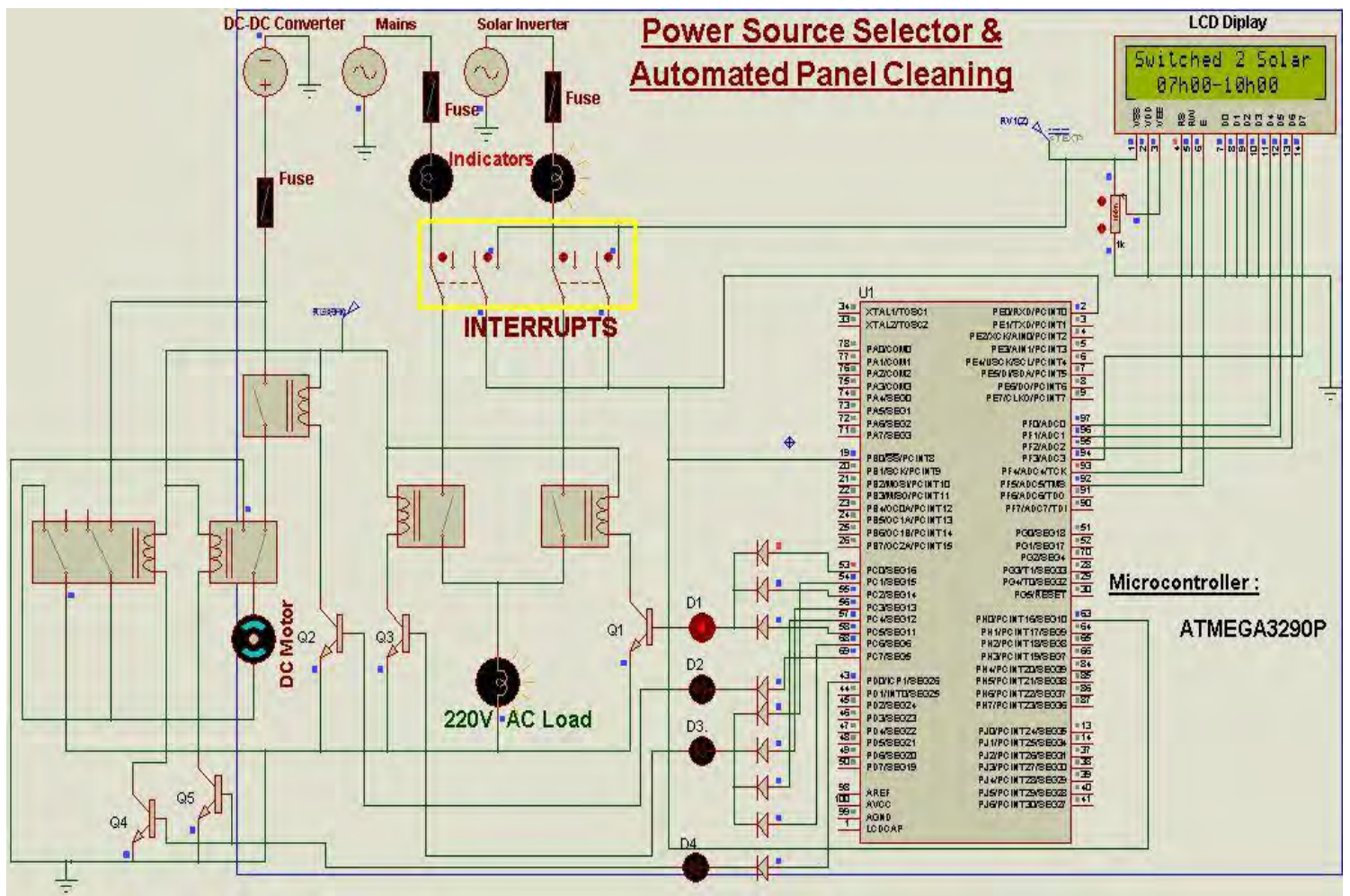

Figure 4-11: Proteus simulation model of automatic power source selector

\subsection{Solar Powered Cleaning Robot}

\subsubsection{Motor Selection}

The block diagram of panel cleaning robot is shown in Figure 4-12. The LCD display for this activity showing the normal Sunday display and panel cleaning schedule is shown in Figure 5-15

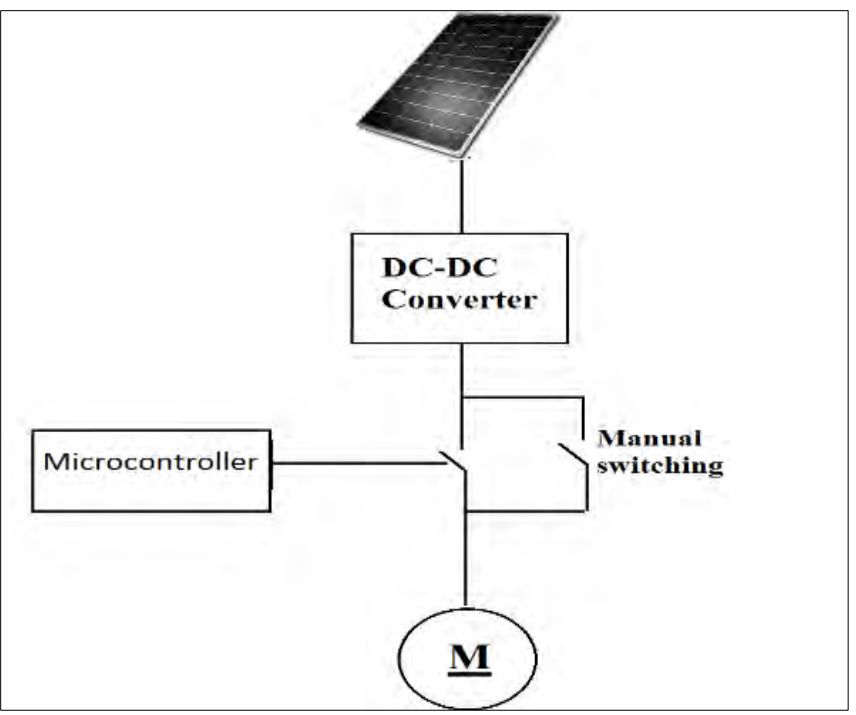

Figure 4-12: Solar powered panel cleaning dc motor switch

The simulation code done in Flowcode for automatic power source selection and panel cleaning robot is attached in the Appendix E 
The selected motor for this task is the brushed DC motor based on the general characteristics of dc motor as shown in Figure 4-13, a brushless DC motor has been found reliable, low cost, little maintenance demand and time tested for this application. A brushless DC motor is designed to run off of straight-line DC voltage and can also be connected directly to a properly sized battery [41].

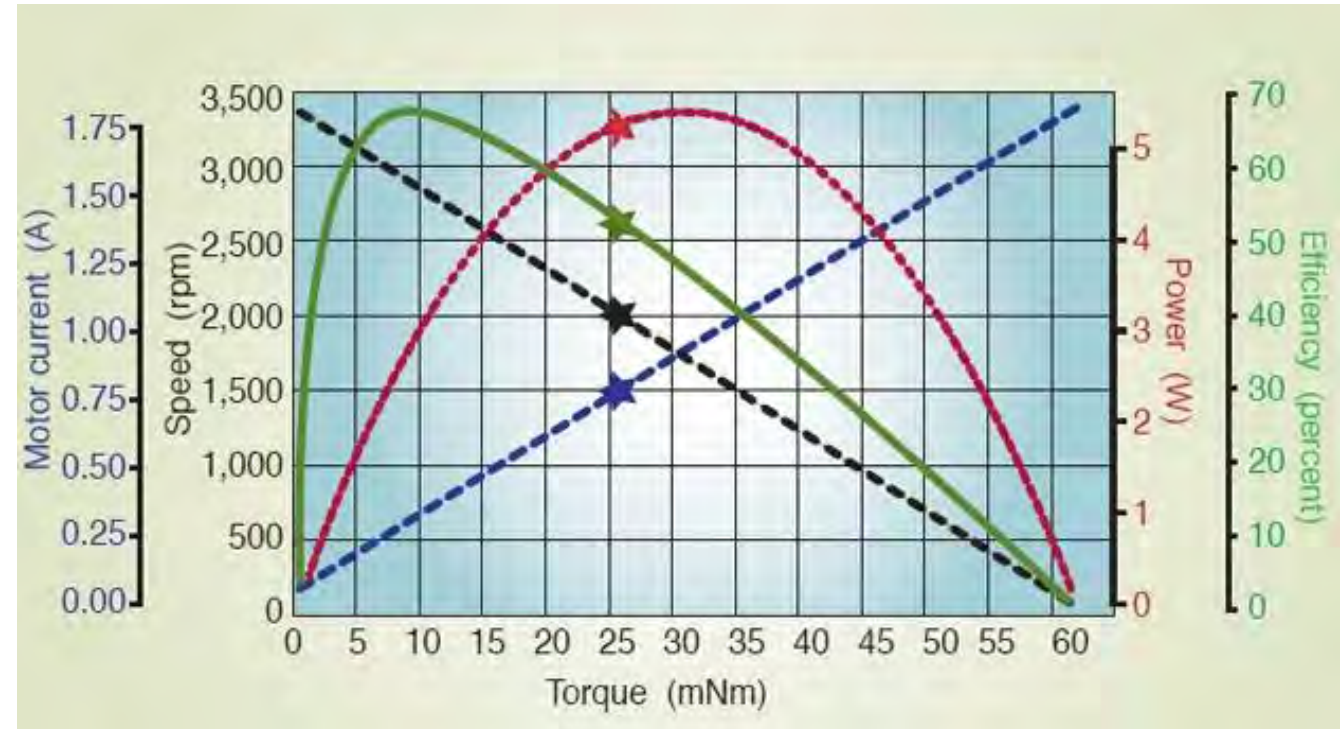

Figure 4-13: DC motor main characteristics curves [41]

The rate of doing work known is the power given by the following formula:

Where:

$$
P_{\text {rot }}=T \omega
$$

$$
\begin{aligned}
& P_{\text {rot }}=\text { rotational mechanical power } \\
& T=\text { torque } \\
& \omega=\text { angular velocity in } \mathrm{rev} / \mathrm{min}(\mathrm{RPM})
\end{aligned}
$$

For the rotational-mechanical power calculation, it is necessary to convert the velocity to units of $\mathrm{rad} / \mathrm{sec}$ by multiplying it with the constant $\frac{2 \pi}{60}$

$$
\omega \mathrm{rad}=\omega \mathrm{rpm} \times \frac{2 \pi}{60} \ldots \ldots .[\mathrm{rad} / \mathrm{sec}]
$$

The torque defined as the quantitative measure of the tendency of a force to cause a rotational motion, or to bring about a change in rotational motion is in fact the moment of a force that produces or changes a rotational motion [34]

The equation of the torque is given by:

$$
T=F R \sin \theta
$$

Where $\mathrm{F}$ is force in linear direction.

$\mathrm{R}$ is radius of the rotating object, and

$\theta$ is the angle, the force $\mathrm{F}$ is making with $\mathrm{R}$ vector as shown in Figure 4-14 


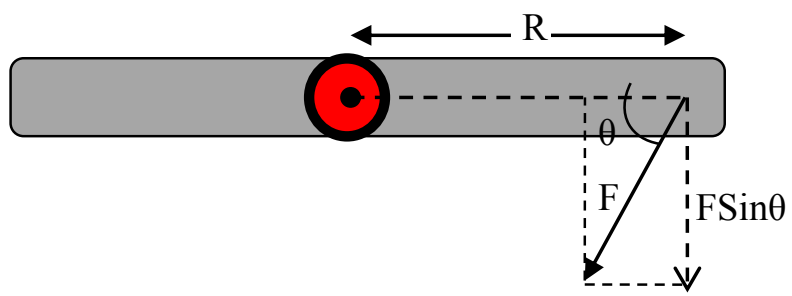

Figure 4-14: Motor torque components [34]

For the dc motor also known as the rotational machine, the torque is very important; and to know its equations will be the basic key for knowing the running characteristics (Figure 4-15).

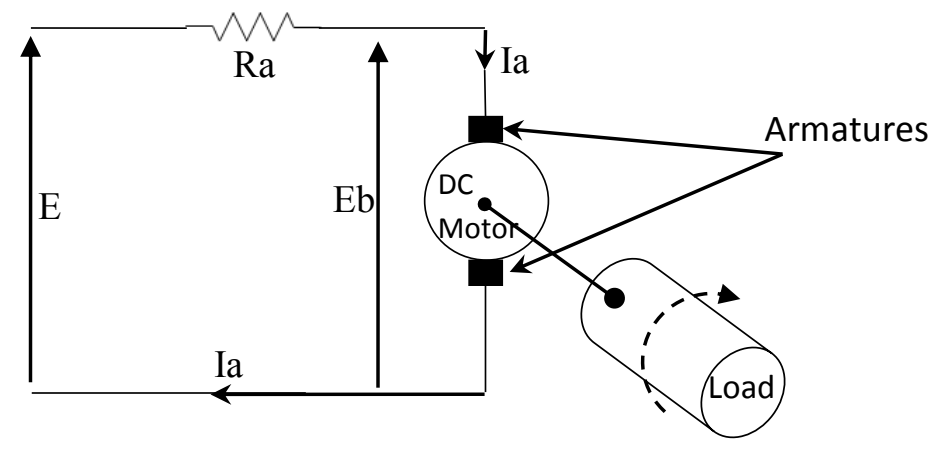

Figure 4-15: The basic circuit diagram of a dc motor [34]

Where:

$\mathrm{E}$ is the supply voltage,

$\mathrm{E}_{\mathrm{b}}$ is the back emf produced,

$I_{a}, R_{a}$ are the armature current and armature resistance respectively

The voltage equation is given by,

$$
E=E_{b}+I_{a} R_{a}
$$

Multiplying both sides of equation (4.20) by $\mathrm{I}_{\mathrm{a}}$ :

$$
E I_{a}=E_{b} I_{a}+I_{a}^{2} R_{a}
$$

$I_{a}^{2} R_{a}$ is the armature heat loss.

The effective mechanical power required to produce the desired torque is,

$$
P_{m}=E_{b} I_{a}
$$

This mechanical power $P_{m}$ is also related to the electromagnetic torque $T_{g}$ as,

$$
P_{m}=T_{g} \omega
$$

Where $\omega$ is angular speed in $\mathrm{rad} / \mathrm{sec}$.

Equating equation (4.22) \& (4.23) we get,

$$
E_{b} I_{a}=T_{g} \omega
$$


For simplifying the torque equation of dc motor we get.

$$
E_{b}=\frac{P \varphi Z N}{60 A}
$$

Where, $\mathrm{P}$ is the number of poles,

$\varphi$ is the flux per pole, in weber

$\mathrm{Z}$ is the number of conductors,

$\mathrm{A}$ is the number of parallel paths, and

$\mathrm{N}$ is the speed of the D.C. motor.

$$
\text { Hence, } \omega=\frac{2 \pi N}{60}
$$

Substituting equations (4.25) and (4.24) in equation (4.26), we get:

$$
T_{g}=\frac{P Z \varphi I_{a}}{2 \pi A}
$$

Where; $T_{g}$ is the electromagnetic torque of dc motor.

Subtracting mechanical and rotational losses from this electromagnetic torque we get the mechanical torque.

Therefore,

$$
T_{m}=T_{g}-\text { mechanical losses }
$$

Then, the torque equation is simplified as:

$$
T_{g}=K_{a} \varphi I_{a}
$$

Where

$$
K_{a}=\frac{P Z}{2 \pi A}
$$

$K_{a}$ is constant for a particular machine and therefore the torque of dc motor varies with only flux per pole $\varphi$ and armature current $I_{a}$.

The flux per pole $\varphi=B A_{r}$

Where $\mathrm{B}$ is the magnetic flux density in Tesla $A_{r}$ is the area per pole in $\mathrm{m}^{2}$

\subsubsection{Design of Motor Parameters}

\section{The speed required for the brush to cover the module surface:}

The overall length of the module is $4 \mathrm{~m}$; the rotating brush will roll on the length of PV module, and from the attached datasheet of the used 300W solar panels (in the Appendix D), the size of one panel is $196 \times 99 \times 5 \mathrm{~cm}$. This means the lengths of the module is $196 \times 2=392 \mathrm{~cm}(\approx 4 \mathrm{~m})$.

The estimated time for the brush to cover this length by rolling and sweeping is 10seconds. This means the speed $\mathrm{S}$ is 4 meters per 10 seconds $(\mathrm{V}=0.4 \mathrm{~m} / \mathrm{sec})$

This will be the speed of the wheel driving the brush. By looking at the Figure 4-10, it is observed that; as the brush will be moving forward and reverse along the panel, it will also be rotating (cleaning) at the speed and torque calculated below. Let's optionally select a wheel of $25 \mathrm{~cm}$ - diameter $(=12.5 \mathrm{~cm}$ of radius) and we are determining the rotation characteristics of the brush. 
The simple formula for converting the linear motion into circular motion is:

$$
V=R \omega
$$

Where:

$\mathrm{V}$ is the linear velocity

$\mathrm{R}$ is the radius

$\omega$, the angular velocity

so, from equation (4.31) we can calculate the angular velocity:

$$
\omega_{\text {rad }}=\frac{V}{R}=\frac{0.4}{0.125}=3.2 \mathrm{rad} / \mathrm{sec}
$$

The most commonly used unit for angular velocity is revolution per minute (rev/min or RPM), so it is necessary to convert the velocity to units of $\mathrm{rad} / \mathrm{sec}$ by multiplying the velocity in RPM by the constant $\frac{2 \times \pi}{60}$. The equation (4.32) becomes:

$$
\omega_{\text {rad }}=\omega_{r p m} \times \frac{2 \pi}{60}
$$

The torque of a DC motor is inversely proportional to the speed; when the speed increases, the torque decreases and vice versa.

$$
\operatorname{Power}_{[K W]}=\frac{T_{N m} \times \omega_{R P M}}{9549}
$$

The constant 9549 comes from: $\frac{60 \times 1000}{2 \pi}$

The calculation of the power requires to have the torque from the equation (4.29) and it will be found from the torque-speed curve as shown in Figure 4:14.

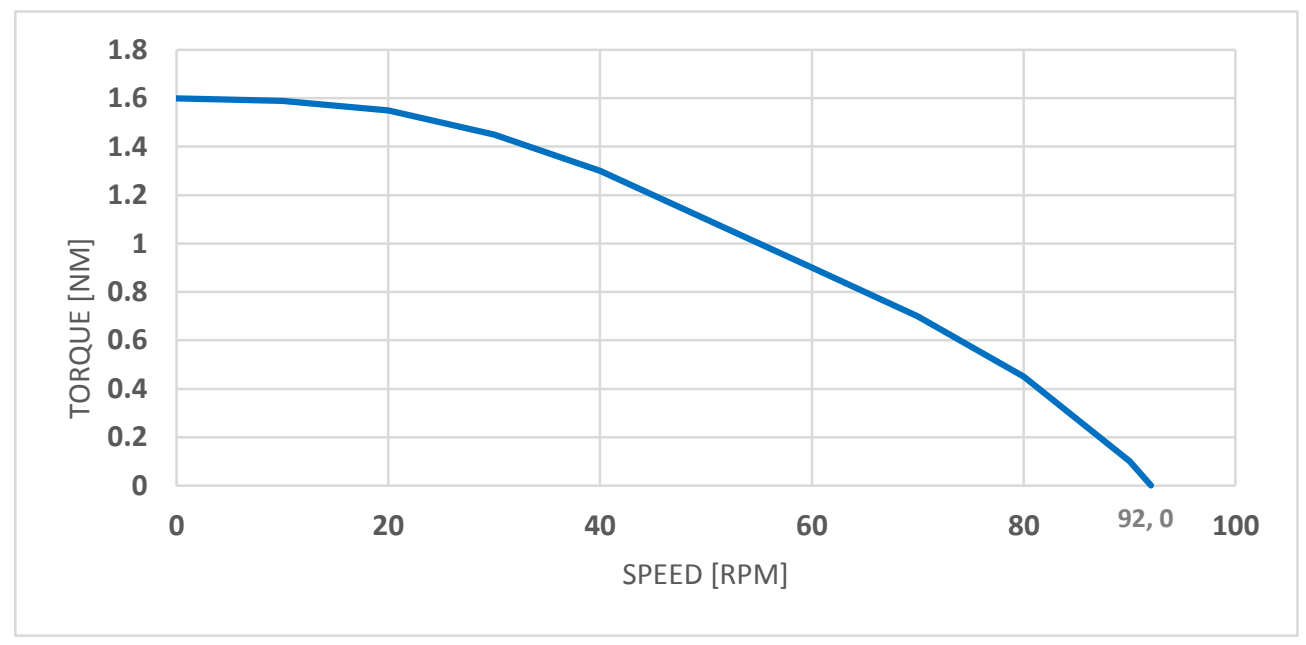

Figure 4-16: The torque-speed for 48V DC motor [106]

Motor type: Bosch MS-L256

The torque of the motor at $30.558 \mathrm{rpm}$ is $1.4 \mathrm{Nm}$.

This is the power of the selected motor to run the robot. The selection of the motor is not exclusive; i.e. the $48 \mathrm{~V}$ and $\pm 30.558 \mathrm{rpm}$ DC motor can be selected with different power ratings. The equation (4.33) shows that the power variation at the constant speed will only have the influence on the torque. 
Practically, it is not easy to find the motor with exactly the specified speed as in our case. So, another motor having different speed can also be used but with the interface of belt, chain, or gear transmission system to get the desired speed. The motor calculation parameters are shown in Table 4-3.

Table 4-3 Motor calculated parameters

\begin{tabular}{|c|c|}
\hline Parameters & Calculated values \\
\hline Angular velocity $(\omega)$ & $30.558 \mathrm{rpm}$ \\
\hline Power $(\mathrm{P})$ & $0.004480 \mathrm{Kw}$ \\
\hline
\end{tabular}




\section{CHAPTER 5}

\section{SIMULATION RESULTS AND DISCUSSION}

\section{Introduction}

The study, design and implementation of the hybrid system leads to the solution of the fluctuations in commercial grid originated from the peak time power demand. The results of the simulations obtained in this study are used as a prototype to guide the implementation of the system in the University of KwaZulu-Natal, Howard College.

The system considerably reduces the electricity cost; the savings and the costs for the design of the current hybrid system were calculated from rates indicated on the Ethekwini Municipality website; (http://www.durban.gov.za). The cost of electricity during peak time was about R2/kWh for domestic customers who consumed more than $1000 \mathrm{kWh}$ a month [78]. In this study, only 5kWh essential loads to be supplied by solar panels during peak time were selected. The $5 \mathrm{kWh}$ load connected to the mains for five hours per day, five days a week cost around R200 a month. This was the amount calculated for supplying load only during peak power demand time; mains outings were not included. To implement the system would be R20 000; paid back after about eight years. In other words this system saves R20 000 in eight years.

The asset of the study does not only go to the reduction of electricity price but it opens out to the environmental conservation of the nature. As said, the use of non-renewable energy sources have got quite number of drawbacks. However with their current availability but limited with time, the hybrid of non-renewable and renewable energy technology is one way found comfortable. The present project shows the sustainability of hybrid solar and mains system since the cost of solar system is gradually decreasing on the global market.

The SVM scheme drives the inverter gating signals from the sampled amplitudes of the reference phase voltages. The real implementation of inverter proceeds according to the MATLAB SIMULINK simulation model presented. The input voltage and current of the inverter is $220 \mathrm{~V}, 3 \mathrm{~A}$ which is the output of the DC-DC boost converter. The inverter output signal is practically a square wave which explains the origin of losses calculated earlier, although these losses are so small. Another simulation of the same inverter is done in Proteus using the programmed AVR microcontroller with the same parameters (input voltage and current values) and the simulation results show a good performance with pure sine wave yielding less power losses. However, the simulation of DC-DC boost converter connected to the inverter in the same Proteus simulation has resulted in a long delay for getting the results as compared to MATLAB SIMULINK. The Proteus simulation and results for DC-AC Inverter and DC-DC boost converter are shown in Figure B-1, Figure B-2, Figure B-3, Figure B-4 and Figure B-5, in the Appendix B.

The switching circuit consists of the power source selection between the power from the mains and solar system. The selection based on the peak time power demands is done by the programmed microcontroller which also drives the dc motor for the panel cleaning robot. The circuit is visualised on the LCD screen indicating every activity being done at the time, for instance if the load is being supplied by the solar source and indicating the reason on the same screen that the time is (for instance) 07:00 to 10:00 which is known as the peak time power demand as shown in the Figure 2-5 provided by ESKOM data source. The program is user friendly, it can be modified and adjusted according to

any variation which can occur about the peak/off times schedules. The Figure 3-18 shows the programming algorithm whereby the interrupts with "if conditions" play an important role; the 
program is written in such a way that if the selected power for its right time is failed due to many reasons, the second one intervenes and this does not affect the normal timing of the program.

The majority of solar panels on today's market come with 25 years long warranty. Solar panel output decreases with environmental factors such as dust. This was handled by the panel cleaning robot in the proposed system. As per a Ministry of New and Renewable Energy, India specification, a dustfree solar panel should give $90 \%$ output for up to 10 year; $80 \%$ output after 25 years.

The core or the prime mover of the panel cleaning robot is the DC motor as for which ratings have been calculated. The speed of the motor is inversely proportional to the torque. However, in this research, the DC motor is considered to run at the "no load speed" since the weight of the brush or the squeegee used to broom the panels as shown in Figure 4-10 is considered to not change the torque of the motor in addition to the gear system of the robot assumed frictionless (with the friction coefficient equals to one). This is achieved by making the gear system properly aligned and the bearings well lubricated.

\subsection{Simulation of MPPT with P\&O Algorithm}

The P\&O MPPT model was designed and implemented in MATLAB SIMULINK and Figure 5-1 shows the MPPT model in MATLAB with the solar panel current and voltage as inputs.

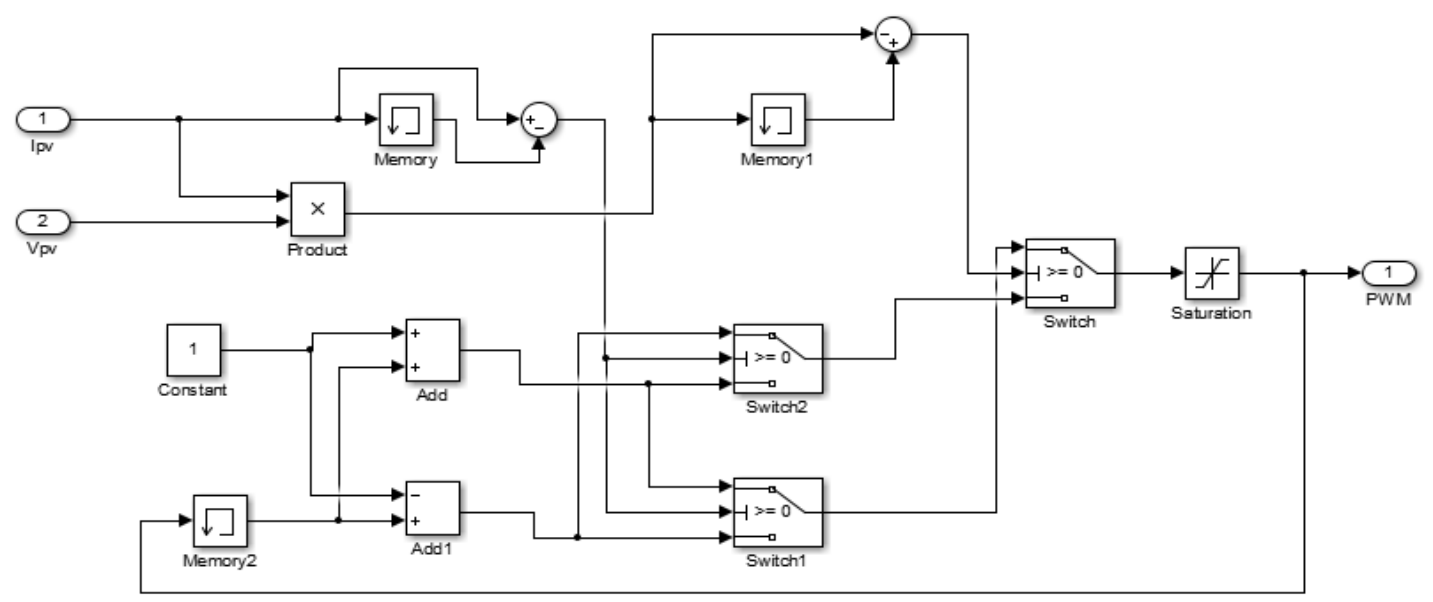

Figure 5-1: MATLAB model of MPPT.

This block receives two inputs, voltage and current. It multiplies them and gets power at that particular time, while the previous power is stored by the memory element. The powers are then subtracted accordingly to check which power is greater to find the maximum power and the switch is switched accordingly as to increase or decrease the duty cycle in accordance to comparing the voltages also. For better understanding, the $\mathrm{P} \& \mathrm{O}$ algorithm is explained in (2.4.1).

In the simulation block, the PWM varies with temperature and constant irradiation. Figures 5-2 and 5-3 show the PWM for different input powers. 


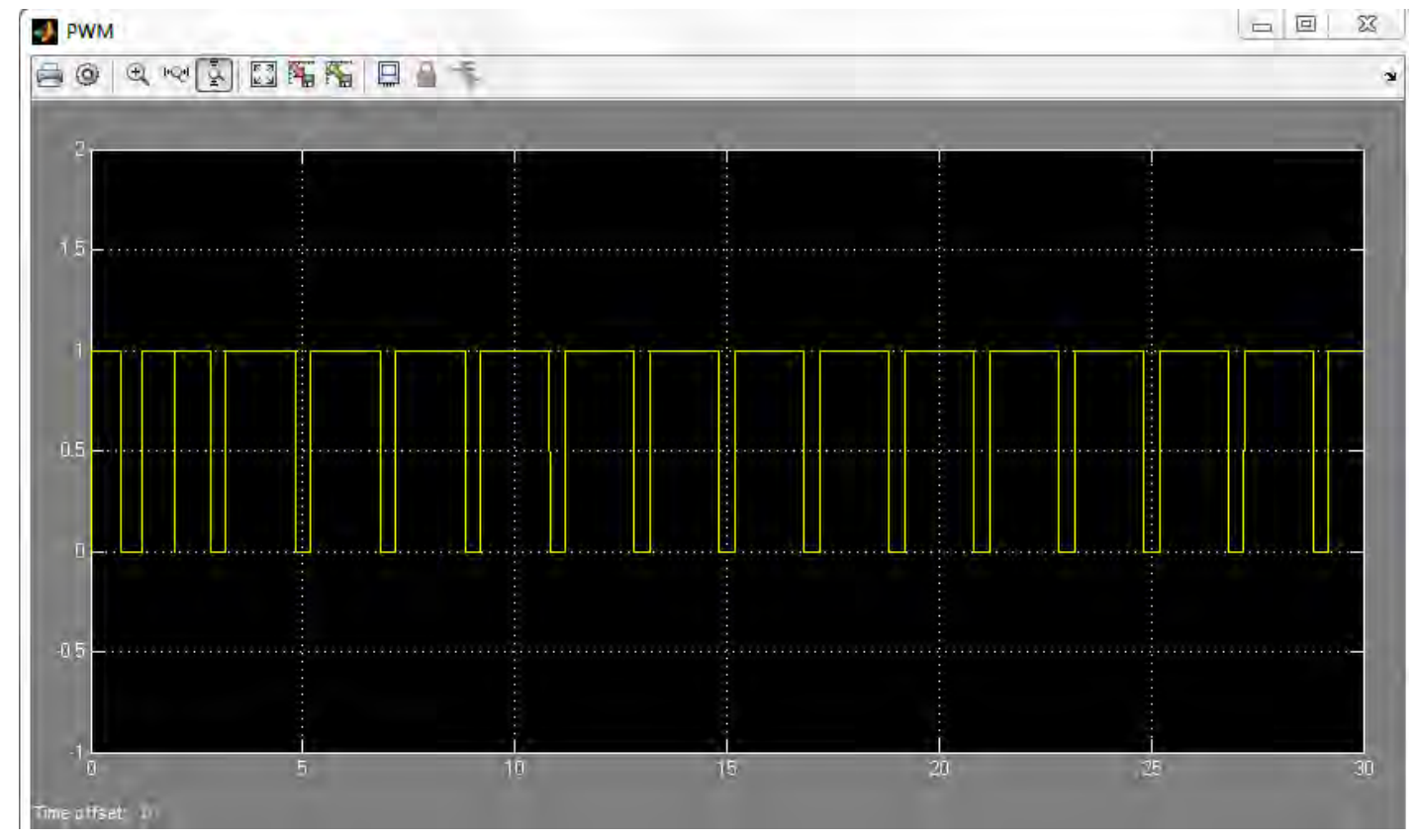

Figure 5-2: PWM for greater input power

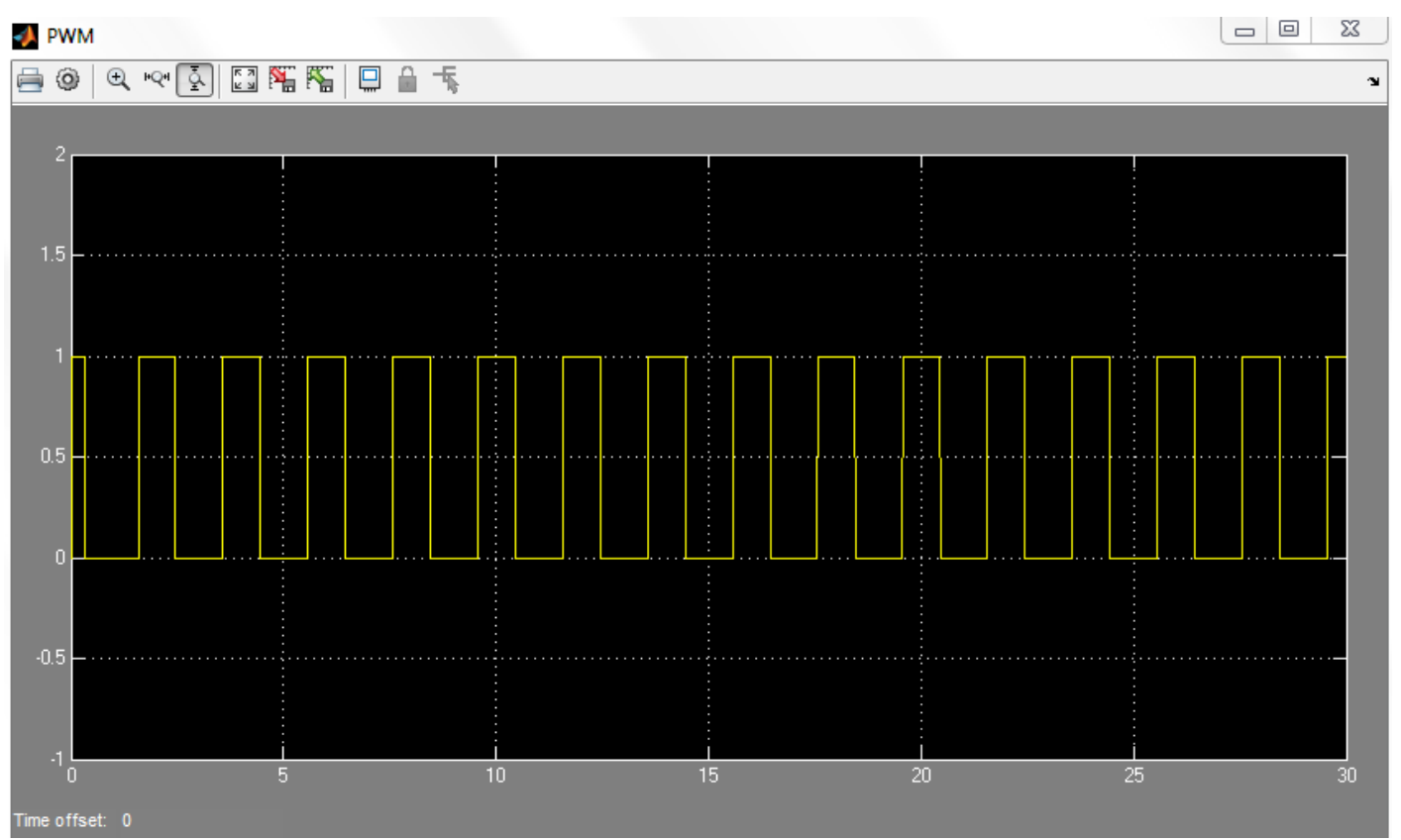

Figure 5-3: PWM for smaller input power

The increase in input power results in a high duty cycle value as the input voltage would not need much boosting and greater for small input as a large boost is needed to obtain the correct maximum power. This can clearly be observed in the PWM from Figure 5-2 and Figure 5-3, as the duty cycle at high input is high also, meaning a lesser increase in output voltage as the duty cycle in inversely proportional to the output voltage, then as for low input the duty cycle decreases accordingly as to largely increase the output voltage, therefore maintaining one constant voltage as the PWM varies accordingly to keep it that way so as to maintain a constant power sufficient to run the motor. 
Figure 5-4 shows the PWM obtained when the 2013 average irradiance and temperatures were used [64].

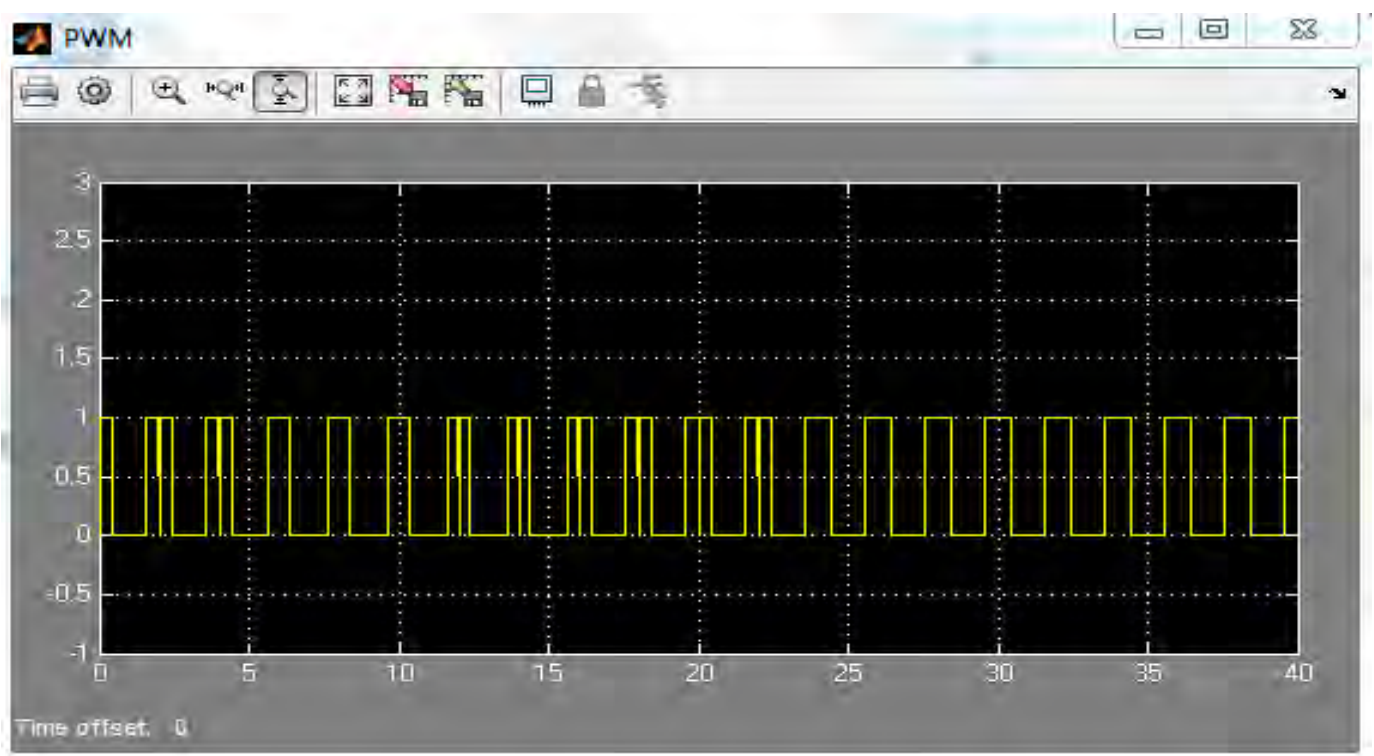

Figure 5-4: PWM for varying irradiance and temperature.

The PWM for varying irradiance and temperature varies constantly, meaning the MPPT PWM will vary the whole day when in operation with a change in temperature and irradiance. By doing this it always therefore track the maximum power as required

\subsection{Simulation of Boost Converter}

The simulation result of boost converter is shown in Figure 5-5. The input of $48 \mathrm{~V}$ is fed to the boost converter from the solar panel through the charge controller. The PWM signal of the boost converter is adjusted according to the power output from the solar panel. The boost converter is operating at continuous conduction mode.

The PWM signal for varying irradiance and the boost converter output are obtained from MPPT P\&O algorithm.

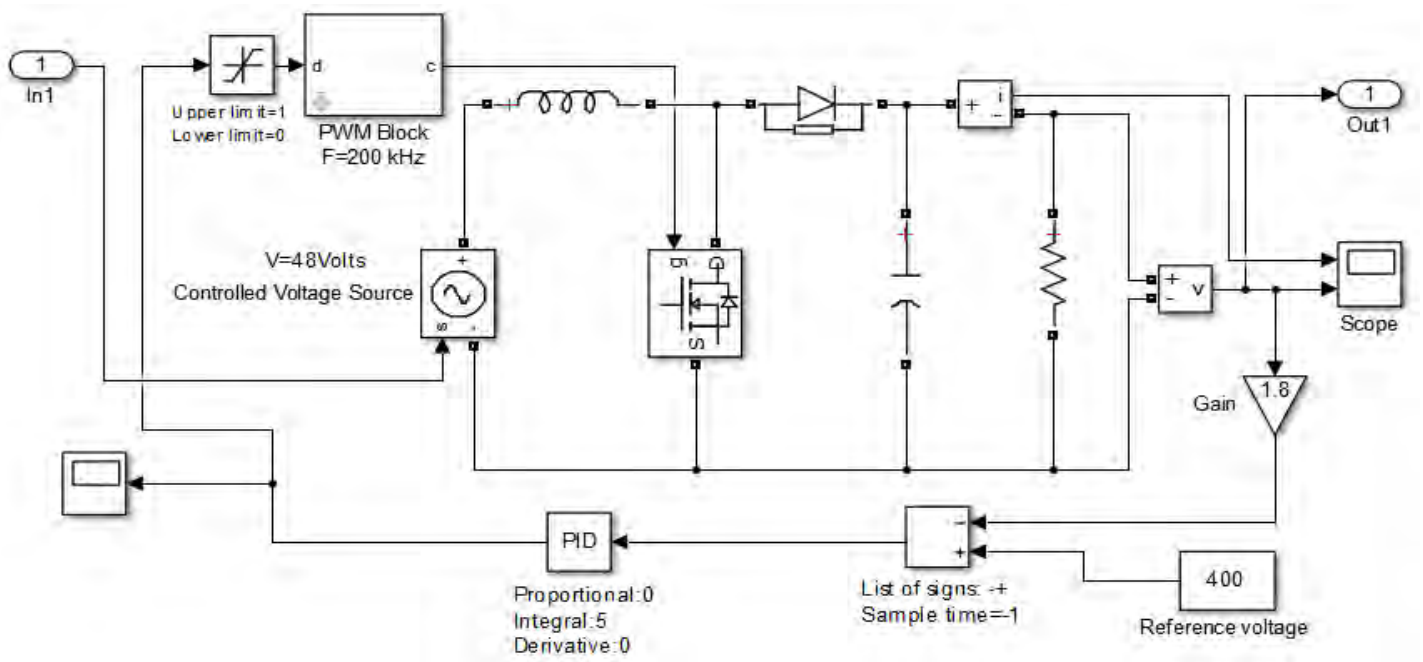

Figure 5-5: Simulation model of boost converter 
The boost converter output is shown in Figure 5-6. It can be seen that the output reaches 220V and $2.75 \mathrm{~A}$ at $0.1 \mathrm{sec}$ delay.

\subsection{Simulation of Voltage Source Inverter}

The simulation of the SVM in Simulink involves the following subsystem [69]:

a) Calculate the sector number $\mathrm{n}$ (Figure 5-7)

b) Determine the time duration $T_{1}, T_{2}, T_{0}$ (Figure 5-8)

c) Calculate the switching times $T_{a}, T_{b}$ and $T_{c}$ for each switch (Figure 5-9)

d) Generate the inverter output voltages (Figure 5-10)

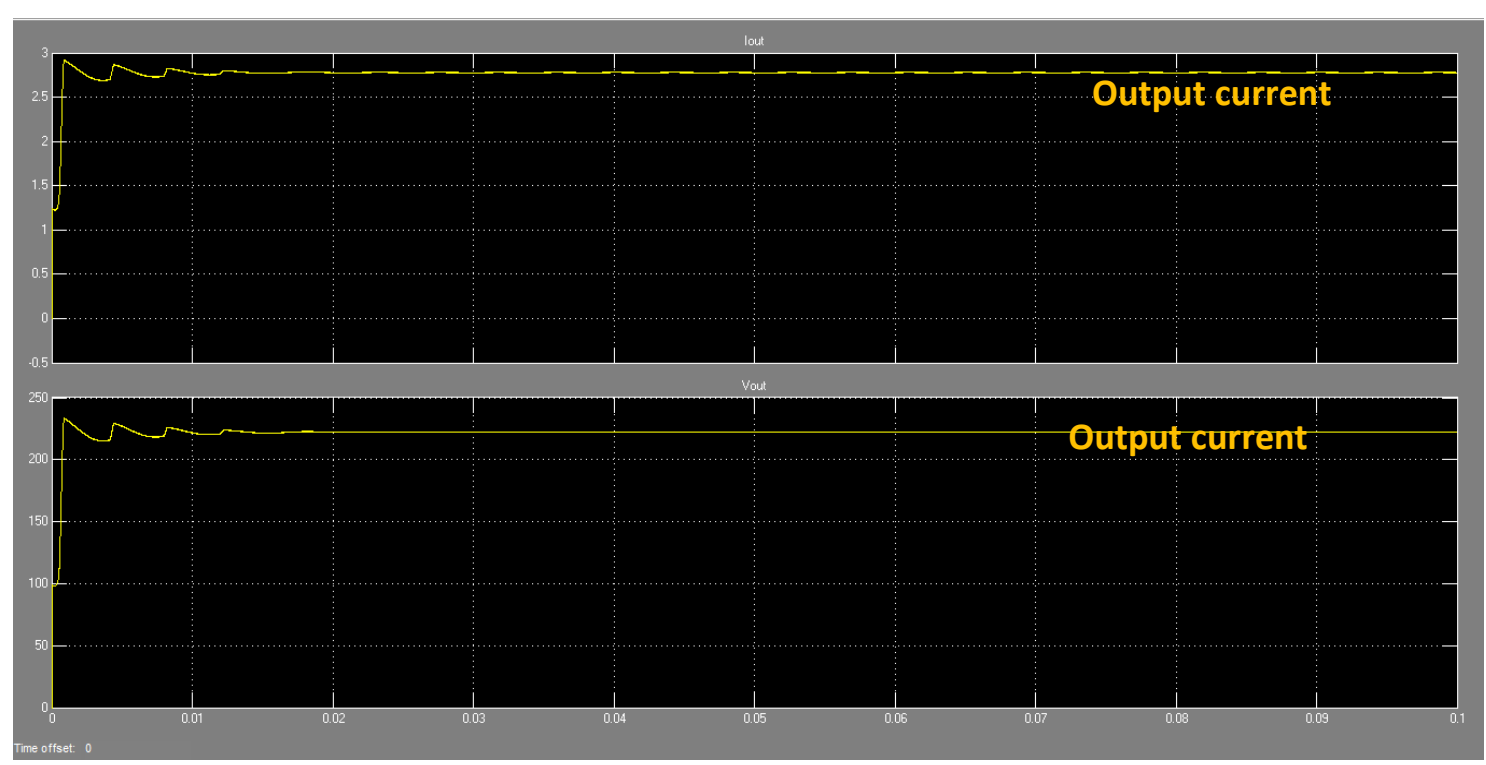

Figure 5-6: Boost converter output voltage and current, stability reached after 0.01 second delay

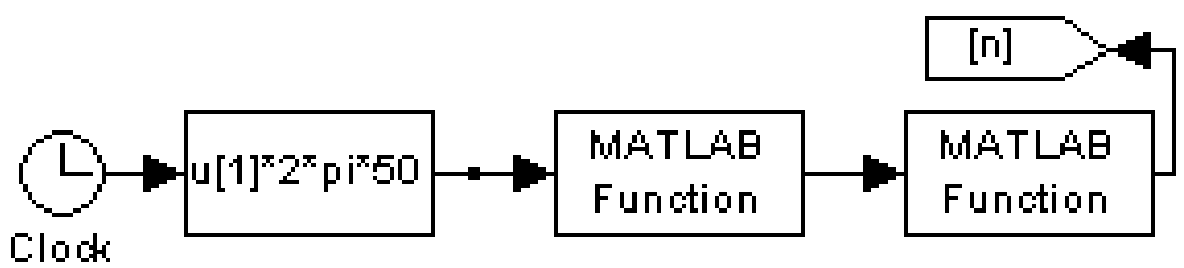

Figure 5-7: Calculation of sector number $n$

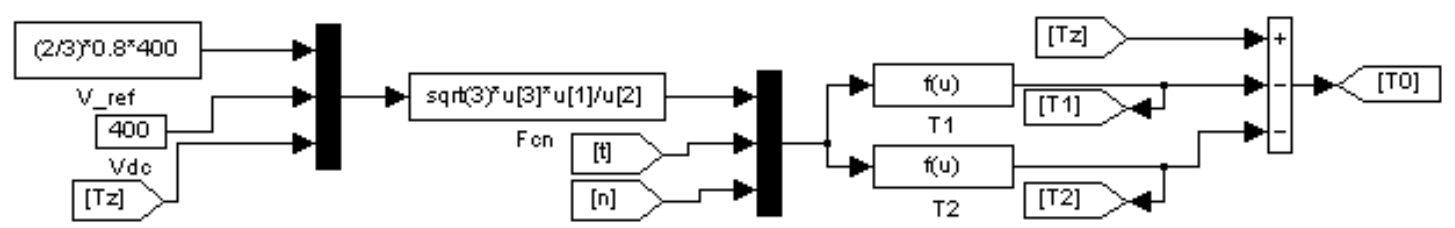

Figure 5-8: Determination of time duration $T_{0}, T_{1}$ and $T_{2}$ 


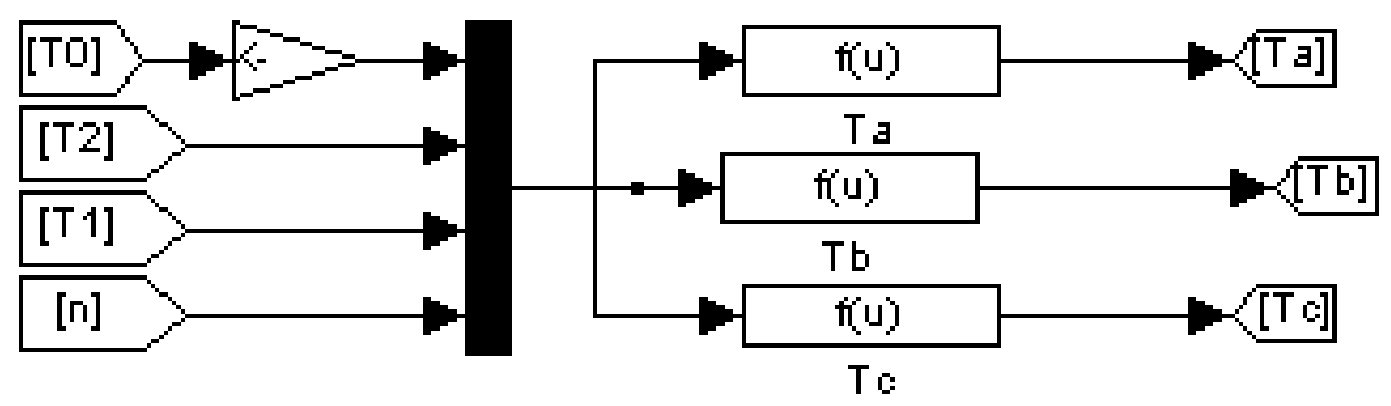

Figure 5-9: Determination of switching time $\boldsymbol{T}_{\boldsymbol{a}}, \boldsymbol{T}_{\boldsymbol{b}}$ and $\boldsymbol{T}_{\boldsymbol{c}}$
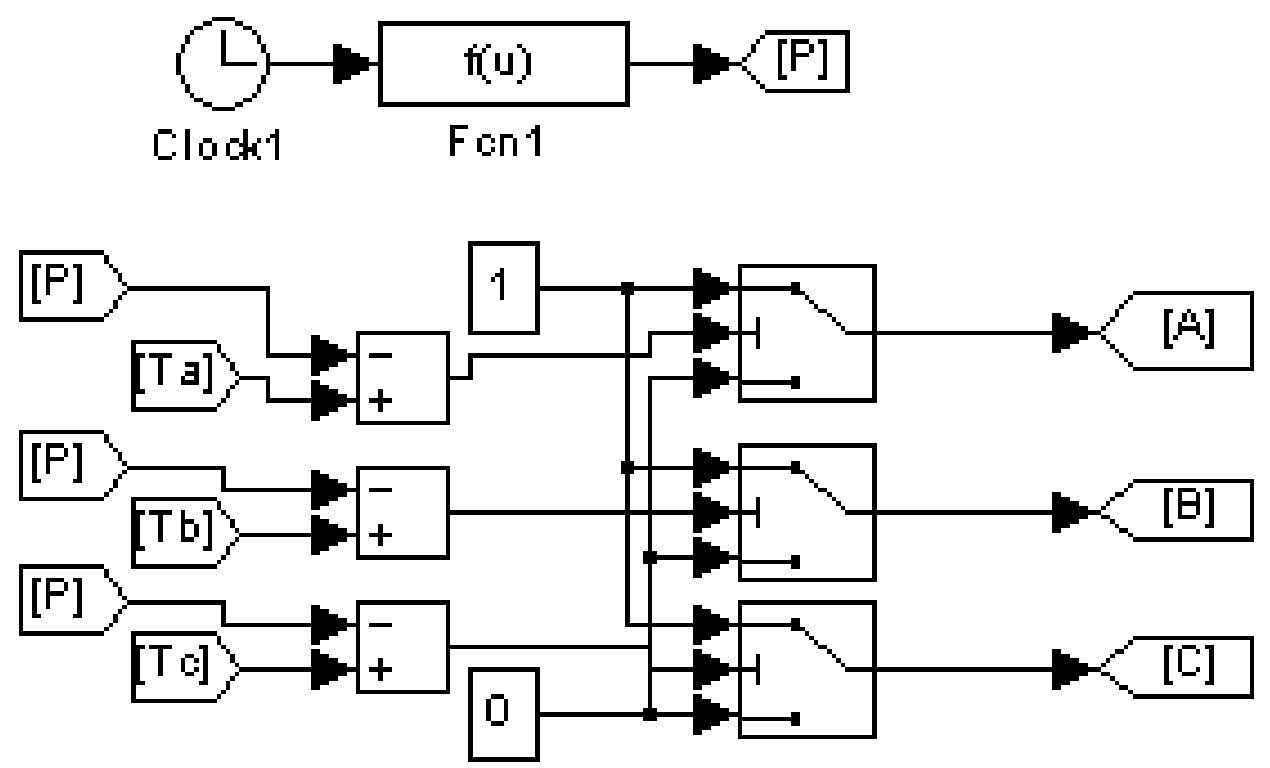

Figure 5-10: Generation of switching pulses

The sector number is determined in the simulation by the scope as shown in the Figure 5-11, and the same sector number is used with the angle $(\boldsymbol{\omega} t), \boldsymbol{T}_{\boldsymbol{Z}}, \boldsymbol{V}_{\boldsymbol{d c}}$ and $\boldsymbol{V}_{\boldsymbol{r} \boldsymbol{e} f}$ (the reference voltage) for the calculation of $\left(\boldsymbol{T}_{\mathbf{1}}, \boldsymbol{T}_{\mathbf{2}}, \boldsymbol{T}_{\mathbf{0}}\right)$ the time duration for each sector using the Equation 4.37 derived in section 4.4.1.3(a).

After calculating the time duration, the switching time $\left(\boldsymbol{T}_{\boldsymbol{a}}, \boldsymbol{T}_{\boldsymbol{b}}\right.$ and $\left.\boldsymbol{T}_{\boldsymbol{c}}\right)$ is determined for each transistor (S1 to S6). These switching times are shown in Figure 5-13. 


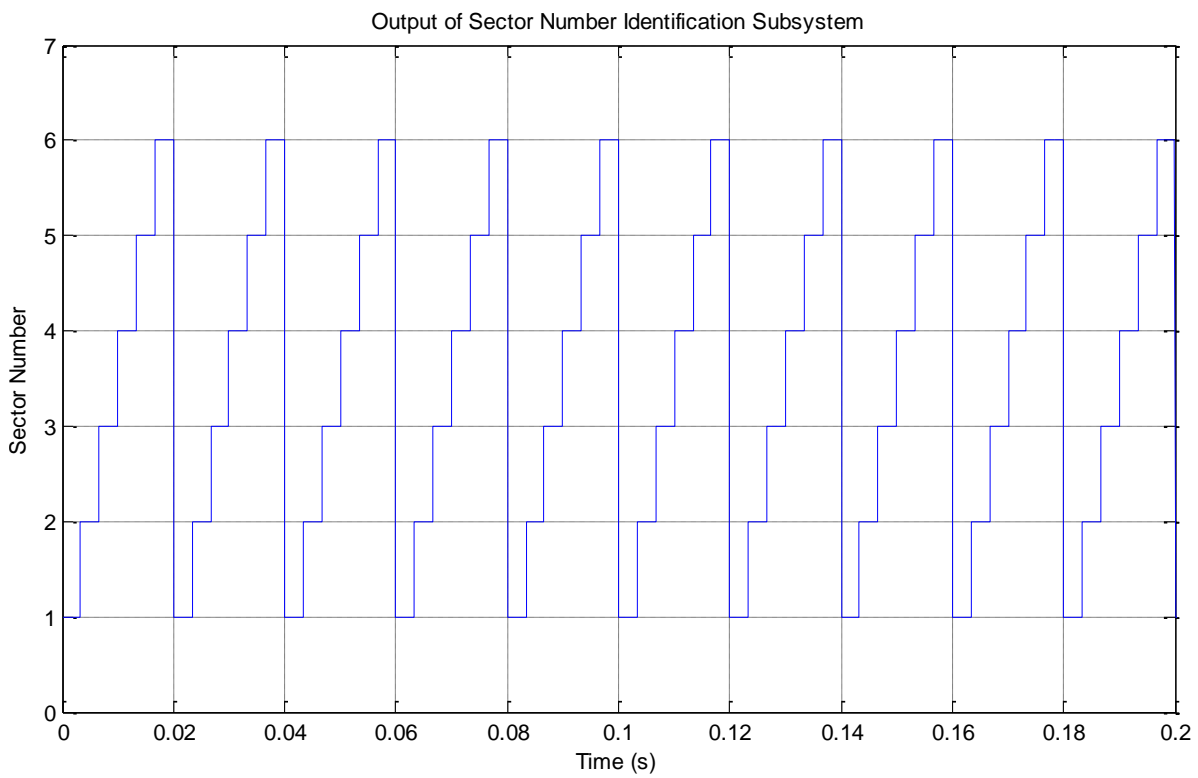

Figure 5-11: Sector Number n.

The simulation model of single phase DC-AC inverter is shown in Figure 5-12. The dc input voltage of $220 \mathrm{~V}$ from the boost converter is fed to the inverter through the controlled voltage source. The ac output voltage of the inverter is shown in Figure 5-14.

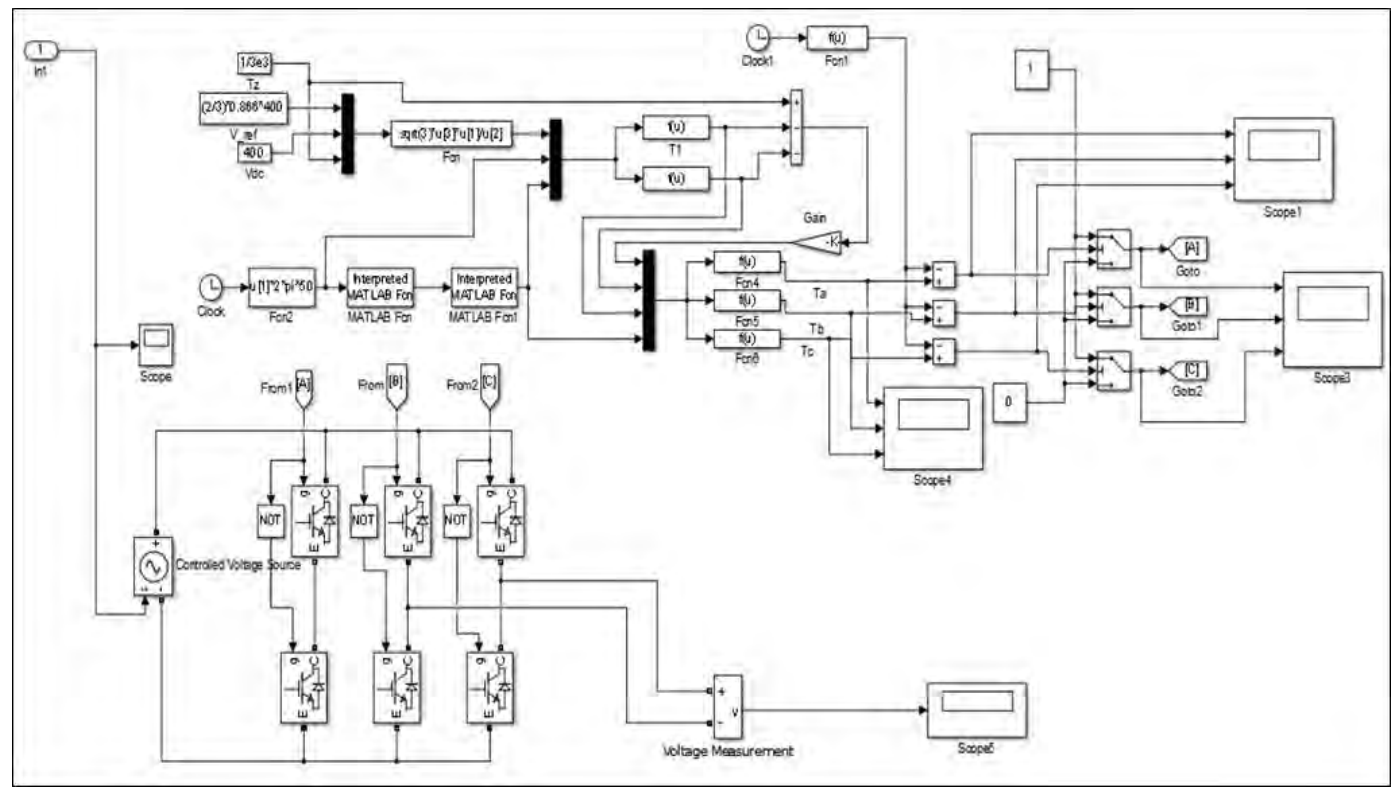

Figure 5-12: Simulation model of DC to AC inverter 


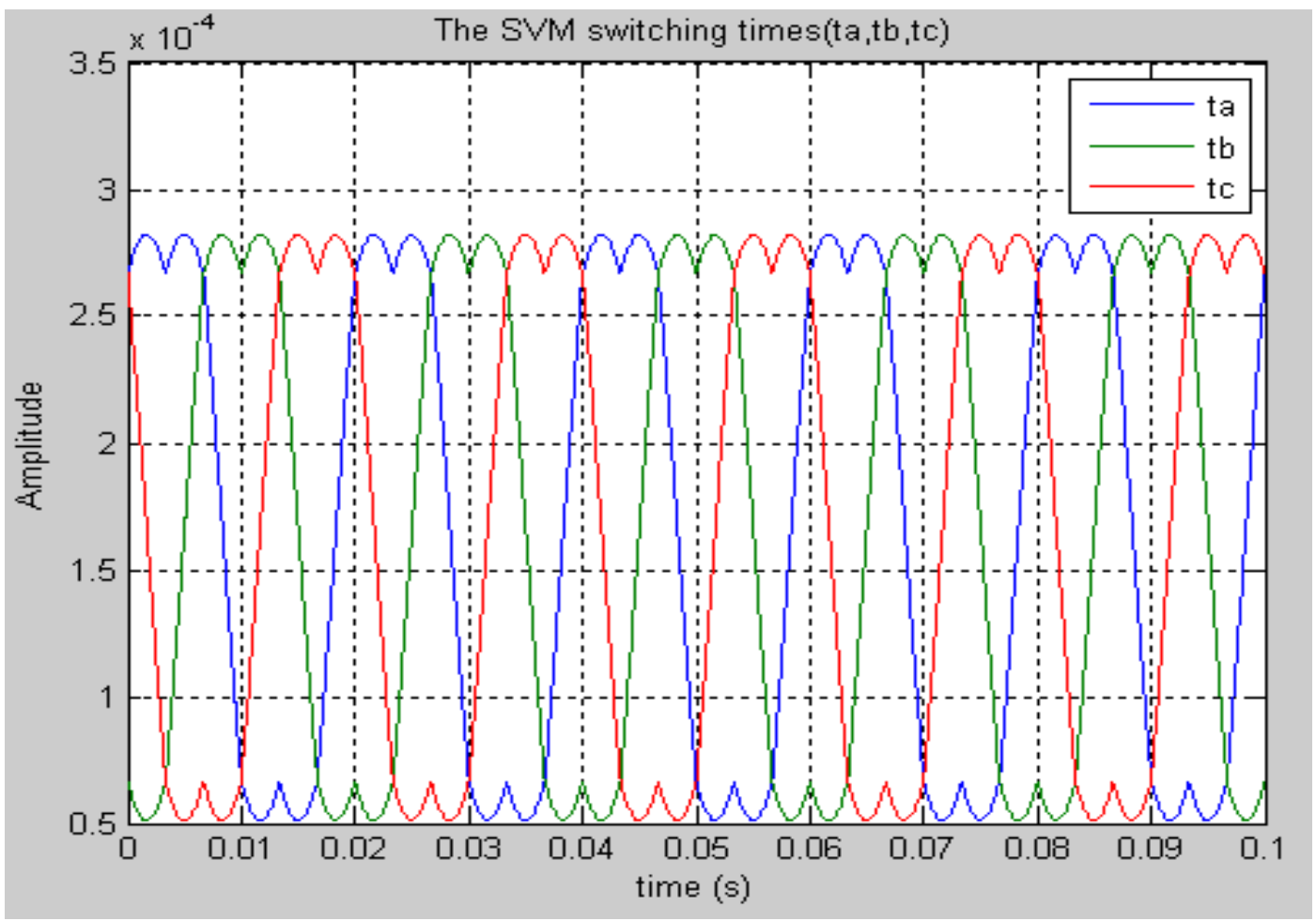

Figure 5-13: SVM Switching timings

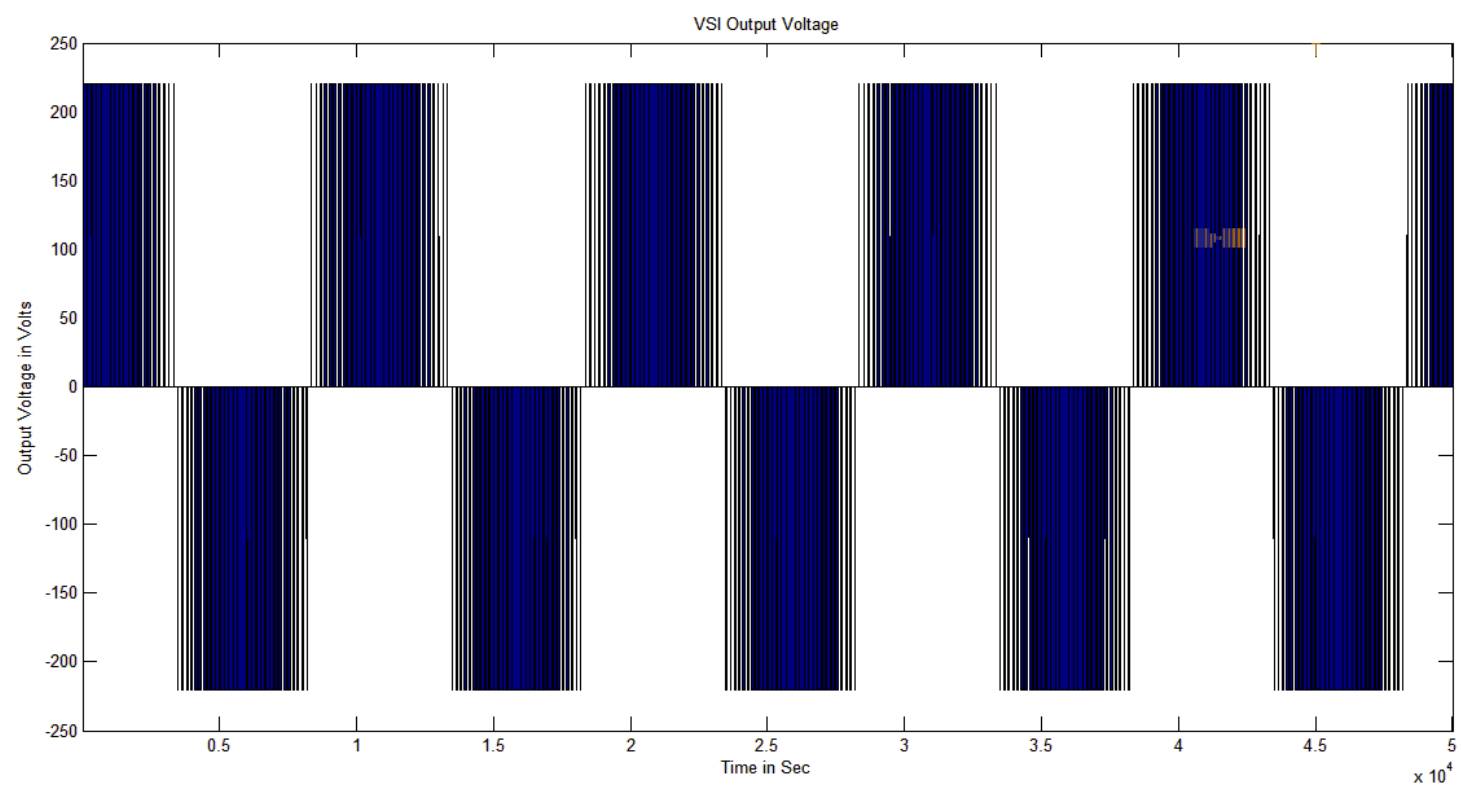

Figure 5-14: Output voltage of inverter

\subsection{Automatic Power Source Selection}

Every activity done for the power source selection is programmed to be displayed on LCD screen as shown from Figure 5-15 and Figure 5-16. 
During the peak time, from 7:00 a.m. to 10:00 a.m. the load is switched to solar power source and the source selection is displayed on the LCD as shown in Figure 5-15 (a).

During the off-peak time, from 10:00 a.m. to 06:00 p.m. the load is switched to the mains power source and the source selection is displayed on the LCD screen as shown in Figure 5-15 (b).

During the peak time, from 06:00 p.m. to 08:00 p.m. the load is switched to solar power source and the source selection is displayed on the LCD screen as shown in Figure 5-15 (c).

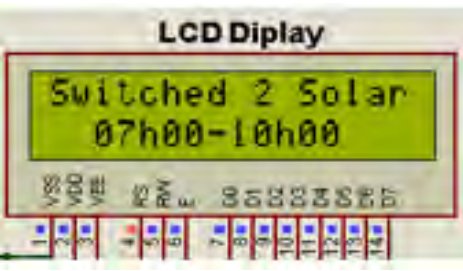

(a)

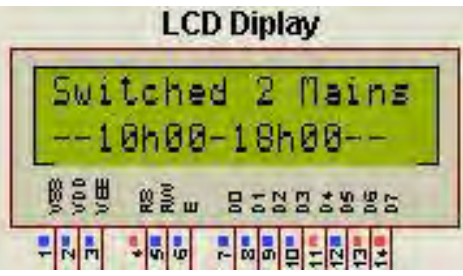

(b)

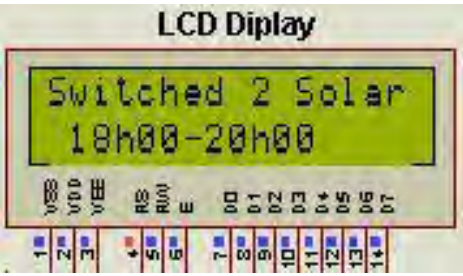

(c)

During the off-peak time, from 08:00 p.m. to 07:00 a.m. the load is switched to the mains power source and the source selection is displayed on the LCD screen as shown in Figure 5-15 (d).

When the mains is faulty at any time and it was selected, the load is switched to solar power source and the source selection is displayed on the LCD screen as shown in Figure 5-15 (e).

When the solar power is faulty during the peak time, the load is switched to the mains power and the selection is displayed on the LCD screen as shown in Figure 5-15 (f).

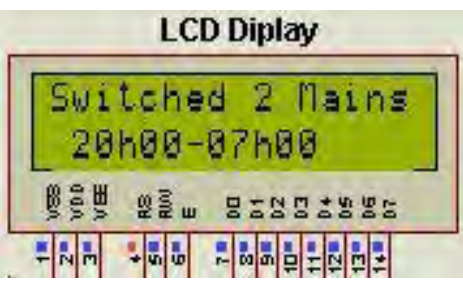

(d)

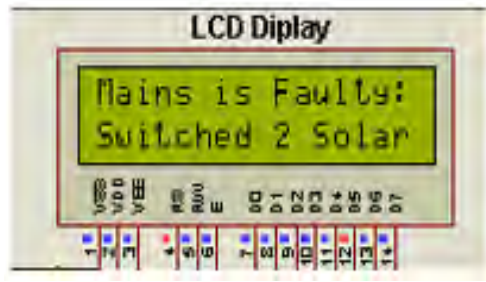

(e)

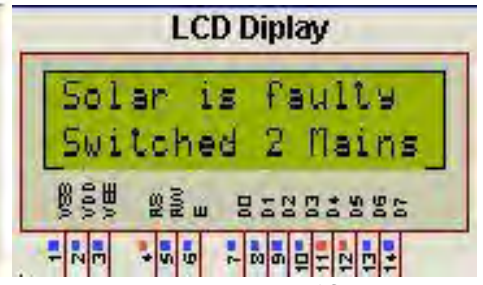

(f)

When the solar power fault is restored during the peak time, the load is switched back to solar and the selection is displayed on the LCD screen as shown in Figure 5-15 (g).

When the mains power fault is restored during the off-peak time, the load is switched back to mains and the selection is displayed on the LCD screen as shown in Figure 5-15 (h).

When the user switches the load to the solar power source manually, the selection is displayed on the LCD screen as shown in Figure 5-15 (i).

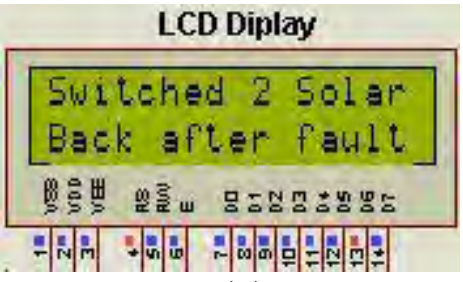

(g)

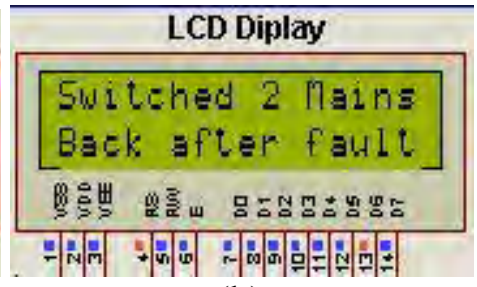

(h)

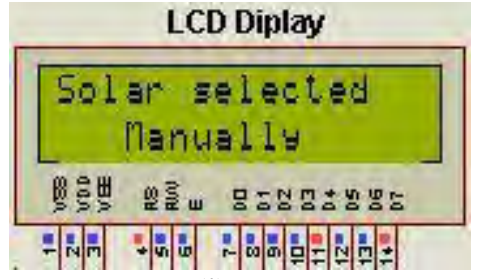

(i) 
When the user switches the load to the mains power source manually, the selection is displayed on the LCD screen as shown in Figure 5-15 (j).

During Saturday and Sunday, the load is switched to mains power source and the selection is shown on the LCD screen as shown in the Figure 5-15 (k).

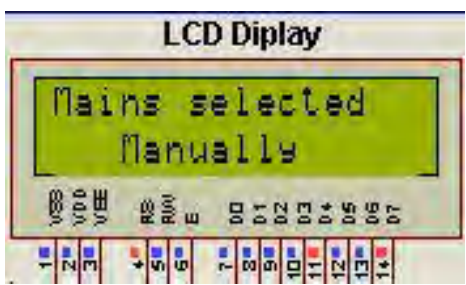

(j)

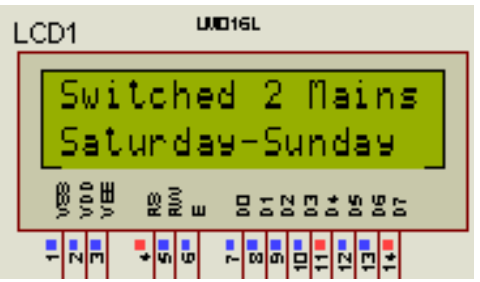

$(\mathrm{k})$

Figure 5-15 (a) - (k). LCD power source selection display

\subsection{Panel Cleaning Robot Schedule}

The panel cleaning activity is scheduled every Sunday from 02:00 p.m. - 02:30 p.m. and the panel cleaning robot cleans automatically and the cleaning activity is displayed on the LCD screen as shown on the Figure 5-16 (a). However, since the panel cleaning robot is directly connected to the solar panels (through DC-DC regulator) it means that the power flow will occur when the sun is available. When the time scheduled for this activity coincides with no sun available, the cleaning is shifted to the next Sunday from 02:00 p.m. - 02:30 p.m.

When the user switches the panel cleaning robot manually for cleaning, the activity is displayed on the LCD screen as shown on the Figure 5-16 (b).

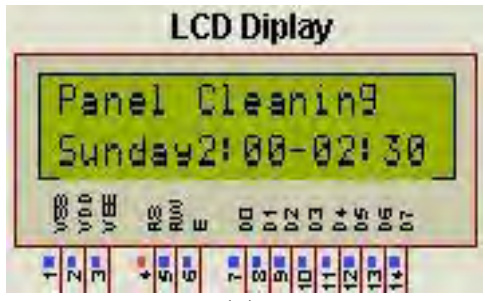

(a)

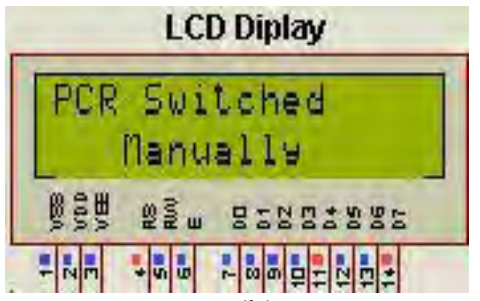

(b)

Figure 5-16 (a) \& (b) Panel cleaning activities

\subsection{Savings on Carbon Emission}

Generally, the amount of fuel used to generate electricity depends on the efficiency or heat rate of the thermal power plant and the heat content of the fuel. According to the U.S. Energy Information Administration (EIA); the mount of coal used to generate 1 kilowatt-hour ( $\mathrm{kWh}$ ) is 0.00052 short tons or 1.05 pounds (or $0.476272 \mathrm{~kg}$ ) [84]. From this information, the amount of coal saved by using this system in one day $(5 \mathrm{kWh})$ is:

$$
0.476272 \mathrm{~kg} \times 5=2.38136 \mathrm{~kg}
$$

Similarly, in one month (say 30days) the amount of coal saved is:

$$
2.38136 \mathrm{~kg} \times 30=71.4408 \mathrm{~kg}
$$


The coal burning involves the following chemical reaction shown in Equation 5-1:

$$
\mathrm{C}+\mathrm{O}_{2} \rightarrow \mathrm{CO}_{2}
$$

Where $\mathrm{C}$ and $\mathrm{O}$ respectively stand for Carbon and Oxygen. Coal is mainly carbon plus small amount of water, hydrogen and oxygen. Depending also on the type of coal, in addition to hydrogen and oxygen, it may contain small amount of nitrogen, sulfur and some other minerals (neglected in this study).

We need to know what quantity of $\mathrm{CO}_{2}$ emitted in the atmosphere when a given amount of coal is burnt [84]:

$$
\begin{array}{ccccc}
C(1 \text { mole }) & + & \mathrm{O}_{2}(1 \text { mole }) & \rightarrow & \mathrm{CO}_{2}(1 \text { mole }) \\
C-C & + & O=O & \rightarrow & O=C=O
\end{array}
$$

The energy for braking the bond:

$$
83 \mathrm{kcal} / \mathrm{mole}+119 \mathrm{kcal} / \mathrm{mole}=202 \mathrm{kcal} / \mathrm{mole}
$$

The released energy:

$$
\begin{aligned}
& 2 \times 177 \mathrm{kcal} / \mathrm{mole}=354 \mathrm{kcal} / \mathrm{mole} \\
& \text { net release }=152 \mathrm{kcal} / \mathrm{mole} \text { of carbon }
\end{aligned}
$$

The complete combustion is done by $12 \mathrm{~g}$ of carbon (this yields $152 \mathrm{kcal}$ of the provided energy).

As seen from the Equation (5-4), $\mathrm{CO}_{2}$ is the main byproduct (= produced as a direct result of the desired reaction) from coal combustion: $44 \mathrm{~g}$ of $\mathrm{CO}_{2}$ is produced for every $12 \mathrm{~g}$ of C burnt.

This means that $1 \mathrm{~kg}$ of burn coal emits $\frac{44}{12}=3.67 \mathrm{~kg}$ of $\mathrm{CO}_{2}$

From the equation (5-2) we can see that in one month, the designed system will save:

$$
71.4408 \mathrm{~kg} \times 3.67=261.9496 \mathrm{~kg} \text { of } \mathrm{CO}_{2}
$$

The same calculation procedure can be done for any given period to see which $\mathrm{CO}_{2}$ gas emission saved by using solar energy, responsible of the global earth warming and climate changes.

Moreover, when burning the coal, an insufficient oxygen supply occurs and results in the emission of carbon monoxide shown in Equation (5.10) which is a very poisonous gas.

$$
\mathrm{C}+\mathrm{CO}_{2} \rightarrow 2 \mathrm{CO}
$$

This gas is colourless and odourless, when breathing in $\mathrm{CO}$, the $\mathrm{CO}$ takes place of $\mathrm{O}_{2}$ in the haemoglobin molecules in the blood supply in the lungs causing many consequences as discussed in Sub-section 1.4.

The energy from the solar panels is directly used when the battery system is fully charged. A programmable microcontroller is used to select the power source, control the operation of the solar panel cleaning robot and display the source that is in use. 


\section{CHAPTER 6}

\section{CONCLUSIONS AND RECOMMENDATION FOR FUTURE STUDIES}

\subsection{Conclusions}

The reduction of fluctuations on the commercial grid during the peak power demand by adopting the use of renewable energy sources in combination with the power from the mains improves the power transmission stability. In this research work, a hybrid solar and mains automatic selection scheme based on off or peak times demand between solar energy and mains, coupled with an automatic solar panel cleaning system has been designed.

Peak time power demand causes fluctuations in the electrical network from the generation, transmission and distribution sections of the power grid. This instability globally causes problems of insufficiency in electricity access in remote areas. This subject has therefore elicited a lot of interest from many researchers that explore different ways on how to satisfy the load demand.

The system developed here shows that the hybrid solar and mains system meets the power demand during the peak time. The MPPT system is simulated using MATLAB-Simulink; a real-time simulator and model testing platform for many physical systems. The MPPT algorithm determines the duty cycle of the boost converter according to the power output from the solar panel. It also tracks the panel along the maximum point in the I-V characteristic.

The regulated solar output charges the battery bank. The boost converter boosts up the input voltage to the required level. Furthermore, the microcontroller determines the duty cycle of the boost converter according to the MPPT algorithm. The automatic selection of power sources for supplying $1 \mathrm{~kW}$ of power during peak power demand period to a coffee shop is demonstrated using Proteus virtual visualization software.

The system is demonstrated to optimally meet this demand according the results obtained. In our design, there is also provision for automatic choice of the power source in case of mains or solar system failure. The design also includes a panel cleaning robot operated by a dc motor supplied by solar panel, and works on a cleaning schedule that is programmed in the microcontroller. The cleaning operation process is also displayed on the LCD display as it is done for other activities.

The designed system is economically feasible and considerably reduces the load connected to the grid during peak time, the window of opportunity to increase the electricity access programs in under developing countries and the positive impact to the global warming reduction issues. Though the initial cost is high, it would be a good alternate to full time engagement of the mains, if subsidy is provided by government.

\subsection{Recommendations for Future Studies}

The clock time for the whole program is the embedded one of the microcontroller. This has the disadvantage of not getting easily adjusted by the user. If the time gets wrong for example instead of running at the corresponding time it happens to run one hour lead or lag due to the failure of the microcontroller battery or any other reason, it will operate according to that wrong time, until the clock adjustment is done by the programmer. The future work may improve this by making the program to run by the external clock which can even be adjusted by any user not a programmer. 
The power source selection to the load may be done with respect to the load power demand in addition to the peak time power demand.

The combination of automatic panel cleaning robot periodically programmed as designed in this research with the remotely controlled panel cleaning robot [107] may result in better achievement. Also, the dirt sensibility program on solar panels may be added so that the cleaning process may automatically be done at any time when the panel gets dirty. 


\section{APPENDICES}

\section{Appendix A. MPPT Modeling Design}

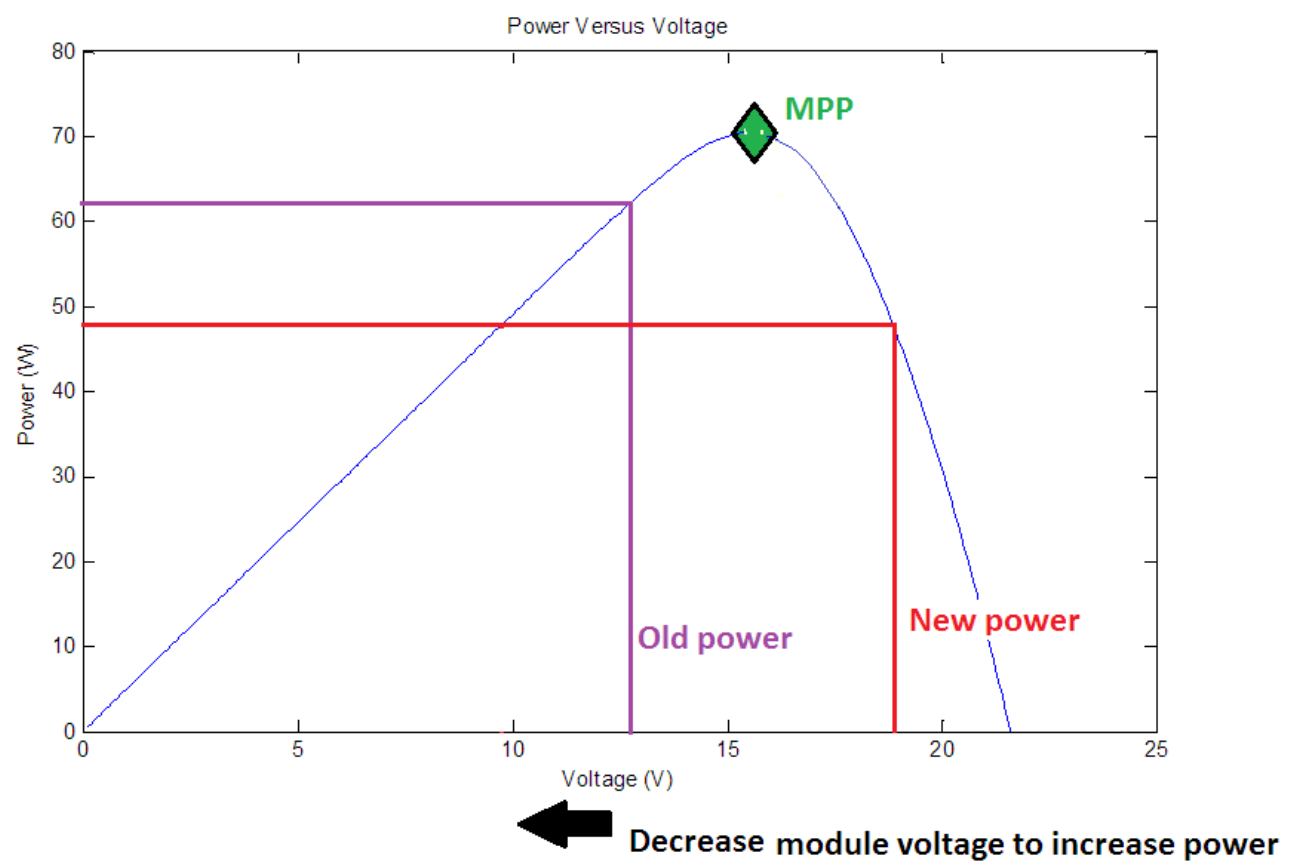

Figure A-1: MPPT algorithm decreasing module voltage

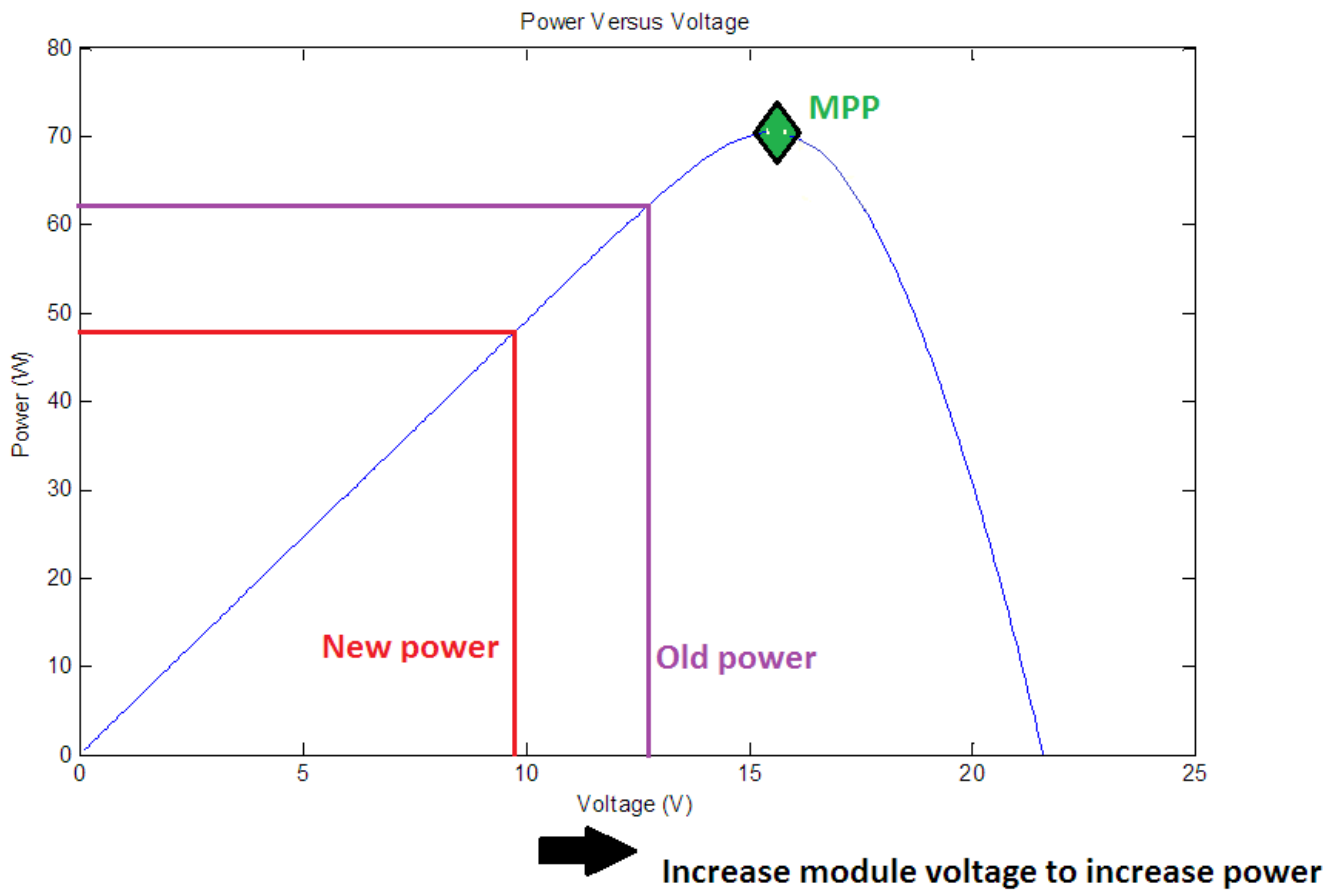

Figure A-2: MPPT algorithm increasing module voltage 


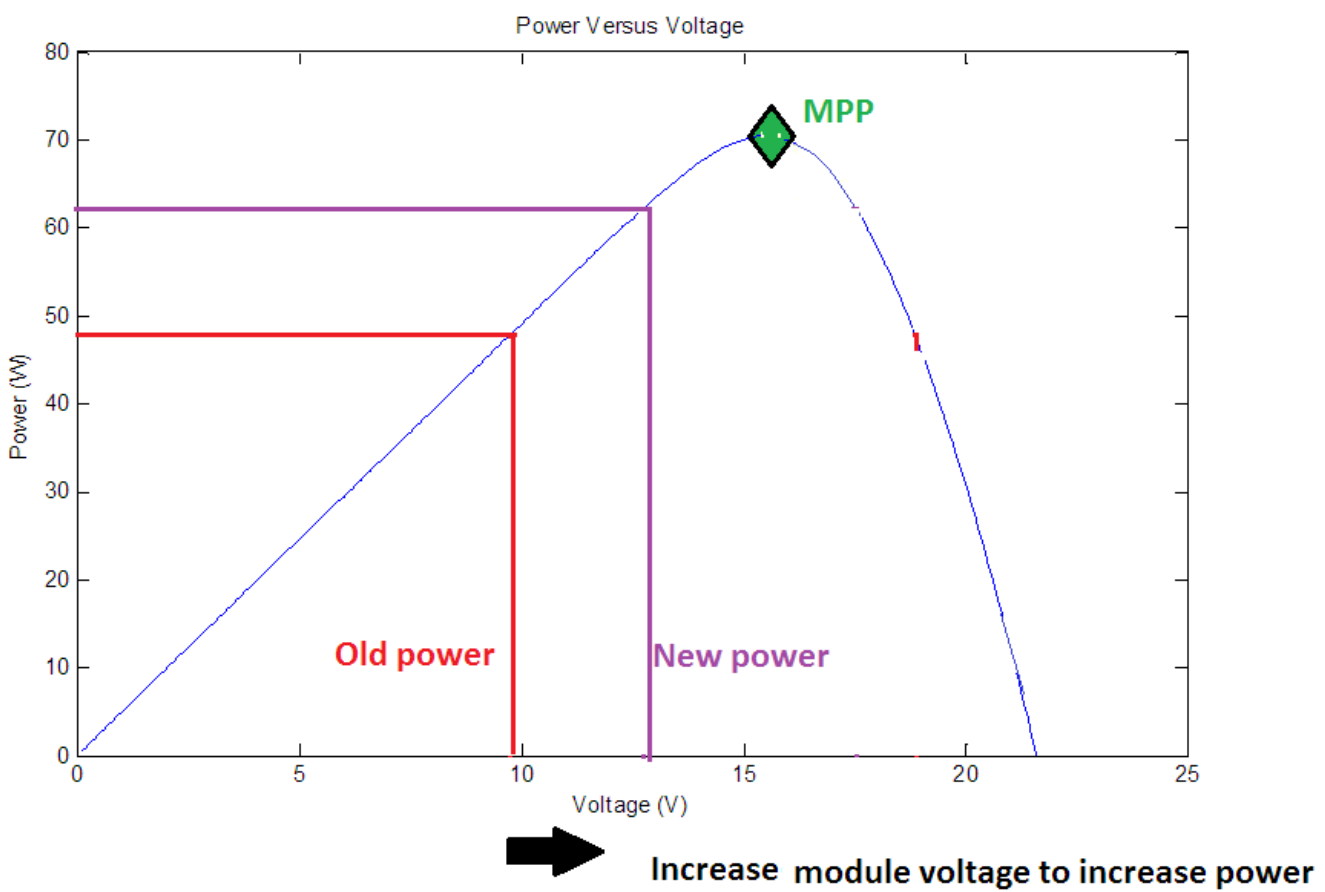

Figure A-3: MPPT algorithm increasing module voltage to increase module power

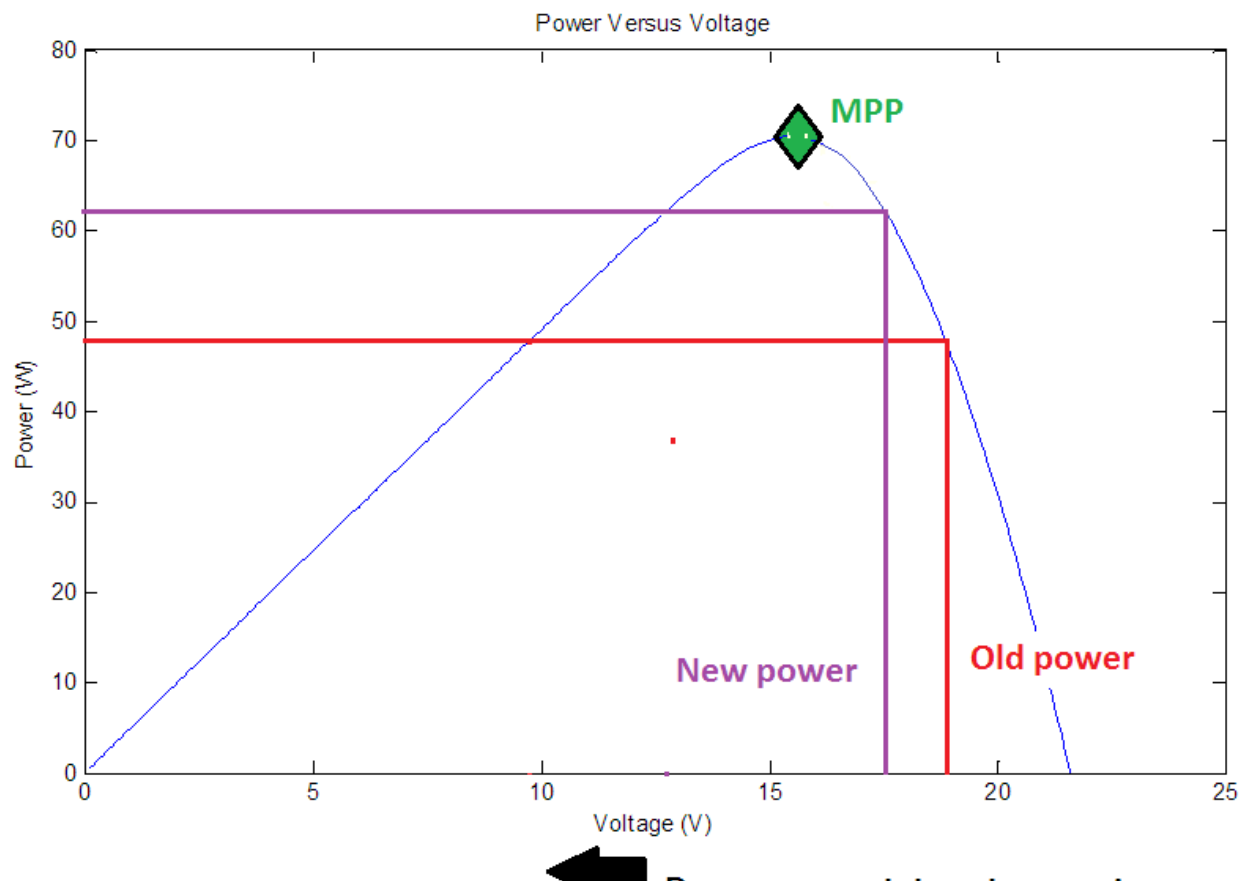

Decrease module voltage to increase power

Figure A-4: MPPT algorithm decreasing module voltage to increase power 
Appendix B. Converters Simulations

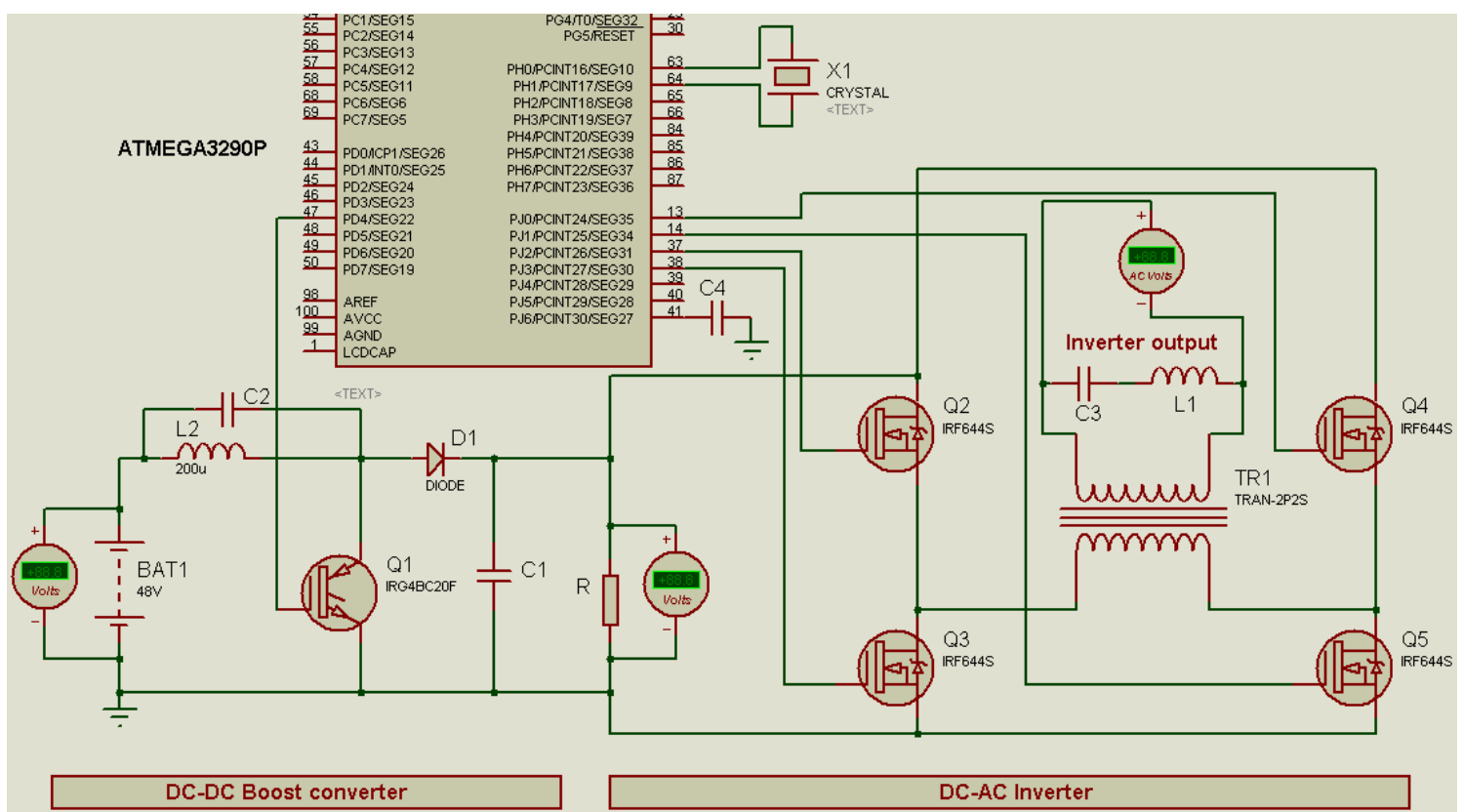

Figure B-1: DC-AC Inverter and DC-DC boost converter simulation in proteus

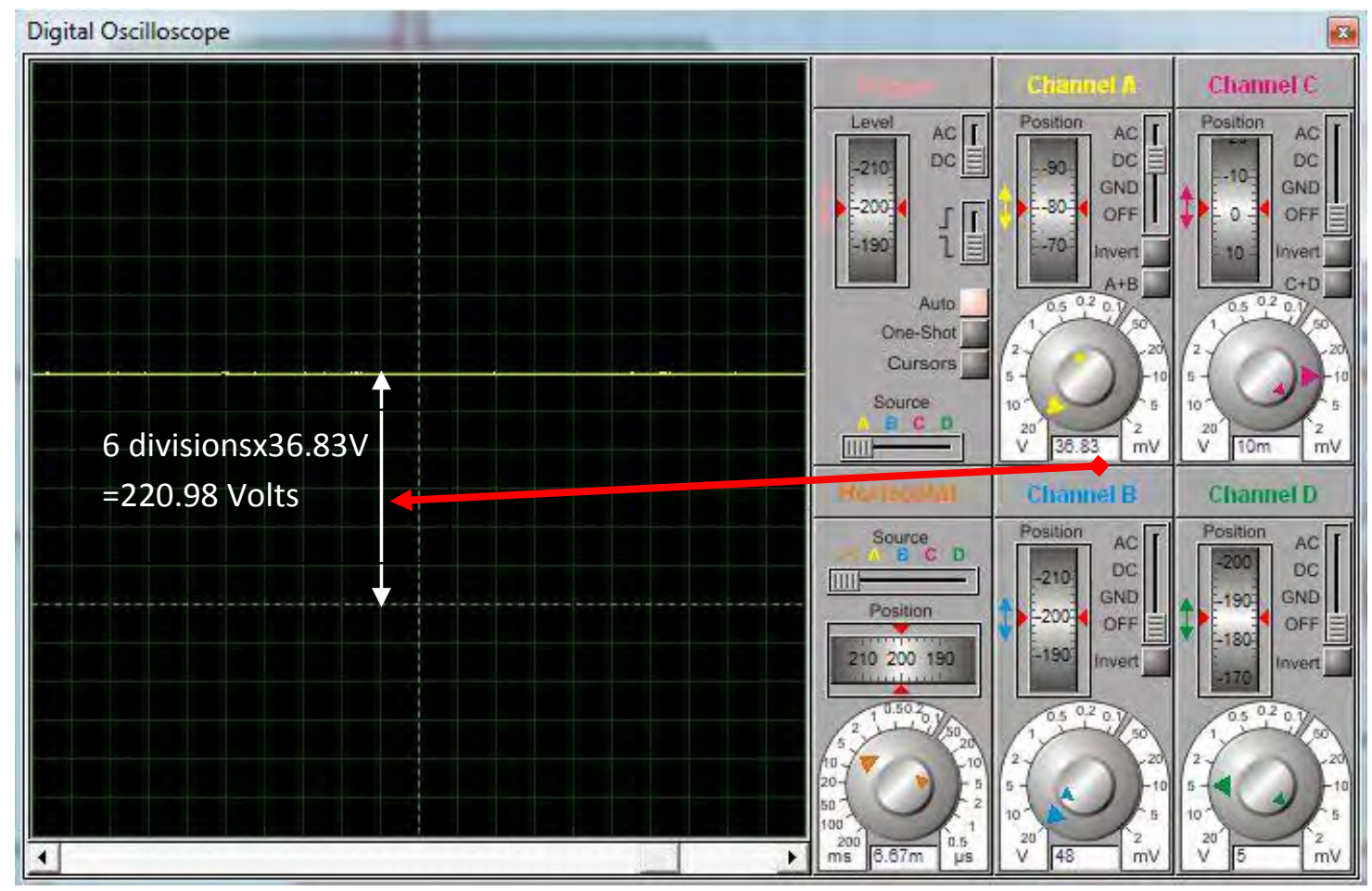

Figure B-2: DC-DC Boost converter output 


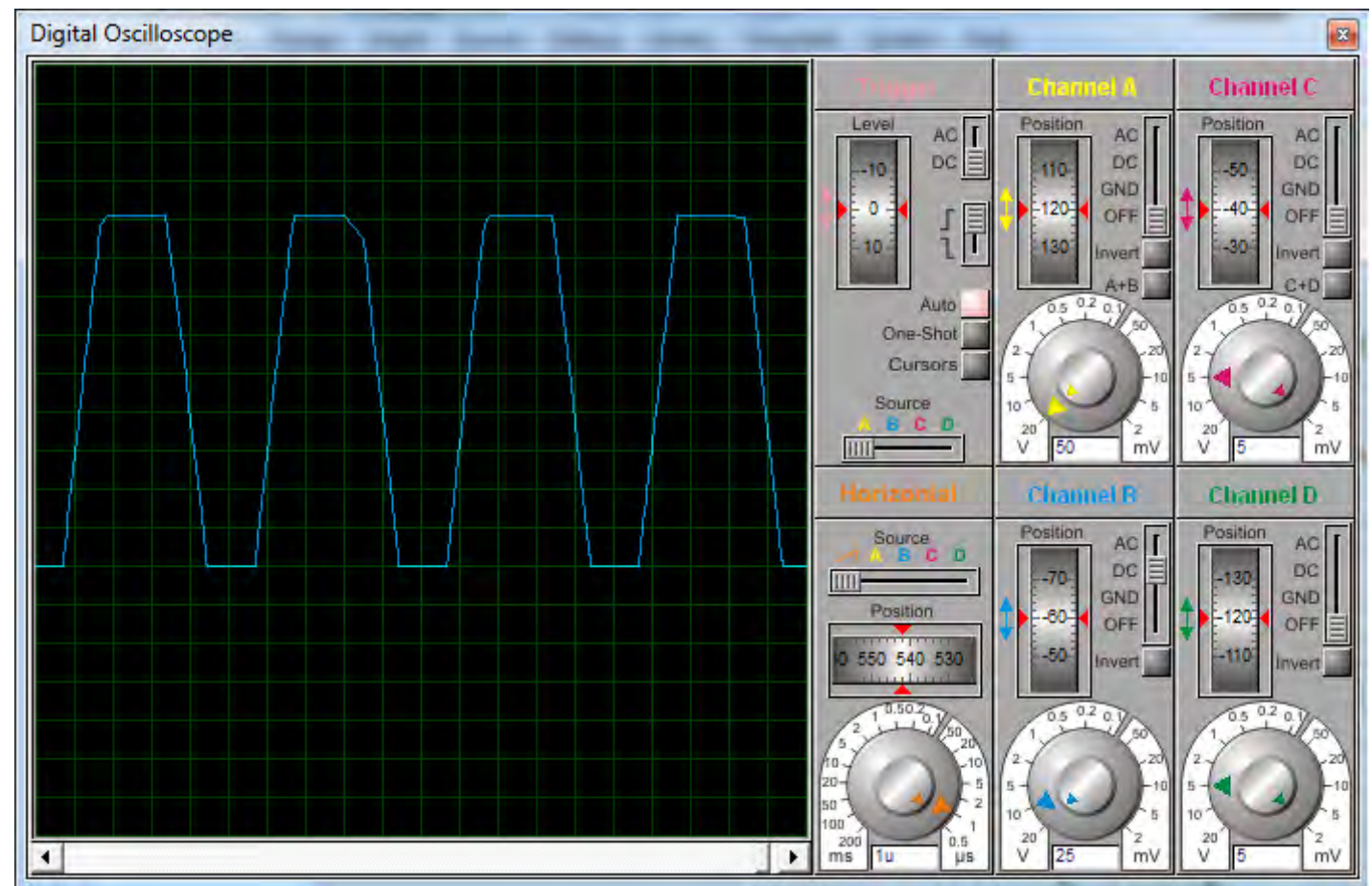

Figure B-3: Pulse width modulation output

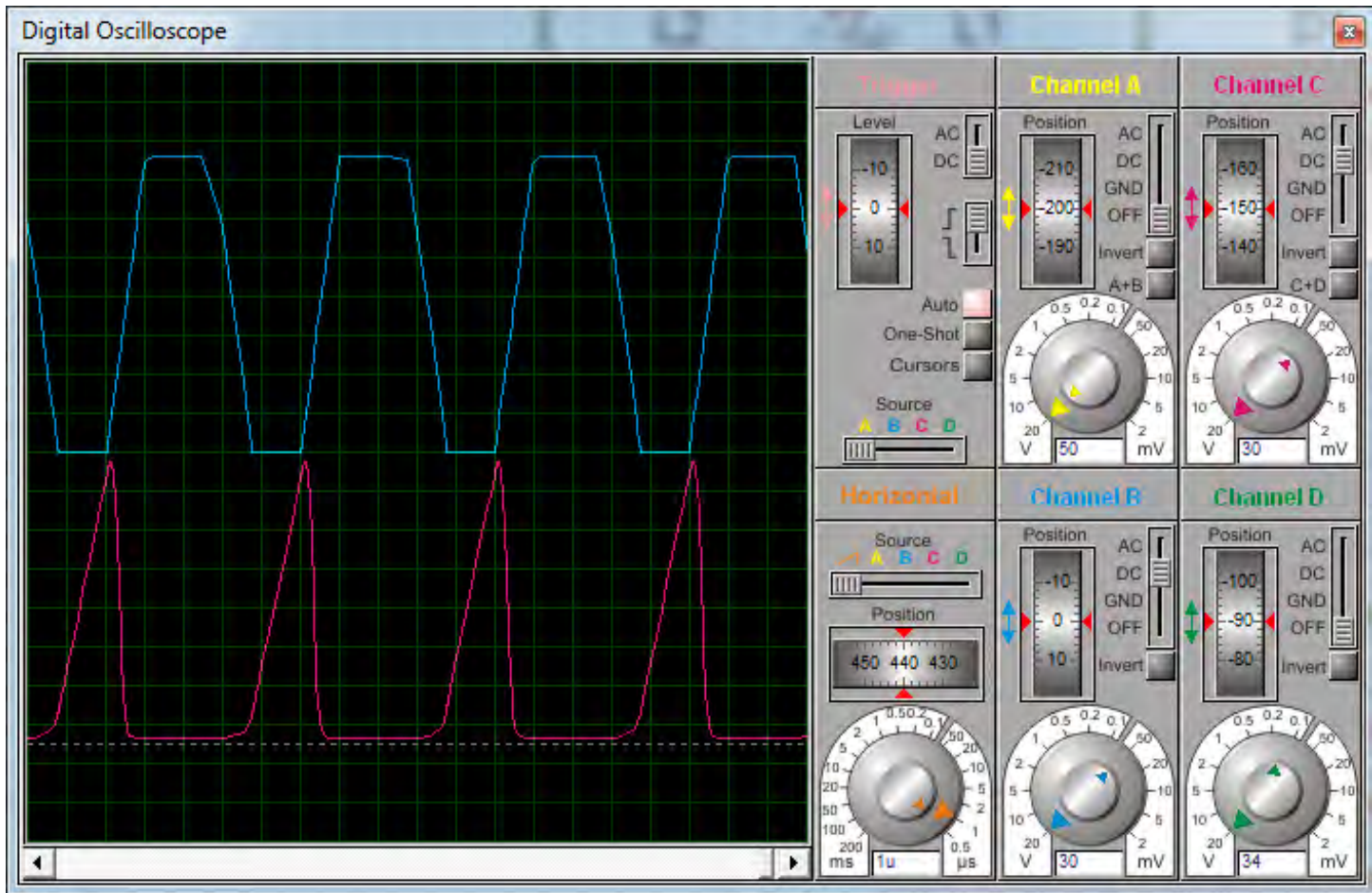

Figure B-4:

PWM output and

the MOSFET 


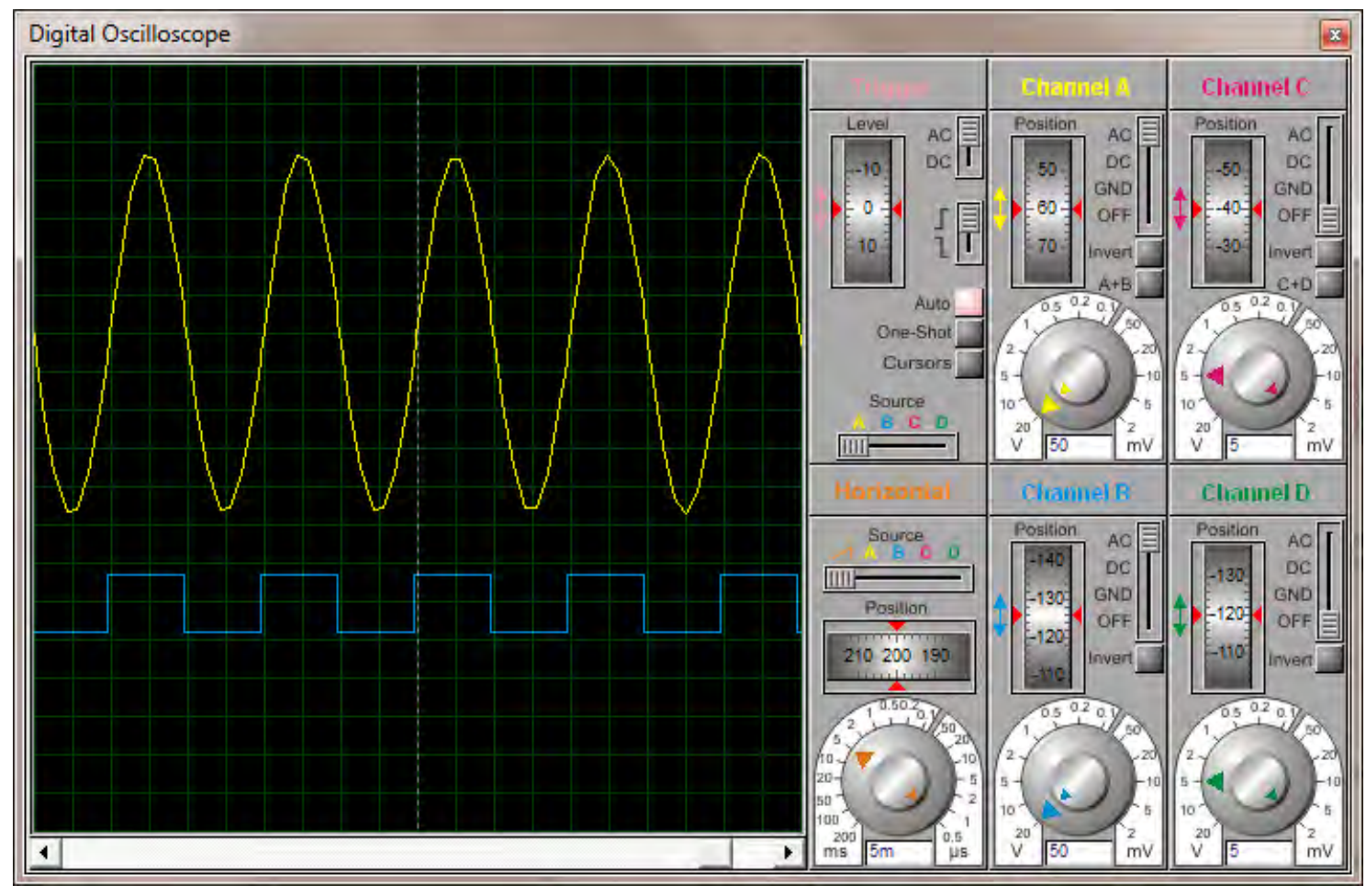

Figure B-5: Inverter output \& Inverter's transformer input

\section{Appendix C. Calculations}

\section{C1: Battery charging and discharging time calculations}

$$
\mathrm{E}=P . t=1,000 w * 5 h=5,000 w h
$$

Charging time:

$$
\begin{gathered}
T_{\text {ch }}=\text { Capacity } /(\text { efficiency } * \text { charge rate }) \\
\frac{300 \mathrm{Ah}}{0.9 * 10 \mathrm{~A}}=33.3 \text { hrs approximately }
\end{gathered}
$$

Discharging time:

$$
\begin{gathered}
T_{d c h}=\frac{\text { Capacity } * \text { Battery Voltage } * \text { Ef ficieny }}{\text { Applied load }} \\
\frac{300 \mathrm{Ah} * 48 \mathrm{~V} * 0.9}{1000 \mathrm{Watts}}=12.96 \mathrm{hrs}
\end{gathered}
$$

\section{C2: Charge controller size calculation}

Charge controller size for $1 \mathrm{Kw}$

$$
\frac{1000}{48}=20.83 \text { amps }
$$


The size of charge controller by considering the safety factor of 1.5:

$$
20.83 A * 1.25=26 \text { amps }
$$

C3. Load Resistance and duty cycle calculation

$$
R=\frac{220}{3}=73.3 \Omega
$$

$$
\text { Duty Cycle, } D=1-\frac{V_{i}}{V_{o}}=1-\frac{48}{220}=0.78
$$

\section{C4. Inductor calculations}

$$
\begin{gathered}
\Delta I_{L}=0.3 \times\left(3 \times \frac{220}{48}\right)=4.125 \mathrm{~A} \\
L=\frac{48 \times(220-48)}{4.125 \times 200 \times 10^{3} \times 220}=45.49 \times 10^{-6} \mathrm{Henry}=45.49 \mu \mathrm{H}
\end{gathered}
$$

\section{C5. Capacitor calculations}

$$
\begin{gathered}
\Delta V_{o}=E S R \times\left(\frac{I_{O}}{1-D} \times \frac{\Delta I_{L}}{2}\right) \\
\Delta V_{o}=0.1 \times\left(\frac{3}{1-0.78} \times \frac{4.125}{2}\right)=2.813 \text { Volts }
\end{gathered}
$$

Replacing the value of equation (3.50) in (3.48) we get:

$$
\begin{aligned}
& C=\frac{3 \times 0.78}{200 \times 10^{3} \times 2.813}=4.16 \times 10^{-6} \mathrm{Farad}=4.16 \mu \mathrm{F} \\
& \text { New ripple voltage }=\frac{I_{o} \times D}{f_{S} \times C}=2.81 \times 10^{-3} \mathrm{~V}
\end{aligned}
$$

\section{C6. The maximum switch current}

$$
I_{S w(\max )}=\frac{4.125}{2}+\frac{3}{1-0.78}=15.605 \mathrm{~A}
$$

\section{C7. Diode Loss}

$$
\begin{aligned}
\text { Diode loss } & =V_{d} \times I_{o}(1-D) \\
& =0.07 \mathrm{~W}
\end{aligned}
$$




\section{Appendix D. Datasheet of the Selected Solar Panels}

\section{SHARP.}

solar electricity

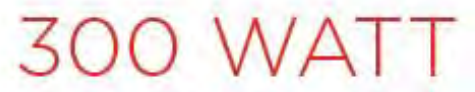

MULTI-PURPOSE MODULE

NEC 2008 Compllant

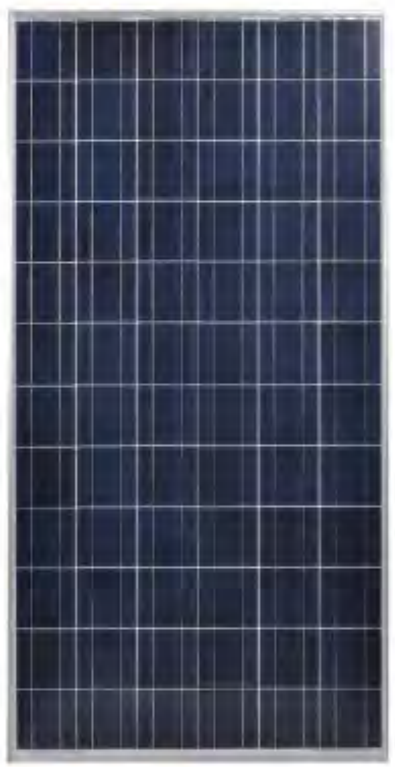

ND-F4Q300

MULTI-PURPOSE 300 WATT

MODULE FROM THE WORLD'S

TRUSTED SOURCE FOR SOLAR.

Using breakthrough technology, made possible by nearly 50 years of proprietary research and development, Sharp's ND-F4Q300 solar module incorporates an advanced surface texturing process to increase light absorption and improve efficiency. Common applications include commercial and residential grid-tied roof systems as well as ground mounted arrays. Designed to withstand rigorous operating conditions, this module offers high power output per square foot of solar array.

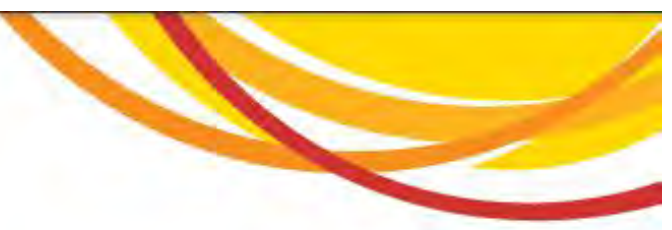

Business leaders install this module in large commercial applications, demonstrating ilnancial astuteness and erivironmental stewardship.

\section{ENGINEERING EXCELLENCE}

High module efficiency for an outstanding balance of size and weight to power and performance.

\section{DURABLE}

Tempered glass, EVA lamination and weatherproof backskin provide long-life and enhanced cell performance.

\section{RELIABLE}

25-year limited warranty on power output.

\section{HIGH PERFORMANCE}

This module uses an advanced surface texturing process to increase light absorption and improve efficiency.

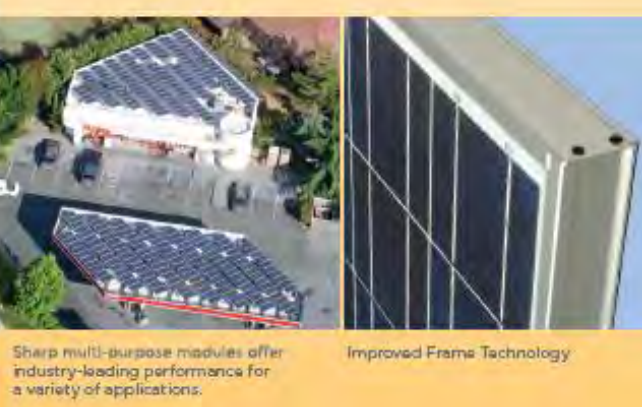

SHARP: THE NAME TO TRUST

The Sharp ND-F4Q300 module is covered by Sharp's 10 year materials or workmanship warranty. When you choose Sharp, you get more than well-engineered products. You also get Sharp's proven reliability, outstanding customer service and the assurance of our 25-year limited warranty on power output. A global leader in solar electricity, Sharp powers more homes and businesses than any other solar manufacturer worldwîide. 


\section{WATT}

ND-F4Q300

NEC 2008 Compllant

Module output cables: 12 AWG PV Wire

\begin{tabular}{ll}
\hline ELECTRICAL CHARACTERISTICS & \\
\hline Maximum Power (Pmax)" & $300 \mathrm{~W}$ \\
Tolerance of Pmax & $0 \% 6 / 5 \%$ \\
Type of Cell & Polycrystalline silicon \\
Cell Configuration & 72 in series \\
Open Circuit Voltage (Voc) & $45.1 \mathrm{~V}$ \\
Maximum Power Voltage (Vpm) & $35.2 \mathrm{~V}$ \\
Short Circuit Current (lis) & $8.94 \mathrm{~A}$ \\
Maximum Power Current (Ipm) & $8.52 \mathrm{~A}$ \\
Module Efficiency (\%) & $15.3 \%$ \\
Maximum System (DC) Voltage & $1000 \mathrm{~V}$ \\
Series Fuse Rating & $15 \mathrm{~A}$ \\
NoCT & $46.2^{\circ} \mathrm{C}$ \\
Temperature Coefficient (Pmax) & $-0.439 \% /{ }^{\circ} \mathrm{C}$ \\
Temperature Coefficient (VoC) & $-0.32196 /{ }^{\circ} \mathrm{C}$ \\
Temperature Coefficient (IsC) & $0.050 \% 6 /{ }^{\circ} \mathrm{C}$
\end{tabular}

(filumination of $1 \mathrm{~kW} / \mathrm{m}^{2}$ (1 surn) at spoctral distribution of AM 1.5 (ASTM 5992 global spectral imrodiance) at a coll temperature of $25^{\circ} \mathrm{C}$.

\section{MECHANICAL CHARACTERISTICS \\ Dimensions (A $\times$ B $\times$ C bolow) \\ Cable Length $(G)$ \\ $39.1 \times 77.6^{*} \times 18^{5} / 994 \times 1971 \times 46 \mathrm{~mm}$ \\ $43.3 / 1100 \mathrm{~mm}$ \\ Output Interconnect Cable \\ Weight \\ 12 AWG with SMK Locking Connector \\ $50 \mathrm{lbs} / 22.7 \mathrm{~kg}$ \\ 30 psf (1440 Pascals) \\ Operating Temperature (coll) \\ -40 to $194^{\circ} \mathrm{F} /-40$ to $90^{\circ} \mathrm{C}$ \\ -pV Wire per UL Subject 4703}

\section{QUALIFICATIONS}

$\begin{array}{ll}\text { UL Listed } & \text { UL } 1703 \\ \text { Fire Rating } & \text { Class C } \\ \text { IEC Listed } & \text { IEC 61215/ IEC 61730 }\end{array}$

\section{WARRANTY}

25-year limited warranty on power output

Contact Sharp for complete warranty information

Design and spectications aro subject to changa without notice

Sharp is a registered tradernark of Sharp Corporation. All other trademaric are property of their respective ownars. Cover photo: Solar irstaliation by Pacific Dower Management, Auburn CA.<smiles>C[Si](C)(C)[Si](C)(C)C12CC3CC(CC(C3)C1=O)C2</smiles>

\section{SHARP.}

Q 2012 Sharp Electronics Corporation. All inghts reserved
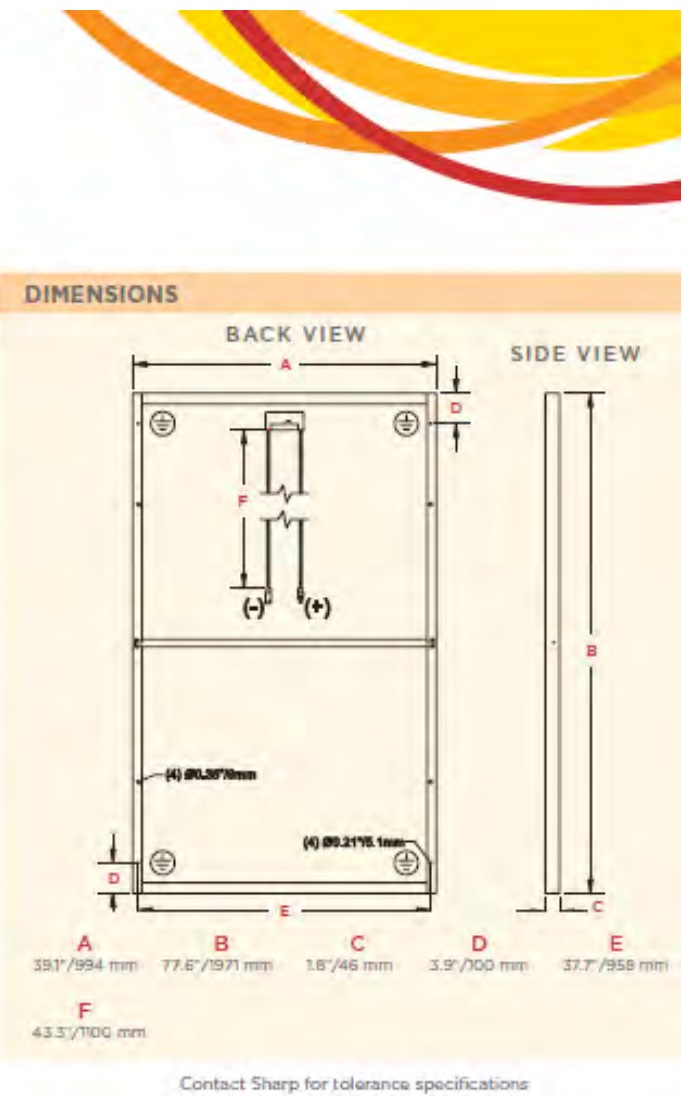

\section{"BUY AMERICAN"}

Sharp solar modules are manufactured in the United States and Japan, and qualify as "American" goods under the "Buy American" clause of the American Recovery and Reinvestment Act (ARRA).
SHARP ELECTRONICS CORPORATION

5700 NW Pacific Rim Boulevard, Camas, WA 98607

1-800-SOLAR-D6. Email: sharpsolar@sharpusa.com

www.sharpusa.com/solar 


\section{Appendix E. The Simulation Code}

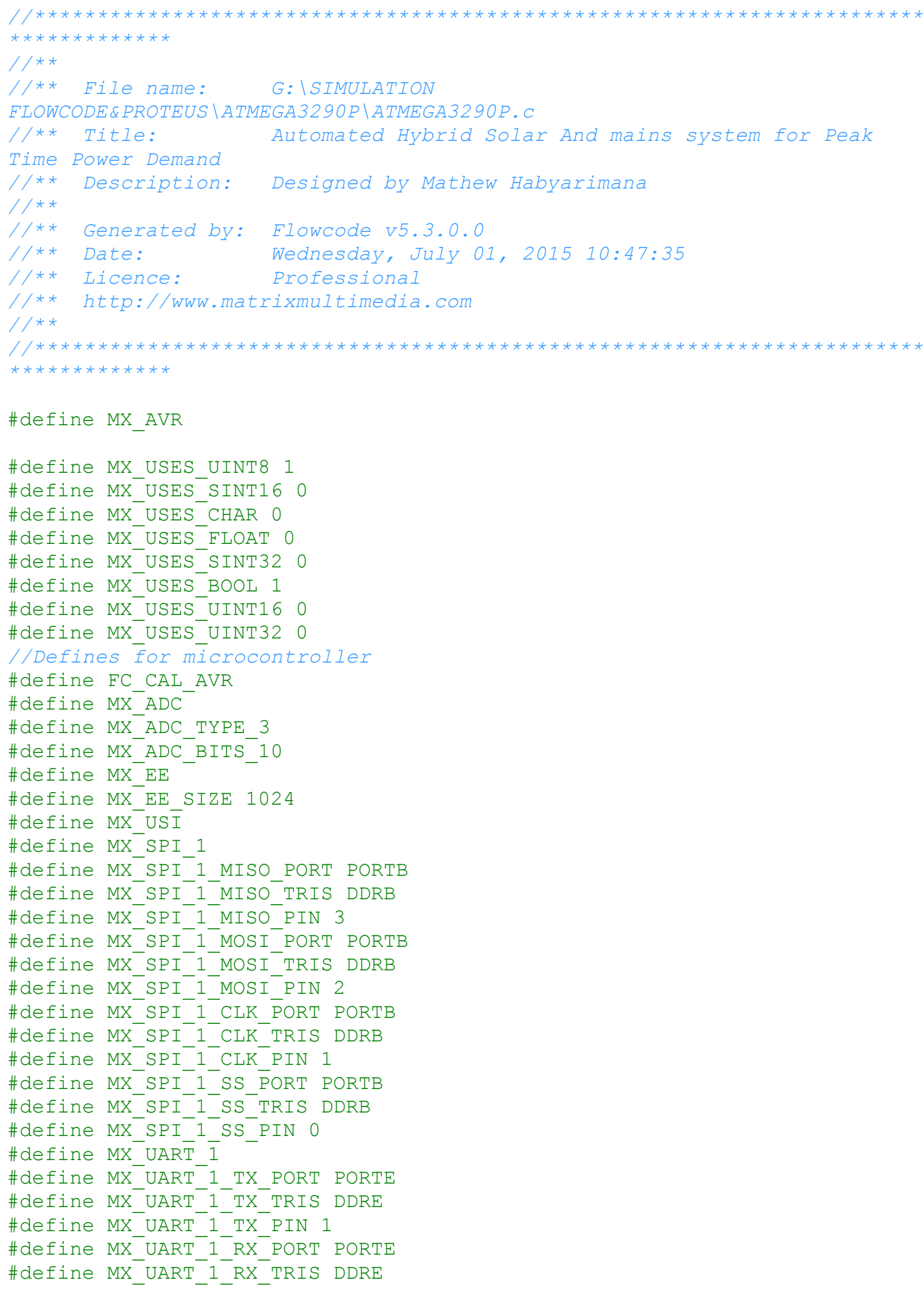




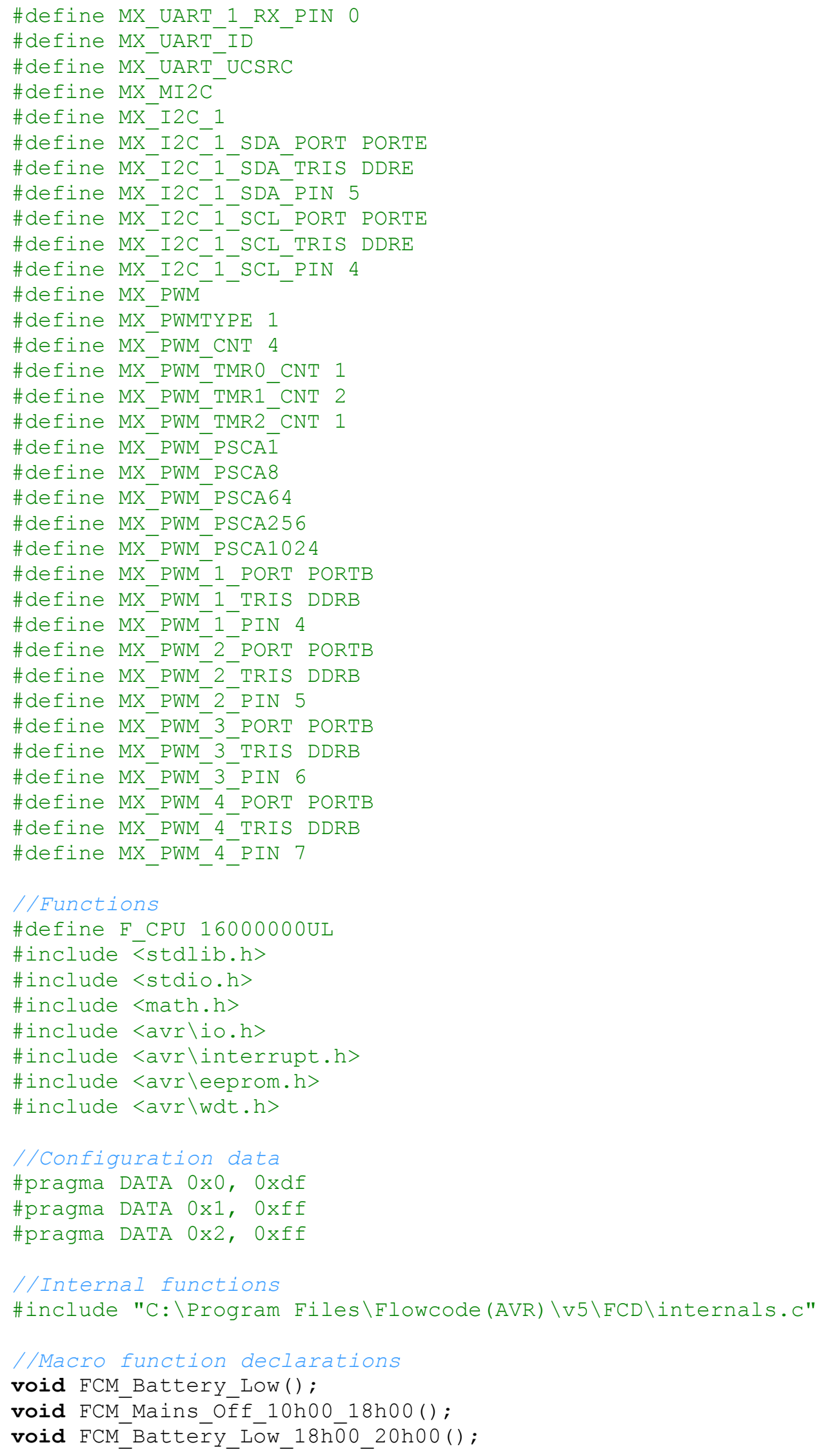


void FCM_Mains_off_20h00_07h00();
void FCM_Batterry_Low_At_07h00_10h00();
void FCM_Mains_Off_At_10h00_18h00();
void FCM_Battery_Low_At_18_ho0_20h00 ();
void FCM_Mains_Off_At_20h00_07h00 ();

/ Variable declarations

\#define FCV_TRUE (1)

\#define FCV FALSE (0)

volatile MX UINT8 FCV MAINS OFF $20 \mathrm{HOO}$ 07H00;

volatile MX UINT8 FCV MAINS ${ }^{-}$AT_ $20 \mathrm{HOO} \overline{0} 7 \mathrm{HOO}$;

volatile MX_UINT8 FCV_SOLAR_AT_07H00_10H00;

volatile MX UINT8 FCV_SOLAR_AT_18H00_20H00;

volatile MX_UINT8 FCV_PANEL_CLEANER;

volatile MX UINT8 FCV MAINS AT $10 \mathrm{HOO}$ 18H00;

volatile MX UINT8 FCV SOLAR FAŪLTY $1 \overline{8} \mathrm{H} 00$ 20HO0;

volatile MX UINT8 FCV_SOLAR_FAULTY_07H00_10H00;

volatile MX_UINT8 FCV_MAINS_FAULTY_10H00_18H00;

MX_UINT8 FCLV_LOOP1;

//LED(0): //Defines:

/**** Macro Substitutions ****

$a=$ Unique Reference

$b=$ LED Port Letter

$C=L E D$ Pin Number

$d=$ LED Active Polarity

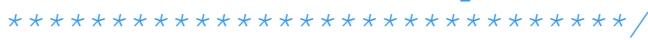

\#define LED_1 LED PORT portC

\#define LED_1-LED_TRIS trisC

\#define LED_1_LED_PIN 0

\#define LED_1_LED_POLE 1

//LED(O): //Macro function declarations

staticvoid FCD LEDO LEDOn();

staticvoid FCD_LEDO_LEDOff();

//LED(1): //Defines:

$/ * * * *$ Macro Substitutions ****
$a=$ Unique Reference
$b=$ LED Port Letter
$c=$ LED Pin Number
$d=$ LED Active POIarity
$\star * * * * * * * * * * * * * * * * * * * * * * * * * * * * * /$
\#define LED_2_LED_PORT portC 


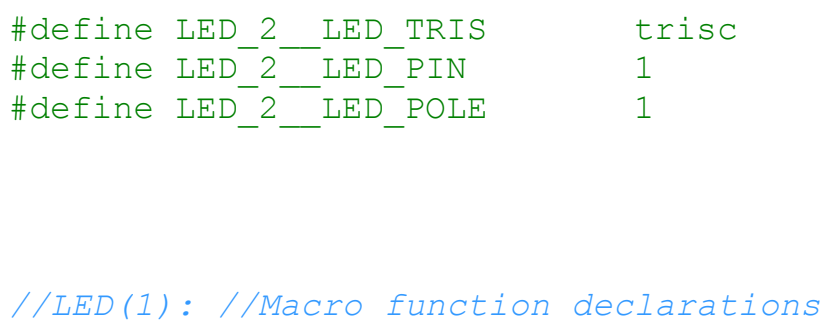




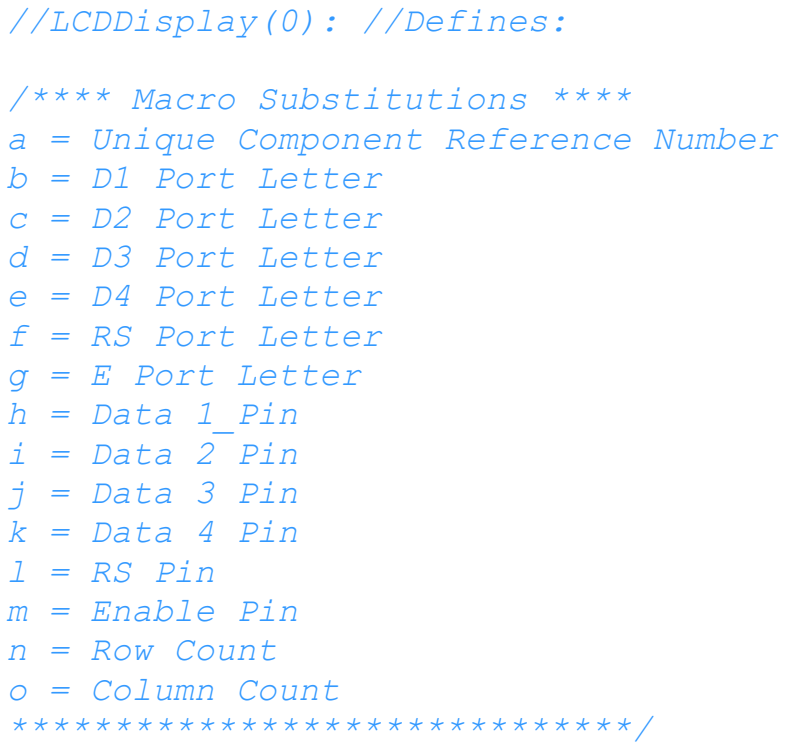




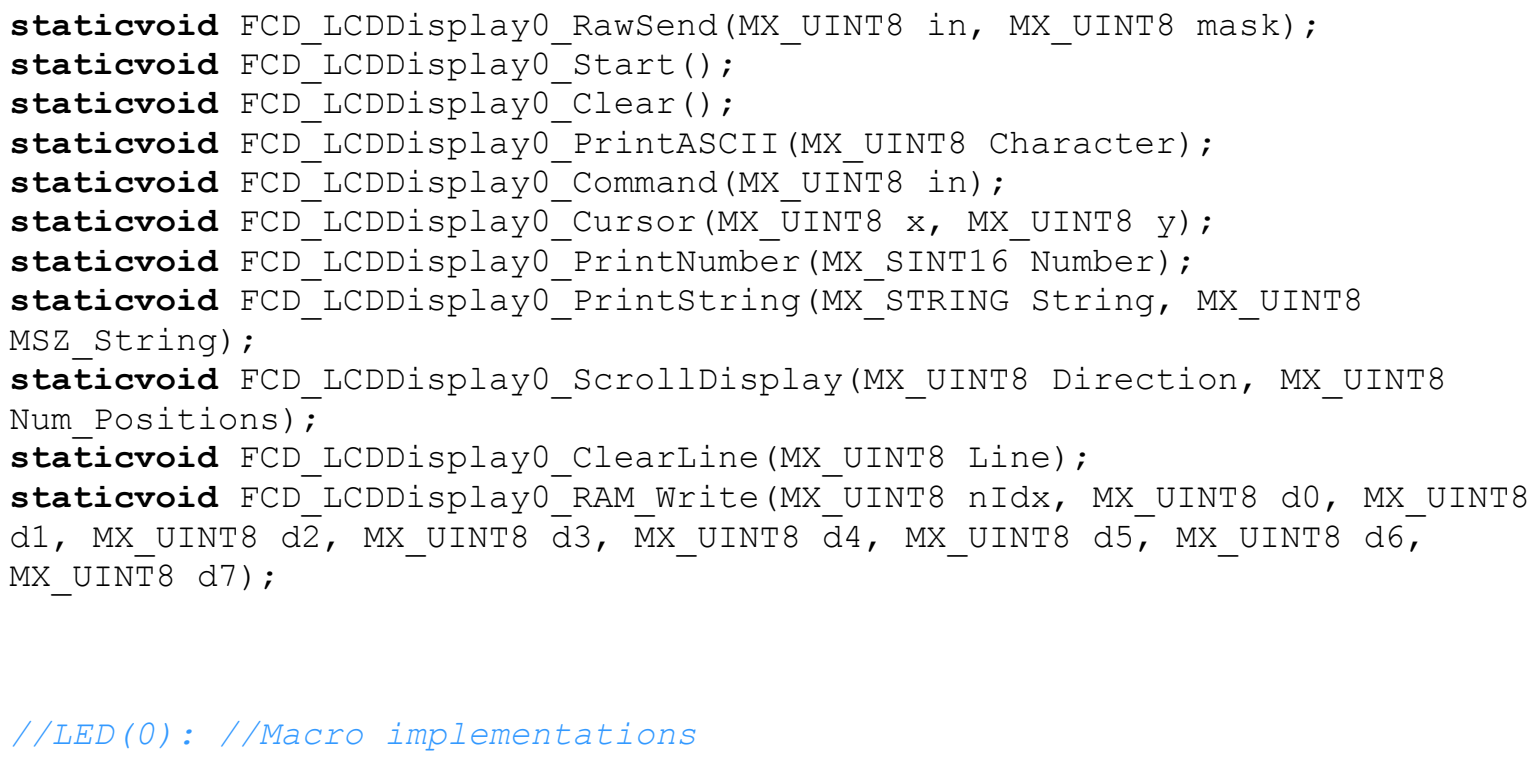


staticvoid FCD_LED1_LEDOn ()

\{

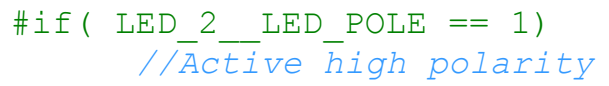




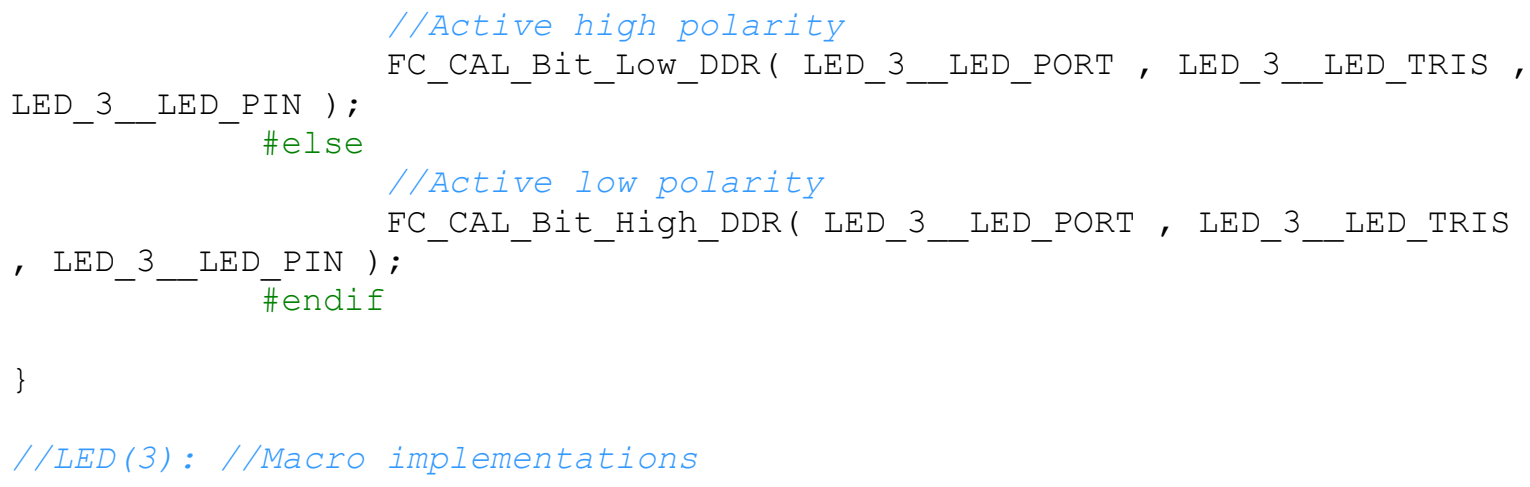

staticvoid FCD_LCDDisplay0_RawSend(MX_UINT8 in, MX_UINT8 mask) \{

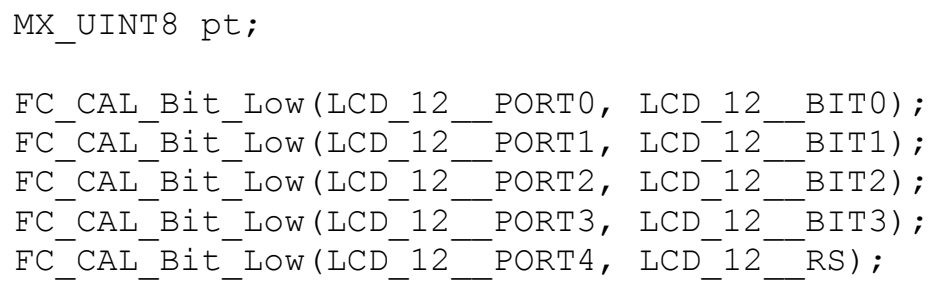




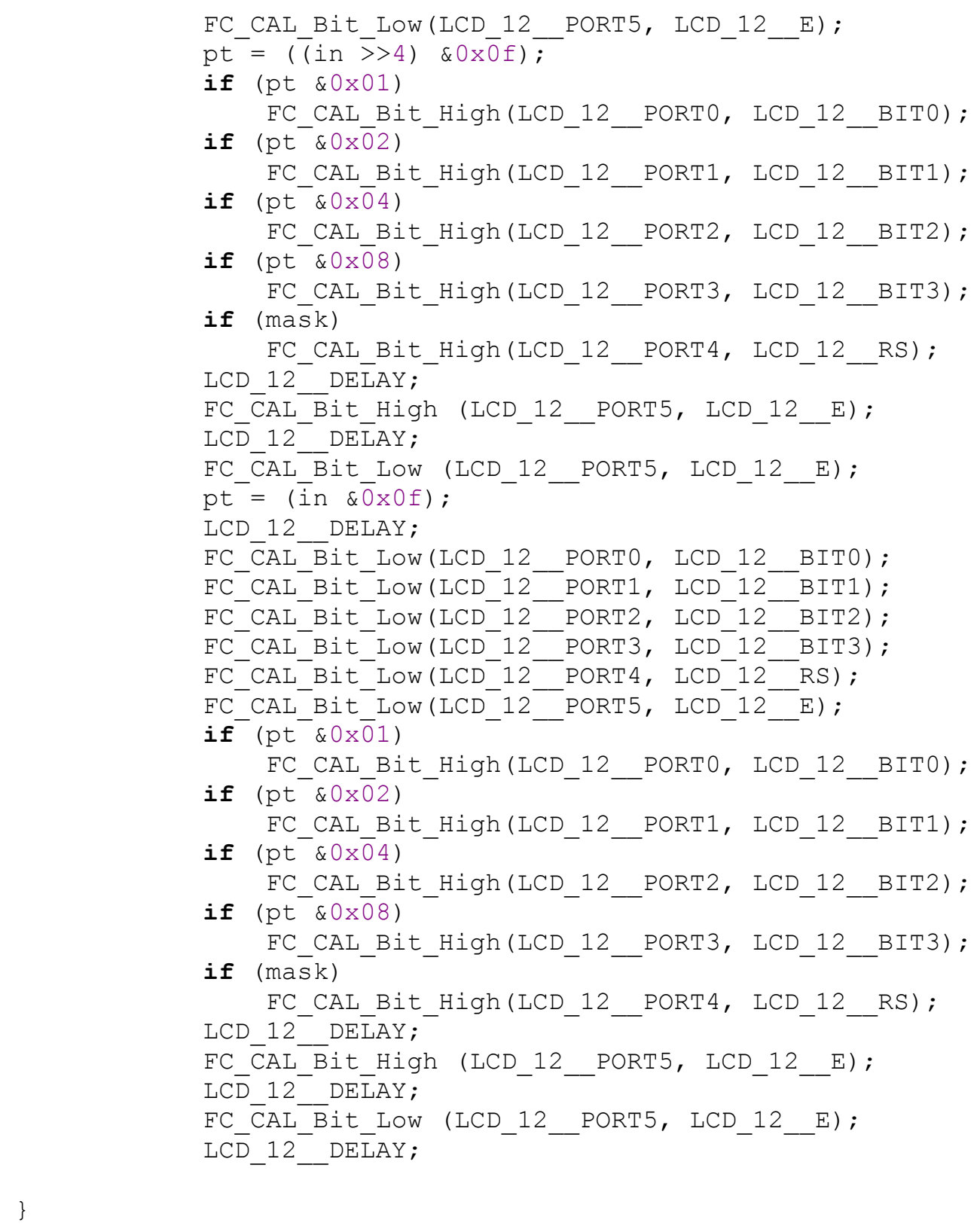

staticvoid FCD_LCDDisplayo_Start()

\{

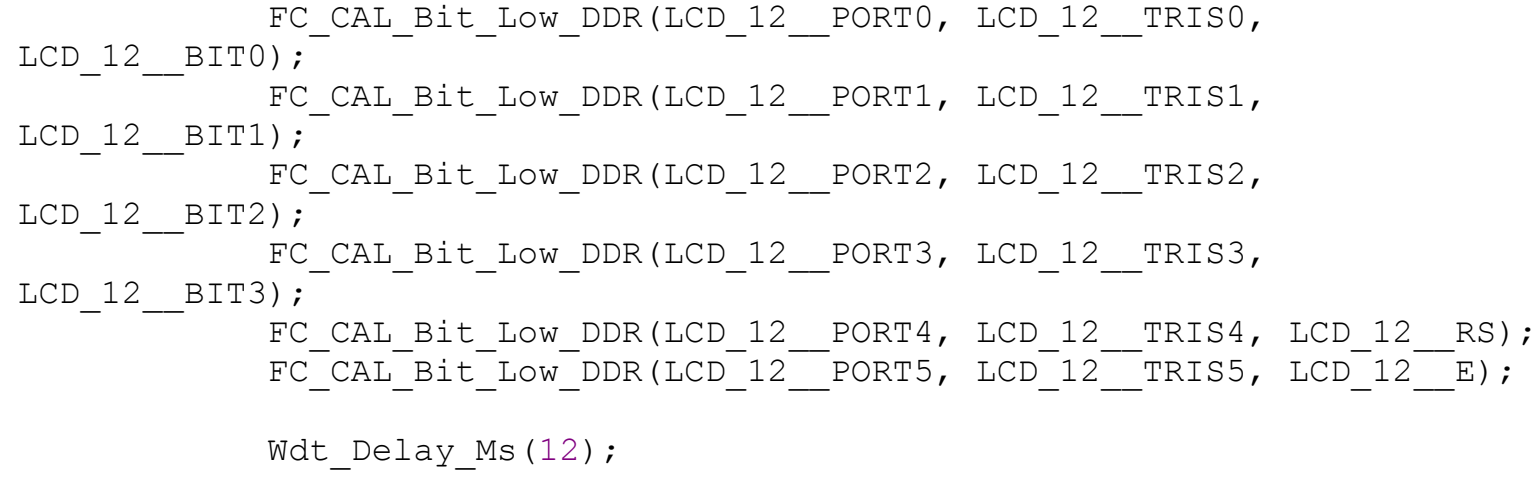




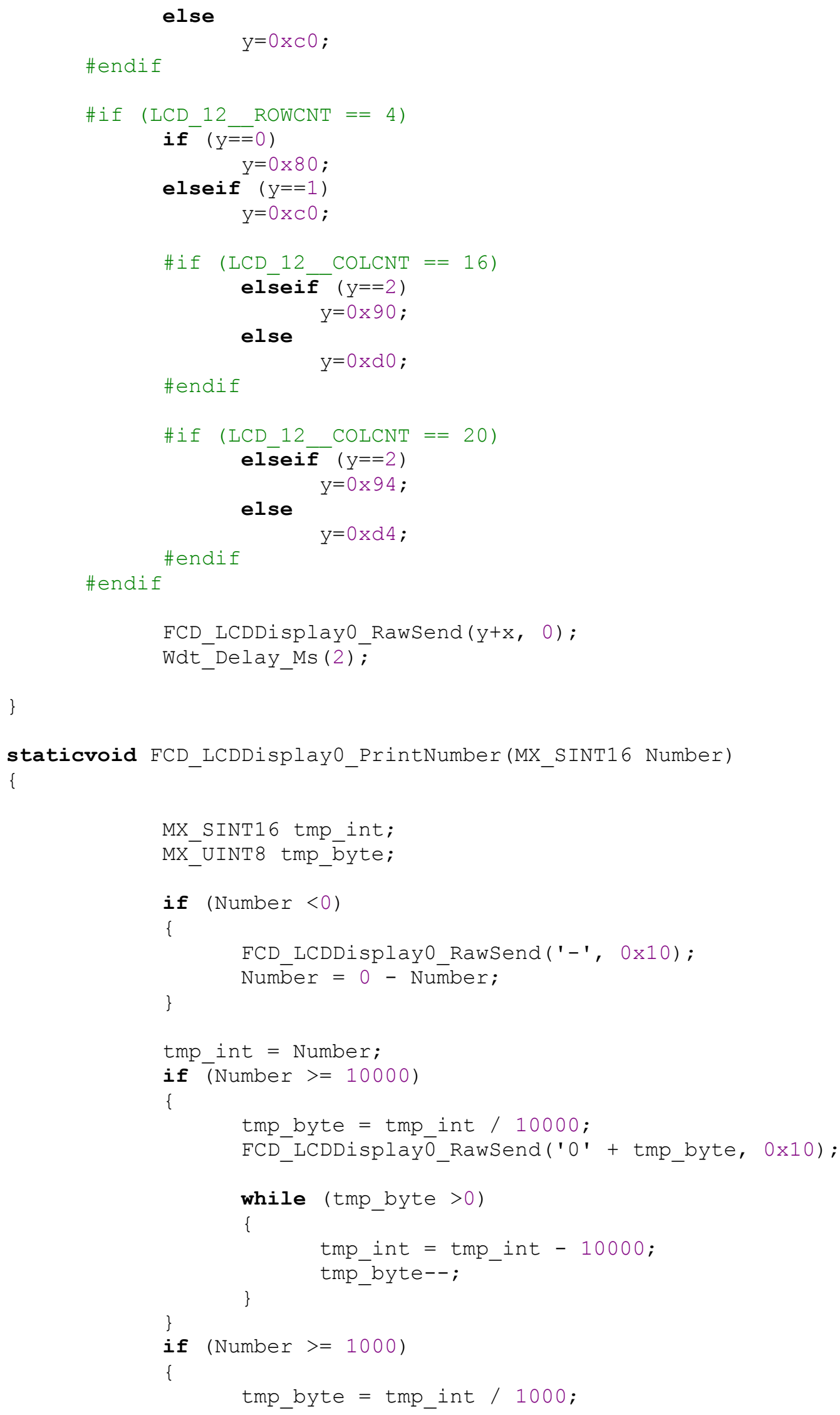




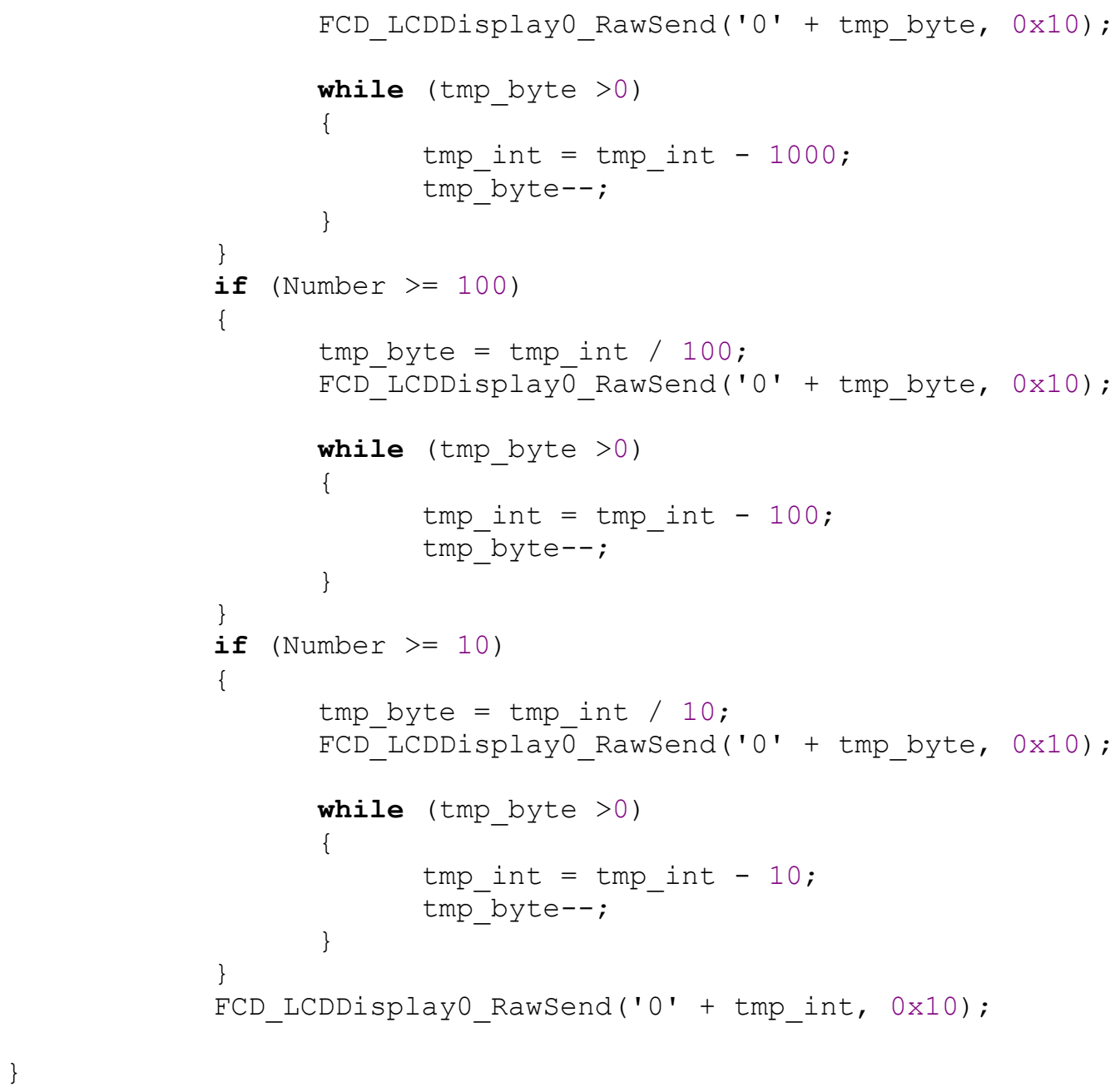




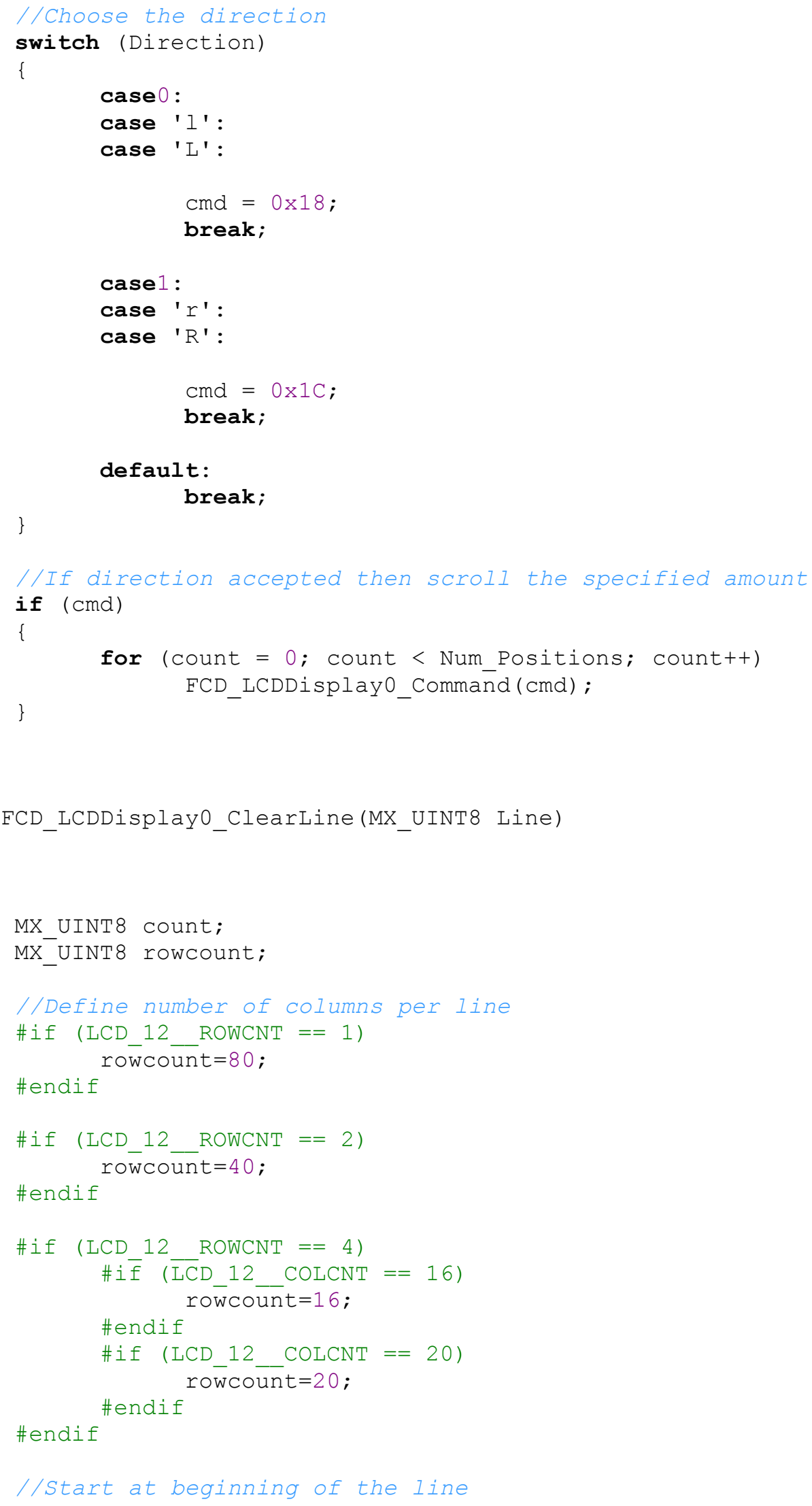




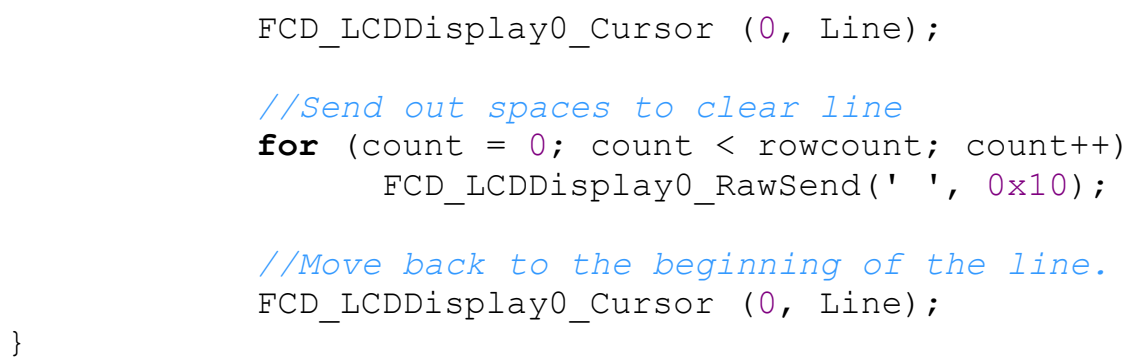


\}

void FCM_Battery_Low_18h00_20h00()

\{

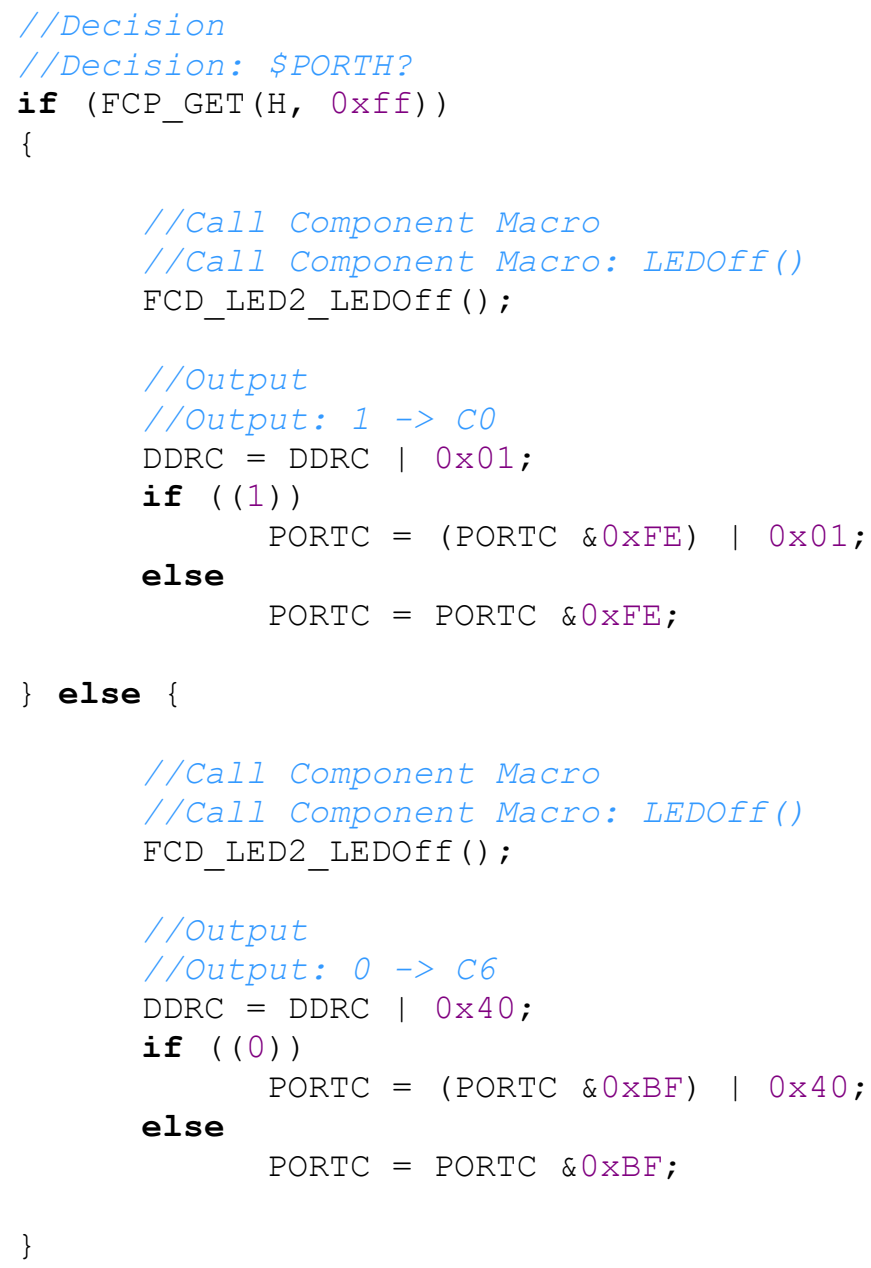


/ / Output

//Output: $1->C O$

$\mathrm{DDRC}=\mathrm{DDRC} \mid 0 \times 01$;

if ( (1))

else

PORTC $=($ PORTC \&OXEE $) \mid$ Ox01;

PORTC $=$ PORTC $\& O X F E ;$

\} else \{

//Call Component Macro

//Call Component Macro: LEDon()

FCD_LED3_LEDOn ();

loutput

//Output: $0 \rightarrow C 0$

$\mathrm{DDRC}=\mathrm{DDRC} \mid \mathrm{0x01}$;

if $((0))$

else

PORTC $=($ PORTC \&OXFE) $\mid$ OX01;

PORTC = PORTC \&OXFE;

\}

\}

void FCM_Batterry_Low_At_07h00_10h00()

\{

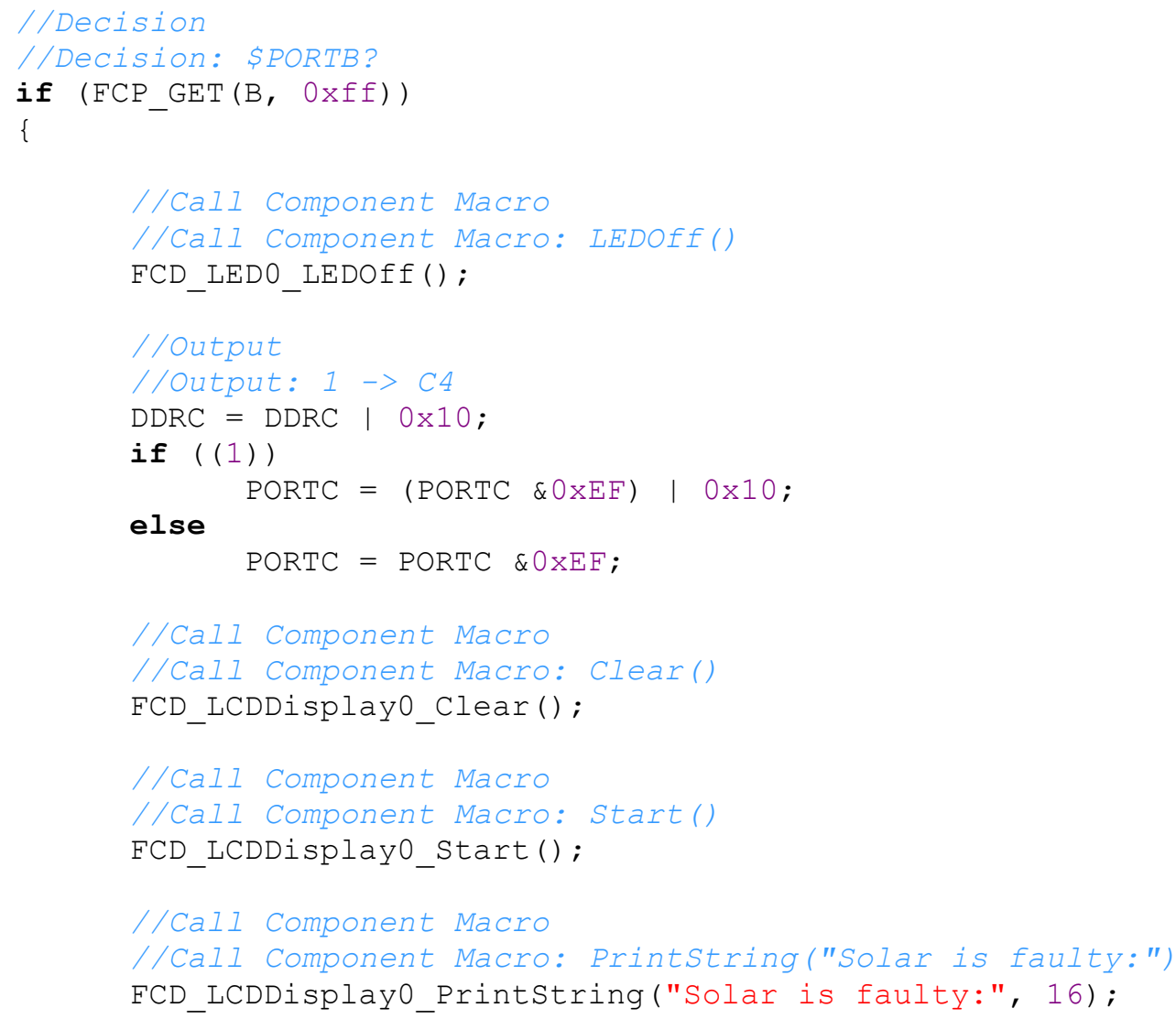




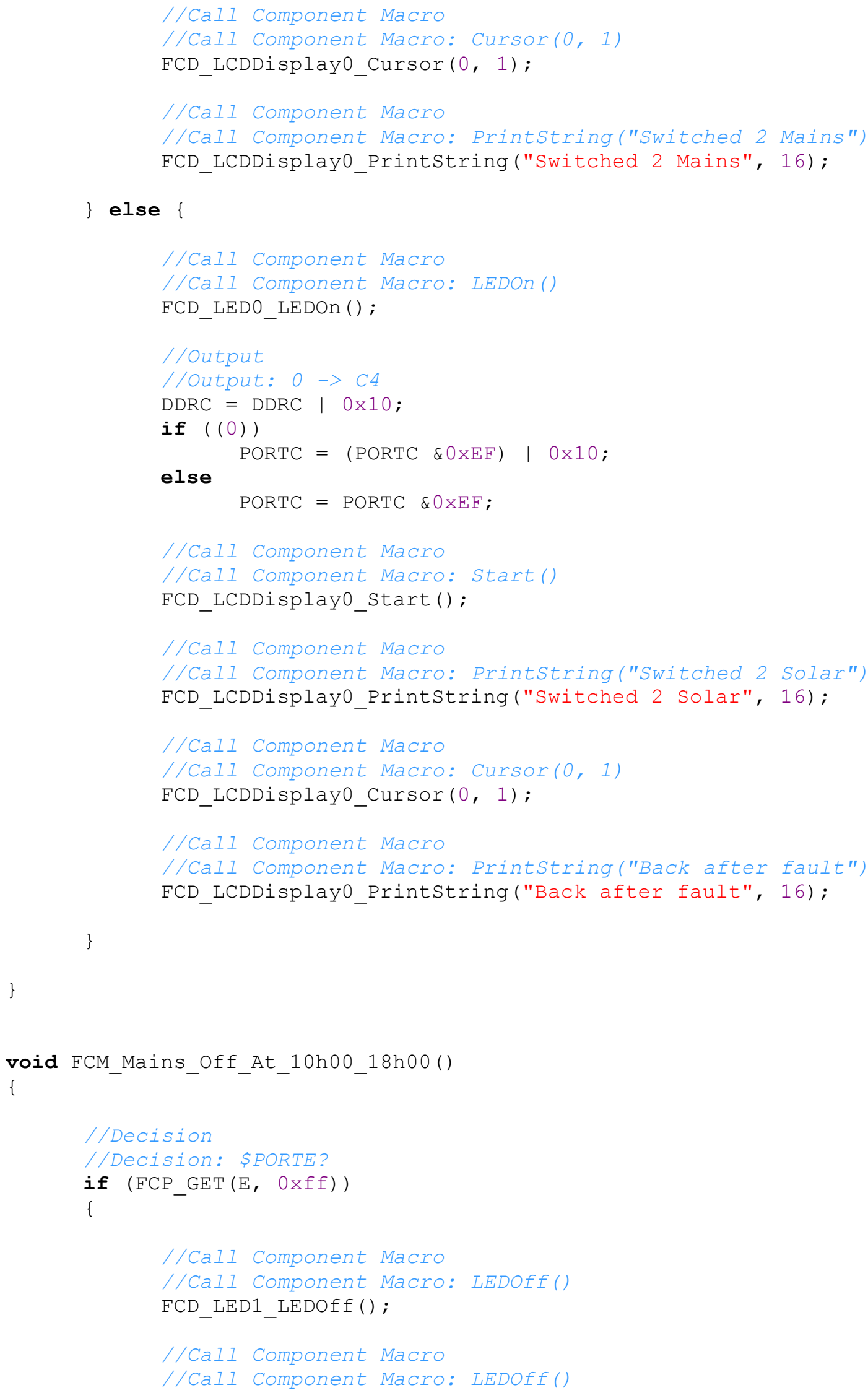




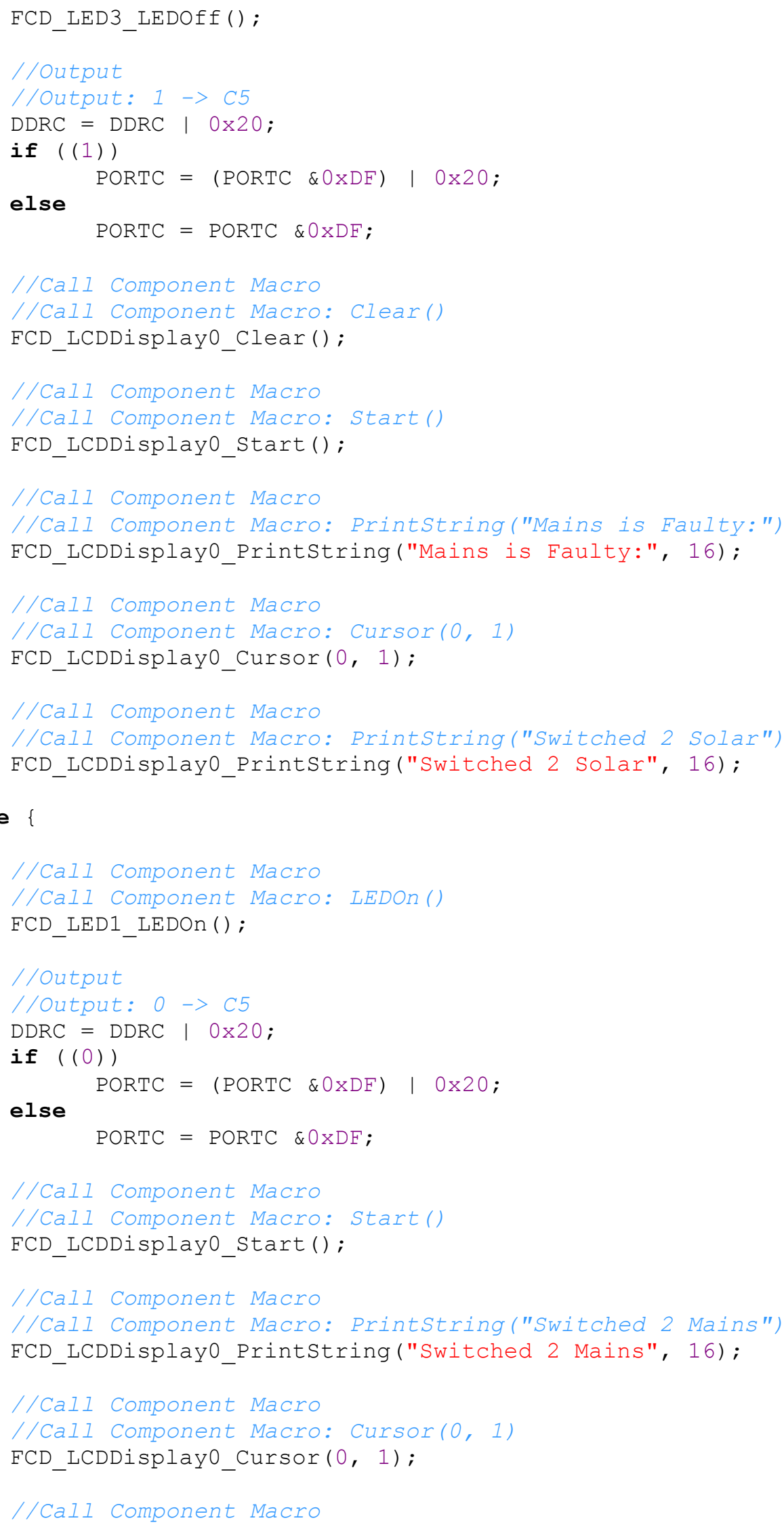


//Call Component Macro: PrintString("Back after fault") FCD_LCDDisplay0_PrintString("Back after fault", 16);

\}

\}

void FCM_Battery_Low_At_18_h00_20h00()

\{

//Decision

//Decision: \$PORTH?

if (FCP_GET (H, Oxff))

\{

//Call Component Macro

//Call Component Macro: LEDOff()

FCD_LED2_LEDOff ( ) ;

loutput

//Output: $1->C 6$

$\mathrm{DDRC}=\mathrm{DDRC} \mid 0 \times 40 ;$

if ( (1))

$\mathrm{PORTC}=(\mathrm{PORTC} \& 0 \times \mathrm{BF}) \mid 0 \times 40 ;$

else

PORTC $=$ PORTC $\& 0 \times B F ;$

//Call Component Macro

//Call Component Macro: Clear()

FCD_LCDDisplay0_Clear () ;

//Call Component Macro

//Call Component Macro: Start()

FCD_LCDDisplayo_Start();

//Call Component Macro

//Call Component Macro: Printstring("Solar is faulty:")

FCD_LCDDisplayo_PrintString("Solar is faulty:", 16) ;

//Call Component Macro

//Call Component Macro: Cursor (0, 1)

FCD_LCDDisplayo_Cursor $(0,1)$;

//Call Component Macro

//Call Component Macro: PrintString("Switched 2 Mains")

FCD_LCDDisplay0_PrintString("Switched 2 Mains", 16);

\} else \{

//Call Component Macro

//Call Component Macro: LEDOn()

FCD_LED2_LEDOn ( ) ;

l output

/Output: $0->C 6$

DDRC $=$ DDRC $\mid 0 \times 40 ;$ 


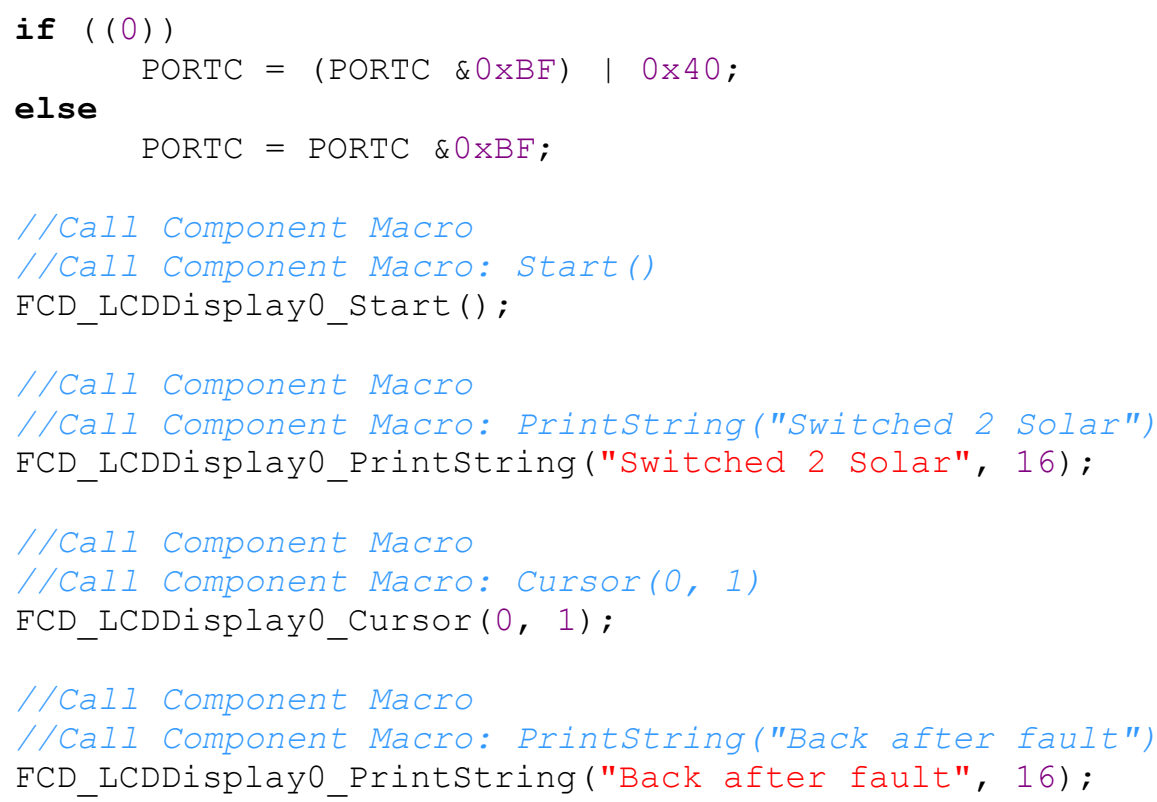




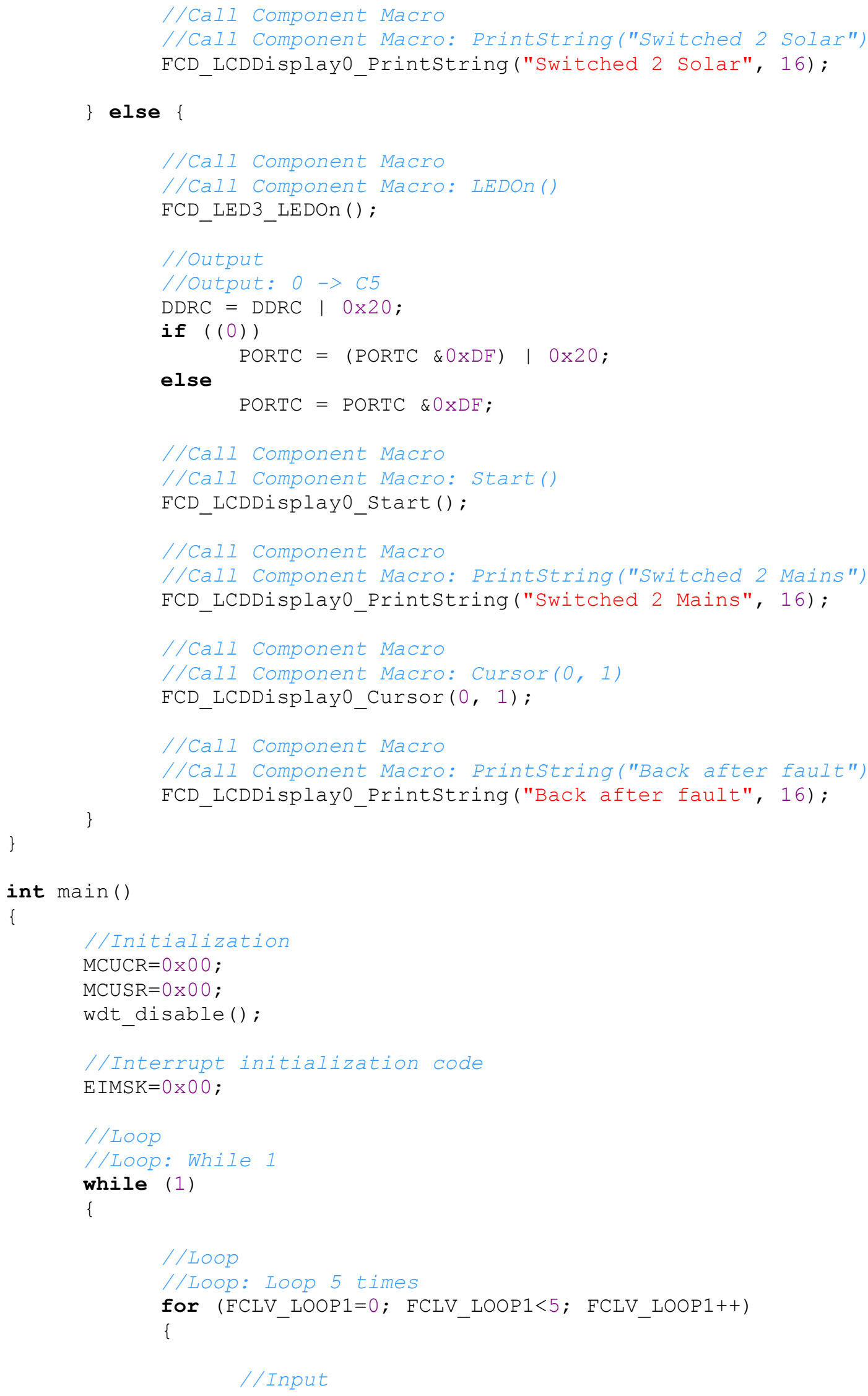




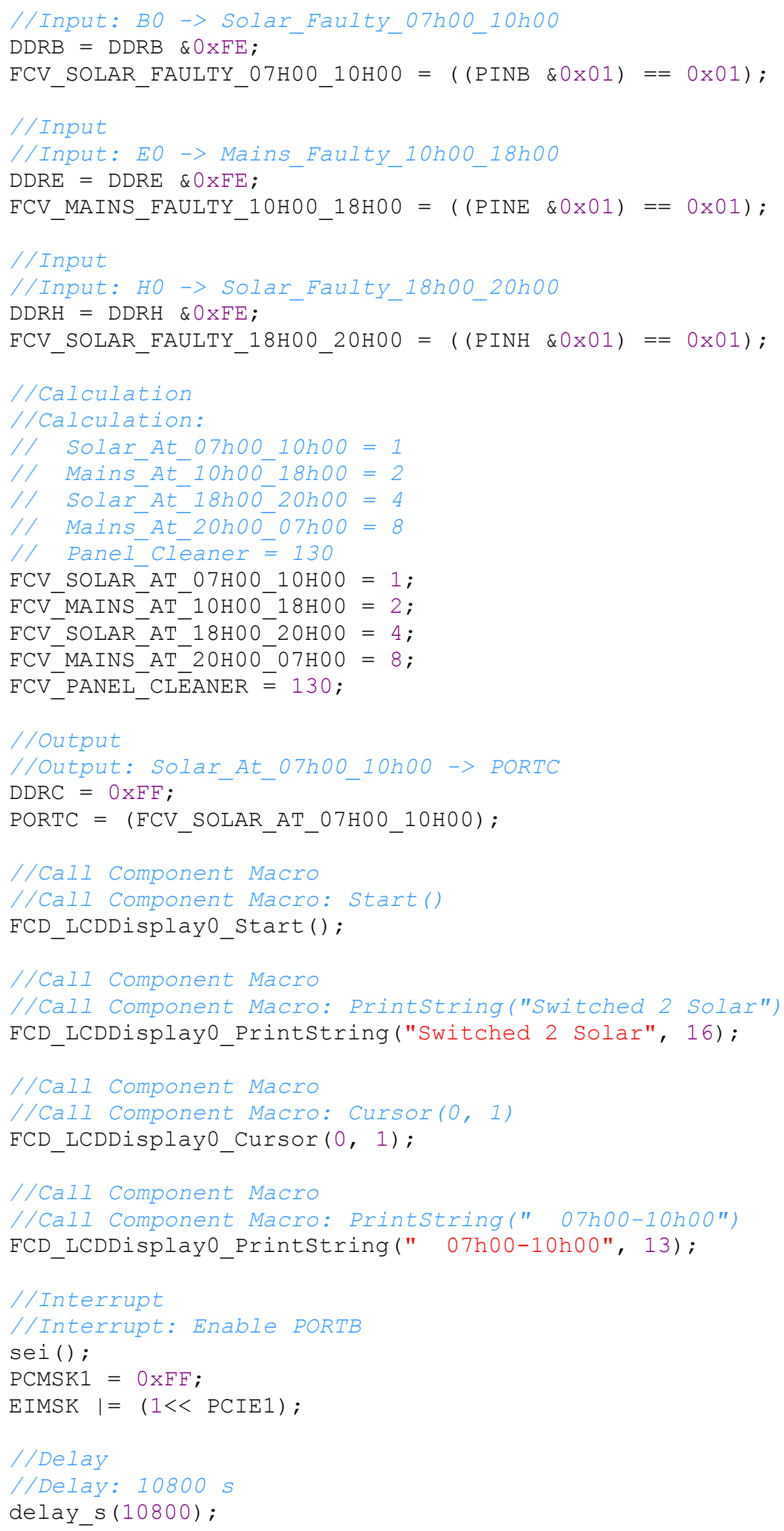




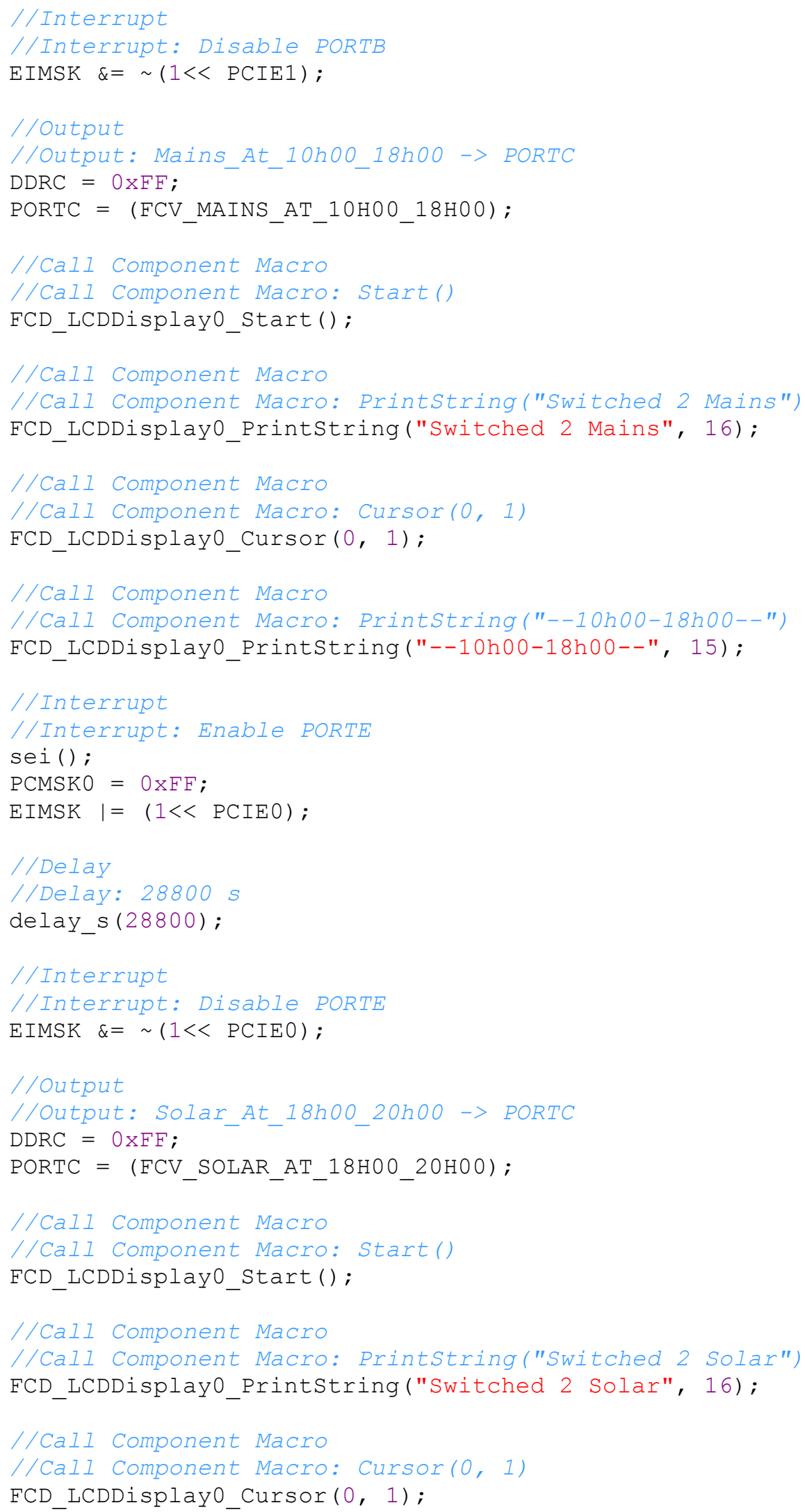




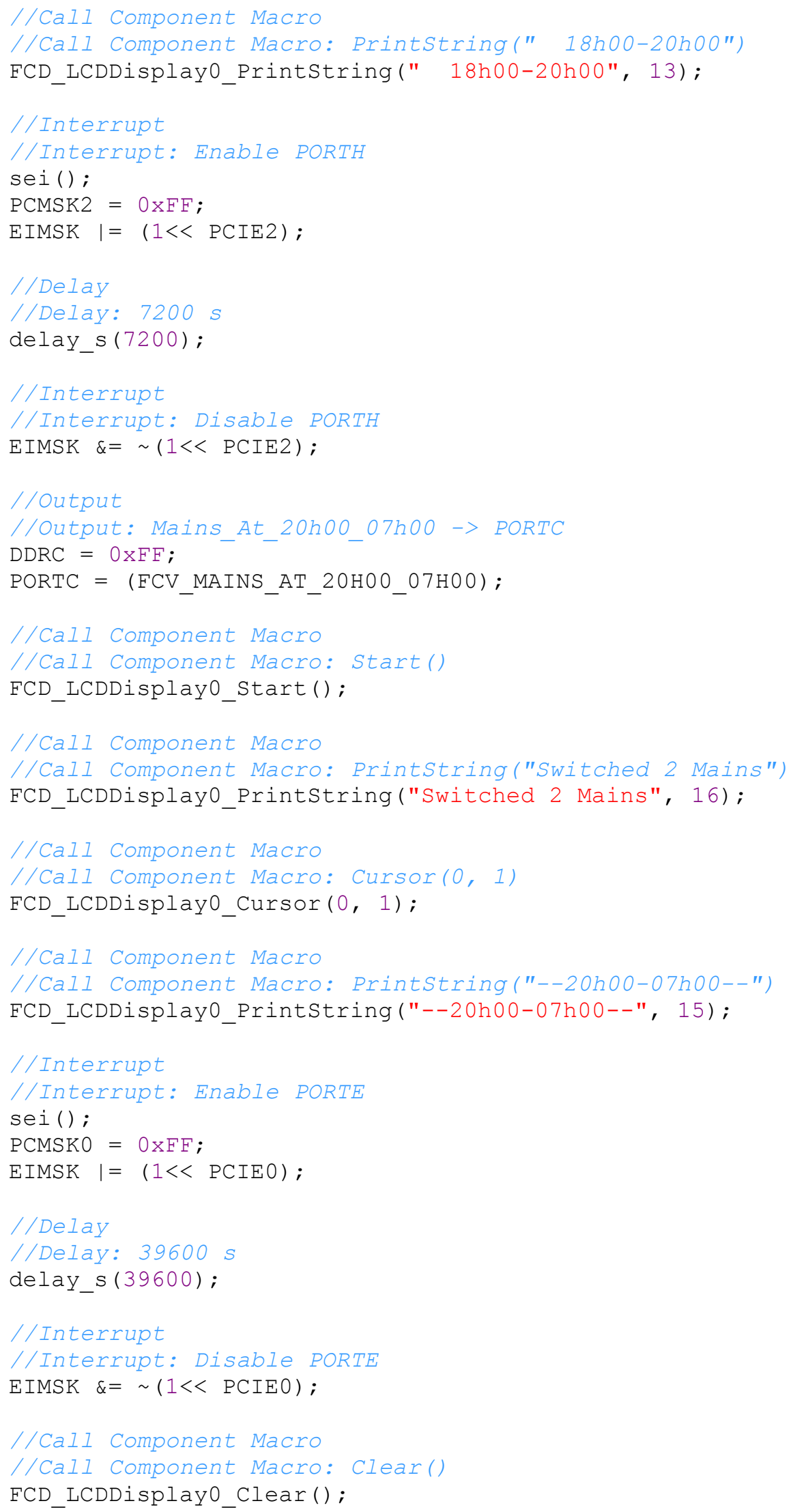




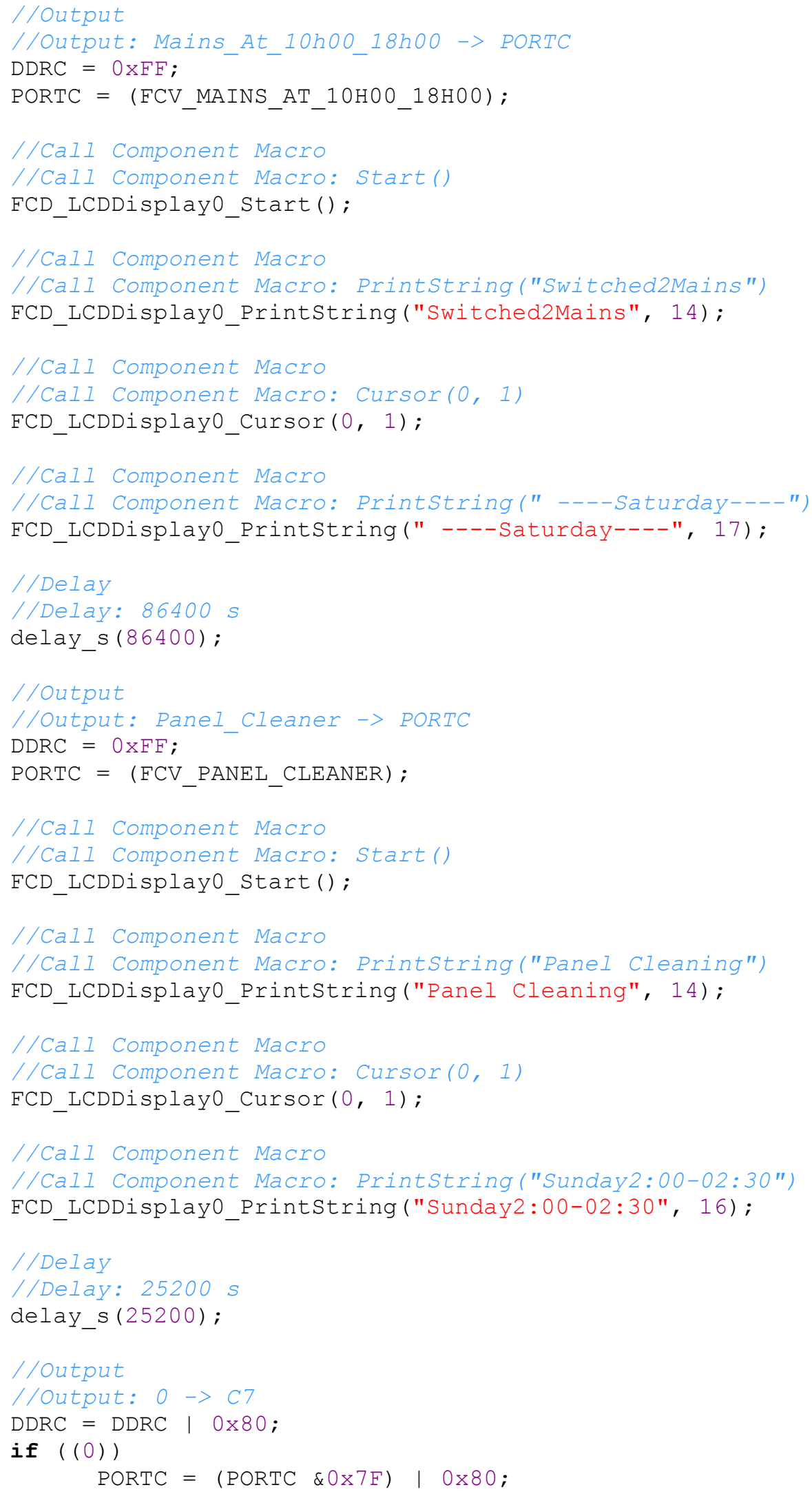




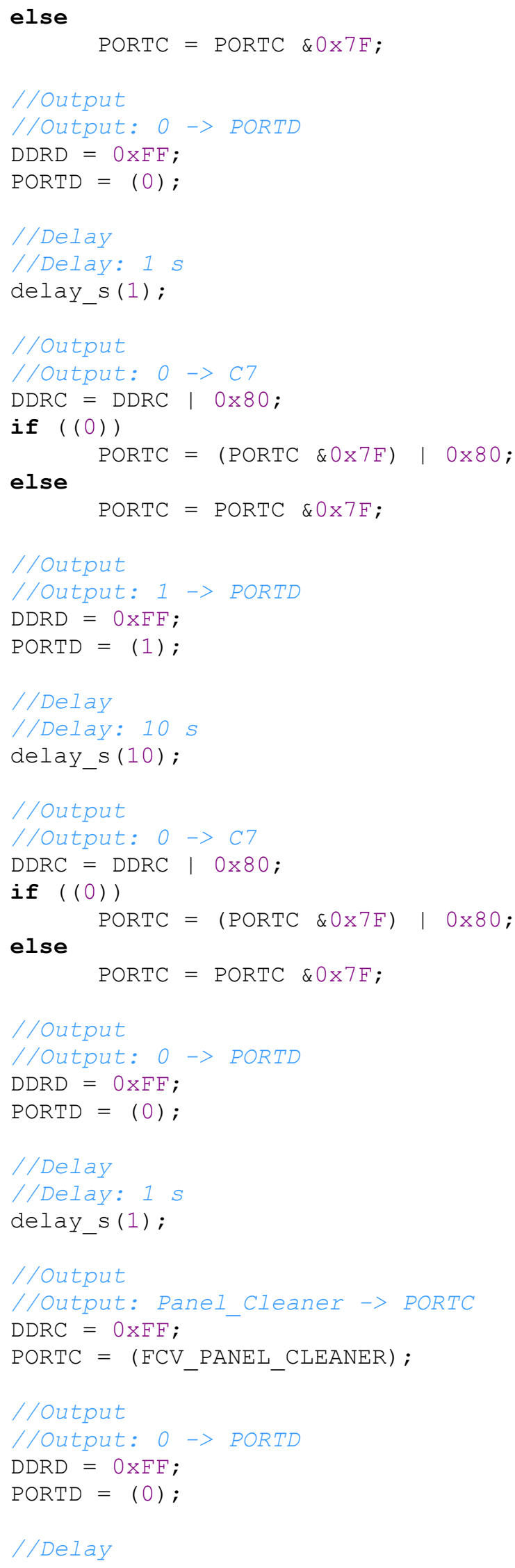




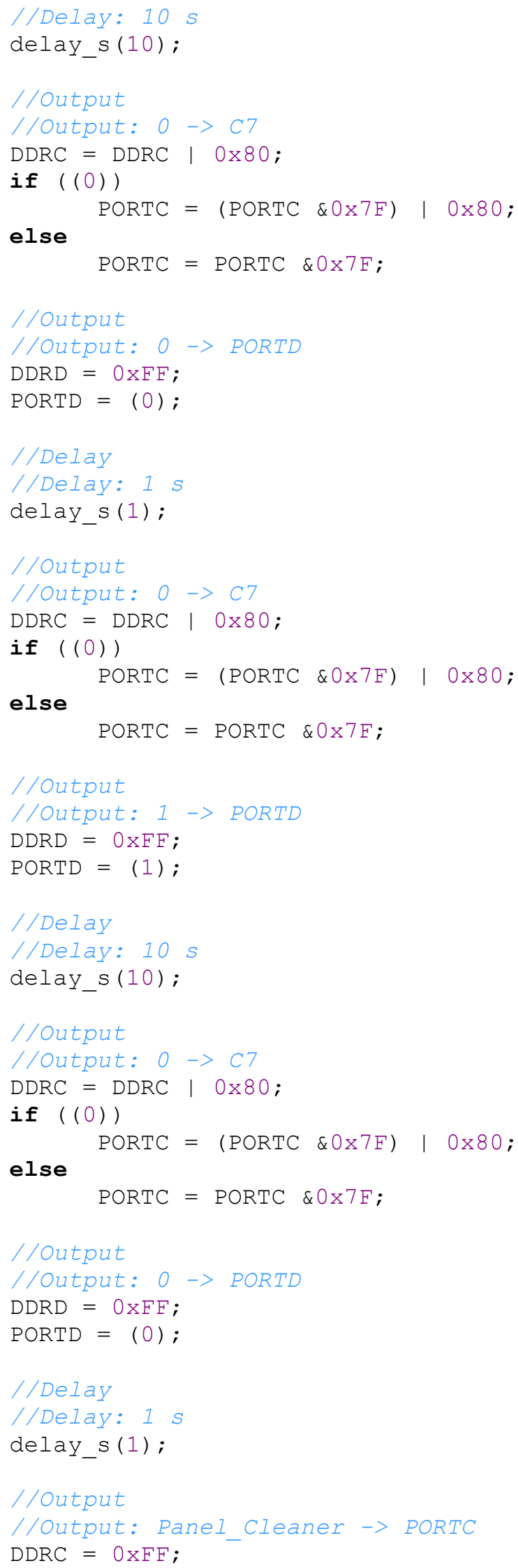




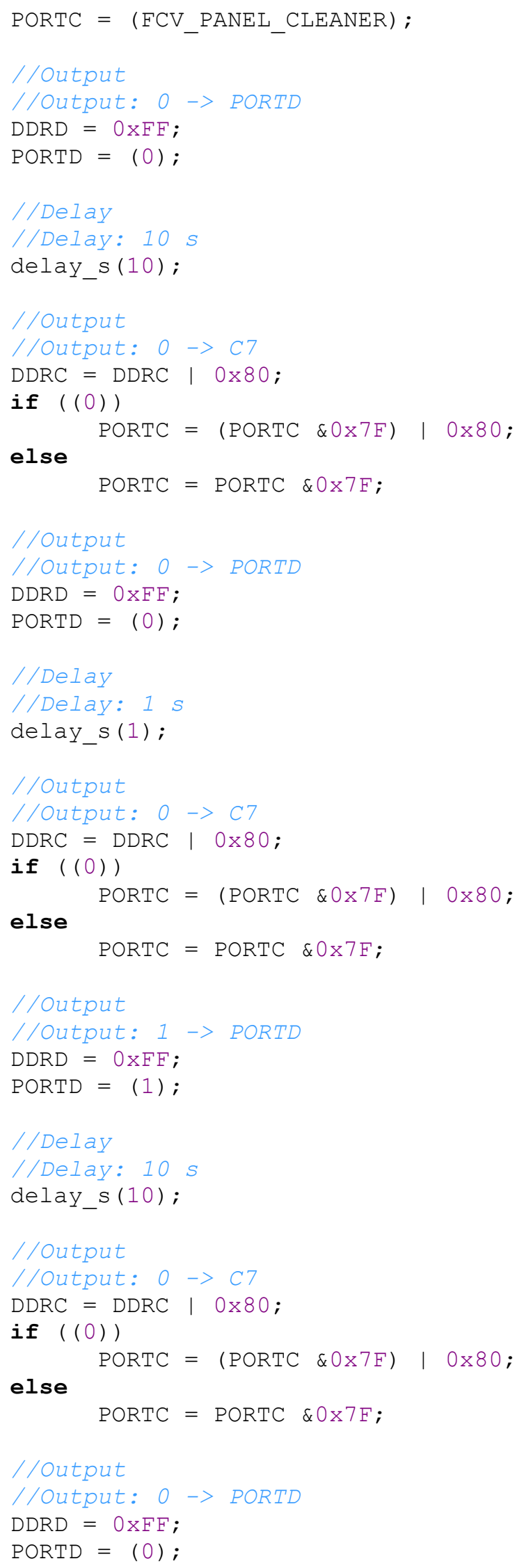




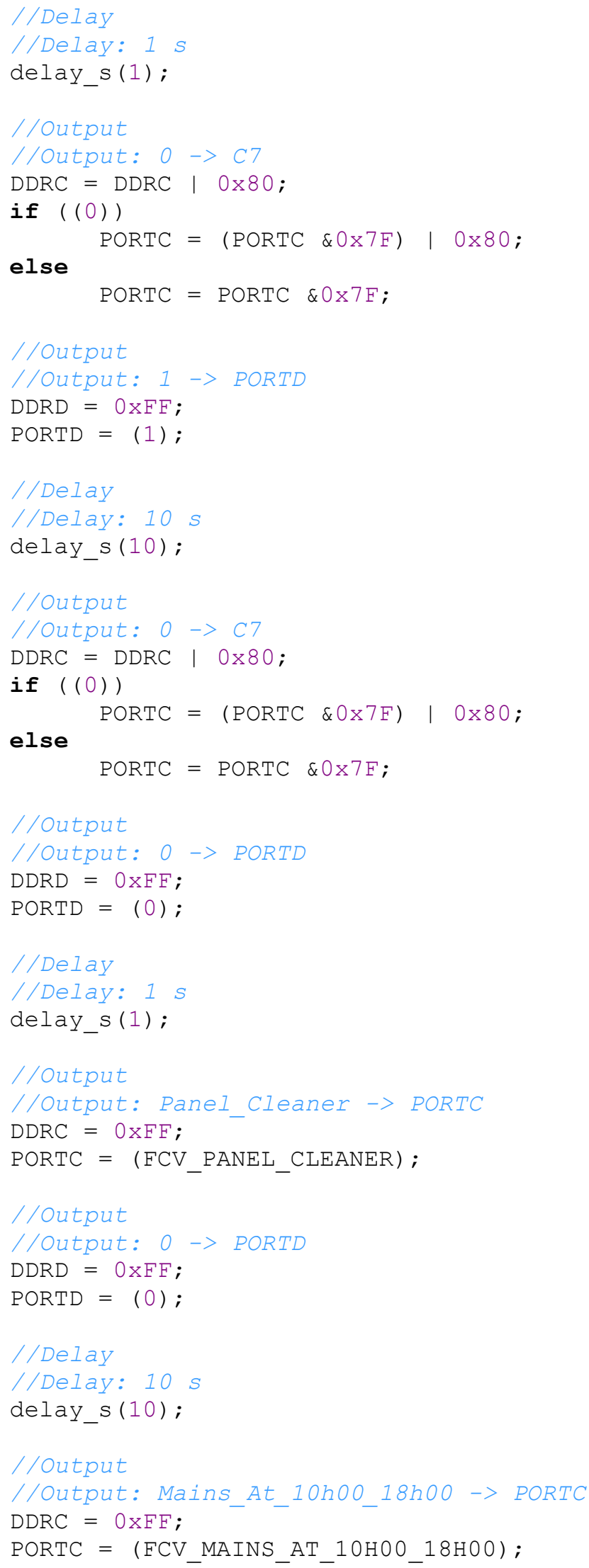




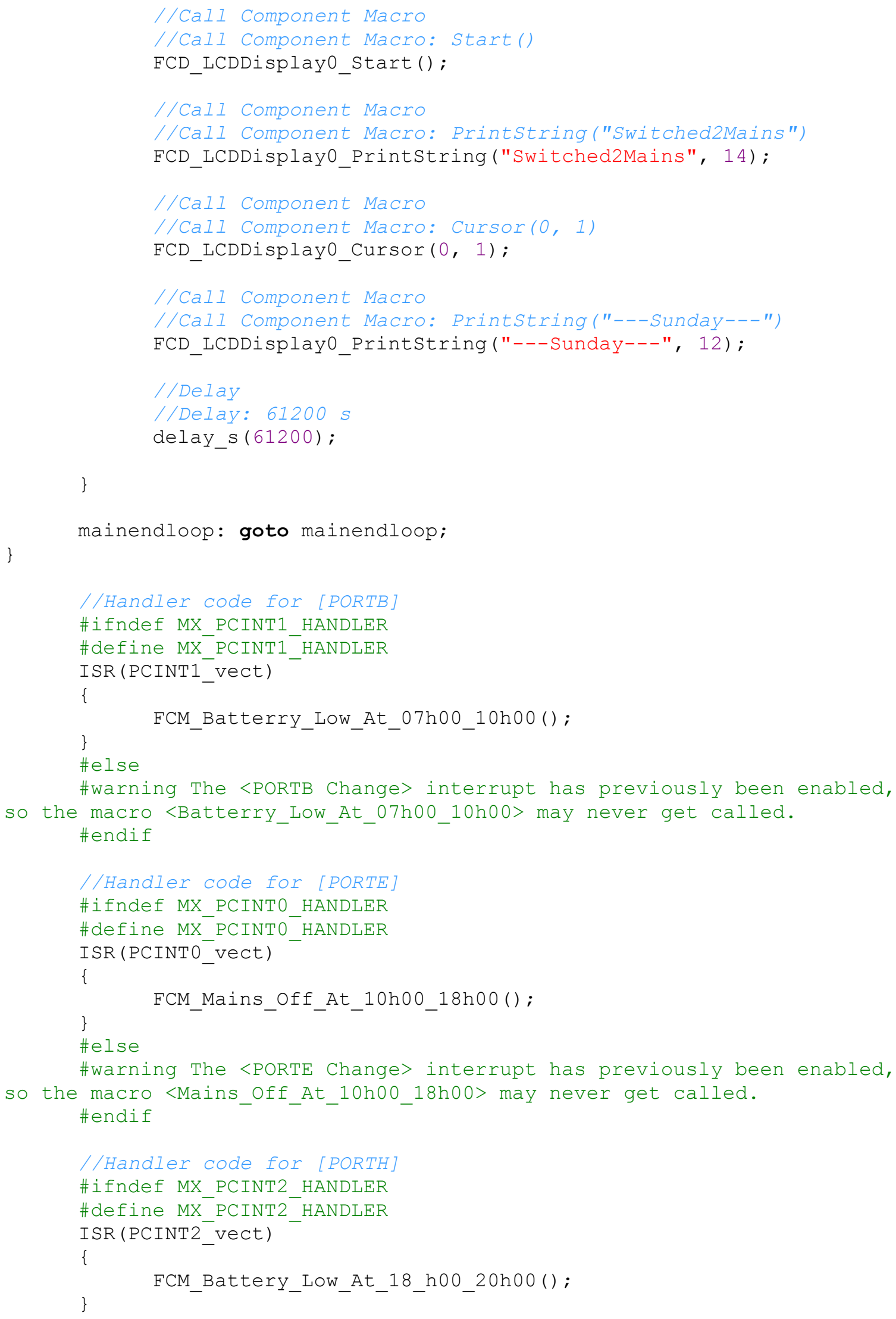


\#else

\#warning The <PORTH Change> interrupt has previously been enabled,

so the macro<Battery_Low_At_18_h00_20h00> may never get called.

\#endif

//Handler code for [PORTE]

\#ifndef MX PCINTO HANDLER

\#define MX PCINTO HANDLER

ISR (PCINTO_vect)

\{

\}

FCM_Mains_off_At_20h00_07h00();

\#else

\#warning The <PORTE Change> interrupt has previously been enabled, so the macro <Mains_off_At_20h00_07h00> may never get called.

\#endif 


\section{REFERENCES}

[1] T. Gonen, "Electric power distribution engineering," 2014.

[2] C. Bayliss, C. R. Bayliss, and B. J. Hardy, Transmission and distribution electrical engineering: Elsevier, 2012.

[3] S. Bhattacharya, Basic Electrical And Electronics Engineering I (For Wbut): Pearson Education India, 2010.

[4] C. Philibert, "Case study 1: concentrating solar power technologies. International Energy Technology Collaboration and Climate Change Mitigation," ed: OECD Environmental Directorate, IEA, Paris, 2004.

[5] L. Schipper and S. Meyers, Energy efficiency and human activity: past trends, future prospects: Cambridge University Press, 1992.

[6] F. Cain, "Life of the Sun," in Universe today, ed. USA: NASA, March, 2012.

[7] InstituteforEnergyResearch. (27/12/2014). Electricity Generation. Available: http://instituteforenergyresearch.org/electricity-generation

[8] D. Hohm and M. Ropp, "Comparative study of maximum power point tracking algorithms using an experimental, programmable, maximum power point tracking test bed," in Photovoltaic specialists conference, 2000. Conference record of the twenty-eighth IEEE, 2000, pp. 1699-1702.

[9] A. M. Zacharias and T. R. Devaprakash, "Modeling and simulation of photovoltaic system with soft switching SEPIC converter," in Emerging Research Areas: Magnetics, Machines and Drives (AICERA/iCMMD), 2014 Annual International Conference on, 2014, pp. 1-6.

[10] M. Bodur and M. Ermiş, "Maximum power point tracking for low power photovoltaic solar panels," in Electrotechnical Conference, 1994. Proceedings., 7th Mediterranean, 1994, pp. 758-761.

[11] J. Lee, Advanced Electrical and Electronics Engineering: Springer, 2011.

[12] S. Dixit, A. Tripathi, V. Chola, and H. P. I. Power, "800VA Pure Sine Wave Inverter's Reference Design," Texas Instruments Application Report SLAA-602, 2013.

[13] M. Boxwell, Solar Electricity Handbook: A Simple, Practical Guide to Solar Energy: how to Design and Install Photovoltaic Solar Electric Systems: Greenstream Publishing, 2012.

[14] F. CAIN, "How Long Does it Take Sunlight to Reach the Earth?," Universe Today, Utah2013.

[15] T. W. W. SCHOOL, "www.theweatherwiz.com," ed, 2015. 
[16] N. R. S. Tutorial, "National Snow \& Ice Data Center," in All About Frozen Ground, ed: National Snow and Ice Data Center (NSIDC), 2008.

[17] E. Burt, P. Orris, and S. Buchanan, "Scientific Evidence of Health Effects from Coal Use in Energy Generation," Chicago and Washington: School of Public Health, University of Illinois and Health Care Without Harm, 2013.

[18] P. Zhang, A Guide to Second Generation Options vol. 2: World Scientific, 1998.

[19] DWAF, "Olifants River Water Resources Development Project Environmental Authorisation Screening Investigation," vol. Department of Water resources and Forestry Report No. P WMA 04/B50/00/1904, Oct 25, 2004 2004a.

[20] T. Dahl, "Photovoltaic Power Systems- Technology white paper," pp. 1-33, 2004.

[21] S. Collavini, S. F. Völker, and J. L. Delgado, "Understanding the Outstanding Power Conversion Efficiency of Perovskite-Based Solar Cells," Angewandte Chemie International Edition, vol. 54, pp. 9757-9759, 2015.

[22] C. V. Nayar, "A Solar/Mains/Diesel Hybrid Uninterrupted Power System A Project Implemented in India," ANZSES Solar, vol. 97, 1997.

[23] M. A. Green, "Crystalline and thin-film silicon solar cells: state of the art and future potential," Solar energy, vol. 74, pp. 181-192, 2003.

[24] M. Ross and J. Royer, "Photovoltaics in Cold Climates," The SolarResource in Cold Climates. London: James \& James. Chapter 3. Perers, Bengt., 1999.

[25] R. Q. Fox, "Time dependent power demand control method," ed: Google Patents, 1979.

[26] H.-R. Wenk and A. Bulakh, Minerals: their constitution and origin: Cambridge University Press, 2004.

[27] A. Kojima, K. Teshima, Y. Shirai, and T. Miyasaka, "Organometal halide perovskites as visible-light sensitizers for photovoltaic cells," Journal of the American Chemical Society, vol. 131, pp. 6050-6051, 2009.

[28] T. Mali, "Energy in South Africa based on South Africa National Energy Development Institute (SANEDI) presentation German Academic Exchange Service (DAAD) at UKZN " March 6, 20132013.

[29] SolaireGuide. (2015). Montage des panneaux solaires : intégrés, surimposés ou au sol? Available: http://www.solaire-guide.fr/03/panneaux-solaires-integres-surimposes-sol/

[30] Trinitysolar. (2012). What type of solar module mounting structure should I use? (macrocyber.com ed.). Available: http://www.trinitysolar.com/index.php?option $=$ com content\&view $=$ article \&id $=11$ : whattype-of-solar-module-mounting-structure-should-i-use $\&$ catid=9\&Itemid=208 
[31] AtlantechSolarInc. (2009). Types of Photovoltaic Solar Mounting Systems - 5 Common Mounting Systems.

Available: http://www.atlantechsolar.com/photovoltaic_solar_mounting_systems.html

[32] A. M. Pavan, A. Mellit, and V. Lughi, "Explicit empirical model for general photovoltaic devices: Experimental validation at maximum power point," Solar Energy, vol. 101, pp. 105116, 2014.

[33] K. Hussein, I. Muta, T. Hoshino, and M. Osakada, "Maximum photovoltaic power tracking: an algorithm for rapidly changing atmospheric conditions," IEE Proceedings-Generation, Transmission and Distribution, vol. 142, pp. 59-64, 1995.

[34] Melanie. (2015). Blue sky energy. Available: http://www.blueskyenergyinc.com/

[35] M. S. Ngan and C. W. Tan, "A study of maximum power point tracking algorithms for standalone photovoltaic systems," in Applied Power Electronics Colloquium (IAPEC), 2011 IEEE, 2011, pp. 22-27.

[36] C. Hua and C. Shen, "Comparative study of peak power tracking techniques for solar storage system," in Applied Power Electronics Conference and Exposition, 1998. APEC'98. Conference Proceedings 1998., Thirteenth Annual, 1998, pp. 679-685.

[37] T. Esram and P. L. Chapman, "Comparison of photovoltaic array maximum power point tracking techniques," IEEE Transactions on Energy Conversion EC, vol. 22, p. 439, 2007.

[38] K. S. Suresh and M. V. Prasad, "PV Cell Based Five Level Inverter Using Multicarrier PWM," International Journal of Modern Engineering Research, vol. 1.

[39] K. T. Yeop, A. H. Gyun, P. S. Kyu, and L. Y. Kyu, "A novel maximum power point tracking control for photovoltaic power system under rapidly changing solar radiation," in Industrial Electronics, 2001, pp. 1011-1014.

[40] B. Liu, S. Duan, F. Liu, and P. Xu, "Analysis and improvement of maximum power point tracking algorithm based on incremental conductance method for photovoltaic array," in Power Electronics and Drive Systems, 2007. PEDS'07. 7th International Conference on, 2007, pp. 637-641.

[41] J. Schoeman and J. V. Wyk, "A simplified maximal power controller for terrestrial photovoltaic panel arrays," in Power Electronics Specialists conference, 1982 IEEE, 1982, pp. 361-367.

[42] G. Hart, H. Branz, and C. Cox, "Experimental tests of open-loop maximum-power-point tracking techniques for photovoltaic arrays," Solar cells, vol. 13, pp. 185-195, 1984.

[43] B. Bekker and H. Beukes, "Finding an optimal PV panel maximum power point tracking method," in AFRICON, 2004. 7th AFRICON Conference in Africa, 2004, pp. 1125-1129. 
[44] A. M. Atallah, A. Y. Abdelaziz, and R. S. Jumaah, "Implementation of Perturb and Observe mppt of PV system with direct control method using buck and buck-boost converters."

[45] F. Liu, S. Duan, F. Liu, B. Liu, and Y. Kang, "A variable step size INC MPPT method for PV systems," Industrial Electronics, IEEE Transactions on, vol. 55, pp. 2622-2628, 2008.

[46] A. Al-Diab and C. Sourkounis, "Variable step size P\&O MPPT algorithm for PV systems," in Optimization of Electrical and Electronic Equipment (OPTIM), 2010 12th International Conference on, 2010, pp. 1097-1102.

[47] M. Yamaguchi, K.-i. Kawarabayashi, T. Takuma, Y. Ueda, and Y. Yamano, "Development of a new utility-connected photovoltaic inverter line back," in Telecommunications Energy Conference, 1994. INTELEC'94., 16th International, 1994, pp. 676-682.

[48] J. Jiang, T. Huang, Y. Hsiao, and C. Chen, "Maximum power tracking for photovoltaic power systems," Tamkang Journal of Science and Engineering, vol. 8, p. 147, 2005.

[49] U. Boeke, M. Wendt, and L. Yseboodt, "Combined solar and AC mains powered LED lighting system," in Power Electronics and Applications (EPE 2011), Proceedings of the 2011-14th European Conference on, 2011, pp. 1-8.

[50] P. Yeung. (2007, June). Reducing Energy Costs with Peak Shaving in Industrial Environments. Available: http://www.schneider-electric.com.hk/documents/energyefficiency-forum/Reducing-Energy-Costs-with-Peak-Shaving.pdf

[51] M. Deshmukh and S. Deshmukh, "Modeling of hybrid renewable energy systems," Renewable and Sustainable Energy Reviews, vol. 12, pp. 235-249, 2008.

[52] P. O. Akuon, "Optimized hybrid green power model for remote telecom sites," in Power Engineering Society Conference and Exposition in Africa (PowerAfrica), 2012 IEEE, 2012, pp. 1-5.

[53] M. Mani and R. Pillai, "Impact of dust on solar photovoltaic (PV) performance: research status, challenges and recommendations," Renewable and Sustainable Energy Reviews, vol. 14, pp. 3124-3131, 2010.

[54] A. L. Inc., "Solar Facts and Advice," ed, 2010-2013.

[55] A. Sharifi, Mousazadeh, Hossein Keyhani, Alireza, "A review of principle and sun-tracking methods for maximizing solar systems output," Renewable and Sustainable Energy Reviews, vol. 13, pp. 1800-1818, 2009.

[56] G. M. G. Khan, Sudeepika, P, "Analysis Of Mathematical Model Of PV Cell Module in Matlab/Simulink Environment," Analysis, vol. 3, 2014. 
[57] R. Spalding-Fecher, A. Williams, and C. van Horen, "Energy and environment in South Africa: charting a course to sustainability," Energy for sustainable development, vol. 4, pp. 8-17, 2000.

[58] P. C. Pelser, "Modelling and evaluation of an energy efficient heating ventilation and air conditioning (HVAC) system in an office building," 2014.

[59] M. A. McNeil and V. E. Letschert, "Future air conditioning energy consumption in developing countries and what can be done about it: the potential of efficiency in the residential sector," Lawrence Berkeley National Laboratory, 2008.

[60] S. P. M. Winnie Lam, "Should you spring clean your solar panels?," Google, Ed., ed, 2009.

[61] ESKOM., "Homeflex Tariffs," ESKOM, Ed., ed. Pretoria, 2012, p. 49.

[62] D. Devos. (2013, 03 May 2013) Eskom's dim understanding of the market. Mail Guardian [Opinion]. Available: http://mg.co.za/article/2013-05-03-00-eskoms-dim-understanding-ofthe-market

[63] R. A. Schneider, G. L. Freed, and R. Lipnick, "Power monitoring and load shedding system," ed: Google Patents, 1978.

[64] T. Taufik and M. Taufik, "The DC House Project: Promoting the use of renewable energy for rural electrification," in 2012 International Conference on Power Engineering and Renewable Energy (ICPERE), 2012.

[65] J. E. Chaidez, "DC House Modeling and System Design," 2011.

[66] P. Nema, R. Nema, and S. Rangnekar, "A current and future state of art development of hybrid energy system using wind and PV-solar: A review," Renewable and Sustainable Energy Reviews, vol. 13, pp. 2096-2103, 2009.

[67] J. Ding and J. Buckeridge, "Design considerations for a sustainable hybrid energy system," 2000.

[68] S. J. Ehnberg and M. H. Bollen, "Reliability of a small power system using solar power and hydro," Electric power systems research, vol. 74, pp. 119-127, 2005.

[69] E. Koutroulis, K. Kalaitzakis, and N. C. Voulgaris, "Development of a microcontroller-based, photovoltaic maximum power point tracking control system," Power Electronics, IEEE Transactions on, vol. 16, pp. 46-54, 2001.

[70] N. Ahmed and M. Miyatake, "A stand-alone hybrid generation system combining solar photovoltaic and wind turbine with simple maximum power point tracking control," in Power Electronics and Motion Control Conference, 2006. IPEMC 2006. CES/IEEE 5th International, 2006, pp. 1-7. 
[71] G. Seeling-Hochmuth, "A combined optimisation concet for the design and operation strategy of hybrid-PV energy systems," Solar energy, vol. 61, pp. 77-87, 1997.

[72] Solar Facts and Advice. Available: http://www.solar-facts-and-advice.com/solar-panelcleaning.html

[73] M. A. Maehlum. (2013, 28/12/2014). Best Way to Clean Solar Panels. Available: http://energyinformative.org/solar-panel-cleaning/

[74] T. Singh. (2014, 24/12/2014). Students Create Award-Winning Robot That Cleans Solar Panels. Available: http://inhabitat.com/students-create-award-winning-robot-that-cleans$\underline{\text { solar-panels/ }}$

[75] D. Harper, ""photovoltaic," in The American Heritage ${ }^{\circledR}$ Science Dictionary," H. M. Company, Ed., ed, 2010.

[76] D. Harper, "Photo," in Online Tymology Dictionary, LogoBee.com, Ed., ed: Dan McCormack, 2001-2015.

[77] D. Harper, "Voltaic," in Online Etymology Dictionary, D. McCormack, Ed., ed: LogoBee.com, 2001-2015.

[78] P. Mouratoglou and P.-G. Therond, "L'énergie solaire photovoltaïque," in Annales des MinesRéalités industrielles, 2009, pp. 61-70.

[79] R. Allan, Reliability evaluation of power systems: Springer Science \& Business Media, 2013.

[80] T. Kioulachoglou, "Who is the author of the Bible and who wrote it?," The Journal of Biblical Accuracy, pp. 1-4.

[81] S. El-Gayar, Gad, Helmy E, "Performance prediction of a proposed photovoltaic water pumping system at south sinai, egypt climate conditions," in Thirteenth International Water Technology Conference, IWTC13, El-Mansoura 35516, 2009.

[82] M. Safya, Gad, Helmy E, "Characterization of PV modules of new generations," Report to NOVEM Contract 1462000.

[83] R. G. Ross, "Flat - Plate Photovoltaic Array Design Optimization," in IEEE Photovoltaic Specialists, San Diego, 1980, pp. 1126-1132.

[84] H. E. Gad and M. Safya, "Using Photovoltaic Array for Solar Water Pumping in Toshka Region, Egypt," in Fifteenth International Water Technology Conference, IWTC .," Alexandria, Egypt Available: http://iwtc.info/wp-contentluploads/20 II.

[85] M. Green, "Solar Cells," in Operating principles, technology and system applications, ed Englewood Cliffs: Prentice Hall, 1982, pp. 85-102. 
[86] S. B, Gauche, P, "Solar Energy," Centre for Renewable Energy and Sustainable Energy Studies, vol. 744/844, 2011.

[87] SAURAN. Solar Radiometric Data for the Public [Online].

Available: http://sauran.net/ShowStation.aspx?station=2

[88] E. L. Meyer and E. E. Van Dyk, "Assessing the reliability and degradation of photovoltaic module performance parameters," Reliability, IEEE Transactions on, vol. 53, pp. 83-92, 2004.

[89] R. F. Coelho and D. C. Martins, "An Optimized Maximum Power Point Tracking Method Based on PV Surface Temperature Measurement," in Sustainable Energy - Recent Studies, A. Gebremedhin, Ed., ed: InTech, October 3, 2012

[90] A. M. ElDin, A. K. Abel-Rahman, A. H. H. Ali, and S. Ookawara, "Effect of dust deposition on performance of thin film photovoltaic module in harsh humid climate," in Renewable Energy Research and Applications (ICRERA), 2013 International Conference on, 2013, pp. 674-679.

[91] EnergyInstructor. (June 2001). PV Installation Guide.

Available: http://www.energyinstructor.info/ess30/images/Orientation $\% 20 \& \% 20 \mathrm{Pitch} \% 20$ $\% 20 \mathrm{~A} \% 20$ GUIDE $\% 20$ TO $\% 20 \mathrm{PV} \% 20$ SYSTEM $\% 20$ DESIGN $\% 20$ AND $\% 20$ INSTALLATI ON\%209-10.pdf

[92] J. J. Wysocki and P. Rappaport, "Effect of temperature on photovoltaic solar energy conversion," Journal of Applied Physics, vol. 31, pp. 571-578, 1960.

[93] E. Lorenzo, Solar electricity: engineering of photovoltaic systems: Earthscan/James \& James, 1994.

[94] A. H. Lockwood and B. Gottlieb, "Coal's assault on Human HealtH," Physicians for Social Responsibility Report, 2009.

[95] Z. Selvans, "http://cleanenergyaction.org." ed: Clean Energy Action, 2014.

[96] I. S. FourPeaksTechnologies, AZ. (2011, 31 May). Solar Cell Central. Available: http://solarcellcentral.com/index.html

[97] S. B. Christiana Honsberg. $(2015,28)$. Battery Information. Available: http://www.pveducation.org/pvcdrom/batteries/remaining\#

[98] J. d. Jong, "letitgo.com.au," ed: LETITGO, 2015.

[99] AtmelCorporation, "ATMEL ATMEGA3290-16AU datasheet," ATMEL, San Jose, CA 95131 USA2015. 
[100] M. Habyarimana and C. Venugopal, "Automated hybrid solar and mains system for peak time power demand," in Domestic Use of Energy (DUE), 2015 International Conference on the, 2015, pp. 169-175.

[101] SAURAN. (2015, 16 February). Southern African Universities Radiometric Network. Available: http://www.sauran.net/ShowStation.aspx?station=2

[102] SHARP-USA. (2012, June). 300 Watt Multi-Purpose Module NEC 2008 Compliant. Available: http://files.sharpusa.com/Downloads/Solar/Products/sol dow_NDF4Q300.pdf

[103] H.-L. Tsai, "Insolation-oriented model of photovoltaic module using Matlab/Simulink," Solar energy, vol. 84, pp. 1318-1326, 2010.

[104] C. Honsberg and S. Bowden. (2013, June). Diode Equation.

Available: http://www.pveducation.org/pvedrom/pn-junction/diode-equation

[105] R. Surtees, "Electricity demand growth in South Africa and the role of demand side management," Eskom, PO Box, vol. 1091, 1998.

[106] V. Mahajan, "PV Module and system fault analysis," Murdoch University, 2014.

[107] E. Meller, "Field-proven, automatic, water-free solar panel cleaning system," Ecoppia, IsraelMay 2015. 